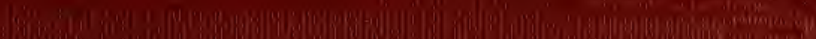
B. of

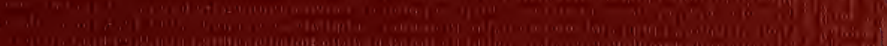
7. $\left(\begin{array}{c}5 \\ 0\end{array}\right.$

(1)

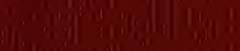
(1) (1) 







\section{THE NERVOUS SYSTEM

\section{OF VERTEBRATES}

BY

J. B. JOHNSTON, Ph. D.

PROFESSOR OF ZOOLOGY IN WEST VIRGINIA UNIVERSITY

With One Hundred and Eighty Illustrations

PHILADELPHIA

P. BLAKISTON'S SON \& CO.

1012 WALNUT STREET

1906 
Copyright, igo6, By P. BLAKISTON'S SON \& CO. 97 


\section{PREFACE.}

The attempt has been made in the following pages to give an account of the nervous system as a whole, to trace its phylogenetic history and to show the factors which have determined the course of evolution. This has been made possible by recent studies directed toward the analysis of the nervous system on the basis of function. The functional point of view, which is the chief characteristic of the present book, brings the treatment of the nervous system into close relation with the work of recent years on the behavior of animals. The study of behavior aims to give an account of the actions of animals in relation to the environment. The study of the nervous system aims to describe the mechanism by which actions are directed and adapted to the conditions of life.

A text-book of comparative neurology at the present time must meet the needs of workers of all grades, students, investigators and instructors. Its descriptions should be intelligible to students who have had one year of work in zoology or medicine, including the anatomy and embryology of some vertebrate. On the other hand there should be included all facts which are important for the functional and phylogenetic mode of treatment. How far these difficult conditions have been met only the use of the book can show. Little space is given to mere descriptive anatomy and some descriptive matter which is well presented in the text-books of zoology, anatomy and histology in common use, is omitted. Thi accounts for the brief treatment of the eye, ear and other sensu organs, the distribution of the spinal nerves, etc. On the other hand, every effort has been made to bring out clearly the functional significance and relationships of the structures described, and to interest and train the student in the interpretation of structure in terms of function, adaptation and evolution.

In the preparation of the text considerable time has been given to the review of the author's earlier work and that of other writers, and to the study of many unsettled questions. In this way much 



\section{CONTENTS.}

\section{CHAPTER I.}

The Study of the Nervous System . . . . . . . . I I

Point of view; anatomical, experimental and physiological methods.

Morphological terms; planes of sectioning; neurological terms.

CHAPTER II.

General Morphology of the Nervous System . . . . .

CHAPTER III.

Development of the Nervous System . . . . . . . .

Neural tube; neural crest; neuromeres; secondary brain segments; auditory and olfactory pits and optic vesicle; histogenesis of central nervous system; longitudinal zones.

Development of peripheral nerves and sense organs; part played by the neural crest and by ectodermal placodes.

Morphology of the head.

CHAPTER IV.

Nerve Elements and their Functions . . . . . . . . 76

Functions of nerve elements; stimuli and impulses; polar differentiation; parts of a nerve cell and course of impulses. Receptive and excitatory cells and reflex actions.

The Neurone Theory.

\section{CHAPTER V.}

The Functional Divisions of the Nervous System . . .

The work of the nervous system in relation to soma and viscera; four kinds of nervous activity and the corresponding divisions of the nervous system. 
Somatic Afferent Division. General Cutaneous Subdi-

General cutaneous endings and general cutaneous components in the spinal and cranial nerves; general cutaneous centers in spinal cord and brain; general survey.

CHAPTER VII.

Somatic Afferent Division. Special Cutaneous SubdiVISION . . . . . . . . . . . . . . . . . . . .

Sense organs, morphology and physiology; special cutaneous components; special cutaneous centers; differentiation of cutaneous and auditory centers and cerebellum.

CHAPTER VIII.

Somatic Afferent Division. The Visual Apparatus . . .

Organism sensitive to light; development of special light percipient organ, the retina; optic tracts; structure of tectum opticum; origin and morphological position of the eyes.

Pineal eyes.

\section{CHAPTER IX.}

The Visceral Afferent Division

General Visceral Subdivision.

Visceral afferent components; visceral sensory centers. Special Visceral or Gustatory System.

Organs of the sense of taste, origin, structure and distribution; innervation; gustatory centers; change of function in higher vertebrates.

CHAPTER $\mathrm{X}$.

The Olfactory Apparatus . . . . . . . . . . 176

Sense organ; nerve; olfactory centers. Relations to other systems.

\section{CHAPTER XI.}

The Somatic Motor Division . . . . . . . . . . . .

Ventral nerves; roots wanting in cranial region; origin, arrangement and distribution of components; plexuses; "hypoglossus"; eye muscle nerves; relations of the somatic motor column in the brain. 
Origin, arrangement and distribution of the components; fibers to the sympathetic; nerves of mastication; of expression; vagus and spinal accessory complex; relations of the visceral efferent column.

\section{CHAPTER XIII.}

The Sympathetic System 206

Development of ganglia and nerves; structure of the system; general constitution and relations.

\section{CHAPTER XIV.}

Centers of Correlation....

General constitution of central system; four chief zones; substantia reticularis; functions and organization of; centers of correlation; their relation to complex activities; materials for study of these centers. Region of the myelencephalon.

\section{CHAPTER XV.}

The Cerebellum . .
Phylogenetic history.

Mammalian cerebellum; hemispheres and vermis; subdivisions and fissures; structure; review of vertebrate cerebellum. Structure of cerebellar cortex; fiber tracts of cortex. Deep gray masses and their fiber connections.

Evolution of structure and function, general survey; function in mammals.

\section{CHAPTER XVI.}

Centers of Correlation. The Mesencephalon and DienCEPHALON . . . . . . .
I. The Cutaneous Apparatus.

The lemniscus system; the differentiation of centers in the tectum mesencephali.

2. The Optic Apparatus.

Tectum opticum; development of optic centers in the thalamus; division of function between centers.

3. Centers related to the posterior commissure. 


\section{CHAPTER XVII.}

Correlating Centers in the Diencephalon (Continued) . . 269

4. The Olfactory and Gustatory Apparatus.

The hypothalamus; its limits, relations, structure and fiber tracts. The nucleus habenulae; structure, relations and fiber tracts. The hypothalamus and nucleus habenulae as derivatives of the visceral sensory zone of the brain.

5. The nucleus of the tractus strio-thalamicus and the substantia reticularis thalami.

6. The Saccus Apparatus.

\section{CHAPTER XVIII.}

The Evolution of the Cerebral Hemispheres . . . . . . 292 Survey of the forebrain of lower vertebrates.

The archipallium and neopallium of mammals.

CHAPTER XIX.

The Neopallium . . . . . . . . . . . . . . 338

Structure of the cortex.

Cerebral localization.

Evolution of the neopallium. 


\section{LIST OF ILLUSTRATIONS.}

FIG.

I. Outlines of the spinal cord with the dorsal and ventral roots in Petromyzon and in a mammal . . . . . . . . . . . I4

2. The brain of Heptanchus . . . . . . . . . . . . . ${ }_{15}$

3. The medulla oblongata of the lake sturgeon (Acipenser rubicundus), to show the longitudinal zones. . . . . . . . . I6

4. Two views of the brain of the buffalo fish, Carpiodes velifer (Raf.); (I) from above; (2) from the right side. From C. Judson Herrick after C. L. Herrick . . . . . . . . . .

5. Simple diagrams of the branchial nerves of lower vertebrates as seen from the left side . . . . . . . . . . .

6. A diagram of the lateral line canals and pit organs together with the nerves which supply them, in a ganoid fish (Amia calva). After E. Phelps Allis. . . . . . . . . . . .

7. A sketch of the brain of Chimaera monstrosa from the left side to show especially the position of the nerve roots. . . . .

8. The outline of the brain ventricles as seen from above; $A$, of a cyclostome fish, Lampetra Wilderi; $\mathrm{B}$, of a selachian, Mustelus canis; C, of a young specimen of a bony fish, Coregonus albus; D, of a tailed amphibian, Necturus maculatus. . . . . . . . . . . . . . . .

9. A diagram of one side of the forebrain in Mustelus to show what is believed to be the primitive relations of the wall and ventricle . . . . . . . . . . . 26

Iо. The outline of the ventricles in man . . . . . . . . . . 26

I1. The mesial surface of the right half of the brain of a selachian, Squalus acanthias. . . . . . . . . . . .

I2. A sketch of the brain of a cyclostome fish, Lampetra Wilderi, as seen from the left side. . . . . . . . . . . 30

I3. Sections of the neural plate and folds in amphibia, Amblystoma tigrinum and A. punctatum. . . . . . . . . . . . . .

I4. Transverse section of the neural tube of Amblystoma punctatum just after closing. . . . . . . . . . 36 
FIG.

I5. Transverse section through the neural tube, neural crest and ectoderm of Amblystoma at a later stage than that shown in Fig. I4.

I6. Same as Fig. I5, later stage.

I7. A part of the spinal cord of an I8-day Catostomus embryo, showing the giant ganglion cells. .

I8. Figures of the brain of a selachian embryo (Squalus acanthias) to show the history of the neuromeres. After Locy. . . .

I9. Figures to show the history of the neuromeres in a bony fish and in the chick. After Hill.

20. The brain of a pig embryo of $\mathrm{I} 2 \mathrm{~mm}$. from the right side. From Minot as drawn and revised by Dr. F. T. Lewis. .

2I. Transverse sections through the region of the optic vesicle in embryos of: A, Torpedo ocellata; B, Gallus domesticus; C, Cavia cobaya. After Froriep . . : . . . . . . . .

22. The development of the optic vesicles in Amblystoma punctatum .

23. A part of a transverse section of the inferior lobe of the sturgeon, stained by the Golgi method . . . . . . . . .

24. A horizontal section of the nucleus praeopticus of the sturgeon, by the Golgi method . . . . . . . . . . . . . .

25. A part of a transverse section of the optic lobe of the sturgeon, by the Golgi method . . . . . . . . . . . . . .

26. The ganglion of the IX nerve in Amblystoma punctatum at the time of formation of the central processes . . . . .

27. A few cells of the trigeminal ganglion of Amblystoma punctatum with the fibers of the ramus mandibularis growing out from them

28. A, a diagram of the head of Petromyzon at a stage when the neural crest is segmented into the anlages of the cranial ganglia. B, a similar diagram at a later stage when all the cranial nerves are to be recognized. After Koltzoff. . . .

29. Three diagrams of the head of Squalus acanthias to show the differentiation of the neural crest into the cranial ganglia. After Neal .

30. A reconstruction of the peripheral nerves in a four weeks human embryo, $6.9 \mathrm{~mm}$. long. From Streeter . . . . . .

3I. Reconstruction of peripheral nerves in four weeks human embryo, 7.0 mm. long. From Streeter 
FIG.

32. Reconstruction of peripheral nerves in six weeks human embryo, $17.5 \mathrm{~mm}$. long. From Streeter . . . . . . . . . .

33. Three stages in the development of the acustico-lateral system in the sea bass. From H. V. Wilson . . . . . . . . .

34. A transverse section through the nasal sac of an embryo of a bony fish at about the time of hatching, to show the origin of the fibers of the olfactory nerve . . . . . . . . .

35. Two figures representing the formation of unipolar cells in the spinal ganglion of the dog embryo. After Van Gehuchten .

36. A median sagittal section of the head of an embryo Amblystoma punctatum.

37. Diagrams representing the development of the buccal cavity, hypophysis and nasal pit in Amphioxus and Petromyzon. After Legros . . . . . . . . . . . . . . . . . .

38. A diagram representing the segmentation in a generalized vertebrate head.

39. Several types of nerve cells from the central and peripheral nervous system of vertebrates . . . . . . . . . . .

40. A unipolar nerve cell from the brain of Carcinas to illustrate Bethe's experiment .

4I. Diagrams intended to show several forms of reflex chains in the nervous system of vertebrates . . . . . . . . . . .

42. A portion of the subepithelial nervous network in the palate of the frog. From Prentiss . . . . . . . . . . . .

43. A portion of the nervous network about the walls of a small vessel in the palate of the frog. From Prentiss . . . .

44. Two ganglion cells of the nervous network in the intestinal wall of the leech Pontobdella, showing neurofibrillae passing through the cells. From Bethe after Apathy . . . .

45. A diagram of the component elements in the spinal cord and the nerve roots of a trunk segment, to illustrate the relations of the four functional divisions of the nervous system

46. Diagrams to represent the extent and arrangement of the functional divisions in the brain of a selachian . . . . . . Ioo

47. A diagram to show the arrangement of the two afferent divisions in the brain of man.

48. General cutaneous endings in the skin of a cyclostome, Lampetra Wilderi. 
FIG.

49. A diagrammatic representation of the general cutaneous components of a trunk segment . . . . . . . . . Iо6

50. A simple diagram of the general cutaneous components in the cranial and spinal nerves of a fish .

5I. A reconstruction of the cranial nerves of Petromyzon dorsatus to show the arrangement and distribution of the several systems of nerve components .

52. The principal sensory collaterals in the spinal cord of the new-born rat. From Cajal . . . . . . . . .

53. Some cells of the dorsal horn in the chick embryo of five days. From Cajal .

54. Transverse section of the substance of Rolando of the cervical cord in the new-born cat. From Cajal .

55. Cells in the dorsal horn of the cord in a chick embryo of nineteen days incubation. From Cajal .

56. Transverse section through the spinal $\mathrm{V}$ tract and the substance of Rolando in a new-born rabbit. From Cajal . .

57. A, transverse section of the spinal cord of Lampetra to show the ceils of the dorsal horn .

58. A, transverse section of the tuberculum acusticum of Lampetra; B, a sagittal section of the cerebellum of the same animal .

59. A diagram representing the centers and fiber tracts related to the general cutaneous components in fishes . . . . . . .

6o. A diagram representing the general cutaneous centers and fiber tracts in the human brain .

6r. A large and a small neuromast from a sucker embryo at about the time of hatching

62. A diagram of the lateral line canals and nerves in Amia. After E. Phelps Allis .

63. A reconstruction of the chief rami of the cranial nerves in a bony fish, Menidia, to show the arrangement of the severa] systems of components. After C. Judson Herrick .

64. Transverse section of the brain of the sturgeon at the level of the VII and VIII nerves . . . . . . . . . . . I3I

65. Transverse section of the brain of the sturgeon at the level of the $\mathrm{V}$ nerve . . . . . . . . . . . . . . . . . . . I32

66. Transverse section of the brain of Scyllium to show the folding of the cerebellar crest and tuberculum acusticum . . . I33 
FIG.

PAGE

67. Transverse section of the acusticum of the sturgeon to show acusticum cells and a Purkinje cell .

68. A section through the same region as in Fig. 67 , to show cell forms intermediate between the acusticum and Purkinje cells. I 36

69. A diagram to show the central endings of the special cutaneous components in fishes .

70. A diagram to show the central ending of the vestibular and cochlear nerves and of the optic tract in man and the chief secondary tracts related to them

I 40

$7 \mathrm{I}$. A, a section through the retina of a mouse embryo of $15 \mathrm{~mm}$.; $B$, a section through the retina of a chick embryo of fourteen days incubation; $\mathrm{C}$, a section of the retina of a dog. From Cajal . . . . . . . . . . . . . . . . I44

72. Cells from the retina of the chicken. From Cajal . . . . I45

73. The tectum opticum of the sturgeon . . . . . . . . . . I47

74. A section of the optic lobe of a bird. From Cajal . . . I 49

75. A series of diagrams intended to illustrate the origin and mode of formation of the optic vesicle in vertebrates . . . . . I $5^{\mathrm{I}}$

76. A sketch showing the relations of the two epiphyses in vertebrates

77. A diagrammatic representation of the general visceral sensory components in a trunk segment.

78. A transverse section through the region of Clarke's column of the thoracic cord of a new-born dog. From Cajal . . . . I 56

79. A reconstruction of the cranial nerve components in a tailed amphibian, Amblystoma. After Coghill . . . . . . . I58

80. A simple diagram of the visceral nerves of the head in fishes. I59

8 I. Four transverse sections through the medulla oblongata of the frog to show the position and ending of the fasciculus communis and nucleus commissuralis .

160

82. Transverse section through the medulla oblongata of a mouse at the level of the nucleus commissuralis. From Cajal . I6I

83. Transverse section through the medulla oblongata of a mouse four days old. From Cajal . . . . . . . . . . . . $\mathrm{I}_{2}$

84. A, a transverse section through the medulla oblongata of the sturgeon at the level of the $\mathrm{X}$ nerve; $\mathrm{B}$, at the level of the

85. Sense organs of bony fishes. A, a taste bud from the oesophaI6 3 gus of Catostomus at the time of hatching; B, a taste bud 
FIG.

from the pharynx of the same embryo; $\mathrm{C}$, two neuromasts from the skin of the same embryo

186. A taste organ from the pharynx of the ammocoetes of Petromyzon dorsatus . . . . . . . . . . . . . . . . 166

87. A taste bud from the skin of an adult Lampetra . . . . . ${ }_{167}$

88. A projection of the cutaneous branches of the communis root of the right facial nerve in a bony fish, Ameiurus. From C. Judson Herrick

89. A parasagittal section through the brain of the spotted sucker, Minytrema melanops, to show the gustatory centers and tracts. From C. Judson Herrick . . . . . . . . . . I70

90. A diagram of the gustatory paths in the brain of the carp as seen from the left side. From C. Judson Herrick . . . . I 72

9I. Part of a sagittal section of the brain of a newly hatched bony fish

92. A diagram representing the centers and tracts related to the visceral sensory components in fishes .

93. A transverse section through the olfactory epithelium of a bony fish at the time of hatching . . . . . . . . . 177

94. An oblique section through the forebrain of Lampetra . . I 78

95. A horizontal section through the olfactory bulb of the sturgeon . . . . . . . . . . . . . . . . 179

96. A spindle cell and two granules from the olfactory bulb of the sturgeon

97. An olfactory glomerulus from the brain of the sturgeon . . I8 I

98. Cells with short neurites in the olfactory bulb. From Cajal. I82

99. A transverse section of the forebrain of the sturgeon at the level of the anterior commissure . . . . . . . . . I84

100. An outline of the median sagittal section of the forebrain of Lampetra . . . . . . . . . . . . . . . . 185

IоI. A diagram of the olfactory conduction paths in the sturgeon. ${ }^{8} 8$ 102. A diagrammatic representation of the somatic motor components of a trunk segment . . . . . . . . . . . . I9I

103. An early stage in the formation of the pectoral fin and brachial plexus in a selachian, Spinax. After Braus . . . 192

104. The formation of the cervical plexus in a selachian, Hexanchus, After Fürbringer . . . . . . . . . . . . . I93

105. A transverse section through the nucleus of origin of the III nerve in Lampetra . 
I06. A diagrammatic representation of the visceral efferent components in a trunk segment .

107. Diagram to show the central relations of the IX, $\mathrm{X}$ and XI nerves in mammals according to Onuf and Collins . . . 201

108. A diagram of the sympathetic system and the arrangement of its neurones in a mammal. Chiefly after Huber . . .

I09. Diagram illustrating the spinal representation of the sympathetic nerve in a mammal. From Onuf and Collins . . . 2 ro

I Io. A diagram to illustrate Langley's "axone reflex" . . . .

II . Tract cells in the spinal cord of the trout. After Van Gehuchten

I I 2. The relations of the cerebellum, brachium conjunctivum and gustatory tracts in selachians (Scyllium) . . . . . . . . 226

II3. Transverse section through the cerebellum of the sturgeon .

II4. Transverse section through the cerebellum and secondary gustatory nucleus of the sturgeon . . . . . . . . . . .

I 5. Transverse section of the brain of the sturgeon at the junction of cerebellum and midbrain . . . . . . . . . 229

II6. Transverse section through the midbrain of the sturgeon . . 230

II 7. The relations of the cerebellum, brachium conjunctivum and gustatory tracts in a ganoid fish (Acipenser). . . .

I 8 . A, the left lateral aspect of the brain of a pouch specimen of Dasyurus viverrinus; $B$, median sagittal section through the cerebellum of the same brain. After G. Elliot Smith .

I I9. A diagram representing the fundamental and more constant secondary fissures of the mammalian cerebellum spread out in one plane. After G. Elliot Smith . . . . . . . . .

I20. The mesial surface of the right half of the brain of Squalus acanthias.

I2I. A diagrammatic transverse section of one fold of the cerebellum. From Koelliker . . . . . . . . . . . . 238

I22. Net-like fiber ending in the human cerebellum. After Cajal. 24I

I23. Two schemes to show the course of impulses in the cerebellar cortex. From Cajal . . . . . . . . . . . . . . . . 242

I24. Two transverse sections through the cerebellum of Scyllium. 244

I25. A transverse section through the cerebellum of Necturus . . 246

I26. A transverse section through the deep gray nuclei of the cerebellum of man . . . . . . . . . . . . . . . 247

I27. Outline transverse sections through the mesencephalon of a 
FIG.

cyclostome, a selachian, a ganoid, a bony fish, an amphibian and a mammal .

I28. Transverse section of the diencephalon of the rat at the level of the body of Luys. From Cajal .

129. Transverse section of the dorso-mesial portion of the posterior corpus quadrigeminum of the new-born dog. From Cajal.

I30. Transverse section of the anterior corpus quadrigeminum of the rabbit of eight days. From Cajal . . . . . . . . .

I3I. Lower part of the corpus geniculatum laterale of a new-born cat. From Cajal . . . . . . . . . . 262

132. Nucleus of posterior commissure in Lampetra . . . . 266

I33. Transverse section through the corpora mammillaria of the sturgeon . . . . . .. . . . . . . . 270

I34. Transverse section through the inferior lobes of the sturgeon.

I35. Transverse section through the posterior commissure of the sturgeon ... . . . . . . . . . .

I36. Scheme of the connections of the mammillary tracts, nucleus habenulae and the nucleus dorsalis thalami. From Cajal. 273 274

I37. Sagittal section of the tuber cinereum of a new-born rat. From Cajal

I38. Sagittal section of the tuber cinereum of the rat of eight days. From Cajal .

I39. A scheme to show the embryological relations of the nucleus habenulae and the inferior lobes in fishes . . . . . . 277

I40. Nucleus habenulae of the sturgeon . . . . . . . . 278

I4I. Transverse sections through the nucleus habenulae and the facial lobe of a young Amia .

I42. Transverse section of the habenular nuclei in the dog. From Cajal .. . . . . . . . . . . . 280

I 43. The efferent tract to the saccus vasculosus in the sturgeon. 283

I44. A general scheme of the saccus apparatus . . . . . . . . 284

I45. A diagram of the fiber tracts in the forebrain of a cyclostome (Lampetra). . . . . . . . . . . . . 294

I46. An oblique section through the inferior lobes and forebrain of Lampetra. . . . . . . . . . . . . . . 296

I 47. A diagram of the fiber tracts in the forebrain of a selachian (chiefly after Kappers) . . . . . . . . . . . . . . . 299

I48. A diagram of the fiber tracts in the forebrain of a bony fish (chiefly after Goldstein) . 
FIG.

149. A transverse section of the brain of the sturgeon behind the anterior commissure

150. A diagram of the fiber tracts in the forebrain of a tailed amphibian (Necturus)

I5I. Simple diagrams to show the history of the epistriatum in fishes and amphibia.

152. Sketches of transverse sections through (A) the caudal part of the epistriatum in amphibia and (B) the corresponding structure in Ornithorhynchus. B after G. Elliot Smith . 3IO

153. A sagittal section of the forebrain and interbrain of a chick embryo of 7.0 days. After Minot.

r54. Part of a transverse section of the cortex of a chameleon. After Cajal .

155. Transverse section through the forebrain of Lacerta at the level of the anterior commissure. After Cajal

156. A transverse section through the right lateral lobe of the forebrain of Lacerta. After Cajal .

I57. A diagram of the mesial surface of the hemisphere of a reptile to show the extent of the hippocampus and related structures.

158. A mesial sagittal section of the brain of an embryo of Sphenodon punctatum. From G. Elliot Smith .

I59. The mesial surface of the right half of the brain of Ornithorhynchus. From G. Elliot Smith .

160. The mesial surface of the cerebral hemisphere of a marsupial (Phascolarctos). From G. Elliot Smith .

r6r. Portion of a transverse section through the brain of a Monitor (Hydrosaurus). From G. Elliot Smith

I62. Transverse section of the cerebral hemispheres of Ornithorhynchus. From G. Elliot Smith .

r63. Plan of cerebral hemispheres, lamina terminalis and optic thalami in horizontal section. From G. Elliot Smith . .

164. Sagittal section of the commissural and precommissural regions of the hemisphere of Ornithorhynchus. From G. Elliot Smith

165. Ventral surface of the brain of Ornithorhynchus. After G. Elliot Smith

x66. Transverse section of the brain of a rat of four days through the anterior commissure. From Cajal .

I67. Diagram of the mesial surface of (A) the hemisphere of a 
FIG.

monotreme and (B) that of a mammal to show the extent and relations of the hippocampus . . . . . . . . . 326

I68. Schemes to explain the expansion of the corpus callosum and the formation of the septum pellucidum. After figures by G. Elliot Smith . . . . . . . . . . . . 328

169. Scheme of cerebral commissures and the margin of the cortex of the human brain. From G. Elliot Smith . . . . 330

I70. Scheme of the structure and connections of the hippocampus. From Cajal . . . . . . . . . . . . . . 332

I7 I. Structure of the cerebral cortex . . . . . . . . . . . 339

172. Diagram showing the probable course of impulses in the cells of the cerebral cortex. After Cajal . . . . . . . . 340

I73. Scheme of long association tracts in the cerebral cortex. After Cajal . . . . . . . . . . . . . . . . . . . 342

I74. Scheme of commissural and projection fibers of the cortex. After Cajal . . . . . . . . . . . . . . . . $343^{\circ}$

I75. The primordial areas in the cerebral hemispheres, lateral surface. From Flechsig . . . . . . . . . . . . 346

I76. The primordial areas in the hemispheres, mesial surface. From Flechsig . . . . . . . . . . . . . . 347

I77. The primordial areas and border zones of the association fields, lateral surface. From Flechsig . . . . . . . . 350

I78. The primordial areas and border zones of the association fields, mesial surface. From Flechsig . . . . . . . . . 350

I79. Diagram of lateral surface of hemisphere showing localization of functions . . . . . . . . . . . . . . 35 I

I80. Diagram of mesial surface of hemisphere showing localization of functions ............................ 35 


\title{
NERVOUS SISTEM OF VERTEBRATES.
}

\author{
CHADTFR T
}

STEM.

ns which stands

ly. The study

an examination

smponent parts

lations to other

al connections

nerve impulses

organs and in

z more general

id other organs

relations of the

rmined by the

brate organism,

e of life is the

controlling principle; and py tne conumuns or emoryonic development, in which special structures adapted to the embryonic mode of life and inherited structures adapted to ancestral modes of life play important parts. The student who wishes to gain a knowledge of the nervous system is of necessity thrown into this maze of complicated relationships, but fortunately he finds methods of investigation adapted to the problems to be solved.

While the student may direct his attention especially to the phase of structure or the phase of function, he should understand from the outset that great progress and permanent results are to be attained only when the study of structure and the study of function go hand in hand. While in general the detailed study of structure must precede the detailed study of function, the interpretation 
FIG.

PAGE

monotreme and (B) that of a mammal to show the extent and relations of the hippocampus . . . . . . . . . . . 326

I68. Schemes to explain the expansion of the corpus callosum and the formation of the septum pellucidum. After figures by G. Elliot Smith . . . . . . . . . . . . . 328

I69. Scheme of cerebral commissures and the margin of the cortex of the human brain. From G. Elliot Smith . . . . 330

I70. Scheme of From Ca

I7I. Structure (

I72. Diagram s] of the cer ERRATA.

I73. Scheme of After Caj:

I74. Scheme of After Caj

I75. The prim surface.

I76. The primı From Fle

177. The prime fields, lat.

In the explanation of Figs. I I and I 20 instead of "Squalus acanthias" read ".Mustelus."

The figure numbered 175 should be transposed with that numbered 177 , and Fig. 176 with 178 . The explanations will then read correctly.

I78. The primi fields, me

I79. Diagram c tion of functions . . . . . . . . . . . . . . 35I

I80. Diagram of mesial surface of hemisphere showing localization of functions . . . . . . . . . . . . . 35I 


\section{NERVOUS SYSTEN OF VERTEBRATES.}

\section{CHAPTER I.}

\section{THE STUDY OF THE NERVOUS SYSTEM.}

The nervous system is a complex system of organs which stands in close relations with all the other organs of the body. The study of the nervous system requires on the one hand an examination of the structure and mode of functioning of its component parts and on the other a consideration of its manifold relations to other organs. There must be considered (a) structural connections which provide for the reception and discharge of nerve impulses which play an essential part in the functioning of organs and in the correlation of their activities; and (b) the more general relations of place, the arrangement of nervous and other organs in the body. In both these respects the actual relations of the nervous system in the organism have been determined by the conditions and course of the evolution of the vertebrate organism, in which the adaptation of structure to the mode of life is the controlling principle; and by the conditions of embryonic development, in which special structures adapted to the embryonic mode of life and inherited structures adapted to ancestral morles of life play important parts. The student who wishes to gain a knowledge of the nervous system is of necessity thrown into this maze of complicated relationships, but fortunately he finds methods of investigation adapted to the problems to be solved.

While the student may direct his attention especially to the phase of structure or the phase of function, he should understand from the outset that great progress and permanent results are to be attained only when the study of structure and the study of function go hand in hand. While in general the detailed study of structure must precede the detailed study of function, the interpretation 
of nervous structures, the statement of problems and the planning of investigations for their solution gain most from more general considerations of function, namely, considerations of the conditions and mode of life of the organism.

ANATOMiCAL METHods.-The method by which the study of the nervous system was first undertaken is also the first to be used by the student of today, namely, dissection. The purpose of dissection is to show the general place relations of the parts of the nervous system to other organs and the apparent structural connections between the two. Even to the investigator of original problems the method is still useful, and as it must be practiced in preparation for physiological experimentation and operation for the study of degeneration phenomena, the importance of thorough training in dissection can scarcely be over-estimated. The refinement of dissecting microscopes and mechanical appliances in recent years has made dissection applicable to more and more minute objects and at the same time has extended its usefulness to problems which could be approached before only by more indirect and tedious methods. The great advantage of handling one's object and of seeing its parts in their three dimensions makes the method of dissection indispensable and warrants every effort to refine and extend it.

When the dissection of the nervous system had reached the height of its efficiency by the appliances known to the earlier workers, as in the studies of the nerves of fishes by Stannius, the introduction of the microtome and the method of studying sections opened the way for great advances especially in the study of the central nervous system and of development. When the sections were stained by carmine or hæmatoxylin, more or less complete pictures were obtained of the structures in each section. By carefully keeping all the sections into which an object might be cut and mounting them in their serial order, it became possible to find the limits and form of structures too small to be dissected and to trace bundles of fibers from section to section throughout their course. Although for special investigations this method is largely replaced by more exact methods, it is still useful for the study of the general morphology of the nervous system and the 
topographical relations of nerve centers and fiber tracts, and for the purpose of reconstructions by which these relations can be shown on an enlarged scale in wax models and the like. Series of sections prepared with such a stain as Delafield's hæmatoxylin, well differentiated, remain one of the best means of studying general anatomical relations, especially in the central nervous system.

Scarcely had this general method been developed when special methods were devised to gain more exact pictures of nerve structures, especially by taking advantage of the selective activity of the chemicals to be employed. First among such methods was the impregnation of nerve elements by metallic salts. Results obtained by this method were published by Golgi in 1875 , but the method did not come into general use for a number of years. The reasons for this were that the procedure followed by Golgi was slow, requiring several months for its completion, and the impregnation was more or less uncertain, while the method of Weigert which was soon introduced promised results more quickly and with less labor. About 1890 new procedures which were both more rapid and more certain in their action were brought forward by Cajal, Cox and others, and since that time the method of metallic impregnation has been more and more widely used. This technique has given some of the most valuable contributions to our knowledge of the nervous system and is still among the most important methods for research. The advantage of the method lies in the fact that it gives incomplete pictures. Few elements are stained, often in great detail; and these are not obscured by the richness and confusion seen in complete pictures. The coloring of the tissue is not a true stain but an impregnation with a metallic salt. Although neuroglia, capillaries and other elements may at times be impregnated, the procedure peculiarly affects the nerve elements. Of these only a few are impregnated, the selection apparently being due in some way to the physiological state of certain elements. The elements which are thus isolated may be studied with great certainty and completeness, but the full study of all the elements in a given region requires a sufficiently large number of preparations to enable the observer to 
make up a composite picture approaching completeness. The method when used alone always has the disadvantage that the observer can never know when he has obtained an impregnation of all the elements present in the organ which he wishes to study. The peculiar value of the method lies in the fact that the nerve elements themselves are brought to view. Not only can the form of the cells and their dendrites be seen but the neurites can be traced directly from their origins to their endings. The polarity of form of the nerve.elements is shown and the direction of flow of impulses can be inferred with little danger of error. The method is especially adapted to the study of the central nervous system and gives facilities for determining the functional relations of centers and tracts scarcely afforded by any other anatomical method. It is equally trustworthy for the peripheral nerrous system wherever clear pictures can be secured, but the technical difficulties are greater on account of the conditions of sectioning and the formation of precipitates between the tissues.

The method of staining myelin sheaths commonly known as the method of Weigert, who introduced it in $188 \mathrm{I}$, differs widely from the method of Golgi in that it stains non-nervous elements only. The picture given by this procedure is complete so far as the myelin sheaths are concerned. Since the gray matter and the non-myelinated tracts are unstained, the myelinated tracts can be traced with relative ease. The method is especially adapted to the central nervous system where it gives quickly and easily the course and general topographical relations of the fiber tracts. The method is limited in its usefulness because it does not give the origin or ending of neurites or the course of nonmyelinated tracts, fibers or collaterals. Since neurites may run a longer or shorter distance before receiving their myelin sheaths and since the terminal branches of neurites run an unknown distance after passing the end of their sheaths, the study of the sheaths may lead to erroneous conclusions as to the groups of cells from which given fibers arise or in which they end. Since in recent years it has become possible to apply the method to material fixed in formalin or in Flemming's fluid, even better preparations are obtained than formerly and with greater ease. When the usual 
Weigert preparations are treated with a sharp secondary protoplasmic stain, such as acid fuchsin, the method gives a much larger number of facts and more reliable pictures. In particular, cell bodies are stained and the origin and endings of neurites are sometimes shown sufficiently well to enable the observer to determine the direction of impulses carried by a given tract. Even when this result is not obtained, the double-stained preparations are preferable to ordinary hæmatoxylin sections for the study of general topographical relations. As a special method, however, the Weigert procedure if used alone and on adult brains, can be relied upon for little in the way of functional relationships. The method is applicable to the study of the course of peripheral nerves by means of sections, and is especially valuable for the analysis of nerve trunks into their components. In addition to the usual Weigert technique, it may be mentioned that with small animals or small brains excellent Weigert effects may be obtained by simple fixatlon with rom Rath's picro-aceto-platino-osmic mixture, with or without after-staining with acid fuchsin.

A third special method which has proved extremely valuable is the intra vitam staining with methylene blue introduced by Ehrlich in 1886 . This differs from both the preceding in that it is an actual stain of nerve elements. The preparations are in general comparable to those obtained by the Golgi technique, since the pictures are incomplete pictures of the same character. The method gives in addition the internal structure of the nerve elements and is extremely useful for cytological study. It gives also more extensive and reliable information than does the Golgi method as to the details of fiber endings and the structural relations between nerve elements. The method is especially adapted to the study of the peripheral nervous system and to small isolated portions of the central nervous system. It has not yet been extensively used for the study of centers and fiber tracts. It reaches the height of its efficiency where the tissues stained are suitable for study in the living condition.

Of the great variety of cytological methods which may be applied to the nervous system two require mention as special nerve methods. The first of these is known as the Nissl method and is a selective 
stain of certain plastic materials within nerve elements which are doubtless either nutritive or excretory in their nature, or both. These materials constitute the so-called Nissl bodies whose form and volume change with changing physiological states of the nerve elements. The study of these elements is therefore of great importance to the physiologist and the pathologist.

The other method includes a considerable number of procedures which may be spoken of collectively as neuro-fibrillar staining methods. These stains affect the more stable colloidal substances in nerve elements and so are complementary to the Nissl method. Besides the methylene blue stain mentioned above a number of methods have been used for this purpose, of which the latest are certain modifications of the photographic procedure introduced by Cajal, Bielschowsky and others.

The methods thus far mentioned are anatomical methods chiefly applicable to the adult nervous system. When the nerrous system is studied with especial reference to its development or by making use of any peculiar characters which it possesses during development, it is proper to speak of embryological methods. These include the study of the development of the nervous system by any of the procedures applicable to embryos and the study of histogenesis by various staining techniques, including those of Golgi and of Ehrlich mentioned above. A special embryological method of great importance, the method of Flechsig, consists in the study of the course and order of myelination of nerve tracts by means of the Weigert technique. This gives especially favorable opportunities for studying the course of fiber tracts because specific tracts can be studied at the time of appearance of their myelin sheaths, certain tracts frequently presenting themselves in entire isolation from others.

EXPERIMENTAL METHODS.--The anatomical study of the nervous system may be greatly extended by means of experiments which produce artificial differences between nerve tracts or nerve centers, which may then be brought to view by suitable staining. Most prominent among these methods is the study of fiber tracts which have been caused to degenerate in accordance with Waller's law. Negative pictures of such tracts are obtained when the 
sections are treated by the usual Weigert stain, or positive pictures are obtained by means of the technique of Marchi. The method is applicable wherever localized and known centers can be destroyed or known tracts can be severed from their cells of origin. The fibers then degenerate in a direction away from their cells of origin, and the course of the fibers is brought to view by selective staining of the degeneration products of their myelin sheaths. Random operations may reveal the position of centers or tracts not before suspected. Many operations and preparations are needed in order to gain complete results. The time necessary for degeneration after the operation must be determined by extended trial and if not accurately determined, either no result or misleading results may follow. The staining technique is not always reliable. A source of serious error is found in the fact that fat globules resulting from the degenerative processes niay be carried by blood or lymph currents to situations far removed from their place of origin, and when stained in those situations they give very misleading pictures. The method is extremely valuable as giving the gross facts regarding the course and functional relationship of myelinated fiber tracts. With regard to the place of ending of fiber tracts the method has the same limitations as the method of Weigert, but in even greater degree because the fibers may not have degenerated throughout their entire length or may have passed the proper condition for staining. The method is more reliable for the origin of the fibers studied, or rather for the direction of the impulses which they carry, provided due care is taken to distinguish between Waller's degeneration and Gudden's degeneration (see p. 9I) which may also occur. The method requires great understanding and caution in its use but promises to be one of the most important of anatomical methods, and one which will greatly increase in usefulness.

Allied to the last is the study of secondary degenerations due to lesions, operative or accidental, in related centers. Nature performs many experiments of the greatest value to the neurologist, lesions in the central nervous system often offering opportunity through the study of primary and secondary degenerations to determine pathways of impulses otherwise difficult to follow. 
Closely related to the embryological methods already mentioned is the study of the processes at work in the degeneration and regeneration of cut nerve fibers. This may be prosecuted on either embryos or adults and throws especial light upon the character of neurones, their histogenesis, their relations to accessory structures and the mode and meaning of histological differentiation within the nervous system.

Recent work upon the rise and histogenesis of nervous elements and organs has shown that the embryological methods may he extended by experimental procedures to a degree little dreamed of a few years ago. Many problems of development and differentiation in the nervous system are capable of re-examination by experimental embryological methods, which will especially throw light on the causes at work in these processes.

Physiological methons.-These may be either experimental or observational. In the one case nervous actions are studied under conditions determined by operative or other artificial means. In the other case actions are studied under natural conditions believed to be sufficiently known. Among the simpler forms of experiments are those to determine the course of impulses. By the help of operations, or otherwise, suitable stimuli are applied to definite sensory areas, to nerve trunks or roots, to certain nerve centers, etc., and the actions called forth are observed and studied. The method is widely applicable and has been used independently for the investigation of the pathways of impulses and hence of functional connections in the nervous system. For its intelligent use it presupposes thorough anatomical knowledge and the most reliable results are obtained by combining one or more anatomical methods with it. Conduction paths may be determined by this method independently and some indications obtained as to the number and arrangement of their several steps. These data may then be tested and confirmed anatomically.

The study of the rate, direction and mode of conduction of impulses in neurones and neurone-chains has been carried on by stimulation under normal and experimental conditions. Opportunity is offered for the extension of this field in the direction of experimentation with chemical conditions combined with cyto- 
logical study to determine the character and mode of action of nerve protoplasm.

Numerous operative experiments have been directed toward the study of the function of various parts of the brain and of other nervous organs by stimulation, extirpation, poisoning, etc. Examples of such work are found in the numerous researches on the function of the cerebellum and upon the localization of function in the cerebral cortex. Other studies take account of the modifications of normal action following upon the destruction of any conduction path or center anatomically known. Still others regard the modifications of responses to stimuli after the application of selective poisons such as curare and nicotin, which affect respectively the motor end plates and certain elements of the sympathetic system.

The functions of sense organs have been studied by experiments to determine the conditions of their functioning, the character of stimuli proper to each kind of sense organ, the range of stimulation, etc. Examples are seen in recently renewed studies upon the ear and lateral line organs and upon the gustatory organs of fishes.

The methods by observation may or may not be experimental in the sense that natural conditions are controlled or simplified by the observer without physical interference with the organism or its nervous mechanisms. This form of study is especially developed in the field of animal behavior and physiological psychology.

The main object in the study of the nervous system is to discover what functional relationships are provided for by each of its parts. The words "functional relationslips" imply actions and organs which act. The nervous system is in relation both structurally and functionally with all parts of the organism. All activities are directly or indirectly dependent upon the proper functioning of the nervous system. The study of the nervous system implies a knowledge of the whole structure and the whole life of the organism. This breadth of view and attention to the functional side are two factors essential to the right attitude in the study of the nervous system which have been scarcely well enough appreciated. 
Although the present book, as an introduction to the study of the nervous system, will deal chiefly with structure it is hoped that the student will be led into full sympathy with the functional point of view in dealing with anatomical facts.

One of the most serious questions before the student of the nervous system at present is, what names and terms will serve best for clear description. Although there is an unfortunate variance in the usage of different writers certain terms are in more or less common use and it is assumed that the reader is familiar enough with the anatomy of vertebrate animals to understand the meaning of these terms. For example, to indicate the two ends of a vertebrate animal the terms front and hind, anterior and posterior, cephalic or rostral and caudal ends are used, and for the relation of direction toward the head or toward the tail the convenient terms cephalad and caudad are frequently used. So the terms right and left, dextral and sinistral sides and dextrad and sinistrad express corresponding relations, while the term median means in the middle vertical plane which divides the body into right and left halves. The terms mesial and lateral, mesad and laterad are similar in meaning to those already mentioned. For the upper and lower surfaces of vertebrate animals the terms dorsal and ventral are regularly used and these together with the other terms mentioned will be applied in the following pages to man in the same sense as to other vertebrates.

Since most of the description of the nervous system is taken from microscopic sections it is necessary to understand the terms used to designate sections cut in different planes. Sections made at right angles to the longitudinal axis of the body are called transverse sections. In many cases, as in embryos with the head bent ventrad, sections transverse to the trunk will not be transverse in the head region. Unless otherwise stated transverse sections are understood to be at right angles to the longitudinal axis in the region under consideration. Sections taken at right angles to transverse sections and passing symmetrically through corresponding organs of the right and left side, such as the limbs, would be parallel with the horizontal plane in animals whose position is prone. In man such sections would be approximately parallel 
with the vertical face of the frontal bone. The terms horizontal and frontal may be used interchangeably to indicate such sections. Sections taken at right angles to both of these and parallel with the median vertical plane of the body are called sagittal sections, since in man such sections are parallel with the sagittal suture of the skull. 
CHAPTER II.

\section{GENERAL MORPHOLOGY OF THE NERVOUS SYSTEM.}

In any vertebrate animal two chief parts of the nerrous system are distinguished, the central system consisting of the brain and spinal cord and the peripheral system. The peripheral system includes the nerves which connect the central system with various parts of the body, the ganglia of those nerves, sense organs, and the sympathetic system. The central nervous system is situated dorsal to the alimentary canal and is surrounded by more or less strong skeletal structures which constitute the greater part of the skull and spinal column.

In the trunk region the central nervous system consists of a . rounded cord which is enclosed within the neural arches of the vertebrae. In fishes this spinal cord extends the whole length of the spinal column. In higher forms the caudal portion is less developed, the cord as a whole grows less rapidly than the trunk and remains in the adult shorter than the spinal column, ending in the lumbar region. Beyond this a slender thread continuing into the tail represents the caudal portion of the spinal cord of fishes. In all vertebrates having well developed limbs the two regions of the spinal cord with which the nerves of the limbs are connected are somewhat thicker than the rest of the cord. These thickened portions are known as the thoracic and lumbar enlargements. The cord is usually more or less flattened dorso-ventrally and upon the dorsal and ventral surfaces in the middle line are to be seen longitudinal grooves, the dorsal and ventral fissures. The ventral fissure is usually a deep furrow. If the cord be cut across and the cut surface examined with a hand lens, the greater depth of the ventral fissure will be evident and in the median plane there will be seen a narrow opening. This is the central canal which extends throughout the length of the cord. The material surrounding the central canal and filling up the inner portion of the cord 
is very soft and somewhat gray in color, while the outer part is more firm and white. The gray matter is composed chiefly of cells, the white malter chiefly of fibers. The whiteness is due to the sheaths covering the fibers. The distinction between cellular and fibrous parts is not apparent in the cord of such an animal as Petromyzon whose nerve fibers are not provided with such sheaths. The gray matter has in cross section somewhat the form of the letter $\mathrm{H}$, the central canal being found in the crossbar of the $\mathrm{H}$. In either half of the cord a part of the gray matter extends dorsal to the central canal and a part extends ventral to it. These parts are called respectively the dorsal and ventral horns of the gray matter. In mammals and man a smaller projection of the gray matter laterally is spoken of as the lateral horn.

Each lateral half of the cord has connected with it the roots of the peripheral nerves. In all vertebrates there is in each typical segment of the body a dorsal root connected with the dorsal surface of the cord and a ventral root connected with the ventral surface. In the lowest vertebrates (Amphioxus and Cyclostomes) the dorsal and ventral roots of the same side alternate with one another along the cord. This is due to the fact that the dorsal nerve is destined to go in larger part to the skin while the ventral nerves go to the muscles of the trunk. Since the muscles are arranged in simple transverse segments following one another, the dorsal nerve is placed in the interval between two segments where it passes in the intermuscular septum of connective tissue to the skin. The ventral nerve, on the other hand, is situated opposite the middle of the muscle segment and is distributed directly to the muscle. Since part of the muscle lies above the spinal cord the ventral root divides into a dorsal and a ventral ramus. The dorsal root, after emerging from the spinal column becomes thickened by a collection of ganglion cells. This thickening is called the spinal ganglion. Beyond the ganglion the nerve divides into dorsal and rentral rami, which go to the skin.

In true fishes and in all higher vertebrates there has come about a shifting of parts such that the dorsal and ventral roots of a given segment come to lie nearly in the same transverse plane of the body and the two roots unite at or just beyond the ganglion 
of the dorsal root (Fig. I, B). The dorsal rami of the two roots unite to form a common dorsal ramus and the ventral rami unite to form a common ventral ramus. From the ganglion or from the common ventral ramus just beyond the ganglion, there arises a branch which enters a ganglion of the sympathetic system, by way of which the viscera are brought into connection with the central nervous system. The branch to the sympathetic system is known as the ramus communicans.

In the head region in all true vertebrates the central nervous system becomes considerably enlarged to form the brain. The
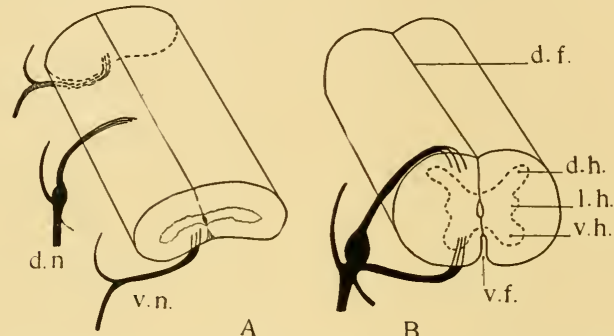

FIG. I.-Outlines of the spinal cord with the dorsal and ventral nerve roots; A, in Petromyzon; B, in a mammal. $d$. f., dorsal fissure; $d$. h., dorsal horn; $d . n$., dorsal nerve; l. $h$., lateral horn; $v$. f., ventral fissure; $v . h$., ventral horn; $v . n$., ventral nerve.

nerves connected with the brain are called cranial nerves. There is no sharp limit between spinal cord and brain or between spinal and cranial nerves, as there is none between trunk and head. The brain presents in the adult five constant and well marked portions which will serve as a guide in the description of the nervous system of the head. These are known as secondary segments of the brain and are named from behind forward: myelencephalon, metencephalon, mesencephalon, diencephalon and telencephalon (Fig. 2).

The myelencephalon, or medulla oblongata, appears as a gradual enlargement extending forward from the spinal cord. As the spinal cord merges into the brain the dorsal portions of the cord spread apart and the dorsal fissure seems to widen out into a 
broad thin membranous roof of the central canal. This canal at the same time becomes enormously enlarged and is known

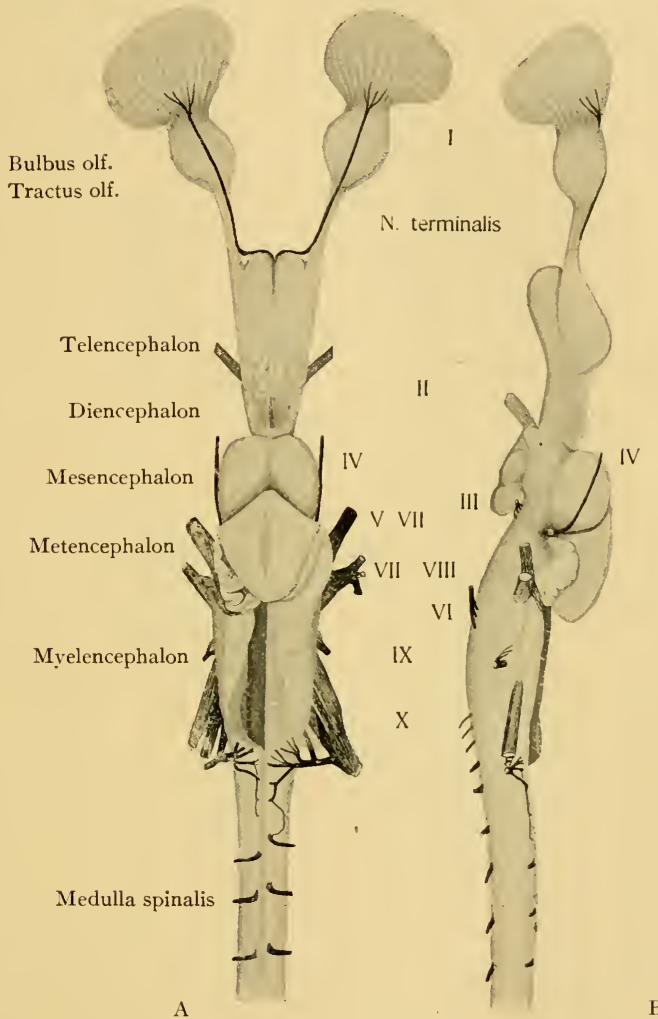

Fig. 2.-The brain of a selachian, Heptanchus. A, dorsal view; B, lateral view. The roots of the nerves are drawn in black as they appear after painting with osmic acid. The left half of the roof of the fourth ventricle is removed.

as the fourth ventricle of the brain. Its roof is called the plexus chorioideus of the fourth ventricle.

If the plexus be removed and the brain examined from within 
as well as from without, certain ridges and grooves will be seen which indicate a division of the myelencephalon into longitudinal zones (Fig. 3). The ventral portion of the myelencephalon appears to be a continuation of the ventral part of the spinal cord with slight modification. In the floor of the fourth ventricle is

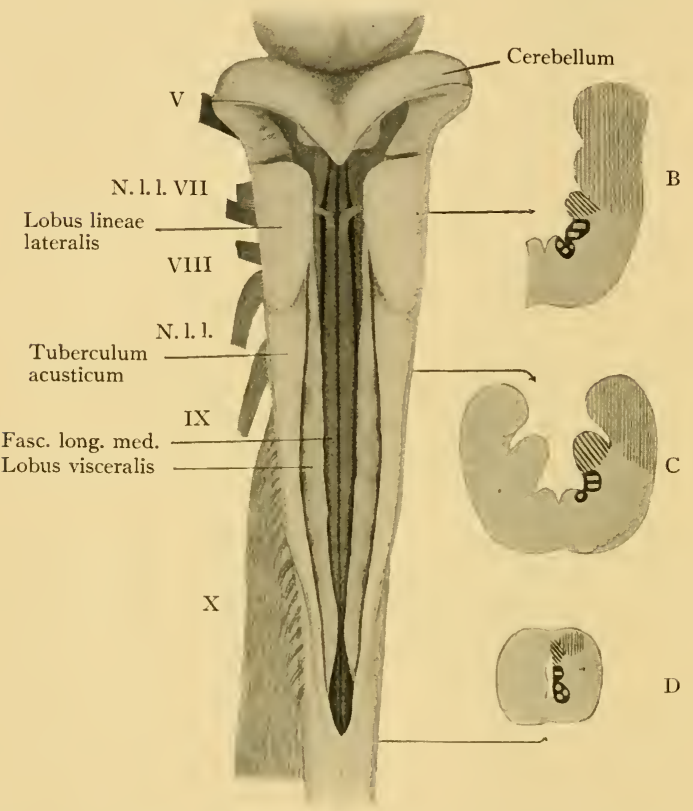

FIG. 3.- The medulla oblongata and cerebellum of the lake sturgeon (Acipenser rubicundus), to show the longitudinal zones. A, dorsal view with the choroid plexus removed. B, C and D, sketches of sections at the levels indicated by the reference lines. The dark area with light circles is the continuation of the ventral horn of the cord. The dark area with rectangular spaces is the continuation of the lateral horn. The area with oblique lines is the visceral sensory column (lobus visceralis). The area with vertical lines is the somatic sensory column.

to be seen a deep median groove bounded by two narrow but usually high ridges. The fiber bundles which make up these ridges bear important relations to the motor nerve roots. The 
ventral horns of the gray matter of the cord continue into the myelencephalon and are marked by two grooves which bound laterally the two ridges just mentioned. In the lateral zones there is much greater change from the cord to the brain. The greater size of the myelencephalon is due chiefly to the greater volume of these lateral parts and to their bulging laterally. From the internal surface of the lateral wall there projects into the cavity a ridge constituted chiefly of a thickening of the gray matter. It extends from the caudal end of the myelencephalon to near the cephalic end, stopping abruptly opposite the seventh or facialis nerve. This ridge has been known as the lobus vagi
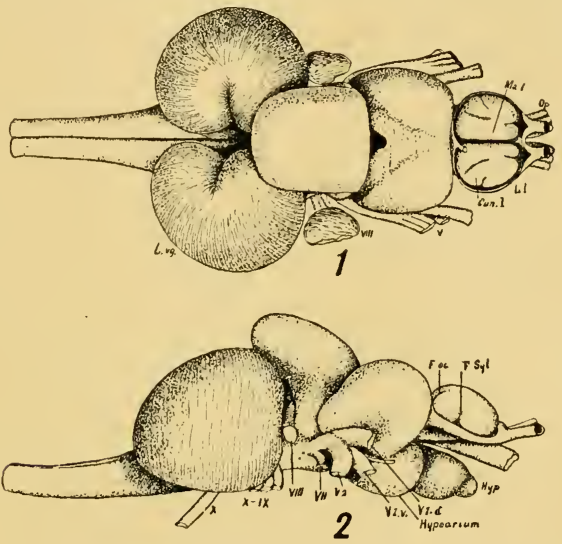

FIG. 4.- Two views of the brain of the buffalo fish, Carpiodes velifer (Raf.); (I) from above, (2) from the right side. Twice the natural size. From C. Judson Herrick after C. L. Herrick.

The vagal lobes $(L . v g$.$) are very large and, with the overhanging cerebellum,$ completely conceal the facial lobe. In the upper figure the cerebellum appears as a nearly rectangular body in front of the vagal lobes and in front of this is the roof of the mesencephalon. The optic lobes are pushed wide apart by the enormous valvula cerebelli within and the shaded area in the figure represents a membranous portion of the roof connecting the optic lobes. In front of this is the basal ganglion of the forebrain, the membranous roof of which has been cut away. The olfactory bulbs are cut away. In the lower figure the large inferior lobes are seen below the optic lobes and behind the latter the cerebellum is produced ventrally as the superior secondary gustatory nucleus. Immediately behind this and above the VIII nerve is the lobus lineae lateralis. The nerves of the trigemino-facial root complex are marked $V_{\text {I. }} d, V_{\mathrm{I}}, v, V_{2}$ and $V I I$, the auditory nerve $V I I I$, and the glossopharyngeus and vagus $I X$ and $X$. 
or the lobus facialis, owing to the relation which it bears to the vagus and facialis nerves. The ridge in cyclostome fishes is small, in selachians of moderate size, in ganoids (Fig. 3) relatively large and in some bony fishes enormous (Fig. 4, L. vg.). In some bony fishes, as in Carpiodes whose brain is shown in Figure 4, it is the caudal part of this ridge which is greatly enlarged. In other cases the cephalic portion is so large that it overtops all other parts of the medulla oblongata, and the ridges of the two sides may fuse in the median plane into a single mass, the lobus impar. As will be seen later (p. I 59) this ridge is the place of ending of the sensory fibers of the visceral surfaces in the head and of the organs of the sense of taste. The ridge would therefore be appropriately named the lobus visceralis. In amphibians, reptiles, birds and mammals the part of the brain corresponding to this lobe, although recognizable microscopically, is much smaller than in fishes and is not to be seen as a projecting ridge. The name visceral sensory column will be used for this whole. structure. When it forms a projecting ridge the term lobus visceralis may be used for the whole, or lobus vagi and lobus facialis for its two parts.

The upper part of the lateral wall of the myelencephalon is formed by a thick ridge of gray matter which is continuous caudad with the dorsal horn of the spinal cord and cephalad with the cerebellum. This ridge is more or less prominent in all lower vertebrates (see Figs. 2, 3) and its equivalent in mammals is to be found in the acustic nuclei and the restiform bodies. The ridge has been known as the tuberculum acusticum on account of its relation to the eighth cranial or auditory nerve. Since the ridge is the place of ending of all the cutaneous nerves of the head and since the term tuberculum acusticum is applied to a restricted portion of this region in mammals, it would be better to call this the somatic sensory column. In selachians and ganoids and to a less extent in cyclostome fishes a short part of this lobe projects prominently dorsad just behind the cerebellum. Since this is related wholly to nerves which supply the so-called lateral line organs, it is called the lobus lineae lateralis.

Most of the cranial nerves are connected with the myelen- 
cephalon. In this region the dorsal and ventral nerves remain separate from one another throughout life. Of the dorsal nerves the most caudal which can be recognized in all vertebrates corresponds to the tenth cranial or vagus nerve of human anatomy. This arises by numerous small roots some of which are sensory, others motor. The motor are situated slightly ventral to the sensory. The roots all unite into one large trunk which descends

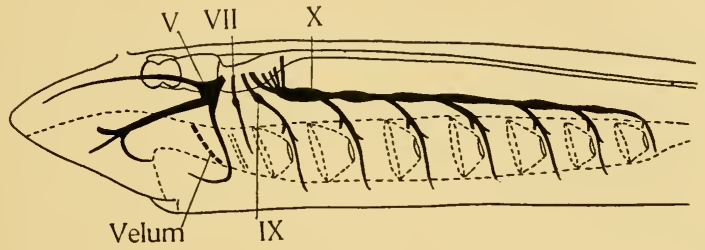

A

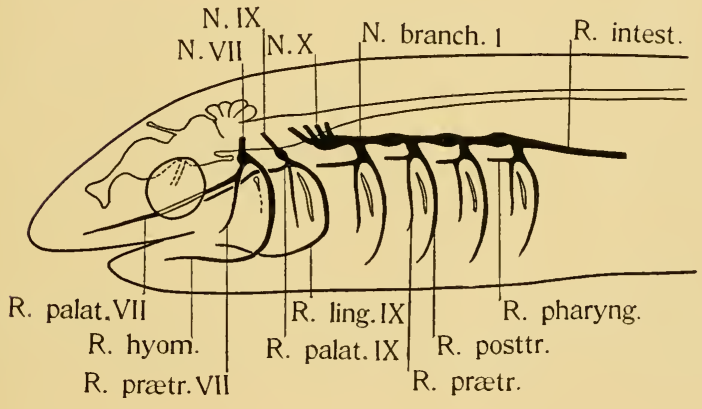

B

FIG. 5.-Simple diagrams of the branchial nerves of lower vertebrates as seen from the left side. $\mathrm{A}$, in a cyclostome; $\mathrm{B}$, in a true fish. In $\mathrm{B}$ the trigeminus nerve is not shown.

to the dorsal border of the second gill slit in fishes and there bears a ganglion (Fig. 5). From this ganglion a main trunk continues caudally and bears a ganglion over each gill slit. From each ganglion two rami arise. The first runs ventrally in front of the slit and is called the ramus praetrematicus. It gives the large 
ramus pharyngeus to the mucosa of the roof of the pharynx, and then supplies the gill filaments and the mucosa of the lateral and ventral walls of the pharynx. The other is the ramus posttrematicus which runs ventrally behind the gill slit and supplies the muscles of the branchial arch, gill filaments, the mucosa and taste buds, and in cyclostomes the overlying skin. Beyond the last gill slit the vagus trunk is continued caudad as the ramus intestinalis. In many forms especially among bony fishes the position of the roots and ganglia of the vagus with reference to the gills becomes modified and is not so simple as indicated in the diagram. Figures $5 \mathrm{I}, 63,79$ will show the arrangement in a cyclostome, a bony fish and an amphibian.

The more caudal motor roots of the vagus series supply certain muscles connected with the shoulder girdle (trapezius musculature). Owing to the disappearance of the gills in higher vertebrates and the consequent reduction of the more cephalic motor roots, these more caudal roots become more prominent higher in. the scale of vertebrates. They have been set apart as an independent nerve under the name of the eleventh cranial or spinal accessory nerve.

A short distance cephalad from the ragus appears the ninth cranial or glossopharyngeus nerve. It arises by a sensory and a motor root, bears a ganglion over the first gill slit, and gives rise to pharyngeal, pretrematic and posttrematic rami as in the case of each of the vagus ganglia. The pharyngeal ramus extends into the palate and is known as the ramus palatinus $I X$, and the posttrematic ramus is known as the ramus lingualis $I X$ because it continues into the tongue.

Above the glossopharyngeus, sometimes in front of and sometimes behind it, arises the nervus lineae lateralis. It is an independent sensory root which usually joins the trunk of the vagus and runs - for some distance with it, then continues separately beneath the skin as the nerve of the special sense organs of the lateral line. This nerve enters the dorsal somatic sensory lobe and cephalad from it two or three other roots enter the same lobe. The most caudal of these is the eighth cranial or auditory nerve. In front of this there are in cyclostomes, selachians and ganoids, two 
roots, the more dorsal connected with the lobus lineae lateralis and the more ventral connected with the tuberculum acusticum, which together supply the lateral line organs of the head. In bony fishes and aquatic amphibia only the more ventral root is present. In terrestrial vertebrates the roots which supply lateral line organs on both the trunk and head disappear because the sense organs are useful only in aquatic life. 'Of this group of nerves only the auditory remains in higher vertebrates. The nerves which supply the lateral line organs of the head enter into close relations

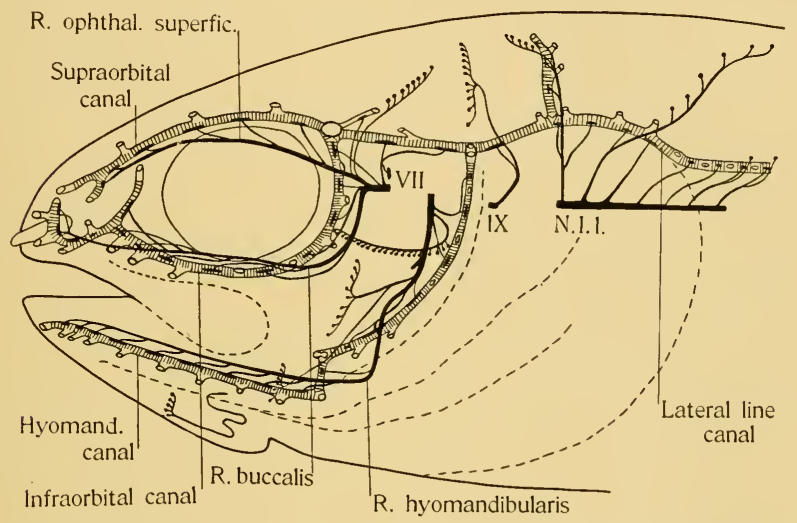

FIg. 6.-A diagram of the lateral line canals and pit organs together with the nerves which supply them in a ganoid fish (Amia calva). After E. Phelps Allis. The canals are shaded with cross lines and the canal organs are shown as black discs in the course of the canals. The pit organs are shown as rows of black dots. Only the peripheral nerve trunks are shown, the ganglia and roots being omitted.

with the facialis or trigeminus nerve and their rami have been variously named as rami of the latter nerves. Three chief rami are formed, a supraorbital, an infraorbital and a mandibular, which will be more fully described in a later chapter (see Chap. VII).

Ventrad or ventro-cephalad from the auditory root are the two roots, a sensory and a motor, which constitute the seventh cranial or facialis nerve. The two roots enter a ganglion from which 
arise the ramus palatinus to the mucosa of the roof of the mouth and a ramus hyoideus which is joined for some distance with the mandibular ramus of the lateral line nerves in the common ramus hyomandibularis, and eventually supplies the hyoid muscles and the mucosa of the floor of the mouth. The ramus hyoideus is a posttrematic ramus, since it runs behind the spiracular cleft when that is present, and there is often a pretrematic ramus running in front of the cleft and arising in common with the ramus palatinus.

The distribution of the organs of the sense of taste innervated by the X, IX and VII nerves is of great importance. In fish-like vertebrates the taste buds are found in the mouth and branchial carities. They are also distributed more or less widely on the outside of the head and in extreme cases, as in some bony fishes, on the fins and orer almost the entire body. They have usually no regular arrangement in rows and differ from the lateral line organs in that they usually project above the surface and are never depressed in pits or canals. In terrestrial forms the taste organs are confined to the mouth cavity.

From the cephalic end of the somatic sensory column of the myelencephalon the fifth cranial or trigeminus nerve takes its origin by a more dorsal sensory and a more ventral motor root. The roots enter a ganglion which is partly divided into two portions, a dorso-cephalic and a ventro-caudal portion. From the dorsocephalic ganglion a large nerve runs forward through the dorsal part of the orbit and supplies the skin of the snout and dorsal surface of the head. This is the nervus ophlhalmicus profundus and its ganglion may be known as the profundus ganglion. The ventro-caudal ganglion is properly known as the trigeminal ganglion. From it arise two large rami: the ramus maxillaris which supplies the skin beneath the eye and the lining of the front part of the roof of the mouth; and the ramus mandibularis which supplies the skin over the lower jaw and the muscles which move the lower jaw. These two rami are apparently comparable to the pretrematic and posttrematic rami of the branchial nerves, the mouth taking the place of a branchial cleft. The nerve complex consisting of the ophthalmicus profundus and trigeminus proper is fairly constant in its relations and size throughout 
the vertebrate series because of the constancy of the sensory area supplied by it, the skin of the anterior part of the head.

Two ventral nerves are connected with the myelencephalon, the so-called hypoglossus and the abducens. The hypoglossus or twelfth cranial nerve arises by a variable number of roots in cephalo-caudal succession in about the region of junction of brain and spinal cord. These roots unite into a common trunk or plexus which supplies the muscles of the tongue. In lower vertebrates it is evident that the roots are the equivalent of several ventral segmental nerves and form a simple continuation forward of the series of ventral nerves of the trunk. The number of such nerves present is greater in the more primitive forms. While in higher vertebrates an interval representing several segments

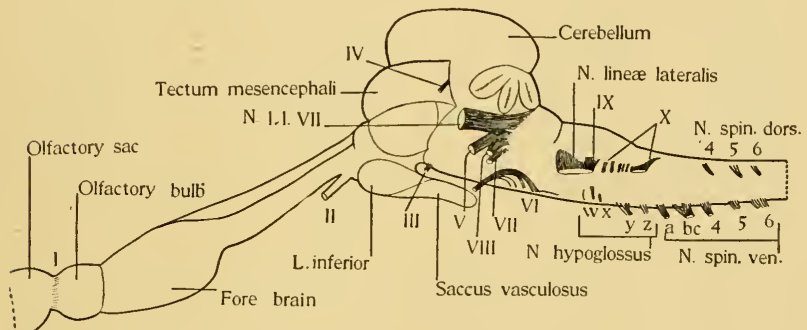

FIG. 7.-A sketch of the brain of Chimaera monstrosa from the left side to show especially the position of the nerve roots. The roots of the nerves were blackened by osmic acid and in this way one or more roots of the abducens and hypoglossus, not to be seen in ordinary dissections, were brought to view. The nerve roots are indicated by the usual Roman numerals. The hypoglossal and spinal roots are numbered $w, x, y, z, a, b, c, 4,5,6$, after Fürbringer's scheme.

intervenes between the roots of the hypoglossus and abducens, in such forms as Chimaera (Fig. 7), Heptanchus and related forms (Fig. 2), and in Petromyzon dorsatus (Fig. $5 \mathrm{r}$ ) only one or two ventral nerves are wanting in the series between the abducens and the ventral spinal nerves. In Bdellostoma the series of ventral nerves is quite complete except the eye-muscle nerves, which are wanting. The abducens or sixth cranial nerve also arises by several rootlets which may extend from the level of the VII nerve root back nearly to the level of the IX nerve. The 
nerve formed by these rootlets supplies the rectus externus muscle of the eye-ball.

The metencephalon is a short segment of the brain which ventrally appears to be merely a continuation forward of the myelencephalon, but dorsally is sharply distinguished by the possession of a massive roof instead of a choroid plexus. This massive roof is the cerebellum. It is large in all true fishes and in some selachians it is the most prominent part of the whole brain. In bony fishes it projects inward also, encroaching upon the fourth ventricle and largely filling the cavity of the mesencephalon. In cyclostomes, dipnoans and amphibians the cerebellum is very small, but in reptiles, birds and mammals it becomes progressively larger and more important. Its size is evidently correlated with the activity of the animal and with the number and importance of the cutaneous sense organs. In all vertebrates the cerebellum consists fundamentally of an arch of gray matter covered externally by a fiber layer which forms a commissure dorsally. The two pillars of the arch are continuous with the somatic sensory column of the medulla oblongata. In mammals and man the ventral wall of the metencephalon is greatly thickened and forms a ventral protuberance known as the pons Varolii.

That portion of the dorsal wall of the brain which connects the cerebellum with the mesencephalon is thin in most vertebrates and is known as the velum medullare anterius. This relum undergoes various modifications which are discussed in a later chapter (see p. I 7 I). The fourth cranial or trochlearis nerve, which crosses with its fellow in the relum and emerges from the brain between the cerebellum and mesencephalon, is reckoned with the cerebellar segment. It supplies the superior oblique muscle of the eye-ball.

The mesencephalon or midbrain is perhaps the most constant portion of the brain in vertebrates. Its ventral and lateral walls are always massive, its cavity a narrow canal, the aqueduct of Sylvius. Its dorsal wall is less thick and is divided by a longitudinal furrow into lateral portions which are known as theoptic lobes, because they serve as the place of ending of the fibers of the optic tract coming from the retina. In mammals the lateral 
lobes become divided by transverse furrows into anterior and posterior parts and the four bodies thus formed receive the name of corpora quadrigemina. The optic lobes vary in size in different classes of vertebrates, being noticeably larger in those animals in which the eyes are especially large and important (bony fishes, some selachians, birds, etc.). In mammals, however, the size of the eyes does not greatly affect the size of the corpora quadri-
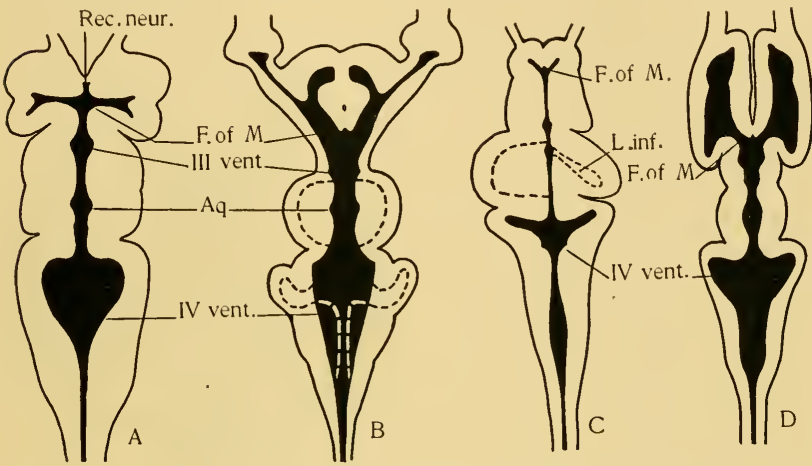

FIGS. 8, 9 and 10.- The outline of the brain and brain ventricles of several vertebrates as seen from above. The relative size of the brains is ignored in the figures but the form of the brain and ventricles is accurately drawn from dissections or microscopic sections.

FIG. 8.-A, the brain of a cyclostome fish, Lampetra Wilderi.

$\mathrm{B}$, the brain of a selachian, Mustelus canis. The outline of the ventricle in the optic lobes and cerebellum is drawn in dotted lines.

$\mathrm{C}$, the brain of a young specimen of a bony fish, Coregonus albus. On the left side is shown in dotted line the form of the optic ventricle, on the right side the outline and cavity of the inferior lobe of the diencephalon.

$\mathrm{D}$, the brain of a tailed amphibian, Necturus maculatus.

gemina (compare Chapter XVI). The cephalic border of the roof of the mid-brain is marked by the posterior commissure. The lateral and ventral walls of the mid-brain are in general comparable to the same portions of the medulla oblongata. From the ventral surface of the mesencephalon arises the third cranial or oculomotor nerve which supplies four of the eye muscles, rectus superior, rectus inferior, rectus internus and obliquus inferior.

The diencephalon or interbrain, although the smallest of the 
secondary segments of the brain, is one of the most interesting and important and presents many points of morphological significance and many variations in different classes of vertebrates. When seen from the side (Figs. 2, 7), it appears as a wedge-shaped segment, the edge of the wedge being upward. The short dorsal wall is mostly membranous, but is thickened at one point by the so-called superior commissure which connects the two small knob-like thickenings of the dorsal border of the lateral wall, the nuclei habenulae. These two bodies which are constantly
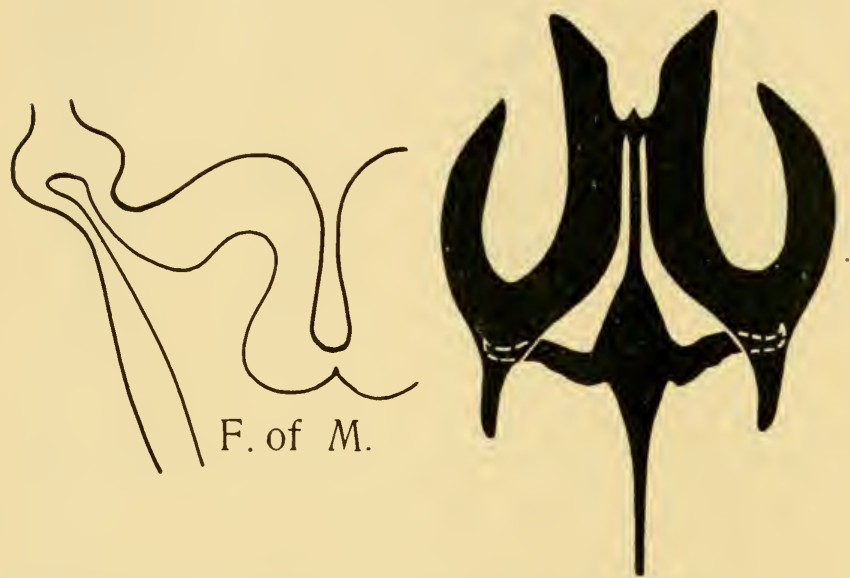

FIG. 9.-A diagram of one side of the forebrain of Mustelus canis to show what is believed to be the primitive relations of the wall and ventricle.

FIG. I0.- The outline of the ventricles in man.

present and of great significance in the vertebrate brain, are usually of unequal size on the right and left sides. Just behind the supe- rior commissure there arises from the dorsal surface of the diencephalon a small sac or tube which in cyclostomes, many fishes and reptiles extends through the cranium to end beneath the skin on the dorsal surface of the head. This sac in the forms mentioned bears some resemblance in structure to an eye and in several cases is probably functional as a light-percipient organ. 
It is hence called the pineal or parietal eye. It will be seen later (Chapter VIII) that there are in vertebrates two of these rudimentary eyes one behind the other. In amphibia, birds and mammals the parietal eye is quite rudimentary and in man is known as the pineal gland or body. The anterior border of the roof of the diencephalon is marked in lower vertebrates and in the embryos of all vertebrates by a deep transverse fold called the velum transversum (Fig. II). The velum forms the cephalic wall of a larger or smaller median sac of the choroid roof of the diencephalon, which may be called simply the dorsal sac. In mammals a median sac occupying nearly the same topographical position bears the name of paraphysis. It is nervous in character and its significance will be treated later (compare Chapter XVIII).

The lateral walls of the diencephalon are known as the optic thalami. They are thick and in lower vertebrates are traversed by the optic tracts on their way to the optic lobes, while in higher forms a large part of these tracts end in the optic thalami themselves. The ventral wall of the diencephalon in lower vertebrates is expanded and is divided by a median ventral furrow into lateral halves, known as the inferior lobes. These lobes are relatively small in cyclostome fishes and become progressively larger in selachians, ganoids and bony fishes. In vertebrates above the fishes the region corresponding to the inferior lobes is less expanded and in mammals it forms a funnel-shaped body with apex ventrad, which is called the infundibulum. (Compare Figs. 2, 7, xr.)

An evagination of the caudal wall of the inferior lobes or infundibulum in all vertebrates forms a pair of bodies projecting somewhat laterally and caudally which bear the name of mammillary bodies (corpora mammillaria, Figs. 2, II). Between and ventral to these the floor is thin and is produced caudally and ventrally into a thin-walled sac which is supplied richly with blood spaces. It is hence called the saccus vasculosus. It is present in all vertebrates but is much larger in the true fishes than elsewhere. Connected with the ventro-cephalic surface of the saccus is a glandular body properly known as the hypophysis (see p.66). The two together constitute the pituitary body. The so-called optic or second cranial nerve is connected with the rentral wall of the 
diencephalon and marks the cephalic border of the inferior lobes. These are not true nerves but central brain tracts, and will hereafter be called the optic tracts. In all vertebrates except bony fishes the two tracts as they enter the diencephalon form a deeussation which is more or less completely hidden in the wall of the brain. This is known as the optic chiasma. In bony fishes the chiasma is carried out from the brain wall and in many cases the two tracts cross one another at a considerable distance from the brain wall, on their way to the eyes.

The telencephalon or forebrain in the different classes of vertebrates presents great differences in both size and structure. The forebrain of some primitive selachians (e.g. Heptanchus, Fig. 2) consists clearly of paired lateral lobes which are somewhat elongated. At its anterior end each lobe is produced forward and laterally as a slender cylinder which becomes enlarged as the olfactory bulb. This lies in contact with the inner surface of the olfactory sac. From the epithelium of the olfactory sac, nerve fibers pass through the wall and directly into the olfactory bulb. These fibers constitute the olfactory or first cranial nerve. The slender portion connecting the bulb with the forebrain proper is the olfactory tract. Dorsally a membranous roof (tela chorioidea) connects and covers the lateral lobes, enclosing the forebrain ventricle. The rentricle in its caudal part is common to both lobes and in its cephalic part divides in $\mathrm{Y}$-shape and continues through the olfactory tracts to the olfactory bulbs. The common cavity together with that of the diencephalon is usually known as the third ventricle of the brain. The lateral or olfactory portions are to be compared broadly with the lateral ventricles of the mammalian brain (see Chapter XVII) and the point of their separation from the third ventricle is the foramen of Monro. It will appear later that the third ventricle extends a short distance forward beyond the opening into the lateral rentricles and these openings are therefore true lateral structures. It is necessary, therefore, to speak of paired foramina of Monro. The caudal border of the roof of the forebrain is marked by the velum transversum. In front of this the roof is produced dorsally into a tube or sac which varies in size and is more or less complexly branched 


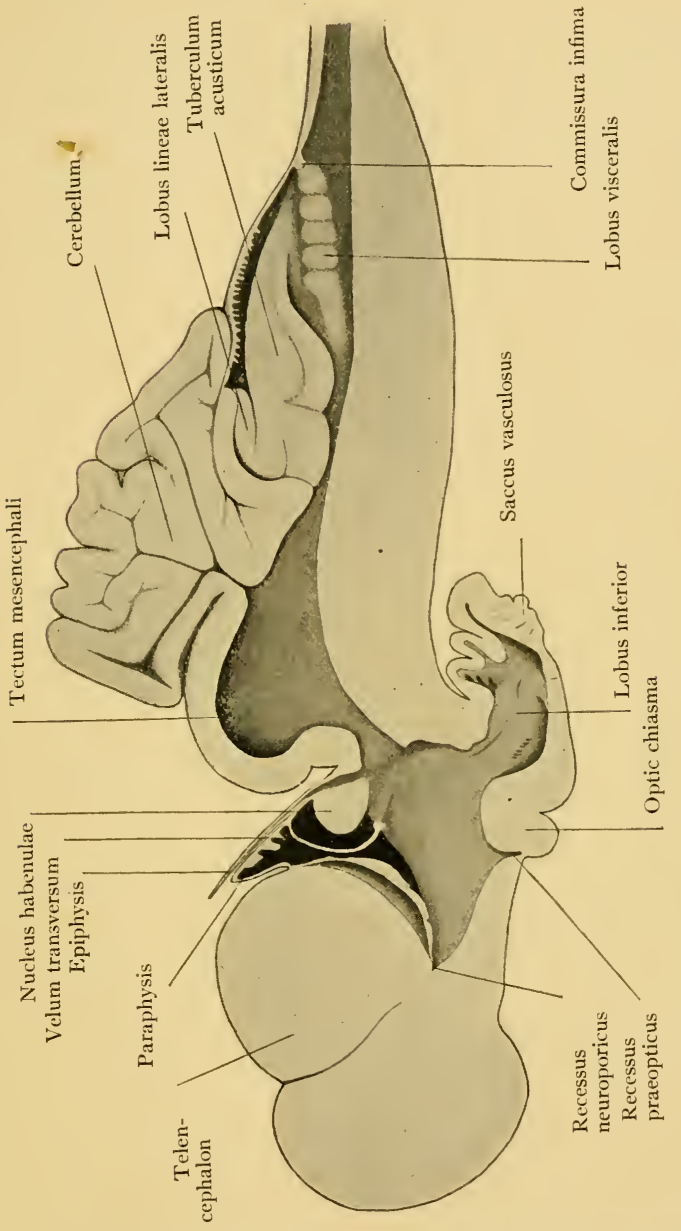

FIG. II - The mesial surface of the right half of the brain of a selachian, Squalus acanthias, to show the secondary segments of the brain, the longitudinal zones of the medulla oblongata, the form of the ventricle and the position of the inferior lobes, dorsal sac, paraphysis, etc. The olfactory bulb is not drawn (compare Fig. I 4 ). 
or folded in different vertebrates. This is properly called the paraphysis and is not homologous with the structure of the same name in mammals mentioned above (Figs. II, 36, I50, I $5^{2}, 158$ ). The latero-ventral walls of the forebrain are thick and are loosely spoken of as the corpora striata. The thin portion connecting these in the mid-ventral line is known as the lamina terminalis and is thickened at one place by the fibers of the anterior commissure.

In many other selachians (e.g. Squalus, Fig. II, Scyllium, Raja) the forebrain is shorter and more compact and massive. The olfactory bulbs are larger and the olfactory tracts usually shorter. The lateral lobes are shorter, thicker, and more rounded. The

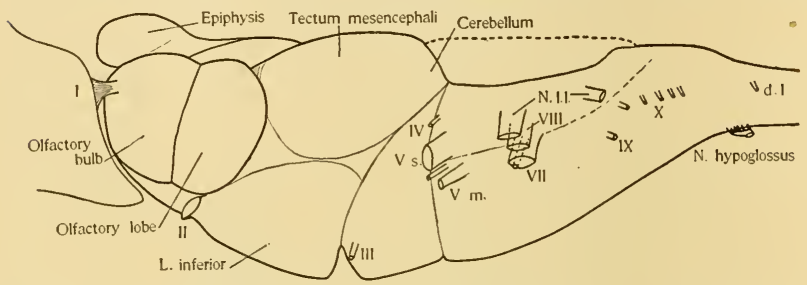

FIG. I 2.-A sketch of the brain of a cyclostome fish, Lampetra Wilderi, as seen from the left side. $d$. I, first dorsal spinal nerve; $N$. l. l., roots of the lateral line nerves; $V m$., two motor roots of the trigeminus, the smaller of which innervates an eye-muscle; $V s$., sensory root of the trigeminus.

brain is wider between the olfactory tracts and the massive nervous structure extends up on the dorsal surface farther, so that the choroid roof is shorter than in Heptanchus. So too, the median ventricle is shorter and the lateral ventricle is relatively more important. (Compare Figs. 2, II.)

The cyclostome forebrain (Fig. I2), although outwardly bearing a resemblance to the massive selachian type, in reality owes its form to the pressure which is exerted upon it by the great buccal funnel in front. The forebrain of ganoids and bony fishes resembles the elongated type of selachian brain, but is more slender and is simpler because the olfactory structures are less highly developed. The tela chorioidea is more extensive and the lateral lobes are smaller and more compact. The olfactory tract varies in length. The lamina terminalis is nearly horizontal (Figs. I48, I39). 
The forebrain of dipnoans and amphibians differs from the compact type in selachians in two ways. First, the olfactory tract is absent as an external feature and the bulb is connected directly with the lateral lobe. Second, the lateral lobes are separated from one another in front (Compare Fig. 8, B, D, and Fig. 9) the median ventricle is still shorter and the lateral ventricles are relatively still more important. The lateral lobes have complete nervous walls and the tela chorioidea covers only the median ventricle. In reptiles, birds and mammals the lateral lobes are fundamentally of the amphibian type but become larger and greatly modified in connection with the development of the cerebral hemispheres. (See Chapter XVII.)

In most vertebrates only one pair of nerves is connected with the forebrain. These are the olfactory nerves which were mentioned above. The olfactory nerve always arises from the sense cells of the nasal epithelium, has no ganglion in its course and enters the olfactory bulb. In addition to the olfactory there is found in many selachian and in some ganoid and dipnoan fishes another pair of nerves connected with the forebrain, whose presence is of the greatest importance in the study of the morphology of the nervous system. This new nerve arises from the upper or lower surface of the forebrain near the median line, bears a ganglion which is often lodged in the angle between the olfactory tract and the forebrain, passes forward along the olfactory tract and over the olfactory bulb, divides into branches and is distributed to the epithelium of the nasal sac (Fig. 2). This nerve differs from the olfactory nerve in that its fibers are myelinated, that it has a ganglion and that it enters the forebrain proper and not the olfactory bulb. Because of its attachment to the front end of the brain, this nerve has been called the nervus terminalis.

The figures in this chapter are intended rather to illustrate the typical form of the vertebrate brain and to bring out features of special morphological significance than to show the varying forms of the brain in different classes. For this the reader should refer to the figures in the larger text-books of zoology and comparative anatomy. 


\section{DEMONSTRATION OR LABORATORY WORK.}

I. Dissect the nerrous system of the dogfish or skate, the frog, and of a mammal (rabbit, cat, dog or man).

2. Compare the brains of representatives of all classes of vertebrates (Petromyzon; Squalus acanthias or Raja; Ameiurus, Catostomus or other bony fish; frog; lizard or turtle; fowl; mammal). Especial attention should be given to the relative size of the different parts and the correlation of these with the activities (habits) of the animals and the number and importance of the sense organs. The brains should be dissected with care in such ways as to expose the ventricles and all of the points mentioned in the text.

\section{LITERATURE.}

Allis, E. P., Jr.: The Cranial Muscles and Cranial and First Spinal Nerves of Amia calva. Jour. of Morphol., Vol. 2, I88o.

Dejerine, J.: Anatomie des centres nerveux Paris, I895.

Edinger. L.: Vorlesungen ueber den Bau der nervösen Zentralorgane des Menschen und der Thiere. 7te Aufl. Leipzig, Igo4.

Fischer, J. G.: Anatomische Abhandlungen über die Perennibranchiaten und Derotremen. Hamburg, 1864 .

Fürbringer, Max.: Ueber die spino-occipitalen Nerven der Selachier und Holocephalen und ihre vergleichende Morphologie. Gegenbaur's Festschrift, Bd. 3, Leipzig, 1896 .

Gaupp, E.: Anatomie des Frosches. Braunschweig, I897.

Gaupp, E.. Zirbel, Parietalorgan und Paraphysis. Merkel u. Bonnet's Ergebnisse, 1897 .

Gegenbaur, C.: Grundriss der vergleichende Anatomie.

vanGehuchten, A.: Anatomie du systeme nerveux del'homme. Louvain, I897.

His, W.: Zur allgemeinen Morphologie des Gehirns. Arch. f. Anat. u. Physiol., Anat. Abth., I8g2.

Merkel, Fr.: Ueber die Endigungen der sensiblen Nerven in der Haut der Wirbelthiere. Rostock, I880.

Museum of the Royal College of Surgeons of England. Catalogue of Physiological Series. Vol. II. (Description of brains chiefly by G. Elliot Smith.)

Quain: Text-book of Human Anatomy.

Rabıl-Rückhard, H.: Zur Deutung und Entwickelung des Gehirns der Knochenfisch. Arch. f. Anat. u. Physiol., Anat. Abtheil., 1882.

Retzius, G.: Das Menschenhirn.

Spalteholtz-Barker: Atlas of Human Anatomy. 1905.

Stannius, H.: Das peripherische Nervensystem der Fische, anatomisch und physiologisch untersucht. Rostock, I 849 . 
Stannius, H.: Handbuch der Anatomie der Wirbelthiere. 2te. Aufl. Berlin, I854.

Wiedersheim, Robert: Vergleichende Anatomie der Wirbelthiere. 6te. Aufl. Leipzig, rgo6.

Ziehen und Zander: Nervensystem. In Handbuch der Anatomie des Menschen. Herausg. von Bardeleben, I899-1903. 


\section{CHAPTER III.}

\section{DEVELOPMENT OF THE NERVOUS SYSTEM.}

It is hoped in this chapter to bring to the attention of the student those features and processes in the development of the nervous system which are of the greatest morphological importance, and especially to bring forward certain facts which have not received full treatment in text-books of embryology. There will not be space for such a full and orderly treatment of the development as an elementary student in embryology would require. For this reason it will be assumed that the student is familiar with the more general facts in the development of some vertebrate such as the frog or chick.

It is commonly believed that all nervous functions are performed by structures derived from the ectoderm. In the early vertebrate embryo a certain area on the dorsal surface is to be recognized as the anlage of the greater part of the nervous system. This area is known as the neural plate. It becomes visible first as an area bounded on either side by slightly elevated ridges or folds, the neural folds. These folds are continuous in front and behind and enclose an area which is broader in front, in the region corresponding to the future brain (Fig. I $8 \mathrm{~A}$ ). This somewhat banjoshaped neural plate and the folds which bound it give rise to the brain and spinal cord, the greater part of the sensory nerves with their ganglia, the motor nerves and the retina. The olfactory epithelium, the sensory epithelium of the ear and lateral line organs, and the ganglia and nerves of these organs are derived from parts of the ectoderm closely related to the neural plate. The organs of taste appear first in the embryo in the entodermal lining of the branchial cavities. In fishes they appear later in the outer skin also and their history requires further investigation.

In all vertebrates the neural plate becomes converted into a tube lying below the surface of the body. In all except cyclostomes 
and bony fishes this is accomplished by the neural plate rolling or folding up so that the neural folds meet above. The folds begin to fuse together at a point which later falls in the region of the mesencephalon or farther caudally, and the fusion continues forward and backward until a complete tube, the neural tube, is formed. The tube remains open for some time at the anterior end; the opening is called the neuropore. At the caudal end the tube remains for some time in connection with the archenteron by way of the neurenteric canal. The extent and relations of the neuropore will be important in later connections; the neurenteric canal need not claim further attention. In the mean time the general ectoderm fuses over the dorsal surface of the neural tube

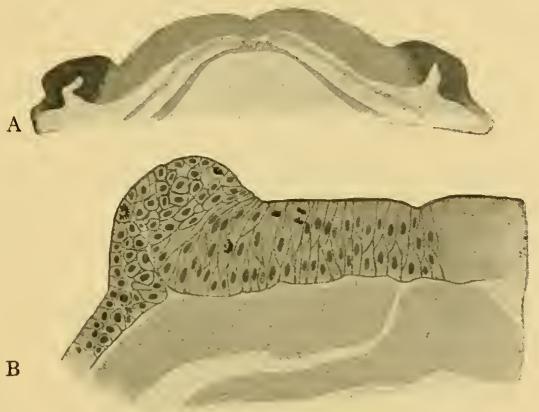

FIg.313.- Sections of the neural plate and folds in amphibia. A, the cephalic portion of the neural plate in Amblystoma tigrinum. The neural folds are more darkly shaded. It is evident that they are actual folds of the ectoderm. B, one side of the neural plate of Amblystoma punctatum at a slightly more advanced stage of development and at a higher magnification.

and when the neuropore closes the tube lies wholly beneath the surface of the body. In cyclostomes and bony fishes the same results are reached by the neural plate thickening and sinking down as a solid cord of cells which comes to lie beneath the ectoderm. Within the cord of cells appear clefts which unite into a continuous canal.

Roughly speaking the neural tube goes to form the spinal cord, brain and motor nerves. During its development, the material 
from which the sensory nerves are derived is taking on definite form in close relation with the neural tube. The accompanying figures illustrate the development of the neural tube and the ganglia of the sensory nerves in amphibia. As seen in Figure 13

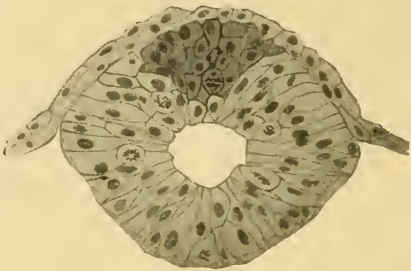

Fig. I4.-Transverse section of the neural tube of Amblystoma punctatum just after closing. The cells which will form the neural crest are more darkly shaded. Mitotic figures are seen at all levels in the wall of the tube.

$\mathrm{B}$, the neural plate consists of columnar cells, while the neural folds which bound it consist of two or more layers of somewhat cubical cells irregularly arranged. As the edges of the neural plate close up to form the neural tube (Fig. I4), the neural folds

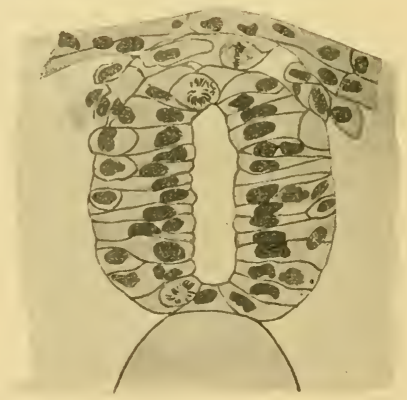

FIG. 15.-Transverse section through neural tube, neural crest and ectoderm of Amblystoma punctatum at a later stage than that shown in Fig. I4.

form a sort of bridge connecting the tube with the ectoderm. Now the cells which originally formed the folds separate from the ectoderm and extend laterally on the surface of the neural tube, between it and the ectoderm (Fig. I5). Some of these cells remain 
connected with, and some actually enclosed within, the dorsal wall of the tube adjacent to the seam of closure. There results a pair of continuous flaps or ridges of cells connected with the neural tube at its mid-dorsal line and spreading laterally between the tube and the ectoderm (Fig. I5). These are known as the neural ridges or crests and contain the cells which enter into the formation of the spinal ganglia. This condition of the ganglionic material may be taken as typical for the embryos of vertebrates. In fishes a relatively large number of neural crest cells remain within the neural tube and there give rise to sensory fibers

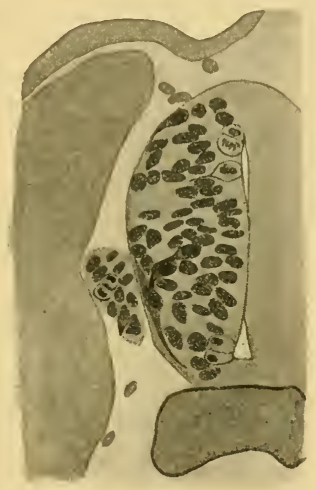

FIG. I6.-Same as Fig. I5, later stage. The cells of the neural crest have migrated ventrally to form a spinal ganglion. Processes are seen upon neuroblasts within the tube and upon one spinal ganglion cell.

which run to the skin. These are the so-called giant ganglion cells of the spinal cord of fishes (Fig. I7). These facts suggest that the cells which give rise to sensory nerve fibers originally lay within the neural tube and have migrated to form the spinal ganglia. Already in Amphioxus, however, a large part of the spinal ganglion cells are situated in the roots of the nerves outside of the spinal cord. In the brain region the neural crest is formed in essentially the same manner as in the trunk, but two very noteworthy facts are to be pointed out. The first is that in the region opposite the ear the neural crest is entirely absent for a short dis- 
tance. The second is that in front of the mesencephalon the crest is either very small or so modified that it can not be readily compared with that of the trunk.

While these changes are taking place two special sense organs are making their appearance, the olfactory and auditory organs. Both are formed from parts of the ectoderm immediately adjacent to the neural plate. The olfactory organ appears as a pair of thickened patches of ectoderm at the cephalic border of the neural plate at either side of the neuropore. These patches eventually become depressed and form deep olfactory pits. The auditory organs arise on the dorso-lateral surface of the head opposite the region of the future myelencephalon. These are also at first thickened patches which sink in and form deep pits, which eventually separate

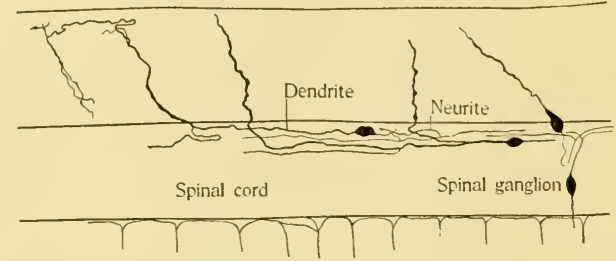

FIG. 17.-A part of the spinal cord of an I8-day Catostomus embryo showing two giant ganglion cells. Golgi method.

from the ectoderm as closed sacs and may press against the neural tube on either side. These auditory sacs exercise a great influence on the form and course of development of other organs.

If now the neural tube be examined either in frontal sections or in embryos so dissected as to lay the tube bare, it will be seen that the tube is divided by slight transverse constrictions into successive segments approximately equal in length. These segments are called neuromeres. The neural crest is divided into corresponding segments and, as shown in Fig. I8, the segmentation of the crest is present in the neural plate stage in selachian embryos. While these neuromeres have been clearly seen and described in the region of the hindbrain and spinal cord in all classes of vertebrates, in the anterior portions of the brain they are of shorter duration and are more difficult to study. In selachians, bony 
fishes and the chick, however, they have been studied and described and some of the important stages in their history are shown in the accompanying series of figures. (Figs. I8, r9.)

In the trunk region where the number of neuromeres corresponds to the number of muscle segments and the neuromeres alternate in positon with the muscle segments, the embryonic condition is essentially continued into adult life. In the head
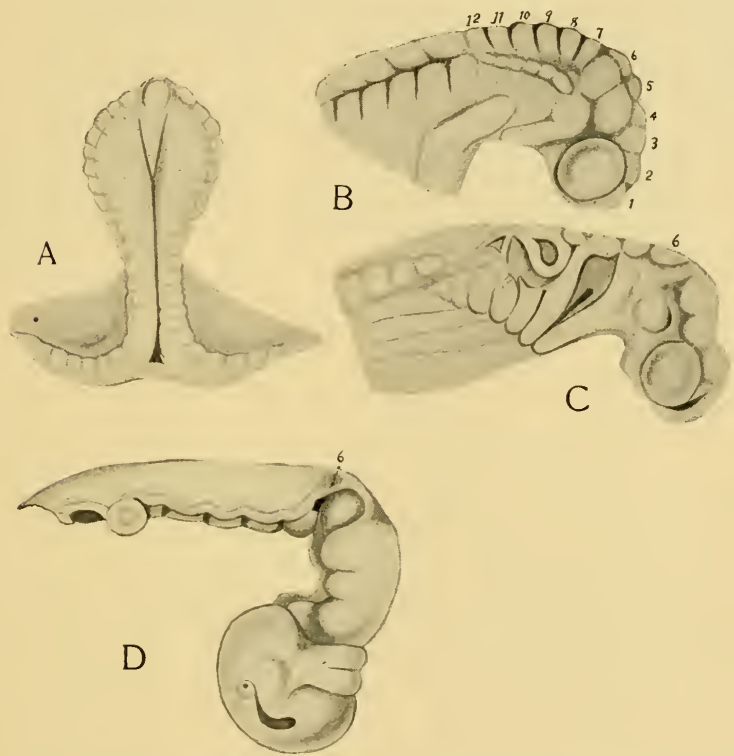

Fig. 18.--Four stages in the development of the selachian brain to show the history of the neuromeres. After Locy. In A, B and C the whole head is shown, in $\mathrm{D}$ the brain alone. The Arabic numerals indicate the neuromeres.

region, where great changes take place during embryonic development, the neuromeres share in these changes and in the adult brain the embryonic neuromeres are lost from view. The causes for this are manifold, but perhaps the chief ones are the bending downward of the head, the crowding of the brain produced by its growing more rapidly than surrounding organs, and above all 
the rapid growth of those parts of the brain which are destined to become large and important in the adult. One result of these forces is the appearance early in embryonic life of certain bends

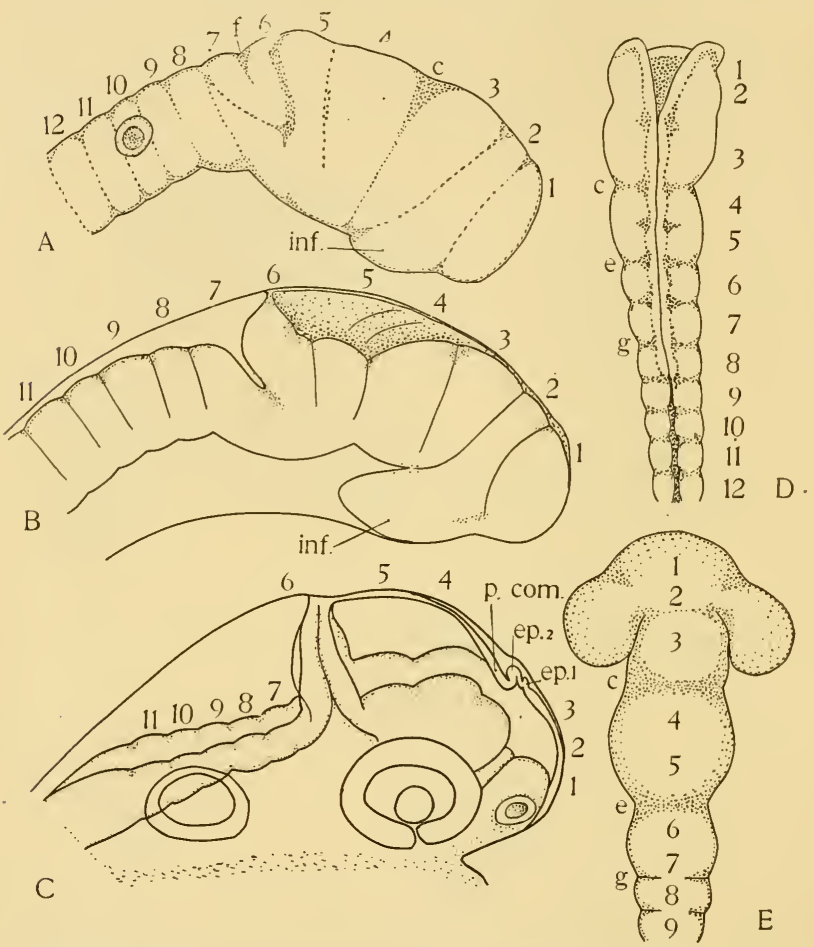

FIG. I9.- The history of the neuromeres in the bony fish and the chick. A, B, C, three stages in the development of the bony fish, as seen from the right side. D, E, the brain of the chick. After Hill. The letters $c . e . g$. mark corresponding furrows in the chick brain; $e p$. I, $e p .2$, anterior and posterior epiphyses; inf. inferior lobe; $p$. com., posterior commissure. The neuromeres are indicated by Arabic numerals.

or flexures. These are illustrated in the figures which show the neuromeres (Figs. I8, I9) and also in Figure 20. In the neck region, owing to the bending of the head, the brain is bent down- 

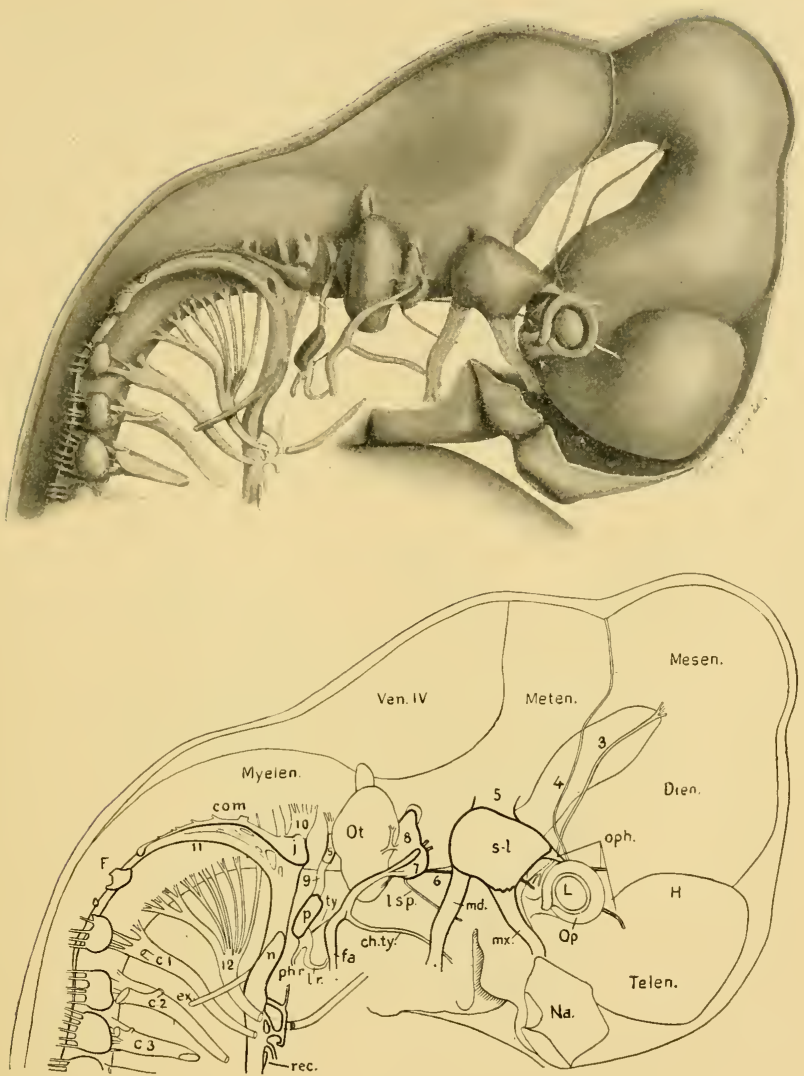

FIG. 20.- Reconstruction of the brain and cerebral nerves in a $12 \mathrm{~mm}$. pig embryo. (From Minot's "Laboratory Text-Book of Embryology." Drawn and revised by $\mathrm{F}$. T. Lewis.)

Nerves. 3, oculomotor. 4, trochlear. 5, trigeminal, with its semilunar ganglion, $s-l$, and three branches,-oph., ophthalmic; $m x$., maxillary; $m d$., mandibular. The motor portion, which goes with the mandibular branch, is concealed in this view by the sensory portion. $\mathbf{6}$, abducens. $\mathbf{7}$, geniculate ganglion of the intermedius. Fibers from this ganglion mix with the motor fibers of the facial nerve, so that both sensory and motor fibers are found in the three branches, -l.s. p., large superficial petrosal; ch. $t y$., chorda tympani; fa., facial. 8, acoustic, showing an upper vestib- 
ular portion, and a lower cochlear portion. 9, glossopharyngeal with its superior ganglion, $s$, above; its petrosal ganglion, $p$, below; and its three branches, $-t y$., tympanic; l.r., lingual ramus; ph.r., pharyngeal ramus. 10, vagus, with its jugular ganglion, $j$, extending posteriorly as a ganglionic commissure, com.; and below, its ganglion nodosum, $n$. Its branches form the laryngeal plexus, beyond which is the recurrent nerve, $r e c$. Just below the jugular ganglion is the auricular branch of the vagus. II, accessory, which joins the vagus; ex., its ramus externus. 12, hypoglossal. F., Froriep's hypoglossal ganglion. C. I, C. 2, C. 3, cervical nerves.

Brain and Sense Organs. Telen., telencephalon. Dien., diencephalon. Mesen., mesencephalon. Meten., metencephalon. Myelen., myelencephalon. H., hemisphere. Ven. IV., roof of the fourth ventricle. Op., optic cup. L., lens. Na., nasal pit. Ot., otocyst.

ward in relation to the spinal cord. Farther forward a sharper flexure in the opposite direction is found, called the pontial flexure, because the pons of higher vertebrates appears at this point. Then the front end of the brain is curved down again in such a way as to bring the ventral surface of the brain just behind the

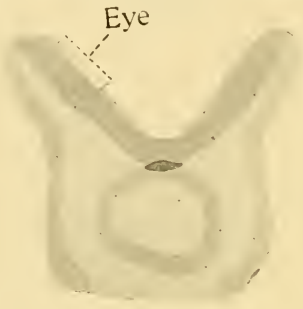

A

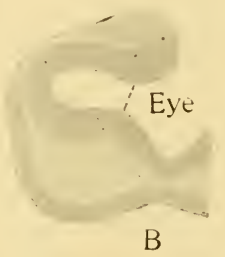

Eye

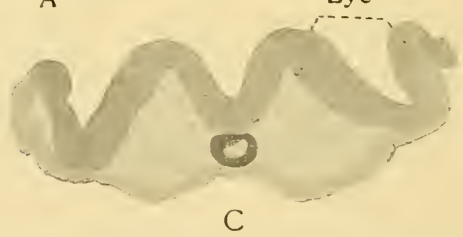

FIG. 2I.-Transverse sections through the region of the optic vesicles in selachian, avian and mammalian embryos: A, Torpedo ocellata: B, Gallus domesticus ; C, Cavia cobaya. After Froriep. These and the following figure show that the optic vesicles arise from the borders of the neural plate.

closed neuropore nearly into contact with the pontial flexure. The last bend, from its position in the parietal region of the head, is called the parietal flexure. It corresponds in position to the future mesencephalon. These flexures are in themselves of no 
fundamental importance, except as the adult form of certain parts of the brain and the position of some of its nuclei are doubtless determined by the influence of the flexures in these early stages. As the head of the embryo straightens out and as the growth of the other organs relaxes the pressure upon the brain, the flexures tend to disappear and they are to a large extent obliterated in the brains of lower vertebrates (compare Figs. 2, II, I2, I 58 ).
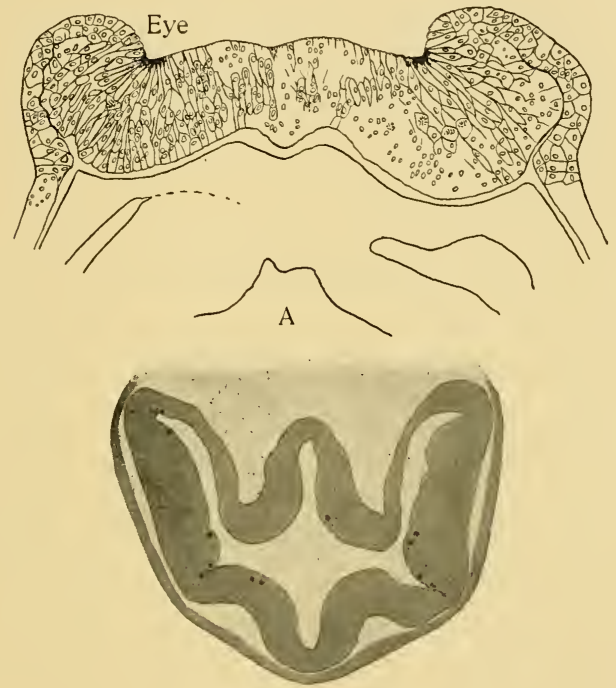

B

Fig. 22.-The development of the optic vesicles in Amblystoma punctatum. Fig. $22 \mathrm{~A}$, should be compared with a similar figure by Eycleshymer. In B the germinal cells in process of division are shown by small black figures.

In the meantime the rapid growth of certain parts of the brain while the flexures are still present, results in deepening the constrictions between certain of the neuromeres and the obliteration of others, and produces the prominent secondary segments which have been described in the previous chapter. Only a brief summary of these changes can be given here, since a full description would 
require much more space than can be devoted to it. The forebrain is formed by the relatively enormous growth of the first neuromere, especially of its dorsal part. The optic vesicle, which will be treated more fully later (Chapter VIII), is formed from the dorsal part of the second neuromere. In the ventral portion of the second neuromere there is a great expansion which results in the formation of the inferior lobes and mammillary bodies. The floor of the second neuromere is depressed just behind the optic stalk and expanded backward beneath the third neuromere. The extreme ventro-caudal portion of the inferior lobes thus formed becomes thin-walled and is supplied with a great profusion of blood spaces. This is the saccus vasculosus which becomes closely related with the hypophysis in the pituitary body. The slight constrictions between neuromeres $\mathrm{i}$ and ii, and ii and ii quite disappear, while that between neuromeres iii and iv remains and is deepened. The formation of the parietal flexure is largely due to the great growth of the dorsal part of neuromeres iv and $\mathrm{v}$, where the optic lobes are to be formed. The whole of neuromeres iv and $\mathbf{v}$ fuses into the mesencephalon and the constriction between neuromeres $\mathbf{v}$ and $\mathbf{v i}$ is deepened more than any other. This marks the boundary between the midbrain and cerebellum and is known in the adult as the isthmus. Neuromere vi forms the metencephalon and the dorsal part of it becomes greatly enlarged in many vertebrates as the cerebellum. The neuromeres from number vii caudally enter into the medulla oblongata and spinal cord, the exact number belonging to the medulla being uncertain, since no definite limit can be fixed between brain and spinal cord. It is possible that this limit varies in different vertebrates. As the result of these changes, the brain loses its primitive segementation and comes to be divided into five secondary segments of unequal size.

The optic vesicle has been mentioned as formed from the dorsal part of the second neuromere, the first of the two which constitute the diencephalon. At a very early stage while the nervous system is still in the form of a flat neural plate, the area which is destined to enter into the retina may sometimes be recognized in the broad cephalic part. The two retinal areas lie near the lateral borders 
of the neural plate. When the neural tube is formed these areas at once bulge laterally. They seem upon casual observation, for example in the chick, to involve nearly the whole lateral wall of the first two or three neuromeres. Careful examination shows clearly, however, that in fishes, amphibia, birds and mammals, these pouches belong strictly to the dorsal part of the brain, and they probably belong to a single neuromere, the second. The pouches grow out farther, retaining a portion of the brain ventricle, and finally come to be constricted next'to the brain so that they remain connected with the brain wall only by a narrow stalk. The pouch is now known as the optic vesicle and the stalk as the optic stalk. Figures 18 to 20 show the optic vesicle in various stages of growth and Figures $2 \mathrm{I}$ and 22 represent it in transverse section. As the vesicle is formed it is crowded between the brain and ectoderm so that it is flattened. The flattening continues until the cavity becomes a narrow cleft and the vesicle becomes somewhat saucer shaped. The constriction from the brain takes place from above downward so that the stalk comes to be attached near the ventral border of the vesicle. As a result of the same process the attachment of the stalk to the brain has shifted ventrad to reach the position afterward occupied by the optic chiasma. In the meantime the two walls of the optic vesicle begin to be differentiated, the outer wall growing thicker to form the retina and the inner wall remaining thin. Finally the portion of the brain ventricle which was carried out into the optic vesicle is obliterated but in many lower vertebrates a restige of the cavity is retained in the stalk. This lumen connects with the preoptic recess, a depression of the floor of the third ventricle in front of the optic chiasma.

Histogenesis.-The development of the microscopic structure, the histogenesis, of the brain, nerves and sense organs is going on at the same time with the development of the form of the brain. The neural tube consists at first of two incomplete layers of cells irregularly arranged (Figs. I3, I4), among which are some columnar cells which extend through the whole thickness of the wall. A little later the columnar cells become radially arranged around the lumen of the tube (Figs. I4, I5), and the shorter cells lie between 
them bordering upon the lumen or upon the external surface. The columnar cells retain their position throughout life, extending from the central canal to the surface. Since they give rise to a sort of meshwork or trellis which serves largely to support the nervous elements, these cells are called spongioblasts. The inner ends of neighboring spongioblasts fuse to form an internal limiting membrane bounding the central canal and the outer ends may form a similar external limiting membrane. The nuclei of the spongioblasts are situated in the middle and internal portions of the wall, the outer portion remaining relatively free from nuclei. Those spongioblasts whose nuclei occupy the internal ends of the cells become the ependyma cells of the adult brain.

Among the spongioblasts are cubical or rounded cells which are multiplying rapidly, so that many of them contain mitotic figures. They are known as germinal cells. While a few of these cells lie in the thickness of the wall or eren upon the external surface, the great majority border on the central canal (Figs. I3 B, I4, I5, r6). The germinal cells are believed to give rise to all the nervous elements in the brain and spinal cord and to the stellate cells which with the spongioblasts make up the neuroglia. In general the history of both nerve cells and glia cells is the same. The cells produced by the division of the germinal cells migrate or are pushed toward the periphery of the cord or brain and then, supported by the meshwork of the spongioblasts, undergo development into specific nerve or glia cells.

Those cells which are destined to form nerve cells are called neuroblasts. These continue to multiply rapidly by mitosis but the number of mitotic figures seen in the nervous system becomes rapidly less in later stages of development and in the adult the division of nerve cells is comparatively rare. The first step in the formation of a functional nerve cell from a neuroblast is the production of processes somewhat similar to the pseudopodia of an amoeba. First the neuroblast becomes drawn out at one end into a slender filament which is recognized as a nerve fiber (Fig. I6). The presence of this cell fiber is the only mark by which the neuroblast can be distinguished with certainty from spongioblasts or glia cells. The nerve fibers may collect into bundles 
as they are formed and in general the fibers run to the outer surface of the cord or brain, forming a peripheral fiber layer. Some time after the formation of the nerve fiber the neuroblast gives off other processes which branch more or less richly in the substance of the brain wall. The nerve fiber first formed remains always a relatively slender fiber of nearly uniform diameter. It is called the neurite. The processes later formed become more or less bush-like and are known as dendrites.

In most parts of the central nerrous system the greater number of nerve cells remain near the central canal and there form the central gray matter. But many cells migrate toward the surface and in some parts of the brain very rich layers of nerve cells are found

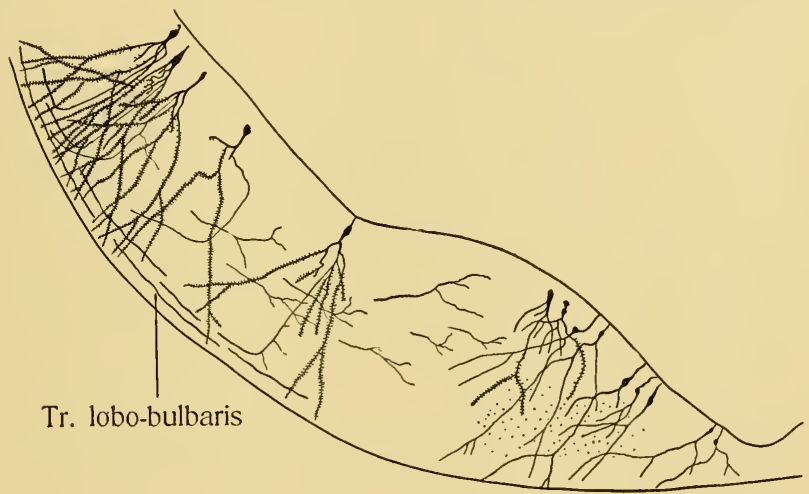

FIG. 23.-A part of a transverse section of the inferior lobe of the sturgeon, stained by the Golgi method. The cells all retain their primitive position adjacent to the cavity.

at the outer surface. In fishes it is observed that in any given part of the brain those cells which are farthest removed from the central canal have undergone the greatest modifications of form as compared with the simple structure of the neuroblasts. The dendrites may become more richly branched, more numerous and more widely extended; they may be disposed parallel with the surface or otherwise modified to increase their 
functional efficiency. It is worthy of notice that in the central gray matter in lower vertebrates a large part of the cells have central processes which reach, and perhaps take part in, the internal limiting membrane. These cells seem to show that the bodies of cells formed from neuroblasts migrate toward the periphery, but their inner ends remain connected with the internal limiting membrane and become drawn out into long central processes. Other cells situated at the extreme periphery in the fish brain are probably derived from peripheral cells of

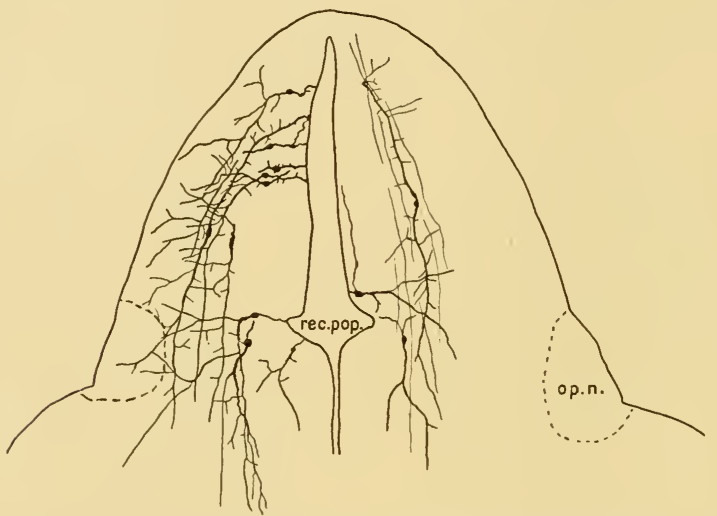

Fig. 24.-A horizontal section of the nucleus praeopticus of the sturgeon. Golgi method. The cells have migrated toward the periphery but retain their connection with the internal limiting membrane by means of central processes.

the neural tube such as are seen in Figures It and I5. Figures 23,24 , and 25 , taken from the brain of the sturgeon, illustrate these relations.

While the histogenesis is in progress certain changes of form in the neural tube are taking place. The most important of these is the appearance of longitudinal zones. In the region of the spinal cord it is noticeable that the walls of the neural tube do not increase in thickness equally. The lateral walls thicken, while along the mid-dorsal and mid-rentral lines the tube remains thin. These thin bands have been named by His roof-plate and floor-plate, 
respectively. They remain relatively thin throughout life. As the spinal cord grows it expands laterally and ventrally at the sides of the floor-plate, so that the floor-plate comes to form the bottom of a deep groove which was mentioned in the last chapter as the ventral fissure. At the mid-dorsal line such an open fissure does not appear but it is represented by a septum of connective tissue. Two other zones which probably have much greater significance are marked by a groove which appears on the inner face of each lateral half of the cord. This pair of grooves causes a widening of the central canal and a thinning of the wall of the tube, so that each half of the cord is divided into a dorso-lateral and a ventrolateral zone or column. These zones were first brought to notice by His, who described them in the human embryo. There is

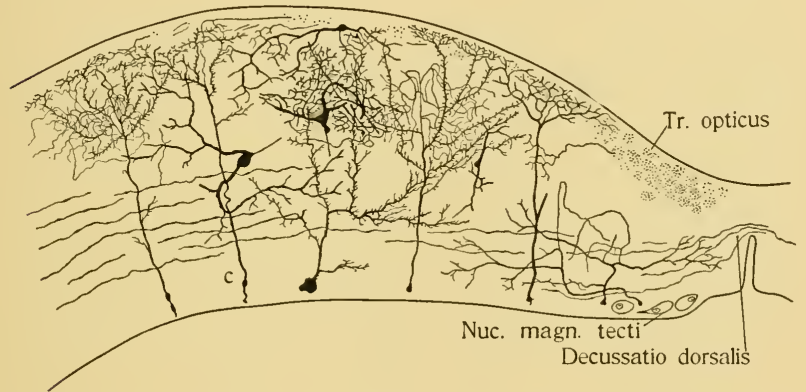

Fig. 25.-A part of a transverse section of the optic lobe of the sturgeon. The cells farther removed from the ventricle are more highly developed.

reason to suppose that the dorso-lateral zone includes the two sensory columns to be described in later chapters and that the ventro-lateral zone includes the two motor columns.

Observations on these zones in embryos of other vertebrates are much to be desired.

The DEVELOPMENT OF THE PERIPHERAL NERVES.-The development of the sensory nerves is a very complex matter, especially in the case of the cranial nerves, and an account of its main outlines only can be given. It was said above that the neural crest 
shared in the segmentation of the neural tube. The cells of the crest multiply by mitosis and in the trunk region each segment moves latero-ventrad at the sides of the spinal cord, between it and the adjacent ectoderm and mesoderm. At the same time the segments separate more and more from one another until there are formed a series of flaps attached to the dorso-lateral surface of the cord and hanging down on its lateral surface opposite the interval between each two mesodermic somites. Each of these segments of the neural crest may now be spoken of as the anlage of a spinal ganglion. Each anlage moves further ventrad and may wholly lose its connection with the cord (see Figs. I5, I6). The cells are now elongated, spindle-shaped and it is soon noticed that each cell elongates further as if each end were being drawn out into a slender thread. In fact a process analogous to a pseudopodium grows out from each end of the cell. The process from the upper end of the cell, or central process, appears first and is from the first distinctly more slender than the opposite, or pheripheral process. The central process is therefore to be considered as the neurite, the peripheral process as the dendrite. Figure 26 is from part of a transverse section of an embryo of Amblystoma punctatum at the level of the glosso-pharyngeus ganglion. The central processes of the ganglion cells are growing upward, the peripheral processes are not yet formed. Figure 27 shows a few ganglion cells of the trigeminus nerve. The peripheral processes of the cells are seen but the central processes bend backward so that they do not fall in the same section.

The central processes soon reach the dorso-lateral surface of the spinal cord and grow into the cord where they form a bundle of afferent or sensory nerve fibers. The peripheral fiber grows also and with its fellows forms a sensory nerve or the sensory portion of a periplieral nerve trunk. The peripheral process sometimes divides, its branches entering two nerve rami. This is analogous to the branching of the dendrites of central nerve cells. The fibers continue their growth, following the path of least resistance between the muscles and other organs, until they reach the area of their ultimate distribution, for example in the skin, where they divide into terminal branches. The cells 
from which the fibers have grown out remain in a mass at the side of the spinal cord and form the spinal ganglion.

It is very important to notice that not all the cells of the neural crest give rise to nerve fibers, but as in the central nervous system, a part of the cells become supporting elements and a part go to form the sheaths of the nerve fibers. It has recently been experimentally proved that cells derived from the neural crest migrate out along the bundles of the peripheral processes and form the
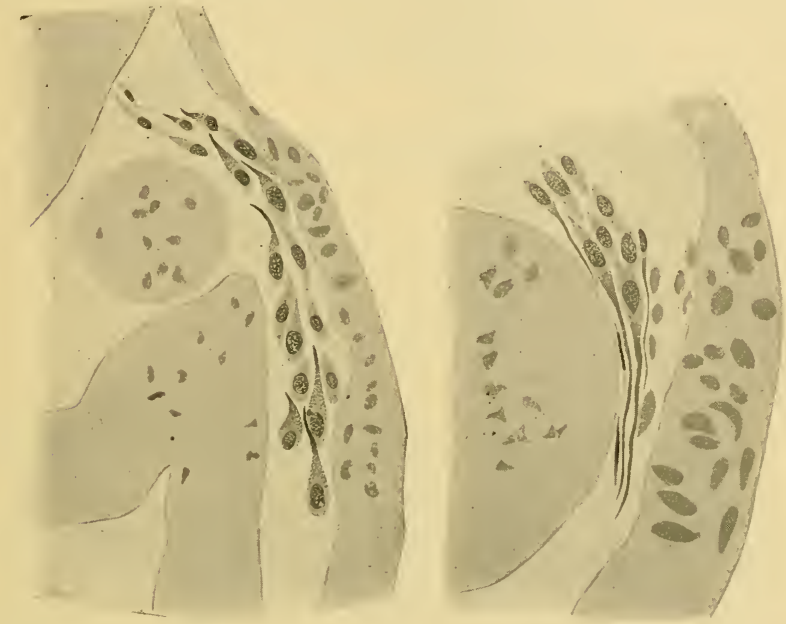

FIG. 26. - The ganglion of the IX nerve in Amblystoma punctatum at the time of formation of the central processes.

FIG. 27.- A few cells of the trigeminal ganglion in Amblystoma punctatum with the fibers of the ramus mandibularis growing out from them.

neurilemma or cellular sheath of Schwann of the nerve fibers. The fibers of the ventral nerve derive their sheath cells partly in this way and in part from the central nervous system, the cells wandering out directly along the ventral roots. The origin of the cells of this sheath shows their genetic relation with the neuroglia cells, and consistent with this is the fact that in the central nervous system the sheath of Schwann is absent, the myelinated fibers being surrounded by glia cells. 
In the region of the caudal part of the myelencephalon in all vertebrates the neural crest is relatively small. In cyclostomes

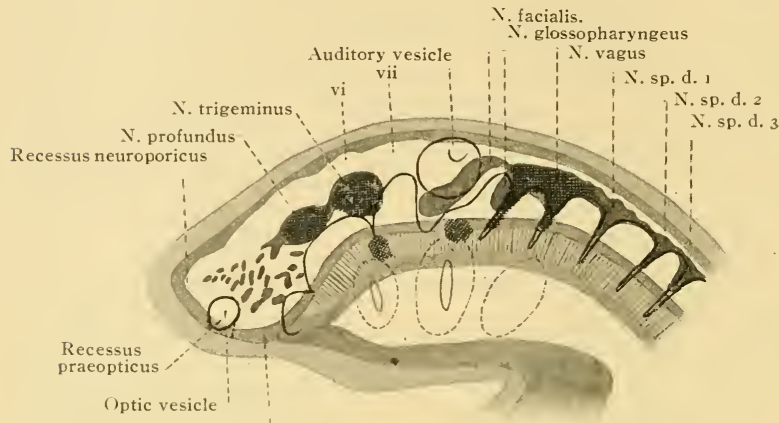

Infundibulum

A

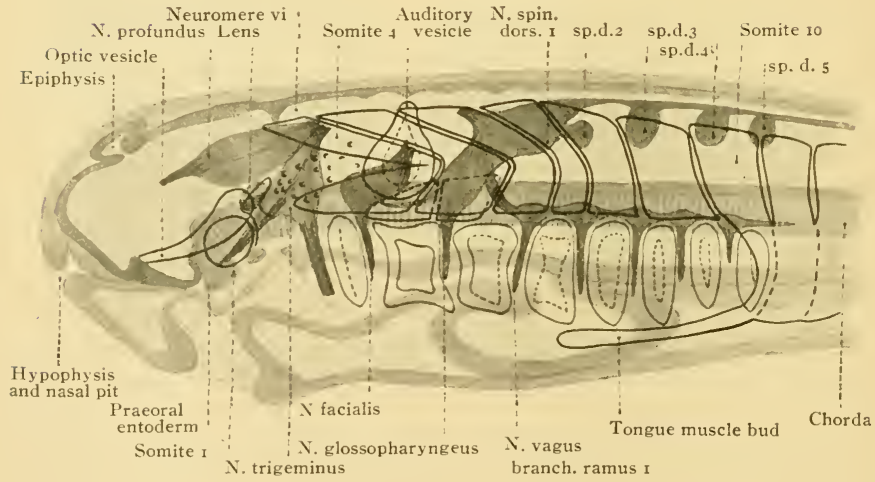

B

FIG. 28 A.-A diagram of the head of Petromyzon at a stage when two gill clefts are open and the neural crest is segmented into the anlages of the cranial ganglia. From the left side. The dorso-lateral placodes are indicated by vertical and horizontal cross-lines, the epibranchial placodes by oblique lines. After Koltzoff's diagram VIII.

FIG. 28 B.-A diagram of the head of Petromyzon at a later stage when all the cranial nerves are to be recognized. After Koltzoff's diagram XIII. 
and some selachians a complete series of segments of the neural crest in this region is formed. These represent the rudiments of nerves corresponding to the sensory nerves to the skin in the trunk region. In cyclostomes these rudiments give rise to per-
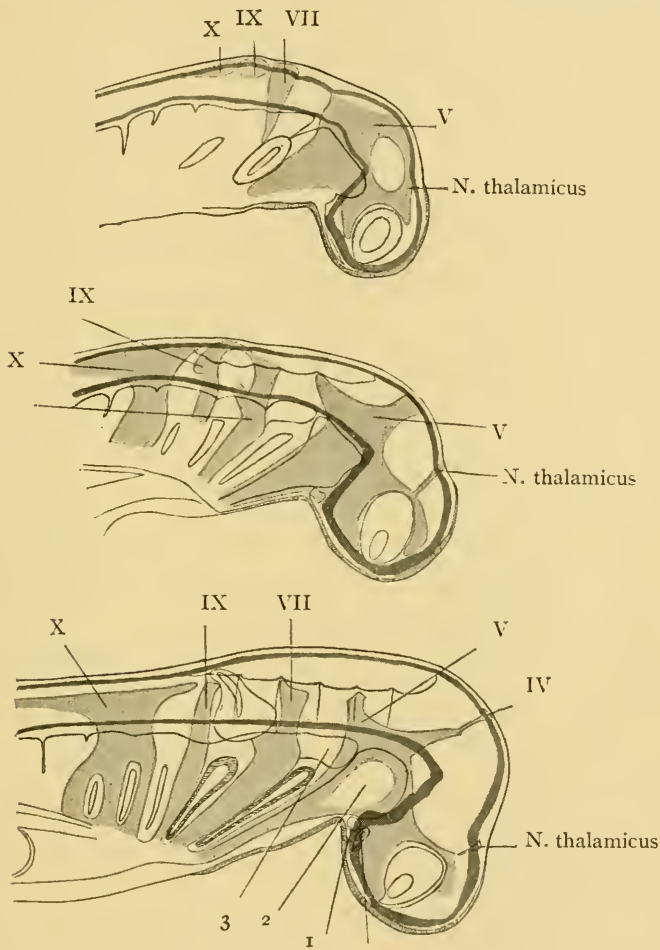

A

Fig. 29.-Three diagrams of the head of Squalus acanthias to show the differentiation of the neural crest into the cranial ganglia. After Neal. A, I, 2, 3, somites.

manent cutaneous nerves, while in all other vertebrates a variable number of these nerves fail to develop. (Compare Chapter VI.) In front of this the neural crest is larger and is divided by a slight 
constriction into a longer caudal segment for the vagus nerve and a shorter cephalic segment for the glossopharyngeus. The development of the ganglia and fibers of these nerves proceeds in essentially the same manner as in the case of the spinal nerves, except that the ganglia migrate somewhat farther from the brain

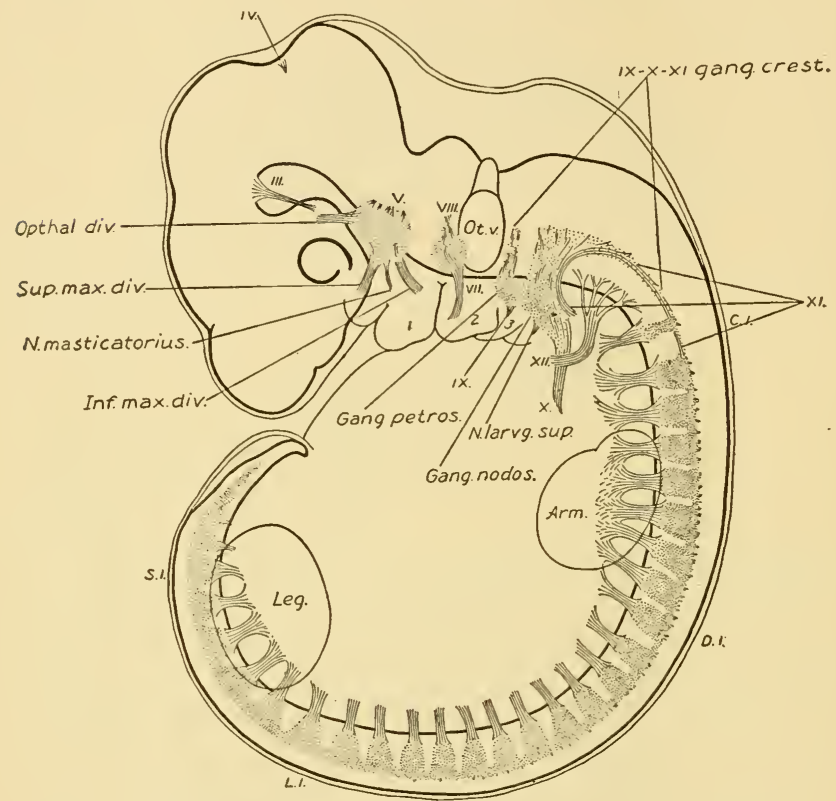

FIG. 30.-Reconstruction of the peripheral nerves in a four weeks human embryo, 6. $9 \mathrm{~mm}$. long. Enlarged $\mathrm{I} 6.7$ diameters. From Streeter. Ot. v., audi tory vesicle; I, 2, 3, visceral arches; $C$. I, first cervical nerve; $D$. I, first thoracic nerve; $L$. I, first lumbar nerve; $S$. I, first sacral nerve.

wall and come to lie outside the muscle somites and against the ectoderm above the gill slits. The ganglion of the glossopharyngeus lies over or nearly over the second gill slit. The vagus is connected with a series of ganglia equal in number to the number of gill slits from the third onward. In cyclostomes (Figs. 28, A and $\mathrm{B}$ ) the ganglion of the vagus is formed first over the third 
slit and then grows backwards until a series of ganglia are formed, one over each gill slit. In bony fishes, amphibia and higher forms these ganglia tend to become consolidated and are not symmetrically placed over the gill slits. Where the ganglia reach the ectoderm over the gill slits the ectoderm becomes thickened by multiplication of its cells and at least in some lower vertebrates, cells proliferate from the ectoderm and join the ganglia. The thickening of ectoderm is called the epibranchial placode. Each ganglion is now composed of two parts, a median part derived from the neural crest and a lateral part derived from the epibranchial placode. The ganglion may now be called the epibranchial ganglion. In man the ganglion petrosum on the IX nerve and the ganglion nodosum on the $\mathrm{X}$ nerve seem to repre-

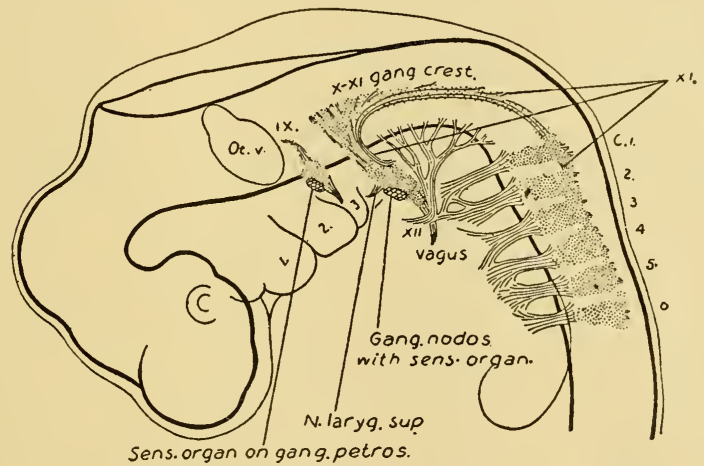

FIG. 31.-Reconstruction of the peripheral nerves in a four weeks human embryo, $7.0 \mathrm{~mm}$. long. Enlarged 16.7 diameters. From Streeter.

sent the epibranchial ganglia of fishes, and ectodermal placodes are described in connection with these ganglia in man (Fig. $3 \mathrm{I}$ ), but no migration of cells from the ectoderm to join the ganglia has been made out. From each ganglion so formed the ramus posttrematicus described in the previous chapter grows downward behind the gill slit and the ramus pharyngeus grows forward and inward to the roof of the pharynx. From the ramus pharyngeus in forms above the cyclostomes the ramus praetrematicus goes 
downward in front of the gill slit. It has been suggested that the epibranchial placodes represent ancestral sense organs whose

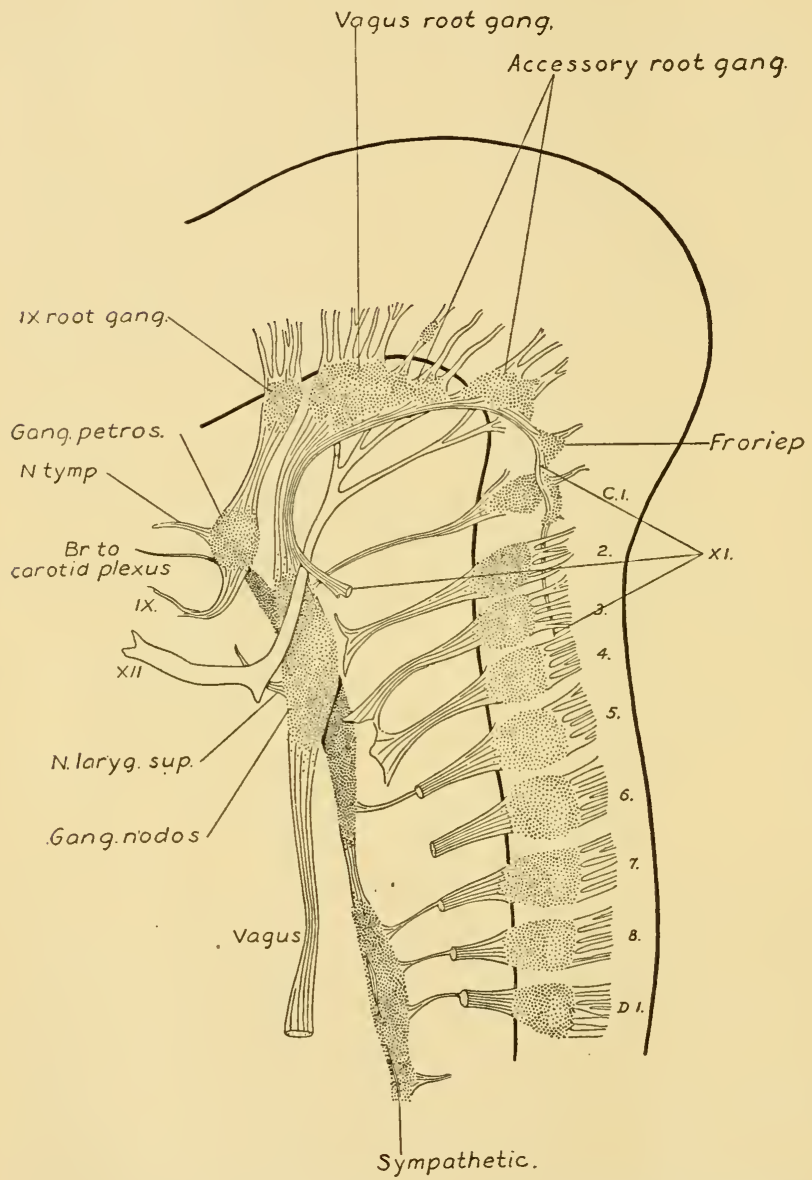

FIG. 32.-Reconstruction of the peripheral nerves in a six weeks human embryo, I $7.5 \mathrm{~mm}$. long. From Streeter. 
sense cells have come to join the ganglia. In fact very little is certainly known as to the nature of these ectodermal thickenings. The presence of the placodes in man and the separation between the root ganglia and those formed in connection with the placodes suggest that the placodes probably have the same history and function in all vertebrates. It is of the highest importance for the morphology of the nerrous system that the exact history and fate of the placodes should be traced in one or more classes of

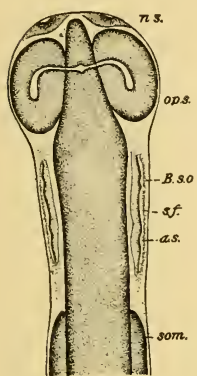

A
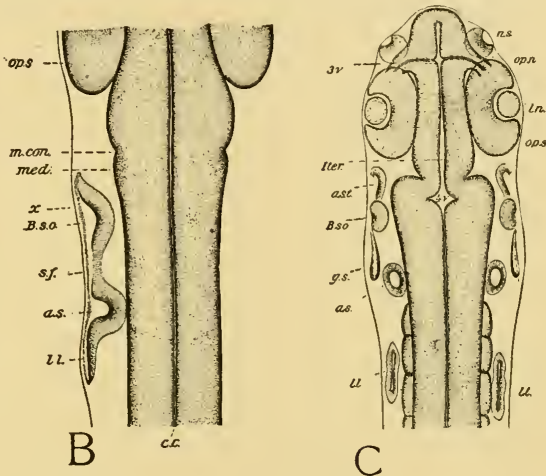

FIG. 33.-Three stages in the development of the acustico-lateral system in the sea bass. From H. V. Wilson. a. s., auditory sac; a. s.t., anterior sensory tract; B. $s$. o., preauditory pit; g. s., gill slit; $l . l$., lateral line anlage; $l n$., lens; $m$. con., furrow between midbrain and hindbrain; med., medulla oblongata; $n$. $s$., nasal sac; op. n., optic tract; op. $s$., optic vesicle; $s$. f., common sensory furrow.

vertebrates and that the distribution, central connections and functions of the fibers formed from ectodermal cells, if any, should be ascertained. This can doubtless be done by extirpation experiments on embryos.

In front of the anlage for the glossopharyngeus nerve there is a segment of the neural crest which gives rise to the sensory root of the VII nerve. This is deeply constricted from the segment for the IX nerve and is wholly separated from the portion belonging to the trigeminus group. While the ganglion of the IX nerve grows down wholly behind the auditory pit, that of the VII nerve comes into contact with the pit, in lower vertebrates in contact with its caudal surface, in higher vertebrates with its mesial wall. 
The ganglion extends ventrally beyond the auditory pit and comes into contact with the ectoderm over the first gill slit (spiracle). An ectodermal thickening fuses with the ganglion and from the fused mass the rami praetrematicus and palatinus of the VII nerve and the visceral sensory portion of the ramus hyomandibularis take their origin. This mass is comparable to the epibranchial ganglion of the IX nerve, but the significance of the ectodermal constituent is equally unknown.

The auditory pit is itself a thickening of ectoderm and it plays a part in the development of certain cranial ganglia which gives it the name of a dorso-lateral placode. Where the neural crest anlage of the VII ganglion comes into contact with the auditory pit, cells undoubtedly wander from the walls of the pit and form the ganglion of the VIII nerve, no part of which is formed from the neural crest. In some selachians and bony fishes (Fig. 33) an ectodermal thickening continues for some distance forward and backward from the auditory pit, so that we may speak of a much elongated dorso-lateral placode. The cells which proliferate from the caudal portion of this placode continue to multiply by mitosis and form a large mass which grows and pushes backward along the inner surface of the ectoderm over the roots of the IX and $\mathrm{X}$ nerves. This mass grows caudally as a narrow band along the side of the body, ploughing through the deeper layers of the ectoderm. The cells derived from the placode behind the auditory pit form a ganglion lying over the ganglion of the IX or the first part of the $\mathrm{X}$ ganglion and send fibers toward the brain, forming the root of the lateral line nerve which is situated near that of the IX nerve as described in the last chapter. The growing placode continues backward along the line of division between the dorsal and the lateral body muscles and at intervals gives rise to sense organs at the surface of the ectoderm. These organs consist of high columnar supporting cells which form the thickness of the epidermis, and shorter pear-shaped sense cells which do not extend to the full depth of the epidermis but do send hair-like processes out beyond the surface. The organs later sink down beneath the surface so that they come to lie at the bottom of the ectodermal pits (pit organs). The pits then be- 
come enclosed as tunnel like canals and finally the successive canals unite to form a continuous canal, the canal of the lateral line. Meanwhile the cells of the ganglion send processes caudally beneath or imbedded in the growing placode, which come into relation with the sense organs as they are formed and constitute the nerve of the lateral line.

The cephalic part of the placode, in front of the auditory pit, grows forward and divides into two branches which continue forward and give rise to sense organs in the same way as does the lateral line placode. One branch extends forward above the eye and forms the supraorbital row of organs, the other goes ventral to the eye and forms the infraorbital line. Ganglion cells which proliferate from the placode in front of the auditory pit give rise to the rami ophthalamicus superfacialis and buccalis which supply these lines and form the one or two roots of these rami which have been described above (p. 20, 2r).

Beneath and in front of the auditory pit a rentral projection of the common placode extends downward and forward on the mandibular arch. This develops in the characteristic manner the hyomandibular line of sense organs. The nerve fibers which supply this row of organs are also derived from the placode cells and form a part of the ramus hyomandibularis.

In this way the acustico-lateral system of sense organs and nerves in most fishes is derived from an extensive thickening of ectoderm on the side of the head, the dorso-lateral placode. Certain important differences in other forms must now be mentioned. The anterior part of the placode is not always directly continuous with the part which forms the auditory pit. Sometimes this part becomes invaginated to form another similar pit lying in front of the auditory pit and in front of the spiracular cleft. This pit may even become an enclosed sac and contain well formed sense cells (Wilson) similar to those of the lateral line organs. In embryos of certain amphibia (Gymnophiona) a deep pit is formed in front of the auditory pit and independently of it. This gives rise to the nerve which supplies the supraorbital row of sense organs. In Amblystoma punctatum this pit appears earlier than the auditory pit. In cyclostomes (Fig. 28) two separate ectodermal placodes are formed 
in front of the auditory pit, one in front of the other, which give rise to the supraorbital and infraorbital lines of sense organs and whose ganglia are closely related to the trigeminus and profundus ganglia. It is evident that in the early history of vertebrates the acustico-lateral system occupied three segments and that pits were formed to contain the sense organs. It is probable that at first the portions of the system in the three segments were independent of one another.

In typical fishes the main rows of sense organs are enclosed in canals similar to the lateral line canal. In addition to these chief rows there are often auxiliary rows or groups of pit organs and in many cases the typical canals are incompletcly formed, the organs remaining as pit organs. In cyclostomes and amphibia canals are not formed. In selachians there appear along the course of the main rows of organs depressions which sink in as pits and then become deep, narrow tubes and eventually extend beneath the surface to end in one of sereral masses of jelly-like tissue lodged in concavities of the skull. The deep ends of the tubes expand and develop sense organs which are related in structure to the lateral line organs. These are the ampullae of Lorenzini. The mode of development of the vesicles of Savi and of the nerve sacs of ganoids, both of which belong to the acusticolateral system of organs, is not known.

The complete hiatus in the neural crest in front of the anlage for the VII nerve is connected in some way with the development of the acustico-lateral system opposite this point. Probably this system actually uses up the material of this part of the neural crest. Forward from this, overlying the region of the cerebellum and midbrain, is a large segment of the neural crest which gives rise to the trigeminus group of nerves. It is necessary to say group of nerves, because the adult trigeminus is formed from two nerves which arise independently in vertebrate embryos.

From the crest covering neuromeres $\mathbf{v}$ and $\mathbf{v i}$ in selachians grow down two ganglionic anlages which remain connected peripherally so that they form an $\mathrm{U}$-shaped loop, having two connections with the brain. The caudal of these two anlages forms the ganglion of the N. trigeminus proper and gives rise to the sensory por- 
tion of the rami maxillaris and mandibularis trigemini. The anterior anlage loses its connection with the brain and the fibers which grow centrally from its ganglion cells follow caudally over the trigeminal ganglion and enter the brain along with the root of the trigeminus. The peripheral fibers from this ganglion run cephalad through the dorsal part of the orbit and form the N. ophthalamicus profundus. Figure 29 shows the early stages in the differentiation of these two ganglia. While the above description applies to selachians it may be taken in a general way as typical for vertebrates. In cyclostomes the two nerves are more independent in their origin and adult relations, and in all vertebrate embryos the two ganglia can be recognized.

In certain selachians an anlage of a sensory nerve is formed

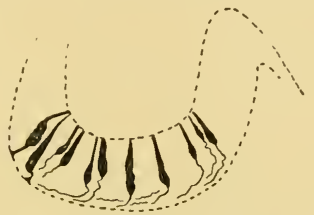

FIG. 34.-A transverse section through the nasal sac of an embryo of a bony fish at about the time of hatching, to show the origin of the fibers of the olfactory nerve.

from the neural crest between the mesencephalon and diencephalon. It is known as the nervus thalamicus (Fig. 29). The anlage is small, comes to be closely related to the profundus trunk and may furnish material for the ciliary ganglion. In the chick the ciliary ganglion is formed in part of cells which migrate out from the neural tube along the fibers of the oculomotor nerve and in part of cells which come from the ophthalamicus profundus ganglion.

In front of this point the neural crest does not give rise to any nerve which is found constantly in vertebrates. In selachians, however, the N. terminalis (see p. $3 \mathrm{I}$ ) possesses a ganglion and in Squalus acanthias develops in much the same way as do other sensory nerves. In the chick ganglion cells are found in connection with the olfactory nerve during its development which may bear some relation to this nerve in fishes.

The olfactory nerve differs from all other nerves in vertebrates 
in that its cells of origin arise and remain in the ectoderm. These are the sensory cells of the nasal epithelium. From the inner end of each of these cells arises a fiber (Fig. 34) which grows toward the forebrain and enters the bulbus olfactorius. These constitute the olfactory nerve. The fibers are never myelinated.

Although so little is certainly known of the details of the part played by ectodermal placodes in the formation of the sensory nerves and ganglia, it is clear that the nervous ectoderm is not limited to the neural plate. It is probable that the limits of the ectoderm which give rise to the nervous system are indefinite and variable. All that can be said is that the neural plate gives rise to the spinal cord and brain with the neural crest, while the olfactory organ and nerve and the ganglia and nerves of the acusticolateral system are derived from ectoderm adjoining the neural plate. These ganglia and nerves, including the olfactory, are to be compared with those derired from the neural crest. All are

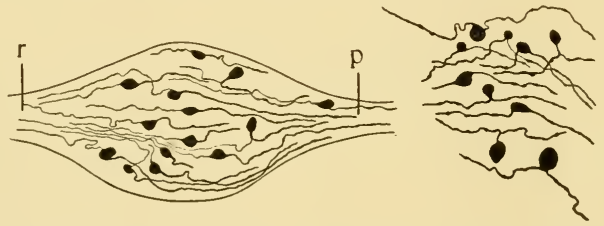

FIG. 35.-Two figures representing the formation of unipolar cells in the spinal ganglion of the dog embryo. After Van Gehuchten. $r$., root; $p$., peripheral nerve.

derived from ectoderm which in the early embryo is closely adjacent to the lateral border of that which forms the central nervous system, and the neural crest is wanting in those segments in which the olfactory and acustico-lateral systems develop. The acusticolateral ganglion cells remain in the general ectoderm for a time, the olfactory permanently so. It is probable that the epibranchial placodes, which are much farther removed from the neural plate, give rise to a part of the visceral sensory nerves, but whether general visceral or gustatory fibers are so formed is unknown.

In Amphioxus and cyclostomes the sensory ganglion cells remain throughout life bipolar, spindle-shaped cells such as have been described. During the course of development in true fishes 
a part of the cells become unipolar and in higher vertebrates most of them do so. This change is brought about by a sort of bending of the cell body by which the fibers at the two ends are brought together at one side (Fig. 35). Then by the growth of that part of the cell to which the fibers are attached both fibers come to be borne on a single process.

The development of the motor nerves takes place somewhat later than that of the sensory nerves. In the ventral part of the spinal cord and brain, where motor nerves are to be formed, certain large neuroblasts send their neurites out on the ventral surface. At this period numerous cells wander out of the cord or brain, following the neurites in their growth, migrate and multiply and eventually form the sheath of Schwann (cf. p. 5I above). The neurites grow until they reach the muscles which they are to innervate, when they branch or expand on the surface of the muscle fibers in the form of special motor end organs. These ventral motor nerves innervate only those muscles which are derived from the mesodermic somites. It has recently been shown that in amphibia fibers of a single nerve are distributed to muscle fibers of two adjacent muscle segments. This fact is wholly inconsistent with the view held by some anatomists that from the earliest embryonic stages processes of nerve cells are in connection with their muscles by means of strands of protoplasm which become elongated to form motor nerve fibers.

The nerve fibers which innervate the muscles derived from the lateral mesoderm are developed in the same way from neuroblasts which lie in the lateral parts of the central gray. In lower vertebrates these fibers pass out of the cord or brain together with or close beneath the dorsal sensory nerve roots and pass through the sensory ganglia. In higher vertebrates a part of these fibers pass out with the ventral roots and in the cat, dog and monkey all of them are said to have this course.

Morphology of THE HEAD. - In order to understand the brain and cranial nerves it is necessary to take into account the morphology of the organs of the head. For this reason a summary of the more important conclusions of comparative embryology and anatomy will be given here. 
At an early stage in the embryo the dorsal border of the sheets of mesoderm becomes divided into a series of segments, which soon separate from the undivided lateral mesoderm and lie as independent blocks or sacs at the sides of the neural tube. These are known as mesodermic somites. The first somites to be formed lie in the region which will form the neck and the segmentation continues from that point forward and backward. In front of this point there are formed in selachians and cyclostomes a definite number of somites which were first described by vanWijhe in 1882 . These head segments bear constant relations to other organs and may be designated by numbers indicating their order from before backward. Somite I lies behind and below the optic resicle and gives rise to those eye-muscles which are innervated by the III nerve ( $\mathrm{mm}$. rectus superior, rectus inferior, rectus internus, obliquus inferior). In front of somite I there is found in selachians a pair of lateral masses of mesoderm known as anterior head carities. These are believed to represent a still more anterior pair of somites which disappear in vertebrates without forming any recognizable structure. Somite 2 is larger and is directly connected with the mandibular arch. It gives rise to the muscle innervated by the IV nerve ( $\mathrm{m}$. obliquus superior). Somite 3 is connected with the hyoid arch and gives rise to the muscle innervated by the VI nerve ( $m$. rectus externus). Somite 4 lies mesial to or slightly behind the auditory pit and is known as the first postauditory somite. It gives rise to muscle on the dorsal surface of the head in cyclostomes; in all other vertebrates breaks down and disappears. Somite 5 in cyclostomes gives rise to a muscle lying next behind that of somite 4 ; in all other vertebrates disappears. In cyclostomes all the following somites form permanent myotomes, and myotome io together with several following it send muscle buds down behind and forward beneath the branchial apparatus to form the sub-branchial muscles corresponding to the tongue musculature of higher forms.

In selachians a variable number of postauditory somites may first form some muscle fibers and afterwards break down and only contribute to the formation of mesenchyme. The first somite to form permanent muscles is number 7 or 8 in most selachians. 
Somite 8 or 9 and several following it send muscle buds ventrad and forward beneath the branchial apparatus to form the subbranchial muscles as in cyclostomes. In higher vertebrates the abortion of certain postauditory somites is more complete and the number which disappear may be greater. In various classes of vertebrates more or fewer vertebral segments may be secondarily fused with the primordial cranium, entering into the occipital region of the skull. In mammals and perhaps man four such vertebrae are added to the cranium. In all vertebrates the sub-branchial or tongue musculature is formed from muscle buds derived from post-branchial somites.

In vertebrates above cyclostomes the breaking down of somites behind the ear produces a shifting of the relative position of the somites and nervous organs. The auditory sac is known to shift backward during development through the length of from one to three hindbrain neuromeres (Fig. I8). Also the permanent somites shift forward somewhat so that at every stage the existing somites lie close behind the auditory sac. The shifting forward of somites at the same time affects their position relative to the branchial apparatus. Also, the disappearance of somites leads to the disappearance of the ventral motor nerves which should innervate them, and apparently the shortening process in the region behind the ear leads to a decrease of the ectodermal area and the reduction or disappearance of one or more nerves of the skin. Finally, the development of the hypoglossal nerve is determined by the migration into the sub-branchial region of the muscle buds which it is destined to innervate.

The lateral mesoderm in the meantime becomes segmented in a passive manner by the formation of the gill slits. In most vertebrates these slits seem to have no definite position relative to the somites. There is evidence, however, that the segmentation of the lateral mesoderm and pharynx in primitive vertebrates corresponded to that of the dorsal mesoderm. The mandibular and hyoid arches are connected with the second and third somites respectively. The third branchial arch is connected with the fourth somite, and in Petromyzon the total number of gill arches (eight) corresponds to the number of somites (somites 2 to 9) 
in front of that one which forms the first sub-branchial muscle bud. The space occupied by the branchial apparatus, however, is always greater than that occupied by the corresponding number of somites and there is apparently a lack of correspondence between muscle segmentation and gill segmentation. The reason for this is found first in the fact that the gills become voluminous structures which require more space than the corresponding number of somites, and second in the disappearance and shifting of somites in the postauditory region mentioned above.

The segment of the lateral mesoderm between each two gill clefts is called a branchiomere and gives rise to the skeleton and muscles of the branchial arch. The mouth is regarded as representing a pair of gill slits and the mandibular arch as a branchial arch. The muscles of mastication which are attached to the lower jaw are derived from the lateral mesoderm and these together with most of the muscles of the branchial arches are risceral muscles, homologous with those in the wall of the alimentary canal in other segments of the body. In front of the mouth some rudimentary structures have been found in selachians which are thought to be vestiges of brancial arches which once existed anterior to the mouth. Possibly two such arches were present in primitive vertebrates.

The shifting of the auditory vesicle mentioned above changes its position with regard to the branchial arches also. From lying over the hyoid arch or second gill slit, it comes to lie over the first branchial arch or third gill slit. The bones of the middle ear in mammals are regarded as modified portions of the skeleton of the mandibular and hyoid arches. Recent researches show, however, that in the rabbit the stapes is a derivative of the auditory capsule.

It is believed that the ancestors of vertebrates had a mouth farther forward than the present mouth. The ancestral mouth is represented by a restigeal structure formed in embryos and retained in the adult as a rudimentary organ, the hypophysis. The hypophysis makes its appearance as a median ectodermal pit slightly ventral to the olfactory pits. Opposite this pit there lies in selachians a median mass of entoderm connecting the two 
anterior head cavities mentioned above. This most anterior mass of entoderm is present in amphibia also (Fig. 36), although the anterior head cavities are not separately developed. In this is seen the vestige of a communication between the hypophysis and the archenteron. In many rertebrates an outgrowth of entoderm from this region, known as Seesel's sac, enters with the ectodermal pit into the formation of the adult hypophysis. In cyclostomes the ectodermal pit becomes deep and large, and in Bdellostoma (Kupffer) has an open communication with the archenteron at an early stage. This communication is afterward oblit-

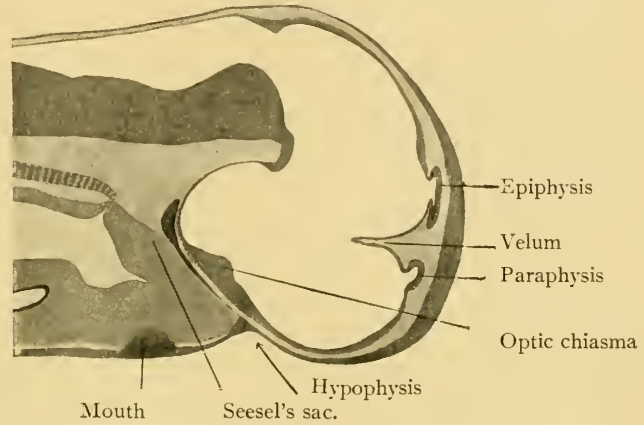

FIG. 36.--A median sagittal section of the head of an embryo of Amblystoma punctatum, to show the relations of epiphysis, velum, paraphysis, hypophysis, Seesel's sac, etc.

erated but the hypophysis remains throughout life as a large sac open to the exterior and extending beneath the brain. The communication with the archenteron has been described also for the sturgeon. Also in Amphioxus, where the permanent mouth is formed from a gill slit, a canal which opens externally farther forward communicates with the archenteron at an early stage of development (Legros). The relations of mouth and hypophysis in Amphioxus and Petromyzon are represented diagrammatically in the accompanying figure from Legros (Fig. 37). The ancient vertebrate mouth, or paleostoma, is to be thought of as lying very near the anterior end of the animal, just beneath the region of the olfactory organs which alone extend farther forward. In the sides of the canal 
which connected this mouth with the present pharyngeal region (paleopharynx) were one or two gill clefts and the present mouth has been formed from the second or third pair of ancestral gill clefts. Behind the mouth a variable number of clefts are present
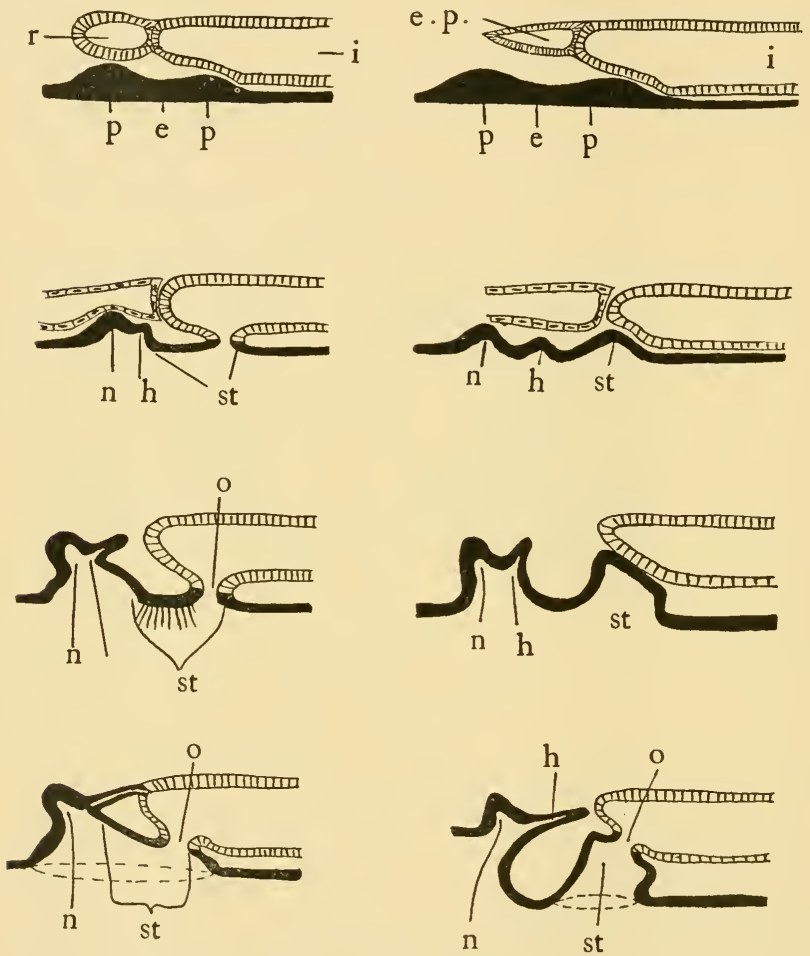

FIG. 37-Diagrams representing the development of the buccal cavity, hypophysis and nasal pit in Amphioxus and Petromyzon. After Legros.

in existing vertebrates: in cyclostomes, 7 to 35 ; in selachians, 5 to 7 ; in amphibia and higher forms, 5 to 4 . It is probable that the number in primitive vertebrates was large. The number of 
clefts has been gradually reduced from behind forwards (except in Myxinoids), probably because the greater development of a few anterior gills and the concentration of organs thus made possible is more advantageous.

At the same time that the disappearance of the more caudal gills reduces the number of aortic arches and tends to bring the heart farther forward, the expansion of the permanent gills actually pushes the heart caudally farther into the trunk. Thus in selachians it is shown that the opening of the duct of Cuvier into the sinus venosus moves back during development from a position in the second trunk segment to a position in the tenth trunk segment (Hoffmann).

We have to think of the development of the head as a gradual process which has been taking place during the phylogenetic development of vertebrate animals, the causes for which are to be found in the conditions of life, the food, habits, modes of locomotion, importance of the various senses, etc. The ancestors of vertebrates were very slightly specialized at the anterior end and the various specialized structures formed there make up the head. Special sense organs are formed in the head region (acusticolateral system, taste buds, ear, eye, olfactory organ) and each of these profoundly affects in a characteristic way the structure of the brain, and often modifies surrounding organs, determines the form of the skull, etc. The formation of the rigid cranium has come about largely for the protection of the sense organs and the existence of this cranium has led to the disappearance of the postauditory somites and to the modification of the preauditory myotomes into muscles which move the eye-ball. Some of the most striking marks of the specialized head are due to the disappearance of various structures, the postauditory somites, the ancient mouth, certain gills, etc. The disappearance of these organs has led to the disappearance of their nerves and to great changes in the central nervous system. Furthermore, both the rise of new structures and the passing away of old ones have brought about shifting of organs which is of great importance in determining the structure of the nervous system. Of chief interest is the shifting of nerve roots due to these or other causes. 
The ophthalamicus profundus nerve arises from the neural crest over the mesencephalon; its root has shifted back to join that of the trigeminus. The trigeminus arises over the metencephalon and in cyclostomes remains permanently attached to that segment. In all other vertebrates it moves back one segment to the first neuromere of the myelencephalon. The facialis has shifted back not only one segment, but two, leaving the neuromere between it and the trigeminus without any nerve root. The shifting of the VII is probably due to the shifting of the auditory sac which has in part pushed it back and in part moved back past it. By this movement the IX and $\mathrm{X}$ nerves are also affected. There is reason to believe that the IX has moved back one segment in cyclostomes, and that the IX and $\mathrm{X}$ have moved back two neuromeres in fishes and three in reptiles, birds and mammals.

A word should be said regarding the complex character of the $\mathrm{X}$ nerve. There is reason for thinking that each one of the epibranchial ganglia of the vagus represents an independent branchial. nerve, and that these nerves one after another beginning at the caudal end of the gills have joined the nerve next anterior until all have united into a single root. In the myxinoids this process has gone one step farther than in other vertebrates, and the vagus itself is joined to the glossopharyngeus. The actual shifting forward and fusion of these nerves does not now take place during the ontogeny, so that it is to be regarded as a very primitive feature of vertebrate development.

It is impossible in this book to follow further the evolution of the vertebrate head. The accompanying tables and figures are intended to make more clear the brief statements that have been made. Figure 38 is meant to show the relations of the various structures which enter into the primitive head segments. The two tables give further facts which should be taken into account in connection with this diagram. Table $\mathrm{A}$ is abbreviated from the tables of Hoffmann showing the shifting of organs which takes place during the development of the selachian head. Table $\mathrm{B}$ is meant to show the elements present in each segment of the head and the more important reductions and changes of position which have taken place. 


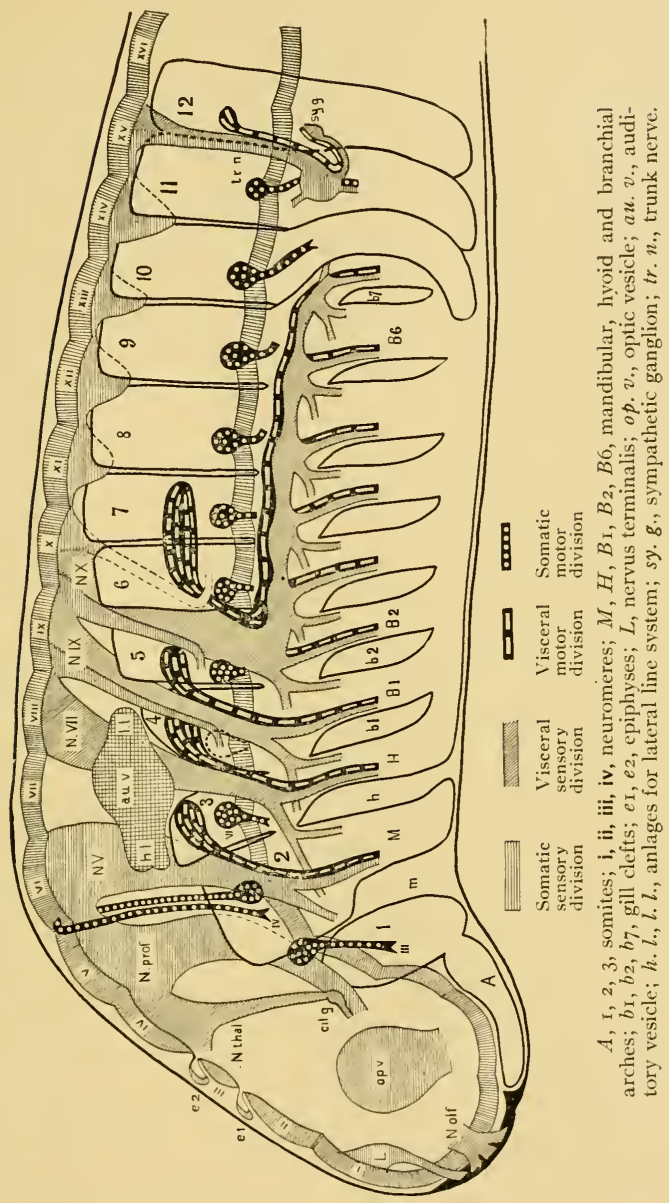

FIG. 38.-A diagram of segmentation in a generalized vertebrate head. In its general features the diagram follows Petromyzon more closely than any other form. So, the number of the gill clefts, their position relative to the somites, the position of the auditory vesicle, and the formation of hypobranchial muscles from myotome Io and following, are taken from Petromyzon. The neuromeres, the nervus 
terminalis, the nervus thalamicus, the relation of the lateral lines of the head to the auditory vesicle, and the praeoral entoderm are taken from selachians. The sensory nerve roots are represented as retaining their attachment to the dorsal surface of the neural tube where they were formed from the neural crest. The segmental position of these roots is about that which they have in the embryo of Petromyzon, except the root of $\mathrm{N}$. X, which has been shifted back a little farther than it is in Petromyzon. The general cutaneous nerve shown in dotted outline over somite 6 is the Vagusanhang of HATSCHEK in Ammocoetes and the nerve which unites with the vagus root in the embryo of selachians. This is the second dorsal spinal nerve in Petromyzon dorsatus and other primitive cyclostomes. The position of the viscero-motor nuclei somewhat caudal to the several roots is indicated. The viscero-motor nucleus of the vagus and accessorius is shown as a single large nucleus extending through two segments. It might more properly have been continued caudally until it came into connection with the viscero-motor nucleus of the trunk nerve. The accessorius nerve is not shown. The somatic motor nucleus and root are shown for all the somites except somite 4 , where they are shown in dotted outline. The nerve for somite 4 is absent in Petromyzon, but is present in Bdellostoma. It is possible that this root has joined with N. VI in gnathostomes.

The process of cephalization in vertebrates has consisted chiefly in (I) the development of special sense organs; (2) the consequent enlargement of the brain; (3) the formation of a rigid cranium to protect sense organs and brain; (4) the disappearance of certain muscle segments and the change of position and function of others (eye-muscles); (5) the reduction in number of gills, the formation of a new mouth and the expansion of the persistence gills; (6) the disappearance of various nerves owing to the reduction of somites and gills; $(7)$ the shifting of position of various organs and nerve roots due to these changes; and (8) the great development in higher vertebrates of the so-called higher brain centers. At every step in the evolution of rertebrates these changes have left their impression on the nervous system so that the nervous system to a greater extent than any or all other organs preserves a record of the course of phylogenetic development. For this reason not only does a knowledge of the nervous system throw light upon the morphology of the head, but a knowledge of the evolution of the head is necessary for a true understanding of the nerrous system.

TABLE A.

\section{Shifting of organs during development of selachian embryo.}

Length of embryo.................. $2_{2}^{1}-13 \mathrm{~mm}$.

$40 \mathrm{~mm}$.

Duct of Cuvier shifts from trunk segment.... 2 to trunk segment ro

Omphalo-mesenteric artery $\quad$ " $\quad \ldots .44^{-} 5 \quad$ " $\quad 12-13$

Sixth branchial artery. from occipital segment . 3 " 3

Ostium of Muller's duct, from trunk segment. . $5^{-6}$ " 
TABLE B.

\begin{tabular}{|c|c|c|c|c|c|c|c|c|c|c|c|c|c|c|c|c|c|}
\hline HEAD SEGMENTS & 1 & 2 & 3 & 4 & 5 & 6 & 7 & 8 & 9 & 10 & 11 & 12 & 13 & 14 & 15 & 16 & 17 \\
\hline NEUROMERES & $\mathbf{i}$ & ii & iii & iv & $v$ & vi & vii & viii & ix & $x$ & $\mathrm{xi}$ & xii & xiii & xiv & $x v$ & $x v i$ & xvii \\
\hline SOMrTES & & & $-\cdots$ & a. h. c. & $x$ & 2 & 3 & 4 & 5 & 6 & 7 & 8 & 9 & 10 & II & 12 & 13 \\
\hline BRANCHIOMERES & & & & --- & --- & $\begin{array}{l}\text { mandib. } \\
\text { arch }\end{array}$ & $\begin{array}{l}\text { hyoid } \\
\text { arch }\end{array}$ & br. I & br. 2 & br. 3 & br. 4 & br. 5 & br. 6 & \multicolumn{4}{|c|}{$\begin{array}{l}\text { a larger number of branchial arches in lower } \\
\text { cyclostomes and primitive vertebrates }\end{array}$} \\
\hline $\begin{array}{l}\text { SOMATIC SENS. DIVISION } \\
\text { general cutaneous } \\
\text { peripheral } \\
\text { central }\end{array}$ & $\begin{array}{l}\text { N. } \\
\text { termin. } \\
\text { pallium }\end{array}$ & retina & $\begin{array}{l}\text { corp. } \\
\text { genic. }\end{array}$ & tectum, & $\begin{array}{l}\text { N. ophth. } \\
\text { prof. } \\
\text { cerebellum }\end{array}$ & $\begin{array}{l}\text { comp't } \\
\text { in N. v. } \\
\text { shifts } \\
\text { to vii }\end{array}$ & $\begin{array}{l}\text { [joins } \\
\text { N. V?] }\end{array}$ & $\begin{array}{l}\text { comp't } \\
\text { in N. IX } \\
\text { shifts to } \\
\text { ix }\end{array}$ & $\begin{array}{l}\text { comp't } \\
\text { in N. X. } \\
\text { shifts to } \\
\text { X in } \\
\text { Gnath. }\end{array}$ & $\begin{array}{l}\text { I sp. Cycl. } \\
\text { joins } \\
\text { N. X, } \\
\text { Gnath. } \\
\text { tract, nuc. }\end{array}$ & $\begin{array}{l}2 \text { sp. Cycl. } \\
\text { rudiments } \\
\text { permanent } \\
\text { funiculi. }\end{array}$ & $\begin{array}{l}3 \mathrm{sp} . \text { Cycl. } 4 \\
\text { in Gnathos } \\
\text { t roots in } \mathrm{He}\end{array}$ & $\begin{array}{l}4 \text { sp. Cycl. } \\
\text { ostomes. } \\
\text { Ieptanchus }\end{array}$ & $\begin{array}{l}5 \text { sp. Cycl. } \\
\text { permanent roots }\end{array}$ & $\begin{array}{l}6 \mathrm{sp} . \text { Cycl. } \\
\text { in Acanthias. }\end{array}$ & $\begin{array}{l}7 \text { sp. Cycl. } \\
\text { permanent } \\
\text { root in } \\
\text { Gnath. }\end{array}$ & $\begin{array}{l}8 \text { sp. Cycl. } \\
2 \text { sp. ? } \\
\text { Gnath. }\end{array}$ \\
\hline $\begin{array}{l}\text { special culaneous } \\
\text { peripheral } \\
\text { central }\end{array}$ & & & & & \multicolumn{10}{|c|}{$\begin{array}{l}\text { acustico-lateral system of organs and nerves. } \\
\text { cerebellum, acusticum, spinal VIII tract to the nucleus spinalis acustici. }\end{array}$} & & & \\
\hline special sense & & $\begin{array}{l}\text { later. } \\
\text { eyes }\end{array}$ & $\begin{array}{r}\text { Ist. } \\
\text { epiph. }\end{array}$ & $\begin{array}{l}\text { 2nd. } \\
\text { epiph. }\end{array}$ & & & & & & & & & & & & & \\
\hline $\begin{array}{l}\text { SOMATIC MOTOR DIVISION } \\
\text { peripheral } \\
\text { central }\end{array}$ & & & & nuc. & $\begin{array}{l}\text { N. III } \\
\text { nuc. III }\end{array}$ & $\begin{array}{l}\text { N. IV } \\
\text { nuc. IV }\end{array}$ & $\begin{array}{l}\text { N. VI } \\
\text { nuc. VI }\end{array}$ & $\begin{array}{l}\text { I } \\
{\left[\begin{array}{l}s \\
\text { Sdell. }\end{array}\right.}\end{array}$ & \multicolumn{5}{|c|}{ somatic motor fasciculus and ventral motor column. } & $\begin{array}{c}7 \text { Bdell. } \\
y \\
\text { notor column. }\end{array}$ & 8 Bdell. & $\begin{array}{l}9 \text { Bdell. } \\
\text { I sp. Fürb. }\end{array}$ & $\begin{array}{l}10 \text { Bdell. } \\
2 \text { sp. }\end{array}$ \\
\hline $\begin{array}{l}\text { VISCERAL SENS. DIVISION } \\
\text { general visceral } \\
\text { peripheral } \\
\text { central }\end{array}$ & & lob. & $\begin{array}{l}\text { nuc. } \\
\text { haben. }\end{array}$ & $\begin{array}{c}\text { N. thal. } \\
\text { ? }\end{array}$ & & $\begin{array}{l}\text { sec. gust. } \\
\text { nuc. }\end{array}$ & $\begin{array}{l}\text { comp't } \\
\text { in N. VII } \\
\text { shifts } \\
\text { to viii }\end{array}$ & $\begin{array}{l}\text { comp't } \\
\text { in N. IX } \\
\text { shifts } \\
\text { to ix } \\
\text { lob. fac. }\end{array}$ & $\begin{array}{l}\text { comp't } \\
\text { in N. X. } \\
\text { shifts } \\
\text { to } x \text { in } \\
\text { Gnath. } \\
\quad \text { lobu }\end{array}$ & $\begin{array}{l}\text { comp't } \\
\text { col'ct'd } \\
\text { into } \\
\text { N. X. } \\
\text { us vagi, nuc }\end{array}$ & $\begin{array}{l}\text { comp't } \\
\text { col'ct'd } \\
\text { into } \\
\text { N. X. } \\
\text { cleus comm }\end{array}$ & $\begin{array}{l}\text { comp't } \\
\text { col'ct'd } \\
\text { into } \\
\mathrm{N} \text {. X. } \\
\text { nissuralis of }\end{array}$ & $\begin{array}{l}\text { comp't } \\
\text { col'ct'd } \\
\text { into } \\
\mathrm{N} \text {. X. } \\
\text { f Cajal and }\end{array}$ & $\begin{array}{l}\text { comp't } \\
\text { in r. } \\
\text { br.-int. X } \\
\text { visceral sensory }\end{array}$ & $\begin{array}{l}\text { comp't } \\
\text { in } \mathrm{r} \text {. } \\
\text { br.-int. X } \\
\text { column of spinal }\end{array}$ & $\begin{array}{l}\text { comp't } \\
\text { in } r . \\
\text { br.-int. X } \\
\text { ord. }\end{array}$ & $\begin{array}{l}\text { comp't } \\
\text { in r. } \\
\text { br.-int. } \mathrm{X}\end{array}$ \\
\hline special visceral & & & & & & \multicolumn{9}{|c|}{$\begin{array}{l}\text { The gustatory components and their centers have not been fully distinguished } \\
\text { from the general visceral in any vertebrate. }\end{array}$} & & & \\
\hline special sense & N. olf. & & & & & & & & & & & & & & & & \\
\hline $\begin{array}{l}\text { VISCERAL MOTOR DIVISION } \\
\text { peripheral } \\
\text { central }\end{array}$ & & & & & $\begin{array}{l}\text { symp. } \\
\text { eff. in } \\
\text { N. III. } \\
\text { nuc. of } \\
\text { same }\end{array}$ & $\begin{array}{l}\text { mot. N.V } \\
\text { shifts } \\
\text { to vii } \\
\begin{array}{l}\text { lat. mot. } \\
\text { nuc. V }\end{array}\end{array}$ & $\begin{array}{l}\text { mot. N. } \\
\text { VII shifts } \\
\text { to viii } \\
\text { lat. mot. } \\
\text { nuc. V }\end{array}$ & $\begin{array}{l}\text { mot. N. } \\
\text { IX shifts } \\
\text { to ix } \\
\text { lat. mot. } \\
\text { nuc. VII }\end{array}$ & $\begin{array}{l}\text { mot. N. } \\
\text { X shifts } \\
\text { to } \times \text { Gn. } \\
\text { lat. mot. } \\
\text { nuc. IX ar }\end{array}$ & $\begin{array}{l}\text { mot. N. } \\
\text { col'ct'd } \\
\text { into N.X }\end{array}$ & $\begin{array}{l}\text { mot. N. } \\
\text { col'ct'd } \\
\text { into N.X }\end{array}$ & $\begin{array}{l}\text { mot. N. } \\
\text { col'ct'd } \\
\text { into N.X }\end{array}$ & $\begin{array}{l}\text { mot. N. } \\
\text { col'ct'd } \\
\text { into N.X }\end{array}$ & $\begin{array}{l}\text { N. access. } \\
\text { n of spinal cord. }\end{array}$ & N. access. & N. access. & N. access. \\
\hline
\end{tabular}



Front edge of anterior fin ( $18 \mathrm{~mm}$. embryo)... 4 to trunk segment 9

$\begin{array}{llllll}\text { Bark edge } \quad \text { " } & \ldots & \text { I4 } & \text { " } & \text { I7 }\end{array}$

Cloaca " " $\quad \ldots 44^{-48} \quad$ " $48-49$

Anterior end of coelom, from occipital segment, 3 "

\section{DEMONSTRATION OR LABORATORY WORK.}

I. Study the development of the neural plate, neural tube and brain in embryos of the salamander, a selachian, pig or chick.

2. In the same material study the neural crest and the formation of the spinal and cranial ganglia.

3. Study the dorso-lateral and epibranchial placodes and the development of the auditory and lateral line organs, eye and olfactory organ.

4. Study the relations of the chorda, the anterior end of the entoderm and mesoderm, hypophysis and olfactory pit and neuropore in selachian or salamander embryos.

5. Notice the neuromeres in the hindbrain of any embryos and look for the shifting in position of the auditory vesicle and the trigeminus and other nerve roots.

6. In any selachians or cyclostomes that are available make careful dissections of the nerves in the spino-occipital region, noting the number of dorsal and ventral roots present and their position relative to the vagus and glossopharyngeus. The smaller nerve roots can be brought to view by painting the surface of the brain with I or 2 per cent. osmium solution, which should be thoroughly washed away with water as soon as the nerves are blackened.

7. Study the formation of the neuroblasts in the central nervous system and the growth of central and peripheral processes from the sensory ganglion cells. This can be done well in amphibian embryos stained with haemalum and acid fuchsin.

\section{LITERATURE.}

Bardeen, C. R.: The Bimeric Distribution of the Spinal Nerves in Elasmobranchii and Urodela. Amer. Jour. of Anat., Vol. 3. Ig०4.

Brauer, A.: Beiträge zur Kenntniss der Entwickelung und Anatomie der Gymnophionen. Zool. Jahrb., Suppl. 7, Ig04.

Braus, Herman: Beiträge zur Entwickelung der Muskulatur und des peripherischen Nervensystems der Selachier. Morph. Jahrb., Bd. 27, I899.

Carpenter, F. W.: The Development of the Oculomotor Nerve, the Ciliary ganglion, and the Abducent Nerve in the Chick. Bull. Mus. Comp. Zool. Harvard College, No. I72. I 906.

Disse. J.: Riechschleimhaut und Riechnerv beiden Wirbelthieren. Merkel u. Bonnet's Ergebnisse. Bd. ir. IgoI. 
Dohrn, Anton: Die Entstehung der Hypophysis bei Petromyzon planeri. Mitth. Zool. Sta. Neapel.

Eycleshymer, A. C.: The Development of the Optic Vesicles in Amphibia. Jour. Morph., Vol. 8. i8go.

Froriep, A.: Ueber ein Ganglion des Hypoglossus und Wirbelanlagen in der Occipitalregion. Arch. f. Anat. u. Physiol., Anat. Abth., I882.

Froriep, A.: Ueber Anlagen von Sinnesorganen am Facialis, Glossopharyngeus und Vagus, ueber die genetische Stellung des Vagus zum Hypoglossus und ueber die Herkunft der Zungenmuskulatur. Arch. f. Anat. u. Physiol., Anat. Abth., I885.

Froriep, A.: Die Entwickelung des Auges der Wirbelthiere. Hertwig's Handbuch der Entwickelungslehre. 1905:

Fuchs, H.: Bemerkungen ueber die Herkunft und Entwickelung der Gehörknöchelchen bei Kaninchen-Embryonen u. s. w. Arch. f. Anat. u. Entwick. 1905. Suppl.-Bd.

Fürbringer, Max: Ueber die spino-occipitalen Nerven der Selachier und Holocephalen und ihre vergleichende Morphologie. Gegenbaur's Festschrift. Bibliography.

Gage, Susanna Phelps: A Three Weeks Human Embryo, with especial Reference to the Brain and Nephric System. Amer. Jour. Anat., Vol. 4. 1905.

Gaupp, E.: Zirbel, Parietalorgan und Paraphysis. Merkel u. Bonnet's Ergebnisse, Bd. 7. I897.

Harrison, R. G.: Ueber die Histogenese des peripheren Nervensystems bei Salmo salar. Arch. f. mik. Anat. u. Entw., Bd. 57. 1901.

Hill, Charles: Developmental History of the Primary Segments of the Vertebrate Head. Zool. Jahrb., Abth. f. Anat. u. Ontog., Bd. I3. I 899.

His, W.: Zur allgemeine Morphologie des Gehirns. Arch. f. Anat. u. Physiol., Anat. Abth., i 892.

His, W.: Ueber das frontale Ende des Gehirnrohres. Arch. f. Anat. u. Entw., Anat. Abth., I803.

His, W.: Anatomie menschlichen Embryonen.

His, W.: Die Entwickelung des menschlichen Gehirns während der ersten Monate. Leipzig, I904.

Hoffmann, C. K.: Ueber die Metamerie des Nachhirns und Hinterhirns und ueber Beziehungen zuden segmentalen Kopfnerven bei Reptilien-Embryonen. Zool. Anz., Bd. I2. I889.

Hoffmann, C. K.: Beiträge zur Entwickelung der Selachii. Morph. Jahrb., Bde. 24, 25, 27. 1896-1899.

Johnston, J. B.: The Morphology of the Vertebrate Head from the Viewpoint of the Functional Divisions of the Nervous System. Jour. Com. Neur. and Psych. Vol. 15. I005. Bibliography.

Koltzoff. N. K.: Entwickelungsgeschichte des Kopfes von Petromyzon planeri. Bull. de la Soc. Imper. d. Natural. de Moscou, Annee 1901, No. 3.-4. 1902 . 
von Kupffer, C.: Studien zur vergleichenden Entwickelungsgeschichte des Kopfes der Kranioten. München u. Leipzig. I894-I900.

von Kupffer, C.: Die Morphogenie des Centralnervensystems. Hertwig's Handbuch der Entwickelungslehre. Ig05.

Legros, Robert: Developpment de la cavite buccale de l'Amphioxus lanceolatus. Archive Anat. Micros., Tome I, I8g8.

Locy, W. A.: A Contribution to the Structure and Development of the Vertebrate Head. Jour. Morph., Vol. II. I895.

Minot, C.S.: A Laboratory Text-book of Embryology. Philadelphia. I903.

Neal, H. V.: The Segmentation of the Nervous System in Squalus acanthias. Bull. Mus. Com. Zool. Harvard College, 31. г898.

Neal, H. V.: The Development of the ventral nerves in Selachii. I. The Spinal Nerves. Mark Anniversary Volume. I903.

Platt, Julia B.: A Contribution to the Morphology of the Vertebrate Head based on a Study of Acanthias vulgaris. Jour. MIorp., Vol. 5. I89r.

Price, G. C.: Some Points in the Development of a Myxinoid (Bdellostoma Stouti, L.) Verhdl. Anat. Ges. Io. Vers. Berlin. I896.

van Wijhe, J. W.: Ueber die Mesodermsegmente und die Entwickelung der Nerven des Selachierkopfes. Amsterdam. I882.

Wilson, H. V.: The Embryology of the Sea Bass (Serranus atrarius). Bull. U. S. Fish Com., Vol. 9. I89i.

Zimmermann: Ueber die Metamerie des Wirbelthierkopfes. Verhdl. d. Anat. Ges. 5 Versam. MIünchen. I8gr. 


\section{CHAPTER IV.}

\section{NERVE ELEMENTS AND THEIR FUNCTIONS.}

The chief functions of nerve elements are the origination and transmission of nerve impulses. A nerve impulse originates as the result of a stimulus. Although the stimulus may be one of several kinds, mechanical, chemical, thermal, photic, etc., it always consists in some change in the environment of the nerve cell. Whatever the character of the stimulus, it produces in the protoplasm of the nerve cell chemical and physical changes of such a character that they may be propagated or transmitted through the protoplasm from one part of the nerve cell to another. These changes within a nerve cell constitute a nerve impulse. Although it is called forth by a stimulus, the impulse is not that stimulus caught up and passed on, but is a new thing consisting in the activity of the nerve cell itself. Besides the origination and transmission of impulses it is believed that other functions may be performed by nerve elements. They may reinforce or strengthen the impulses during their transmission; they may store up weak impulses so as to discharge a stronger one after an interval (summation); such discharge may be repeated at more or less regular intervals (rhythmical nerve action); or the impulses may be more or less completely blocked or impeded in their transmission (inhibition). The consideration of these processes within nerve elements belongs to the field of general nerve physiology with which the present book does not deal.

Although the chemical and physical nature of a nerve impulse may and probably does differ in relation to the internal structure of the nerve cell and the character of the stimulus, the importance of the nerve impulse to the organism consists in the effect produced when the nerve impulse is delivered by the nerve element to some other tissue element. What tissue element shall receive the impulse; after how long a time it shall be delivered; whether it shall 
be delivered in full force, strengthened or inhibited,-these things which are all-important in the life of the organism depend upon the form of the nerve elements and the manner in which they are arranged. While the work done by the nervous system is our primary interest, we can understand this only by first understanding the construction of the mechanism which does the work. On the other hand the work done must be held in mind in order that we may truly interpret the constituent parts of the mechanism.

The study of the minute structure and physiology of the nervous systems of various classes of animals has shown that nerve elements usually transmit impulses in a given direction. This is equivalent to saying that the elements have a specific form, as otherwise all directions would be alike. In vertebrates as a rule nerve elements present structurally and functionally a polar differentiation; the two ends of the element differ in both form and function. The nerve element consists of a mass of protoplasm containing a nucleus, it is a cell. Usually the nucleus is immediately surrounded by a larger mass of protoplasm which is called the cell-body. From this cell-body there extend more or less slender strands of protoplasm called processes. In nearly all cases the processes are seen to be of two forms. Some are relatively thick, irregular and have numerous branches; one is relatively slender, uniform in diameter, gives off collateral branches and is profusely branched at the end of its course. The former bear a general resemblance to a bush or branch of a tree and are hence called dendrites or dendrons; the latter is more thread like and since it forms the axial and essential portion of a common nerve fiber it is called a neurite or axone. A nerve cell commonly possesses two or more dendrites but usually has only one neurite. The volume of all the dendritic processes may exceed by many times the volume of the cell-body, and even the volume of the neurite may be considerable when it is very long or has many end branches. In certain cases the cell-body is elongated and the dendrites arise from one end and the neurite from the other. Most nerve cells, however, do not so clearly illustrate polar differentiation in their form. The dendrites may arise irregularly from various parts of the cell-body and the neurite may take its origin 
from one of the dendrites at some distance from the cell-body. Figure 39 shows several forms of nerve cells with reference to polar differentiation.

With respect to the form and disposition of their neurites, two chief types of nerve cells are distinguished. In the first and more common type (type I) the neurite is long and serves to make a connection with some distant nerve cell, muscle cell, gland cell, etc. In the second type (type II) the neurite is short and divides

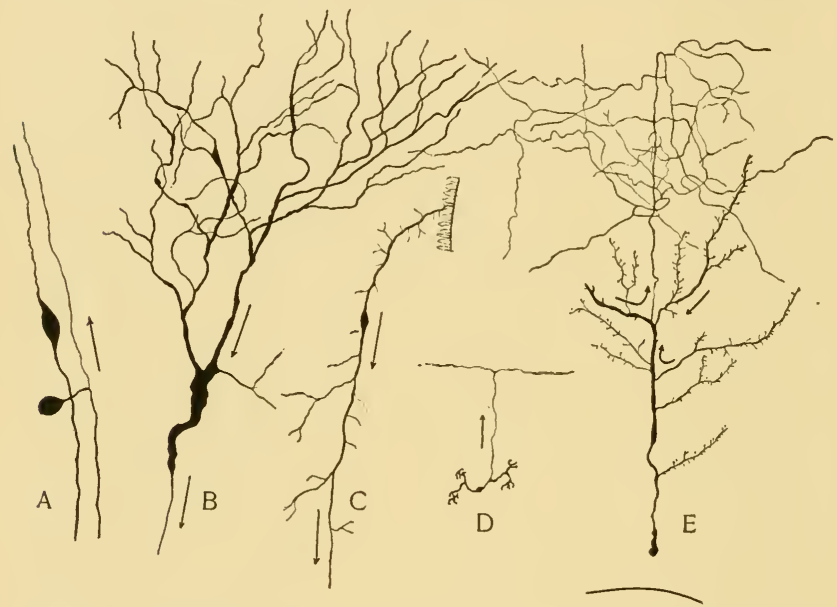

FIG. 39.- Several types of nerve cells from the central and peripheral nervous system of vertebrates. A, spinal ganglion cells; B, a Purkinje cell from the brain of the sturgeon; C, a cell from the nucleus praeopticus; D, a granule from the cerebellum; E, a cell of type II from the tectum opticum.

into terminal branches in the near vicinity of its cell, serving to make connection with sereral other cells of the same nerve center (Fig. 39, E).

The structural differentiation of the cell is correlated with a functional polarity. For, the nerve impulse within a given cell, whatever its source, begins in the dendrites or cell-body and is transmitted toward and along the neurite until it is passed on to some other cell through the branches of the neurite. In the case 
of the spinal ganglion cell there are but two processes from the cell and both these are slender, like neurites. As shown in the last chapter (p. 50) the process which receives the impulse, the peripheral fiber, corresponds in form and time of development to the dendrite of a cell of the usual form (Fig. 39, A and B). In the retina and in the olfactory epithelium the sensory cells seem to have no dendrites but instead only rod-like or hair-like peripheral processes.

In the cells which are usually regarded as typical nerve cells in the central nervous system of vertebrates the impulse starting in the dendrites passes through the cell-body and along the neurite. Probably in most cells in the central nervous system, however, and in the unipolar spinal ganglion cells the neurite arises from a dendrite at a longer or shorter distance from the cell-body. In these cases the most direct route for the nerve impulse is to pass from the dendrites to the neurite without entering the cell-body. Although it has long been supposed that such is probably the course of the impulse, it has not been possible actually to demonstrate it in vertebrates. In the crab Carcinas, Bethe has found a ganglion in which it was possible to secure experimental proof of this hypothesis. In the ganglion which supplies a sensory nerve to the second antenna the sensory cells have a form analogous to that of the unipolar spinal ganglion cells of higher vertebrates. Each cell body gives off a single process which is very much elongated and divides into a dendrite which serves as a sensory fiber to the antenna and a neurite which makes connection with motor cells in another part of the ganglion (Fig. 40). Without explaining the arrangement in detail, it may be said that the unipolar sensory cells are so placed that by very careful manipulation with fine instruments it was possible to remove the cell-bodies without disturbing the point of division of the single process into dendrite and neurite or the course and terminations of these processes. By artificial stimulation of the antenna, now, it was found that the same muscular reflexes followed as in the normal animal. Evidently the nerve elements perform their functions in the usual way in spite of the cell-bodies being cut away. The phenomenon of summation was also wit- 
nessed. It was further observed, however, that after a few days the functional responses ceased, presumably because of the death of the nerve fibers whose cell-bodies had been cut away.

It was supposed by the older anatomists and physiologists that the dendrites of a nerve cell were merely protoplasmic expansions which served to absorb the nutrient materials necessary for the cell, and they were called "nutritive processes." It was thought that the cell-body and neurite carried on all the specific nervous functions. Since it has been shown that the dendrites play a part

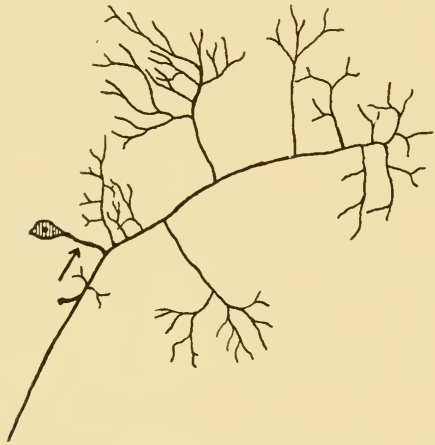

FIG. +0.-A cell from one of Bethe's figures to illustrate the experiment described in the text. The arrow shows where the single process was cut.

in the nerve activities not less important than that of the cellbody and neurite, they have not on that account lost their importance for nutrition. Since they offer by far the greatest surface for absorption of nutriment, together with a sufficient bulk of protoplasm for the purpose, it is probable that absorption does take place chiefly through the dendrites. But the final result of Bethe's experiment shows that the cell-body, or more especially the nucleus which it contains, is necessary for the nutritive activities. In nerve cells as in other cells the nucleus plays an essential part in the metabolic processes. Deprived of its nucleus the nerve cell soon dies, although it may carry on its normal functions so long as the nutrient materials contained in the protoplasm suffice for the necessary metabolic activities. 
As each nerve cell has two poles, an in-coming and an outgoing, so the nervous system as a whole receives stimuli from or through other tissues and gives out stimuli to other tissues. The nerve elements are so arranged in the nervous si stem that certain elements serve to receive all the stimuli, while others give out impulses to the rest of the body. The former cells may be called receptive cells; the impulses which they carry into the central nervous system, afferent impulses. The cells which give out impulses may be called excitatory cells; and their impulses efferent or out-going impulses. The afferent impulses do not always give rise to sensations. When they do, the impulses may properly be called sensory impulses and the fibers which carry them, sensory fibers. The efferent impulses go to glands as well as to muscles. Those which go to muscles may properly be called motor or excitomotor impulses; those which go to glands may be called excitoglandular impulses; and the fibers concerned may be given corresponding names.

The elements of the nervous system are so arranged that the dendrites of the receptive cells are directed toward the periphery and constitute what are commonly known as sensory nerve fibers. The neurites of the excitatory cells likewise extend to the periphery and constitute excito-motor and excito-glandular fibers. These two sets of fibers, together with numerous sense organs, constitute the peripheral nervous system, within the limits of which the cell-bodies of the receptive cells may also be included. A great number of other cells, which make up the central nervous system, are engaged in transmitting impulses from the receptive to the excitatory cells, and in distributing and coordinating the impulses in such ways as to produce through the excitatory cells definite responses to the stimuli received. The only collective term for all the various categories of cells performing such functions is the term central cells. The relations of the sympathetic system to the peripheral and central portions of the nervous system will be taken up in a special section (Chapter XIII).

In order to understand the functional relations of the several kinds of nerve cells to one another and to the rest of the organism, a certain type of relatively simple actions which are performed 
by all animals may be examined. If a frog be touched or pinched it will usually make a single prompt movement which may result in drawing the part concerned out of danger. If a flash of light suddenly falls on the eye of a fish, or if a swiftly moving shadow crosses the water, the fish may make a quick dart due to a single stroke or a few strokes of the tail. Further movements of either frog or fish may be indirectly connected with the stimulus mentioned, but it is the initial, relatively simple morement which concerns us here. We ourselves make similar movements under certain conditions. In our sleep we may move a hand to brush away a fly without being conscious of the act. We commonly toss about more or less in our sleep, and quite unconsciously. Certain waking movements are also of the same simple class, as when the eye-lid is suddenly closed to shut out a flying insect which is not consciously seen, or when sudden coughing is caused by some object entering the trachea. Probably many simpler mechanical operations, such as walking, fall at least at times under the same category of simple actions.

If these simple actions are studied experimentally under proper conditions we can determine what nerve elements are engaged and how they act. First, if in a frog or other lower animal the brain be entirely destroyed, the sort of actions mentioned are still performed with normal efficiency. Only the spinal cord and the peripheral elements connected with it are necessary. In the simplest case a single receptive cell whose body is situated in the spinal ganglion, receives the stimulus through the terminal branches of its dendrite in the skin and transmits an impulse along its centrally directed neurite. Within the spinal cord lateral branches are given off from the neurite and one of these collaterals carries the impulse to one or more excitatory cells lying in the ventral horn of the cord. These cells send impulses out along their neurites in the ventral root of a spinal nerve to certain muscles whose contraction produces the observed movement. Thus only receptive and excitatory cells are engaged in the whole action from the reception of the stimulus to the movement in response. This is illustrated in the left half of Fig. $+1, A$. The movement is called a reflex movement, the whole act including the nervous processes 
is a reflex act and the chain or series of nerve cells concerned is known as the reflex chain or refiex arc. In this simplest case the reflex chain has but two links. Probably only the simplest movements, such as a jerk or twitch, are produced by so simple a chain.

Usually the afferent impulse instead of being handed over directly to an excitatory cell, is spread more widely through the spinal cord by means of a larger number of branhces of the incoming neurite and by means of central cells (Fig. 4I, B, D). The arrangement of these cells will be treated later (Chapter XIV) but it may

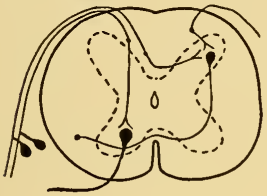

A

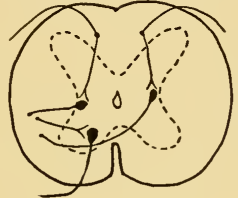

B

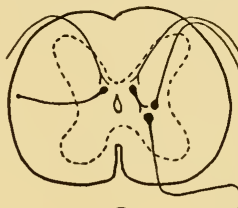

C

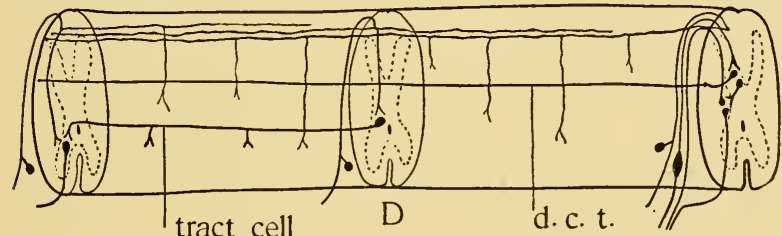

FIG. 4I.-Diagrams intended to show several forms of reflex chains in the nervous system of vertebrates. A, somatic sensory and motor reflex; B, reflex by way of tract cells; C, visceral sensory and motor reflex; D, a diagram of the spinal cord and nerve roots from the side, showing the same elements as in $\mathrm{A}, \mathrm{B}$ and $\mathrm{C}$. $d . c$. $t$., direct cerebellar tract.

be said that at least one set of cells usually intervenes between the receptive and the excitatory cells. The function of these cells is to spread the impulse so that it will affect a larger number of excitatory cells and so provoke a more ample or more intense movement in response. The extent to which the muscles of the body may be called into movement by such a reflex mechanism depends chiefly upon the strength and the duration of the stimulus. A larger number of links may be introduced into the reflex chain and the excitatory impulses 
may pass out over several nerves and give rise to coordinated contractions of many muscles. In this case we may speak of a complex reflex. A large number of the ordinary actions of the body are carried out in this way without the intervention of the brain. A large part of the brain also, even in man, may take part in such reflexes without voluntary effort or effect in consciousness. When the brain is involved, however, even in the frog or other lower animal, the actions are likely to become so long continued, so complex and varied that they are difficult to analyze into their simple constituents and to describe as reflexes. Nevertheless in all these cases essentially the same events are taking place. Receptive cells when stimulated transmit impulses which, after passing through a larger or smaller number of central cells, are sent out by excitatory cells to provoke contraction of muscles. If we speak of the cells through which an impulse is transmitted as the path of the impulse, the path in this case instead of being simple and direct is more complex, and the movements resulting may be much more complex and the means by which the end is attained more indirect than when the spinal cord alone is involved.

It is evident that there is no limit to the extent to which this conception of the reflex activity may be carried. So far as the nervous activities are concerned they are always of the same general type as that represented in the reflex. The term reflex is properly used only when a stimulus, through the medium of the nervous system, provokes a responsive action in the organism. But, given a nerve impulse of any kind, aroused in any way, the series of erents in the nervous system is similar to that of a reflex act. The impulse may pass from cell to cell, the motor response may be inhibited, and the impulse traveling into the sensory areas of the cerebral cortex, a sensation may result. This may mark the beginning of a new series of events within the cerebral cortex, associations, memory, thought processes. In all cases we are dealing with the origination of nerve impulses and their transmission over definite paths which may be anatomically studied. It is these anatomical pathways, themselves determined by experience, hereditary and individual, which determine the course taken by nerve impulses and the responses 
of the organism to stimuli. Our object therefore is to trace out these pathways of impulses, to arrange them into systems of nerve elements with reference to their appropriate stimuli and responses, and to give an orderly account of these systems.

\section{THE NEURONE THEORY.}

The cell theory of Schleiden and Schwann (I838-39) was a statement of the general conclusions of anatomists and embryologists up to that time regarding the mode of construction of the animal and plant organism. In brief, it was to the effect that every higher animal or plant is made up of many individual organisms known as cells. The cell was regarded as the unit of structure. Each cell carried on its own processes and had its own life history, and at the same time joined with others to produce the structure and actions of an organism of higher order. The cells of each tissue were like one another and the differences between tissues depended upon the characters of the cells constituting each. As the knowledge of various animal and plant tissue was increased, this theory was extended and amplified and remained for fifty years the best expression of our knowledge. In I89r the cell theory was stated in a special form as it applied to the nervous system. This statement of the cell theory of the nervous system has since been known as the neurone theory of Waldeyer, who formulated it. The theory may be stated as follows. The nervous system consists of cells each of which (I) arises from a single embryonic cell, processes of which grow out to form the neurite and dendrites; (2) remains as an independent cell in adult life, making connections with other cells only by contact of its processes with the processes or cell-bodies of other cells. The constituent elements of the nervous system were called by Waldeyer neurones. As the result of later discussion of this theory two further points have been added to it; (3) the structural and functional polarity of the neurone; and (4) that all parts of the neurone constitute a trophic unit for whose continued metabolic activity the presence of the nucleus is necessary. When the neurone is cut in two in any way only that part which retains the nucleus is capable of long continued functional existence. 
Even before this theory had been expressed the cell theory itself was being severely criticized and it may be said that since the year 1890 it has undergone important modifications. Although we may still speak of many-celled animals and may regard cells in a general way as units of structure, we can no longer consider

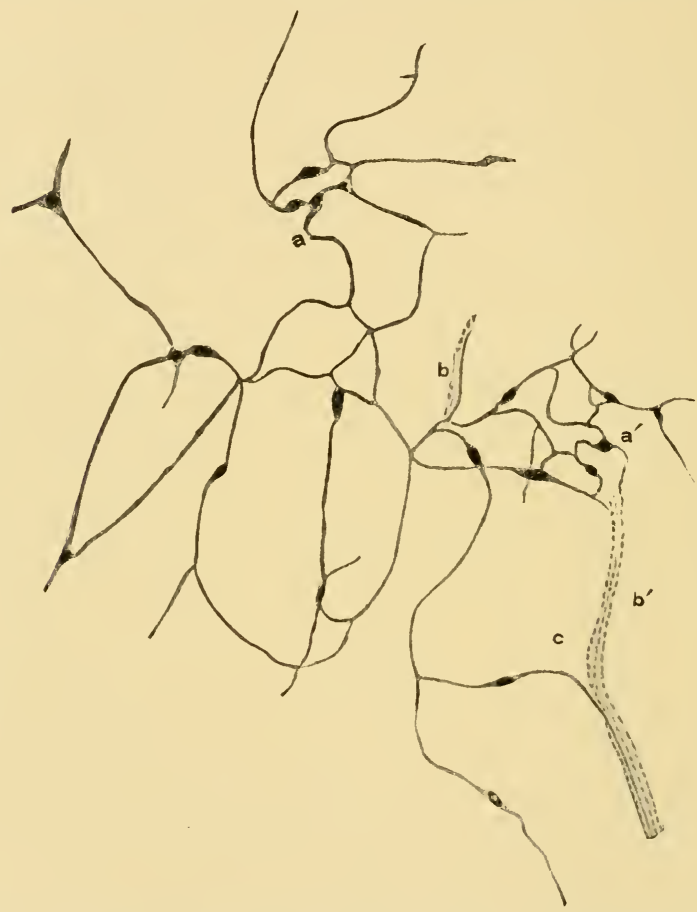

FIG. 42.-A portion: of the subepithelial nervous plexus in the palate of the frog. From Prentiss.

cells as unit organisms which join in the formation of an organism of a higher order. Cells are not always completely bounded by cell walls and in many cases adjacent cells are directly continuous with one another by means of strands of protoplasm. Moreover, 
in the course of embryonic development the number, form, position and multiplication of cells do not determine the course of differentiation. The cells are not controlling organisms which possess the iniative and directive power in these processes, but are perhaps only mass divisions made necessary by the metabolic relations of the nucleus and cytoplasm. The course of developmental differentiation is determined by a more fundamental organization which exists in the whole protoplasm of the organism before its division into cells, and by the interactions between the organism and its environment during development. The cells are rather the plastic material of differentiation. As the processes of differentiation complete themselves, however, cells and groups of cells become the means or organs for the performance of certain

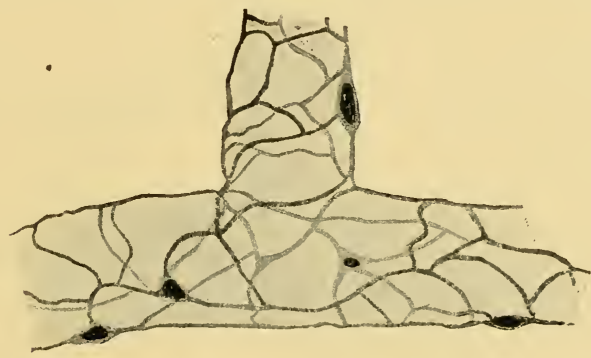

FIG. 43.-A portion of the network about the walls of a small vessel in the palate of the frog. From Prentiss.

functions. Organs are cell-complexes and the function performed by an organ is the mass result of the functioning of its constituent cells. Thus it may be stated as a general rule that each mass of protoplasm containing a nucleus is essentially a structural and functional unit of the organ. It is the nucleated mass of protoplasm which maintains itself as a structural entity although it may be connected by plasm strands with its neighbors, and which performs its specific part of the function of the organ.

These considerations apply to the nerve cell as well. It has been clearly shown that in many cases nerve cells are in continuity with one another. In the case of some peripheral plexuses (Figs. 
$42,43)$, dendrites are fused with dendrites into an intricate network. In other cases neurites are fused with the protoplasm of other nerve cells instead of merely ending in contact with them. That part of the neurone theory which states that nerve cells make connections with one another only by contact is defi-

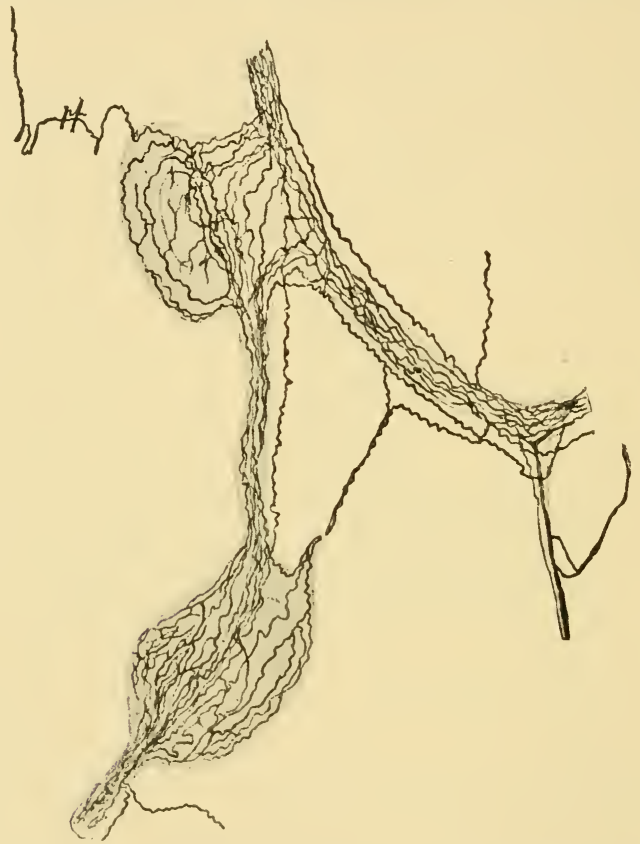

FIG. 44.-Two ganglion cells of the nervous network in the intestinal wall of the leech, Pontobdella, showing neurofibrillae passing through the cells. From Bethe after Apathy.

nitely disproved. Other criticisms which have been brought against the neurone theory are rather in the nature of extensions and corrections of the conception of neurones.

The relationships of the neurofibrillae have been represented as antagonistic to the neurone theory. Although the existence 
of fibrillæ in the protoplasm of nerve cells has been known for nearly fifty years, it is only in the last few years that they have been extensively studied and described. They have been found in many classes of animals and in many kinds of cells in the nervous system of invertebrates and vertebrates, so that their existence as structures characteristic of nervous tissue is quite certain. Further, it has been clearly shown that when two nerve cells are connected by strands of protoplasm the neurofibrillae may extend from one cell into the other. Neurofibrillae have been described as running through two, three or more cells without interruption. With regard to the origin, structural character and function of these fibrillae, further study is needed. It is said that they are formed outside of nerve cells and grow into them, that they may extend beyond the limits of the protoplasm of nerve cells as in nerve-muscle endings, and that they are the medium of conduction of nerve impulses, while the nerve cells perform only the incidental function of nutrition. Indeed the neurofibrillæ are regarded by some as quite new structures in the nervous system in addition to nerve cells;--structures which are more intimately and essentially concerned in specific nervous functions than are the nerve cells themselves.

Certainly in the present state of knowledge this view is extreme. It seems more reasonable to regard the neurofibrillæ as a dense portion of the colloid substances in the cytoplasm of nerve cells, whose definite form and arrangement are conditioned upon the intimate structure of the protoplasm as a whole. Thus if the protoplasm has the structure of a foam, then the colloid substances forming the walls of the vesicles and filling the solid angles, in elongated strands such as dendrites and neurites would certainly appear as threads. In more rounded cell-bodies the colloid substance would be more irregularly arranged and there would be the appearance of branching and crossing of threads, as is actually the case with the neurofibrillae. When the dendrites of two cells fuse together the neurofibrillae would of course continue from one cell into the other. In the most minute end branches of neurites the plasm may be so slight in amount that in preparations in which the colloid substance alone is sharply stained, 
the slender branches would appear to be composed of a neurofibrilla alone. Finally, in nerve-muscle endings it is conceivable that the neuroplasm and sarcoplasm should be fused together and that the neurofibrillae should continue into the sarcoplasm. This is at present the most probable interpretation of the appearances presented by the neurofibrillae. Whether the fibrallae constitute a special conducting substance in the nerve cell is doubtful. It is scarcely conceivable that any one substance in the nerve cell can originate and conduct a nerve impulse without interaction with other substances in the cell. However, if the nerve impulse and its transmission are phenomena in the production of which the various substances in the cell cooperate, then the neurofibrillae by reason of their density and their staining properties may reasonably claim our attention as indicators of the course taken by impulses.

The process of regeneration of injured nerves, although it may not coincide with the processes of normal growth of nerve elements, is instructive as to the nature of the neurone. The course of regeneration of a cut nerve seems to be as follows. The part distal to the cut, i.e. away from the cell-body, degenerates in agreement with the observations of Waller. The fibers proximal to the cut remain in a healthy condition and grow along the line of the degenerated distal part. Whether the growth of the fibers is sufficient to replace the whole length of the part cut away has not been positively demonstrated but is presumed in the absence of evidence to the contrary. When the proximal ends are not prevented from growing down along the degenerated nerve the naked extensions of the axis cylinders may be traced for a considerable distance. The degeneration of the distal part of the axis cylinders leads to changes in the sheaths. The myelin is resorbed and the sheath cells, or some of them, form strands of plasm which are to be regarded as in the nature of embryonic tissue. When the proximal end of the nerve is tied to one side so that its fibers cannot grow out along the nerve bed, it is said (Bethe) that the embryonic strands develop neurofibrillae and become able to conduct impulses. In adult animals the strands do not acquire this power and in any case connection with the 
central end of the nerve is necessary; without it the strand formed from sheath cells degenerates. The conditions of the experiments of Bethe are not such as to show what takes place in the course of normal regeneration. It is not shown that the strands derived from sheath cells form part of the nerve when the proximal stump is undisturbed. The later researches of Cajal are opposed to this "autogenetic regeneration" of Bethe and give positive evidence that the nerve is regenerated by outgrowth of the proximal stumps of the cut fibers.

For the continued performance of its normal functions all parts of the neurone are necessary. The fact that a neurone may continue to function for some days after the cell-body containing the nucleus has been cut away shows that impulses follow the shortest path from dendrites to neurite. The further fact that the dendrites and neurite die after a few days proves the trophic unity of the neurone. The Wallerian degeneration is evidence of the same. It appears also that injury to one of the processes of the neurone may start destructive changes which the neurone is unable to combat and the whole neurone may degenerate as the result of the cutting of its neurite (Gudden's degeneration). It is quite unnecessary to think that all parts of the neurone must enter at once into the chemical and physical changes which constitute any single act of the neurone. The notion that the cell-body acts as a ganglionic center with reference to its dendrites and neurite is no part of the neurone theory. Facts opposed to such a conception were known long before that theory was formulated, namely the unipolar form of spinal ganglion cells and the origin of neurites from the dendrites of many cells in the brain.

The neurone theory as an expression of our general ideas regarding the structure and functioning of the nervous system may be tentatively re-stated as follows.

I. The nervous system is formed of cells each of which is derived from a single cell in the course of development. From each cell grow out one or more processes which are comparable in a general way to the pseudopodia of unicellular animals. Such cells may be called neurones.

2. Although in their primitive condition, as commonly in 
invertebrates, neurones do not show a functional differentiation of their processes, typical neurones in vertebrates present a structural and functional polarity. Each neurone consists of dendrites, cell-body and neurite; and the impulse passes through the parts in the order named, or passes from dendrites to neurite without passing through the cell-body. Certain peripheral plexuses in which the dendrites of adjacent neurones are fused into an intricate network require further study with reference to this statement.

3. When the neurite of one neurone has a functional connection with some part of another neurone, the plasm of the two neurones at the point of connection may be fused. Whether such a continuity of structure between the neurones of a chain or pathway is universal, or how frequent it is, must be determined by further study.

4. In the protoplasm of neurones the apparent fibrillar structure is a constant and normal feature. The real nature of the neurofibrillae in the living cell, the mode of their formation, and the structural changes which they may undergo during the different phases of functional activity of the neurone are not yet understond. When a fusion between two neurones takes place the neurofibrillae take part in it.

5. The whole neurone is necessary for continued functional existence. Any part of the neurone which is cut away from the nucleated portion degenerates. The mode of repair of such injury is by growing out of the cut fiber.

6. The form and position of the neurones and especially the disposition and connections of their processes determine the pathways of impulses and hence the work done by the nervous system.

The practical value of the neurone theory is found in the last statement. The linking together of neurones in pathways is determined in part by inheritance of the general plan of arrangement and in part by the experience of the individual. The nervous system considered as a complex of neurones variously linked together into functional systems, is at once the mechanism by which certain work is done and a record of the experience of the individual and the race. A knowledge of how neurones are linked together in functional systems is necessary for the pathologist 
and psychologist. The factors which determine the manner of linking of neurones are the chief interest of the social psychologist, the educator and the social reformer.

\section{DEMONSTRATION OR LABORATORY WORK.}

I. Study in Golgi preparations the form and structural polarity of nerve cells of types I and II in various parts of the nervous system.

2. Study the spinal reflexes of the frog by the methods in use in the physiological laboratory.

3. Study the structure of nerve cells by the method of Nissl and by the methylene blue and other methods for neurofibrillae.

\section{LITERATURE.}

Apathy, Stefan: Das leitende Element des Nervensystems und seine topographischen Beziehungen zu den Zellen. Mitth. Zool. Sta. Neapel, Bd. I 2. 1897 .

Bethe. Albrecht: Studien über das Centralnervensystem von Carcinus maenas u. s. w. Arch. f. mik. Anat., Bd. 44. 1895. Bd. 51. I898.

Bethe, A.: Allgemeine Anatomie und Physiologie des Nervensystems. Leipzig. 1903.

Cajal, S. R.: Mecanismo de la regeneracion de los nervios. Trav del Laborat. de investig. biol. de la Univ. de Madrid. Tomo 4. 1905.

Dohrn, A.: Studien zur Urgeschichte des Wirbelthierkörpers. No. I 7: Nervenfaser und Ganglienzelle. Mitth. Zool. Sta. Neapel. Bd. ro. I891. No. 20: Die Schwannschen Kerne, ihre Herkunft und Bedeutung. Mitth. Zool. Sta. Neapel., Bd. r5. r9or.

Golgi, C.: Untersuchungen über den feineren Bau des Centralen und Peripherischen Nervensystem. Uebersetung von Teuscher. Jena. 1894.

Harrison, R. G.: Ueber die Histogenese des peripheren Nervensystems bei Salmo salar. Arch. f. mik. Anat., Bd. 57. 190r.

Harrison, R. G.: Experimentelle Untersuchungen über die Entwickelung der Sinnesorgane der Seitenlinie bei den Amphibien. Arch. f. mik. Anat., Bd. 63. 1903.

Harrison, R. G.: Neue Versuche und Beobachtungen über die Entwickelung der peripheren Nerven der Wirbelthiere. Sitzungsb. d. Niederrhein. Gesell. î. Natur. u. Heilkunde zu Bonn. I904.

Held, H.: Beiträge zur Structur der Nervenzellen und ihre Fortsätze. Arch. f. Anat. u. Physiol., Anat. Abth., I897.

His, W.: Die Neuroblasten und deren Entstehung in embryonalen Mark. Arch. f. Anat. u. Physiol., Anat. Abth., I899.

His, W.: Histogenese und Zusammenhang der Nervenelemente. Arch. f. Anat. u. Physiol., Anat. Abth., I 890 Supplement.

Howell, W. H. and Huber, G. Carl: A physiological, histological and 
clinical study of the degeneration and regeneration in peripheral nerve fibers after severance of their connection with the nerve centers. Jour. of Physiol., Vol. I3, I4, I892, 1893.

Langley, J. N.: Note on the experimental junction of the Vagus nerve with the cells of the superior cervical ganglion. Proc. Roy. Soc., Vol. 62. I897.

Langley, J. N., and Anderson, H. K.: Observations on the Regeneration of Nerve Fibers. Jour. of Physiol., Vol. 29. 1902.

Lenhossek, M. Frage nach der Entwickelung der peripherischen Nervenfasern. Anat. Auz., Bd. 28, 1906.

Neal. H. V.: The Development of the Ventral Nerves in Selachii. Mark Anniversary Volume. 1903.

Nissl, Fr.: Ueber die Sogenannten Granula der Nervenzellen. Neurol. Centralb., Bd. 13. I894.

Nissl, Fr.: Die Neuronlehre und ihre Anhänger. Jena. I903.

Perroncito, A.: La rigenerazione della fibre nervose. Bollet. de Soc. Medico-Chirurg. di Pavia. Igo5.

Prentiss, C. W.: The Nervous Structures in the Palate of the Frog; the Peripheral Networks and the Nature of their Cells and Fibers. Jour. Comp. Neur. and Psych., Vol. I4. Ig०4.

Sedgwick, A.: On the Inadequacy of the Cellular Theory of Development, and on the early Development of Nerves, etc. Quart. Jour. Micr. Sci.,. Vol. 37. 1895 .

Verworn, M.: Das Neuron in Anatomie und Physiologie, Jena. rgoo.

Waldeyer, W.: Ueber einige neuere Forschungen im Gebiete der Anatomie des Centralnervensystems. Deutch. med. Wochenschr., I8gr.

Waller, A.: Sur la reproduction des nerfs et les fonctions des ganglions spinaux. Müller's Archiv, 1852. Also articles in Comptes Rendus, Tome $34, \quad 185^{2}$.

Whitman, C. O.: The Inadequacy of the Cell Theory of Development. Jour. Morph., Vol. 8. 1893 . 


\section{CHAPTER V.}

\section{THE FUNCTIONAL DIVISIONS OF THE NERVOUS SYSTEM.}

The nervous system can be understood only by studying it from the standpoint of the work which it does. It must be insisted that a knowledge of mere structure is of little value and may be misleading without a knowledge of function. For this reason in speaking of the nervous system the term mechanism is preferable to architecture; for mechanism implies work as well as structure. It implies structure in action. The work of the nervous system is to adapt the activities of the animal to the conditions of its life and of the perpetuation of the species. As the necessary adaptations and correlations are successfully carried out the organization of the nervous system is perfected through experience. In all vertebrates the same general plan of organization is seen; the degree of organization is a measure of adaptation and is correlated with the survival of the best adapted. The higher animals are adapted to more complex and changing conditions of life and have more highly organized nervous systems.

We may distinguish two main groups of activities in the vertebrate organism which have determined the general plan of organization of the nervous system: actions in relation to the external world, and internal activities having to do with the processes of nutrition and reproduction. The actions toward the external world consist of the finding and capturing of food, fighting with other animals, preparing nests or homes for protection against the physical elements, and many minor reactions to changes in heat, light, moisture, etc. The internal activities include all the processes related to metabolism, the distribution of nutritive material to various parts of the organism, and the various processes connected with the formation of the reproductive elements and the nutrition of the embryo. 
With regard to each of these groups of activities the work of the nervous system is two-fold. On the one hand it receives stimuli from the external world or the internal organs; on the other hand it directs the responses to those stimuli. All actions are in response to stimuli; directly or indirectly. The stimuli usually affect the organs only through the nervous system. It is noticed that certain characteristic responses habitually follow upon certain stimuli, either as the result of heredity or of individual experience. For example, a frog will jump to catch an object which moves in a manner characteristic of its usual food. So a hellbender will pay no attention to a living earthworm so long as it is quiet, even although the worm be lying on the animal's nose. The moment the worm wriggles vigorously it is snapped up. This is because these animals habitually judge their food by its movements. In other animals the reactions necessary for capturing food are called forth by stimuli received through the organs of smell or taste. In any case the reactions toward the external world are in the nature of reflex acts, simple or complex. As far as the nervous processes are concerned the internal reactions are of the same character, although their reflex nature is not so readily seen as in the case of external activities.

With regard to the stimuli, then, those which affect the bodily welfare of the animal in its surroundings must be distinguished from those which affect the internal activities. A morphological distinction has long been made between the soma and the viscera. The soma comprises those organs (skin, muscle, skeleton, etc.) by which the animal deals with its environment. The viscera comprise those organs (alimentary canal and appendages, circulatory, excretory and reproductive apparatus) concerned with the processes of metabolism by which the organism is built up and the reproductive elements are formed. A part of the soma, the skin, comes into contact with the external world and offers the medium by which stimuli reach the nervous system. The remainder of the soma (muscles and skeleton) responds to these stimuli by appropriate movements under the direction of the nervous system. The peripheral nerve fibers and the central mechanisms which have to do with stimuli affecting the welfare 
of the animal in its surroundings are arranged on a common plan in all segments of the body in all vertebrates, and constitute a distinct portion of the nervous system both structurally and functionally. These structures are best called collectively the somatic afferent division of the nervous system.

The stimuli having reference to food and the visceral activities include those arising in the viscera and those produced by chemical changes in the surrounding medium. Chemical changes in the surroundings do not stimulate the somatic sense organs. The special organs of the sense of taste, which in fishes lie in

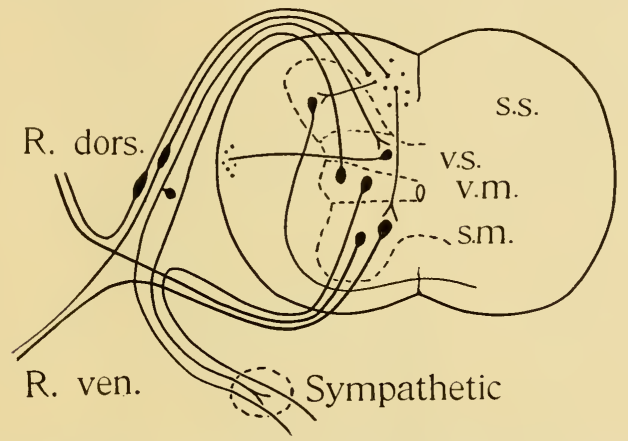

FIG. 45.-A diagram of the component elements in the spinal cord and the nerve roots in a trunk segment, to illustrate the four functional divisions of the nervous system. s. s., somatic sensory; v. s., visceral sensory; v. $m$, visceral motor; s. m., somatic motor.

the skin as well as in the branchial and mouth cavities, and the olfactory organs are affected by chemical stimuli and are used in finding food. All the nervous structures concerned with impulses arising in the viscera, in the taste organs and in the olfactory organ are closely related and constitute the visceral afferent division of the nervous system.

The movements of the soma are aroused chiefly by somatic afferent impulses and have to do with the relation of the animal to its surroundings. Thus, all the usual movements of locomotion, of offense and defense, and so forth, are directed ordinarily in response to stimuli from without. Somatic movements are also 


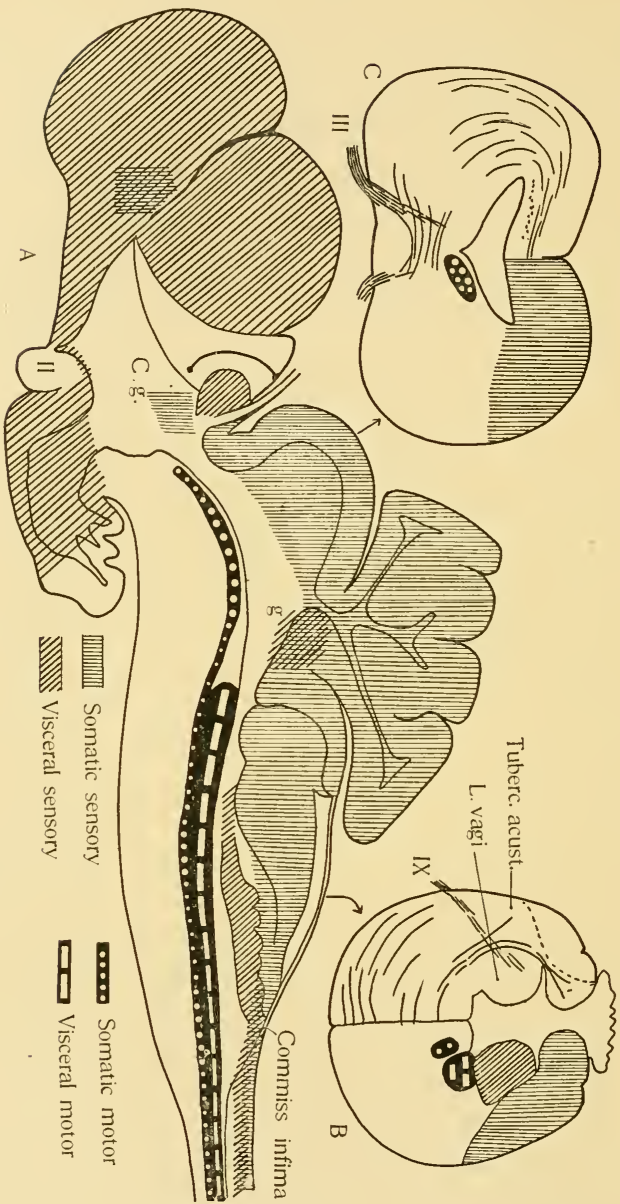

FIG. 46.-Diagrams to represent the extent and arrangement of the functiona divisions in the brain of a selachian. A, projection upon the mesial plane; B and C, sections taken at the levels indicated by the arrows. C. $g$., corpus geniculatum. g., superior secondary gustatory nucleus. Other legends and symbols are explained in the figure. Compare with Figure II. 
performed in response to gustatory and olfactory stimuli and have for their object the capturing of food. It is shown by experi-

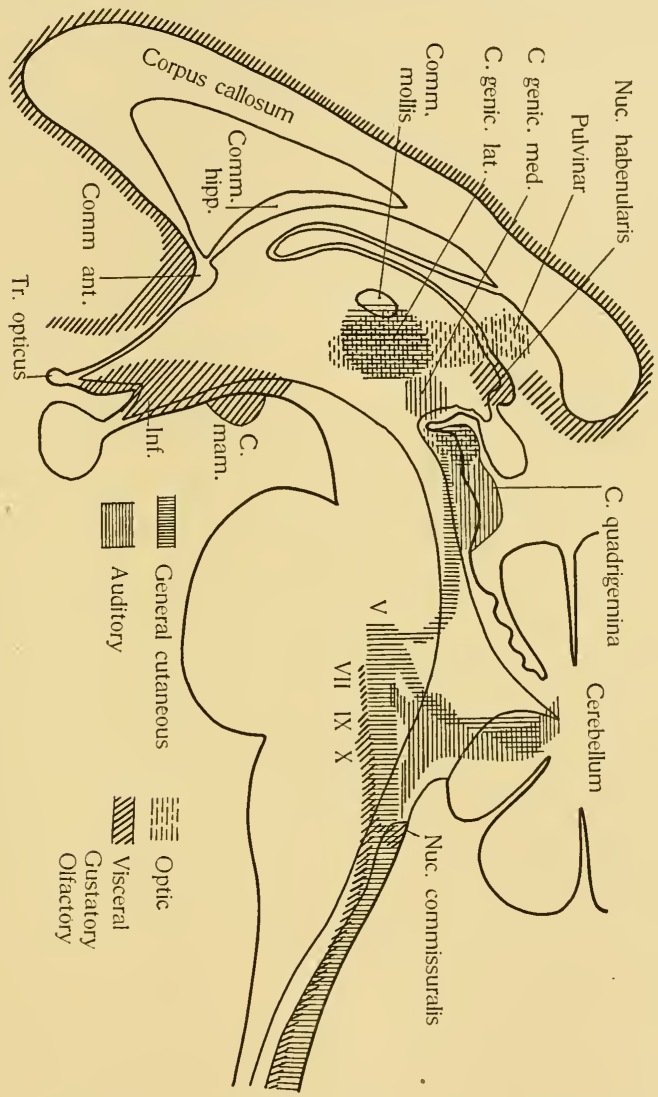

FIG. 47.-A diagram to show the arrangement of the two afferent divisions in the brain of man. Compare with Fig. 46. A cutaneous mesencephalic root of $\mathrm{V}$ is hypothetical in man.

ments on fishes and by clinical observations on man that very strong gustatory stimuli can be localized without the help of 
tactile stimuli, but the responses given by fishes to such stimuli are less constant and precise than the reactions to combined gustatory and tactile stimulation. Usually the localization of objects detected by the gustatory or olfactory organs requires concurrent somatic stimuli. This is easily illustrated in our own experience. We can not tell with certainty the location of an object which we smell. If a wind brings the odor to us we can tell the direction of the object, but not its distance. The direction is known only by the pressure (somatic) stimuli due to the wind. If we are blindfolded in a room and wish to find the position of a boquet of flowers which we detect by its odor we must go about and sniff until we find the place where the odor is strongest. In general, while somatic movements may be called forth by visceral stimuli they are more typically called forth by somatic stimuli and are more precise when they are directed in response to somatic stimuli. The nerve centers and peripheral nerves which direct somatic movements constitute a distinct portion of the nervous system called the somatic efferent (motor) division.

The visceral activities consist of contractions of visceral muscles, secretory processes, vaso-motor regulation, etc. These all contribute directly or indirectly to the processes of nutrition in the widest sense, or of reproduction. These activities are aroused chiefly by visceral afferent impulses, including gustatory and olfactory impulses. How far they may be called forth by somatic stimuli is not fully understood. It is a fact of common experience that the concept of food aroused by sight or tactile perception may cause salivary secretion. Vaso-motor regulation is in large part the result of heat and cold stimuli in the skin. Perspiration is called forth by rise in temperature within the body. The nerve centers and fibers which control visceral activities constitute the visceral efferent division of the nervous system.

In the life of any vertebrate animal four kinds of nervous activities are called for: (I) the reception of somatic stimuli; (2) the direction of somatic movements; (3) the reception of visceral stimuli; (4) the direction of visceral activities. Corresponding to these four sorts of activities there are four anatomically distinct divisions of the nervous system: somatic afferent and efferent, 
visceral afferent and efferent divisions (Fig. 45). With exceptions to be noted in their proper places, the four kinds of activities are called for in all segments of the body, and consequently each of the functional divisions is represented in each segment of the body and all the segments of a given division are serially homologous with one another. These longitudinal divisions of the nervous system are therefore the most fundamental and important divisions both structurally and functionally. The segmentation of the nervous system is to be regarded as a segmentation of each of the functional divisions. It is probable that the functional divisions of the nervous system are more fundamental than the metamerism of the body.

One point of contrast should be noted between the two somatic divisions on the one hand and the two visceral divisions on the other. Although somatic afferent impulses may produce somatic reflexes directly without sensation, very commonly sensations are produced. When present the sensations are definitely localized and the responses may be consciously directed. Visceral afferent impulses, on the other hand, usually produce reflexes without sensation. When present the sensations are vague, general, poorly localized, and consciously directed visceral activities are very exceptional if not abnormal. The somatic activities are par excellence related to the conscious life.

There is given here for reference a table of the four functional divisions with the structures included in each. In addition to the structures included in this outline there are certain brain centers which with their fiber tracts serve functions of correlation between the four primary divisions. These will be treated in later chapters (Chap. XIV and following).

A. Somatic sensory division.

r. General cutaneous subdivision. Consists of:

free nerve endings in the skin, general cutaneous system of components,

dorsal tracts of the cord, spinal $\mathrm{V}$ tract in the medulla oblongata, together with their accompanying nuclei: the dorsal horn, nucleus funiculi, nucleus spinalis trigemini, acusticum and cerebellum, secondary tracts and centers: internal and external arcuate fibers 
forming the tractus spino- and bulbo-tectalis (lemniscus), tectum mesencephali, and other nuclei, tertiary tracts to motor nuclei and coördinating centers.

2. Special cutaneous subdivision. Consists of: neuromasts (acustico-lateral sense organs), neuromast components, spinal VIII tract and nucleus, nucleus funiculi, acusticum, cerebellum, secondary tracts and centers and tertiary tracts as in $\mathrm{x}$, the cochlea, its nerve and centers in higher vertebrates.

3. Special sense organs belonging to the somatic sensory division.

Lateral eyes. Consist of:

retina, which includes the equivalent of sensory ganglion, nerve component, and primary brain center.

optic tract and tectum opticum corresponding to the secondary tracts and centers of the cutaneous subdivision.

Pineal eyes. (Compare Chap. VIII below.)

B. Visceral sensory division.

r. General visceral subdivision. Consists of:

free nerve endings in the mucosae,

fasciculus communis system of components,

Clarke's column or its equivalent, nucleus commissuralis CAJAL, lobus vagi, and lobus facialis,

secondary visceral tract and its continuation in the cord, $=$ the direct cerebellar tract in higher forms,

secondary visceral nucleus, = end nucleus of direct cerebellar tract in the vermis of higher forms,

tertiary tracts to the hypothalamus in lower vertebrates.

2. Special visceral subdivision. Consists of:

end buds (taste buds).

components and central nuclei and tracts not yet distinguished from those of the general visceral subdivision.

3. Special sense organ belonging to the visceral sensory division.

Consists of: olfactory epithelium and nerve, bulbus olfactorius, tractus olfactorius, area olfactoria, and tertiary tracts to coördinating centers in the diencephalon.

4. Sympathetic system, afferent portion. An outgrowth or offshoot from visceral sensory ganglia which reaches a high specializa tion in the vertebrate series. Consists of simple visceral sensory component fibers and of ganglion cells which together with the efferent portion control contraction of smooth muscles and glandular secretion.

C. Somatic motor division. Consists of:

ventral horn of the cord, nuclei of origion of Nn. XII, VI, IV, III, and nucleus of somatic motor fasciculus, 
motor components in ventral roots supplying musculature derived from the somites.

D Visceral motor division. Consists of:

I. Motor nuclei in lateral horn or intermediate zone of the cord and corresponding region of the medulla oblongata,

motor component in dorsal and ventral roots supplying musculature derived from lateral mesoderm.

2. Sympathetic system, efferent portion. Consists of ganglion cells and fibers concerned with glandular secretion, and the contractions of smooth muscle. They receive impulses from visceral efferent fibers.

To illustrate the positions of the four divisions in the brain of vertebrates two diagrams are given, Figures 46 and 47 . These show by conventional symbols the areas occupied by the functional divisions in the brain of a fish and of man. In these figures as in others the shading by right lines, either vertical or horizontal, indicates somatic sensory areas; the oblique lines indicate visceral sensory areas. The figures should be compared with Figs. 2, 3 , II, and with figures of the human brain in a text-book of anatomy.

\section{DEMONSTRATION OR LABORATORY WORK.}

I. Dissect the cranial nerves of a fish, a frog and a mammal with especial reference to the cutaneous and visceral rami.

2. Dissect the brain of a large dogfish or skate and of a large Ameiurus, or other bony fish which has large vagal or facial lobes. Examine the form relations of the functional divisions in the medulla oblongata, and of the cerebellum, tectum mesencephali, inferior lobes and olfactory lobes and bulbs by means of hemisections and dissections of the brain and by sections under low power of the microscope.

3. Compare the brain of some mammal with those of the fishes with regard to each of these points.

The importance of dissections of the brain cannot be over-estimated. Very satisfactory results in demonstrations can be obtained by no more elaborate means than dissections and well prepared sections stained by Delafield's haematoxylin.

\section{LITERATURE.}

Allis, E. P., jr.: The Anatomy and Development of the Lateral Line System in Amia calva. Jour. Morph., Vol. 2. 1889.

Cole, F. J.: On the Cranial Nerves of Chimaera monstrosa Linn., etc. Trans. Roy. Soc. Edinb., Vol. 38. ז896. 
Ewart, J. C.: On the Cranial Nerves of Elasmobranch Fishes, Proc. Roy. Soc., Vol. 45. I889.

Ewart, J. C.: The Lateral Sense Organs of Elasmobranchs. I. The Sensory Canals of Laemargus. Trans. Roy. Soc. Edinb., Vol. 37. I893.

Gaskell, W. H.: On the Structure, Distribution and Function of the Nerves which innervate the Viscera and Vascular Systems. Jour. of Physiol., Vol. 7. 1886 .

Herrick, C. J.: The Cranial and First Spinal Nerves of Menidia; a Contribution, etc., Jour. Comp. Neur., Vol. 9. 1899.

Herrick, C. J.: The Doctrine of Nerve Components and some of its Applications. Jour. Comp. Neur., Vol. I4, I904.

Johnston, J. B.: An Attempt to Define the Primitive Functional Divisions of the Central Nervous System. Jour. Comp. Neur., Vol. I2. I902. Johnston, J. B.: Das Gehirn und die Cranialnerven der Anamnier. Merkel u. Bonnet's Ergebnisse, Bd. II. Ig02. Bibliography.

Johnston, J. B.: The Morphology of the Vertebrate Head from the Viewpoint of the Functional Divisions of the Nervous System. Jour. Comp. Neur. and Psych. Vol. 15. I905.

Osborn, H. F.: A Contribution to the Internal Structure of the Amphibian Brain. Jour. Morph., Vol. 2. 1888.

Strong, O. S.: The Cranial Nerves of Amphibia. A Contribution, etc. Jour. Morph., Vol. זo. I895. 
CHAPTER VI.

\section{SOMATIC AFFERENT DIVISION. GENERAL CUTANEOUS SUBDIVISION.}

In the skin of all vertebrates certain fibers belonging to the dorsal nerves end by free branches between the cells of the epidermis (Fig. 48). These are the fibers of the sense of touch. In the trunk these fibers form the largest component of the dorsal spinal nerves and are distributed by way of both dorsal and ventral rami. The rami reach the skin in the myosepta and may be distributed forward or backward from the myoseptum in which
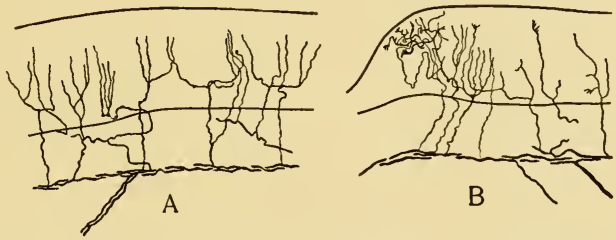

FIG. 48.-General cutaneous endings in the cyclostome Lampetra Wilderi. B is taken from the border of a neuromast pit.

they run, or both forward and backward, i.e. to the two adjacent segments. A diagram to show the central relations of the general cutaneous components is given in Fig. 49.

Passing forward into the head we find a region between the permanent first spinal nerve and the vagus in which general cutaneous nerves are apparently absent. In cyclostomes, however, the full number of cutaneous nerves are present, and the same is apparently true in the primitive selachian Heptanchus, as shown in Figure 2. In the embryo of other selachians there is one vestigeal ganglion for each segment, which probably represents a cutaneous nerve. Even in mammalian embryos, as in the pig (Fig. 20) and in man (Fig. 32), rudimentary ganglia which may 
represent the cutaneous roots of this region accompany the spinal accessory roots. These remain in the adult as a few scattered clumps of ganglion cells among the vagus roots. The reason for the failure of these nerves to develop has been suggested in a previous chapter (p. 65). Since a certain number of somites in this region have disappeared and the trunk somites have shifted forward, it is probable that the cutancous area has been lessened and one or more nerves have disappeared in most vertebrates.

The arrangement of the cutaneous components in the cranial nerves varies in different vertebrates. In cyclostomes such fibers form large components of the X, IX and VII roots. In selachians, ganoids, bony fishes and amphibia general cutaneous components are found in the $\mathrm{X}$ and IX roots, but rarely (Kingsbury) in the

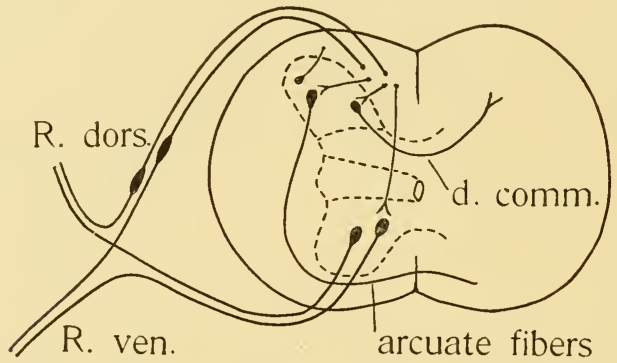

FIG. 49.-A diagrammatic representation of the general cutaneous components of a trunk segment.

VII root. In mammals and man a general cutaneous component in the $\mathrm{X}$ nerve has its cells of origin in the jugular ganglion and forms the ramus auricularis. A rudimentary root ganglion in the IX nerve probably represents this component (Figs. 2O, 30, 3I, 32). In all vertebrates the sensory trigeminus and the ophthalmicus profundus nerves are formed chiefly or exclusively of general cutaneous fibers. Finally, that small nerve which is found connected with the forebrain in many selachians, Amia and Protopterus, the nervus terminalis, is probably general cutaneous in character.

The distribution of the general cutaneous components is rela- 
tively simple. The arrangement is shown in a generalized scheme in Figure 50. In cyclostomes (Fig. 5I) the dorsal spinal nerves in the branchial region send dorsal rami to the skin of the back and their ventral rami join the epibranchial trunk. From this the cutaneous fibers are distributed by the posttrematic rami to the skin of the lateral and ventral surface of the gill region. The cutaneous component in the vagus root goes to the first posttrematic ramus of the vagus. In true fishes and all higher forms the cutaneous component of the $\mathrm{X}$ root is distributed by dorsal rami to the dorsal surface of the head. In fishes provided with an operculum general cutaneous fibers are not found in the branchial rami, but a ramus from $\mathrm{X}$ helps to supply the skin on the operculum. The cutaneous components in the branchial nerves

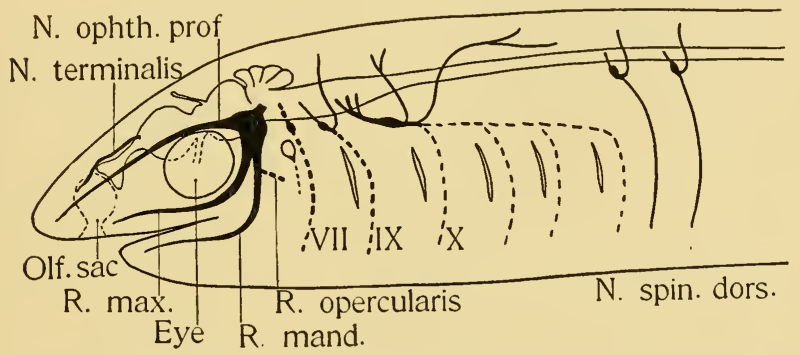

FIG. 50.-A simple diagram of the general cutaneous components in the cranial and spinal nerves of a fish. The dotted lines (except $\mathrm{R}$. opercularis) represent components present in cyclostomes but not yet found in other fishes.

of selachians have not been described. The cutaneous component in the IX nerve in cyclostomes goes by way of the ramus posttrematicus to the skin of the region of the first branchial arch. In other vertebrates only a dorsal ramus is present.

The absence of a general cutaneous component from the VII nerve in most vertebrates requires to be explained. In forms provided with an operculum, the operculum is innervated by rami from the $\mathrm{V}$ and $\mathrm{X}$ nerves and rami from the $\mathrm{V}$ nerve supply the ventral surface in the gill region. In cyclostomes, where there is no operculum, a simpler and more primitive arrangement is found. 
There is a large cutaneous component in the VII nerve which is

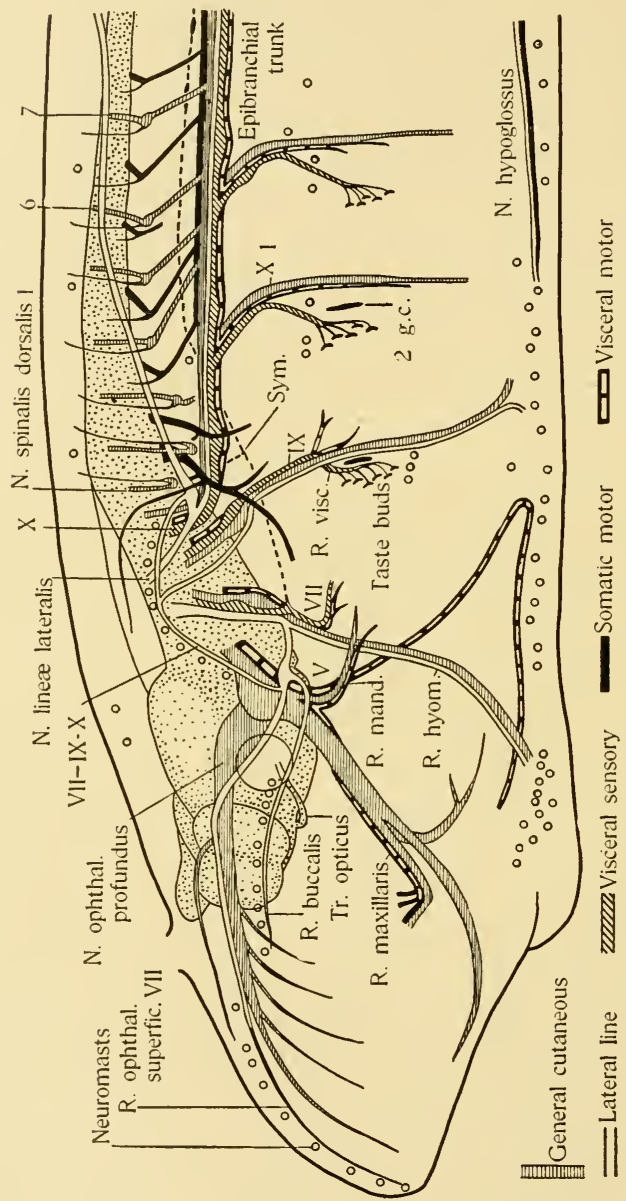

FIG. 51.-A reconstruction of the cranial nerves of a cyclostome fish, Petromyzon dorsatus, to show the arrangement and distribution of the several systems of nerve components. Sym., sympathetic trunk; 2 g. c., second gill cleft. 
distributed by way of the posttrematic ramus to the skin of the hyoid segment, just as in the more caudal branchial segments. The skin of the corresponding dorsal area, however, is innervated

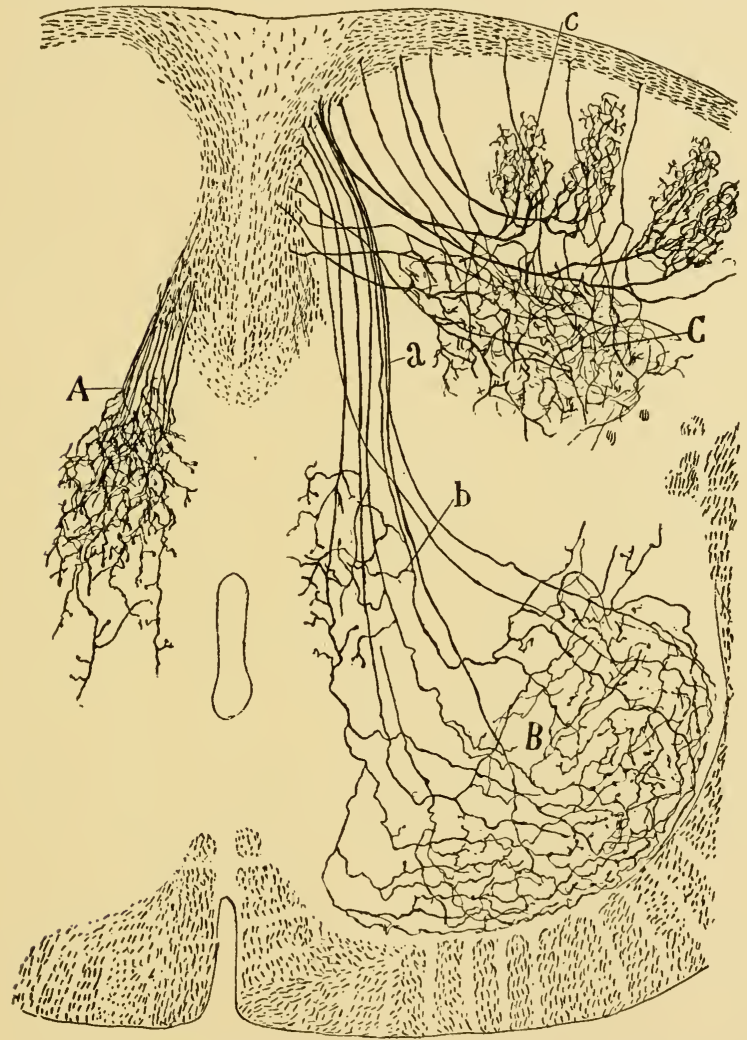

FIG. 52.-The principal sensory collaterals in the spinal cord of the"new-born rat. From Cajal (Textura, etc.). $A$, visceral sensory collaterals to the intermediate nucleus; $B$, collaterals to the somatic motor column; $C$, collaterals to the somatic sensory column, dorsal horn; $b$, branches of somatic motor reflex collaterals ramifying in the intermediate nucleus (visceral motor); $c$, deep collaterals to the substance of Rolando. 
by rami from the $\mathrm{V}$ nerve. From this it would appear that the hyoid segment had originally its own cutaneous innervation and that when the operculum was formed the component in VII disappeared and the $\mathrm{V}$ nerve supplied the parts of the hyoid segment remaining exposed.

The trigeminus gives small branches to the dorsal surface of the head behind the eye, and in fishes it gives a larger ramusophthalmicus superfacialis trigemini to the skin above the eye. It then forms the rami maxillaris and mandibularis which supply the skin of the upper and lower jaws and the lining of the stomodaeum.

The ophthalmicus profundus nerve supplies the area in front of the eye to the tip of the snout. In tailed amphibians the maxillary nerve is greatly reduced and the profundus takes on the innervation of the territory of the maxillaris.

The CENTRAL APPARATUS FOR CUTANEOUS IMPULSES.--This consists of the dorsal horn of the gray matter in the spinal cord and secondary tracts and centers connected with it, and of corresponding structures in the brain. The cutaneous fibers have their ganglion cells in the spinal ganglia. The central processes of these ganglion cells enter the dorsal part of the cord and there bifurcate in $\mathrm{T}$ - or $\mathrm{Y}$-form. The two branches run one cephalad and one caudad, forming the dorsal tracts of the cord. In man it is known that the cephalic branch is the longer and this seems to be the case in lower vertebrates as well. In man and mammals the cephalic branches of fibers in the more caudal roots are pushed toward the median plane by the incoming fibers of the successive roots farther forward, so that the long cephalic branches come to form a definite bundle (the mesial funiculus) mesial to the fibers of the more cephalic roots (the lateral funiculus). Each branch of a cutaneous fiber as it runs forward and backward in the cord gives off fine collateral branches. These are distributed to the same and to the opposite side, to the ventral horn, and to other parts of the cord as shown in Figs. 4I, 52. The collaterals going to the ventral horn serve for the simplest reflexes. The other collaterals spread the impulses widely through the adjacent regions of the cord and so make possible mose ample responses. The ascending and descending branches end finally 
in the dorsal horn. While the collaterals make connections which serve for relatively simple and direct reflexes, the connections by way of the dorsal horn serve for complex reactions and for sensation.

The structure of the dorsal horn and its secondary connections are best understood in the region at the junction of the spinal cord and brain where the dorsal tracts of the cord have their ending and where a part of the cutaneous fibers of the head also

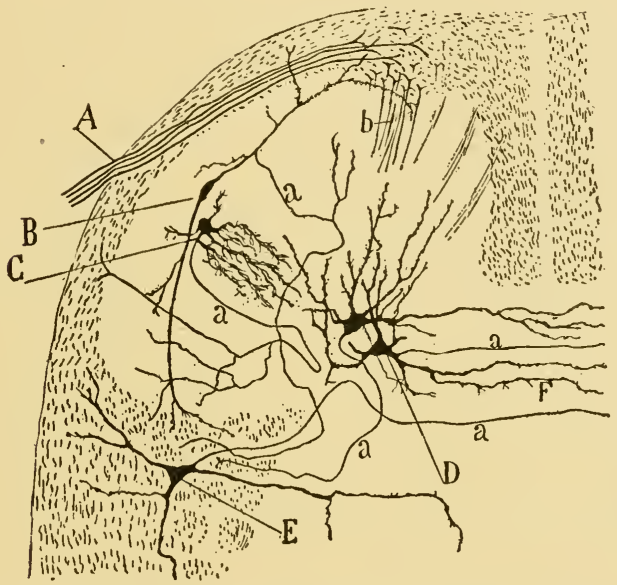

Fig. 53.-Some cells in the dorsal horn of the chick embryo of five days. From Cajal (Textura, etc.). $A$, dorsal root; $B$, transverse cell of the substance of Rolando; $C$, cell of the substance of Rolando; $D$, cell of the posterior horn whose neurite goes to the dorsal commissure; $E$, interstitial cell whose neurite goes to the dorsal commissure; $F$, dorsal commissure.

end. In this region the dorsal horn is considerably enlarged in all vertebrates and in man it forms the two large nuclei of the dorsal funiculi. In lower vertebrates there is a single large nucleus of the dorsal funiculus. This nucleus consists of large and small nerve cells imbedded in a very rich and intricate interlacing of their own dendritic branches and of the end-branches of cutaneous nerve fibers. The small cells have relatively short and simple dendrites and send their neurites among the cells of the dorsal 
horn itself either at the same level or farther forward or backward. Such cells are seen in Figs. 53, 56. The function of these cells is to spread the incoming impulses more completely to all parts of the nucleus. A part of the neurites of these cells pass across the median plane dorsal to the canal, forming a part of the dorsal commissure of the cord, and end in the dorsal horn of the opposite side (Fig. 53).

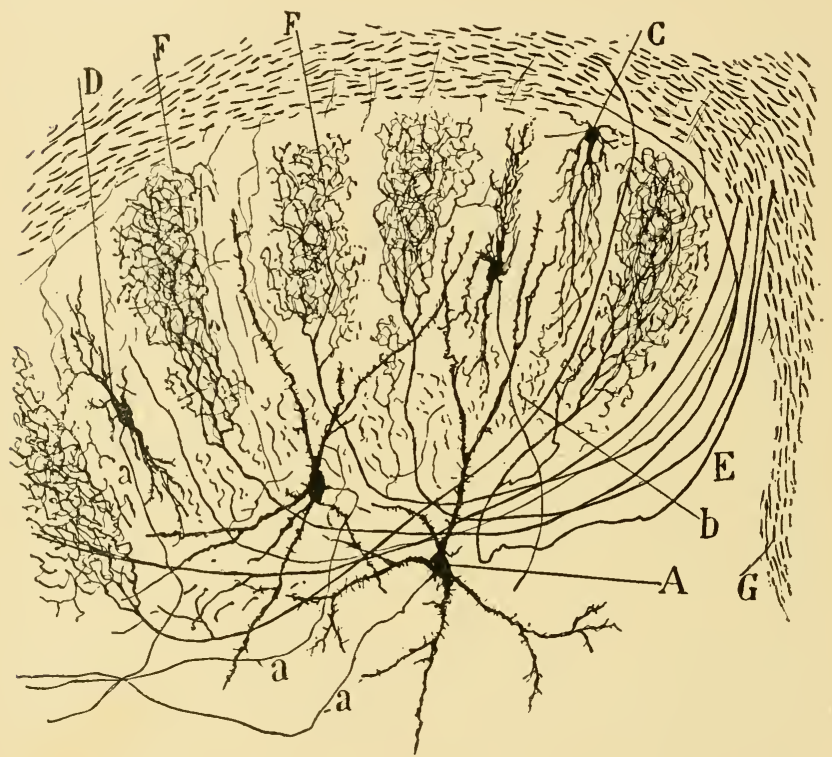

Fig. 54.-Transverse section of the substance of Rolando in the cervical cord of the new-born cat. From Cajal (Textura, etc.). A, cells of the vertex of the dorsal horn; $D, C$, cells of the substanee of Rolando; $E$, deep collaterals; $F$, endings of same; $a$, neurites.

The large cells have larger dendrites with long branches which spread through the dorsal horn and the dorsal tracts (Figs. $54,55,57)$. The neurites go ventrally beyond the dorsal horn, either in the gray or the white matter; and, crossing the median line ventral to the central canal, form what appears in transverse 
section as a loop. They are therefore spoken of as arcuate fibers. The greater number of them run deeply imbedded in the wall of the cord (or brain) and are known as internal arcuate fibers to distinguish them from the remainder which have a part of their course on the surface and are known as external arcuate fibers. The internal arcuate fibers after reaching the opposite side of the cord or brain bend forward and help to form the ventro-lateral

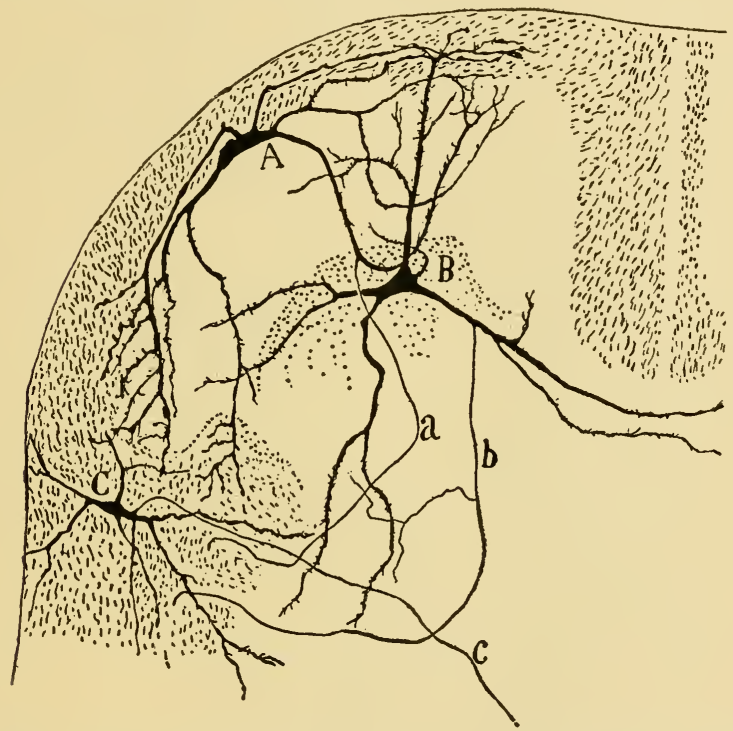

FIG. 55-Cells in the dorsal horn of the cord of a chick embryo of nineteen days incubation. From Cajal (Textura, etc.). $A$, large marginal cell; $B$, giant cell of the center of the horn; $C$, cell of the interstitial nucleus; $a, b, c$, neurites.

fiber tracts. Continuing forward these fibers collect into a bundle which is more definitely limited in higher vertebrates than in fishes. In man this bundle is known as the ascending lemniscus. In fishes the fibers go to the nuclei in the tectum mesencephali and form what is known as the tractus bulbo-tectalis. Its relations in mammals are more complex and will be treated later (Chap. XVI). 
In man the cutaneous fibers in the cranial nerves (trigeminus and vagus) form a longitudinal tract in the medulla oblongata which corresponds to the dorsal tracts of the spinal cord and continues caudally to the level of the first cervical nerve, the tractus

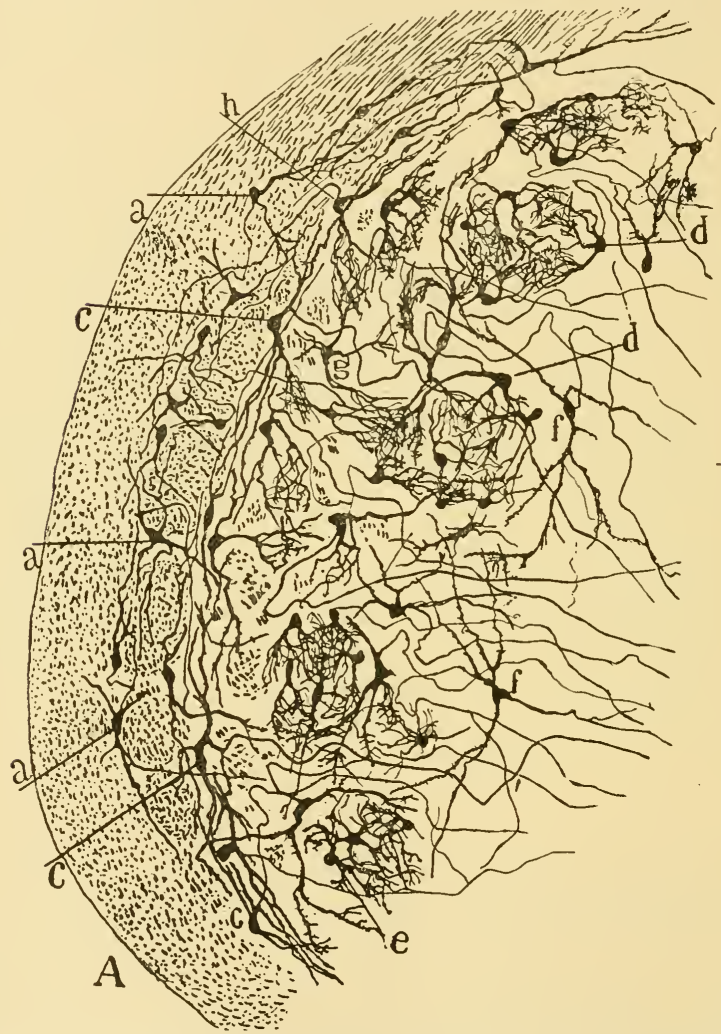

Fig. 56.-Transverse section through the spinal $\mathrm{V}$ tract and the substance of Rolando of a new-born rabbit. From Cajal (Beiträge u. s. w.). $A$, ventral part of the root; $a$, interstitial cell; $c$, border cell; $d$, cell-islands of the substantia gelatinosa; $e$, smalljcells of the islands; $f$, stellate cells not arranged in islands; $g$, cells between islands; $h$, a cell whose neurite seems to go into the white substance or toward the root. 
spinalis trigemini. A small part of the fibers of the trigeminus, however, run directly to the cerebellum. The tractus spinalis trigemini is accompanied by an end-nucleus which is directly continuous with the gelatinous substance of the dorsal horn of the cord. This substantia gelatinosa is made up of small and large cells. The neurites of the small cells are either short, ending in the immediate vicinity, or are directed forward or backward within the substantia gelatinosa itself. The neurites of the large cells go as internal arcuate fibers to the opposite ascending lemniscus or to a part of the lemniscus system on the same side. The structure of the substantia gelatinosa of the rabbit is shown in Figure $5^{6 .}$

The primitive condition of the general cutaneous centers as

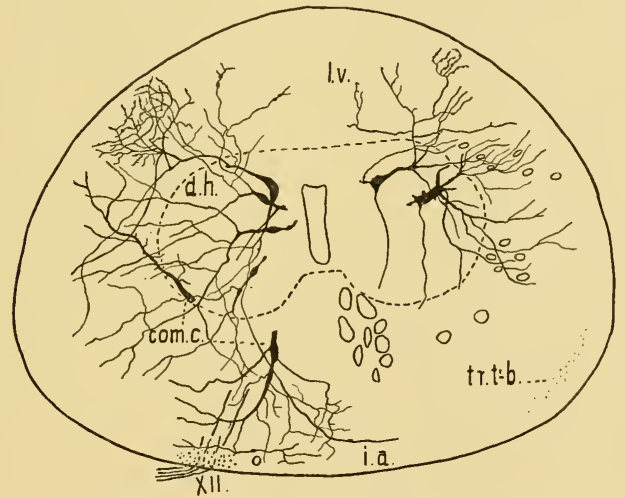

Fig. 57.-A transverse section of the spinal cord of a cyclostome fish, Lampetra Wilderi to show the cells of the dorsal horn $(d . h$.).

seen in lower vertebrates differs considerably from this. In fishes the trigeminus and ophthalmicus profundus fibers may or may not bifurcate on entering the medulla oblongata. When they bifurcate one branch goes to the cerebellum and the other either into the tractus spinalis trigemini or into the deeper part of the tuberculum acusticum. When they do not bifurcate the fibers may take any one of these courses. Further, in selachians, 
ganoids and amphibians a bundle of very coarse fibers enters the brain with the sensory trigeminal root and ends in the tectum mesencephali. This may be called the mesencephalic root of the trigeminus and corresponds in position to the bundle which in man is usually described as a motor root. Thus in lower vertebrates the cutaneous fibers are widely distributed through all that most dorsal column of gray matter which connects the dorsal horns of the cord with the cerebellum and the dorsal part of the mesencephalon. Indeed, in cyclostomes there is no marked distinction in structure between the different parts of this column.

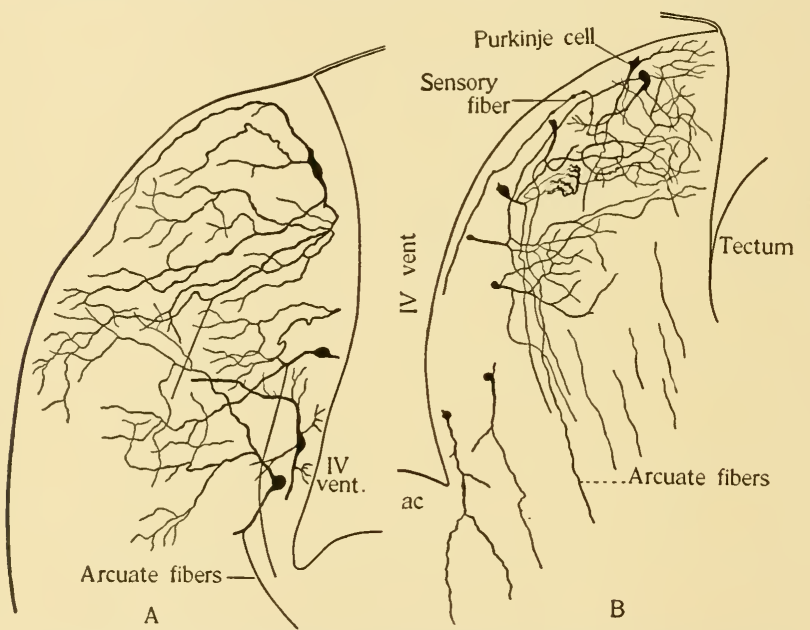

FIG. 58.-A, transverse section of the tuberculum acusticum of Lampetra; B, a sagittal section of the cerebellum of the same animal. ac., acusticum.

The structure and secondary connections of these centers in cyclostomes may now be described as showing the most primitive known condition of the general cutaneous centers in the brain of vertebrates. The nucleus funiculi, although simple, has essentially the structure above described. The tuberculum acusticum differs from it in being somewhat more voluminous and in possessing a larger number of cells. The neurites of the 
small cells form a thin layer of fine fibers covering the outer surface of the acusticum and cerebellum. This represents the molecular layer and the cell layer corresponds to the granular layer, which are such conspicuous features of the cerebellum of higher forms. The large cells are larger and more conspicuous and are arranged with more regularity, their bodies being near the fourth ventricle and their dendrites spreading in the fiber layer. Then neurites of these cells go as internal arcuate fibers to join those from the nucleus funiculi and run forward. The large cells of the acusticum and of the cerebellum are shown in Fig. 58. The cerebellum is very small and consists of a continuation of the acusticum forward, upward and mesially so that the two halves of the cerebellum meet over the fourth ventricle. Here there occurs a commissure formed by the neurites of the small cells. By means of these fibers the cutaneous impulses are carried from the centers of one side to those of the other. In histology also the cerebellum differs little from the acusticum. Its large cells are not specialized as are the Purkinje cells in the cerebellum of higher forms, although by comparing them with the Purkinje cells in other fishes one can see that they are the forerunners of such cells. The neurites of the large cells go as internal arcuate fibers to the opposite side of the brain, but whether they join those from the nucleus funiculi and acusticum is uncertain. The latter fibers pass forward and upward to enter the roof of the mesencephalon, forming the tractus bulbo-tectalis.

The roof of the mesencephalon is thus a secondary center for general cutaneous impulses. Its structure and the differentiation of centers in it will be described in the chapters on the visual apparatus and on the higher correlation centers (Chaps. VIII and XVI). Here it is necessary only to state the course of tracts arising in the tectum mesencephali which are of importance for the cutaneous apparatus. The first is a tract of fibers which arise from the cells of the tectum and run in a direction opposite to, but parallel with that of the tractus bulbo-tectalis and have their endings in the medulla oblongata or spinal cord. The tract is called the tractus tecto-bulbaris et spinalis. It descends from the tectum over the outer surface of the mesencephalon and bends 
backward along the ventro-lateral surface of the myelencephalon.

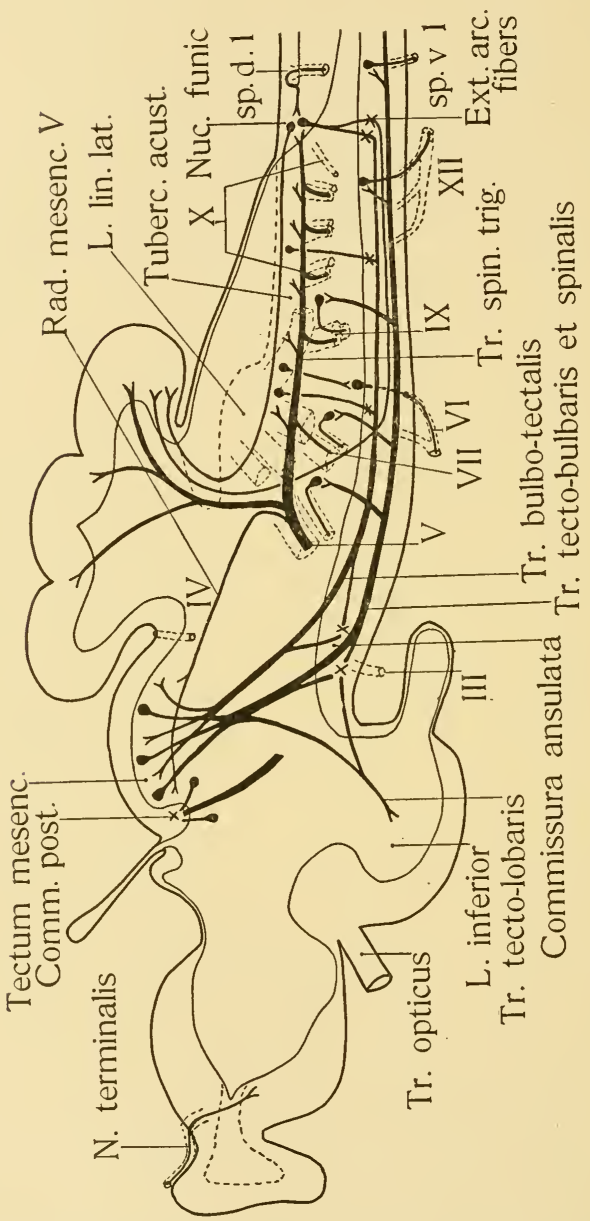

FIG. 59.-A diagram representing the centers and fiber tracts related to the general cutaneous components in fishes. 
Here the fibers give collaterals inward and themselves turn inward to come into relation directly or indirectly with the cells which give origin to the motor nerves. A part of the tract, when it descends over the lateral face of the mesencephalon, instead of going backward along the same side of the brain crosses to the opposite side through the ventral wall of the mesencephalon, helping to form the large ventral commissure of this region of the brain. The fibers then join the tract of the opposite side and continue with it to similar endings. The tractus tecto-bulbaris et spinalis thus consists of a crossed portion and of an uncrossed or direct portion. Another tract from the tectum descends over the side of the mesencephalon and bends forward to end in the inferior lobe, the tractus tecto-lobaris. By means of tracts which run from the inferior

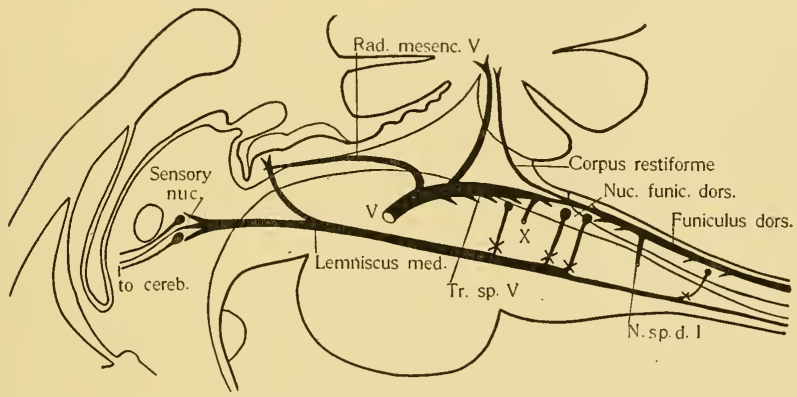

FIG. 60.-A diagram representing the general cutaneous centers and fiber tracts in the human brain.

lobes to the forebrain and to the hindbrain and spinal cord, probably wider connections are set up and more complex correlations provided for. The several central tracts and nuclei belonging to the cutaneous apparatus in fishes are shown in the accompanying diagram (Fig. 59). The outline of a selachian brain is drawn schematically and the various tracts are shown as seen from the left side and as if projected upon the median plane. The cutaneous components in the roots of the V, VII, IX, and $\mathrm{X}$ nerves are shown, but the ganglia of those nerves are omitted. In Fig. 60, the cutaneous fibers and the ascending lemniscus in man are shown. 
In higher vertebrates the acusticum and the cerebellum become more and more higher specialized in their histological structure and secondary connections. Since this specialization is largely due to the fact that these are the centers for the special cutaneous (acustico-lateral) system of nerves, the special structure and the course of differentiation will be described in the next chapter. At the same time that the specialization is going on the general cutaneous fibers for the most part cease to enter the acusticum and cerebellum and come to be concentrated in the spinal $\mathrm{V}$ tract, so that in higher vertebrates by far the greatest part of the cutaneous fibers end in the nuclei of the spinal $\mathrm{V}$ tract and of the dorsal funiculi. While this concentration of the primary tracts and nuclei is going on, a change takes place in the secondary connections as well. The secondary tract from the spinal cord and the nucleus funiculi, the lemniscus, now ends only in part in the roof of the mesencephalon. A larger part of its fibers end in nuclei situated in the lateral walls of the diencephalon. (See Chapter XVI.)

We should expect the general cutaneous system of nerves to be the most primitive and widespread part of the nervous system, unless the general visceral nerves be excepted. And so it is, but there is reason to think that even in the lowest vertebrates the system has undergone considerable modification. A pair of cutaneous nerves and corresponding centers is to be expected in each segment, but in cyclostomes the first five segments of the brain are without cutaneous roots and the corresponding area of the skin is supplied by nerves whose roots enter the brain in the sixth neuromere. The fact that one of these, the ophthalmicus profundus, arises in the embryo from the fifth neuromere is taken as evidence that it once held that position in the adult. Even so, the first four segments of the head are without cutaneous nerves of their own and are supplied by cutaneous rami coming from more caudal segments. In selachians, however, the $\mathrm{N}$. terminalis connected with the first neuromere is probably the cutaneous nerve of that segment. Reasons will be given in a later chapter (ChapterVIII) for thinking that the cutaneous nerves of the second, third and fourth segments have been modified into visual organs, while the ophthalmicus profundus has come 
to supply the corresponding area of skin. In higher forms the differentiation of the gills and the development of an operculum have led to changes in the general cutaneous components, such that the VII and in some cases the IX nerve are without cutaneous fibers. Then in the occipito-spinal region a variable number of cutaneous nerves have been gathered into the single vagus root and others have disappeared on account of the shifting of the mesodermal organs and shortening of the cutaneous area. Within the brain correlated changes have taken place. A general cutaneous center probably persists in the forebrain of selachians but little is known of its structure or relations. In other vertebrates the most cephalic cutaneous center is the tectum mesencephali. The ophthalmicus profundus nerve once arose from this segment of the brain and the trigeminus from the cerebellar segment. Both of these regions still receive general cutaneous fibers, at least in lower vertebrates, but both these and the tuberculum acusticum have lost most of the fibers of this component which once entered them.

All these facts may be expressed or implied in a word by saying that there has been a process of concentration of the tactile apparatus of the head toward the caudal part of the cranial region. This has been due in part to the usurpation of the cephalic part of the brain by highly specialized somatic sensory organs, the eyes and acustico-lateral system, and in part to some undefined advantage that is probably gained by the concentration of a system of nerves and centers instead of their being equally distributed segmentally. Such is the general cutaneous system; the most primitive and the least specialized system of nerves and centers, yet progressively more and more modified in its arrangement, chiefly through the influence of more highly specialized organs.

\section{DEMONSTRATION OR LABORATORY WORK.}

I. Review dissections of the dorsal spinal nerves and the trigeminus.

2. Trace the position and relations of the dorsal tracts, acusticum, and cerebellum in the brain of a large fish, bullfrog and a mammal, by dissection.

3. Trace the spinal $\mathrm{V}$ tract in Delafield haematoxylin or Weigert 
sections of a fish, frog or mammalian brain. Note its relations with the dorsal tracts of the cord, and the relations of the substantia gelatinosa of medulla oblongata and cord.

4. In Weigert sections of the brain of a selachian or frog, look for the sensory fibers of the trigeminus running to the tectum mesencephali and to the cerebellum.

5. Study the nerve elements in the dorsal horn, acusticum, substantia gelatinosa and cerebellum in Golgi sections of the fish brain.

6. Trace the ascending lemniscus in fish, frog or mammal in transverse or sagittal sections by the method of Weigert.

\section{LITERATURE.}

Cajal, S. R.: Beiträge zum Studium der Medulla Oblongata. Leipzig. I896.

Cajal, S. R.: Textura del sistema nervioso del Hombre y de los Vertebrados. Madrid. I904.

Coghill, G. E.: The Cranial Nerves of Amblystoma tigrinum. Jour. Comp. Neur., Vol. I2. Igo2.

Cole, F. J.: On the Cranial Nerves of Chimaera monstrosa Linn., etc.. Trans. Roy. Soc. Edinb., Vol. 38. 1896.

Cole, F. J.: Observations on the Structure and Morphology of the Cranial Nerves and Lateral Sense Organs of Fishes, with especial reference to the Genus Gadus. Trans. Linn. Soc. London, Ser. 2, Zool. 7. 1898.

Herrick, C. Judson: The Cranial and First Spinal Nerves of Menidia. Jour. Comp. Neur., Vol. g. I899.

Herrick, C. Tudson: A Contribution upon the Cranial Nerves of the Codfish. Jour. Comp. Neur., Vol. ı. ז900.

Herrick, C. Judson: The Cranial Nerves and Cutaneous Sense Organs of North American Siluroid Fishes. Jour. Comp. Neur., Vol. Ir. I90I.

Johnston, J. B.: The Brain of Acipenser. Zool. Jahrb., Abth. f. Anat. u. Ontog., Bd. I5. IgOI.

Johnston, J. B.: The Brain of Petromyzon. Jour. Comp. Neur., Vol. I2. 1902 .

Johnston, J. B.: The Cranial Nerve Components of Petromyzon. Morph. Jahrb., Bd. 34. 1905 .

Johnston, J. B.: The Cranial and Spinal Ganglia and the Viscero-motor Roots in Amphioxus. Biol. Bull., Vol. 9. I905.

Kappers, C. U. A.: The Structure of the Teleostean and Selachian Brain. Jour. Comp. Neur. and Psych., Vol. 16. Igo6.

Kingsbury, B. F.: The Structure and Morphology of the Oblongata in Fishes. Jour. Comp. Neur., Vol. 7. I897.

Locy, W. A.: On a newly recognized Nerve connected with the Forebrain of Selachians. Anat. Anz., Bd. 26. 1905. 
Pinkus, F.: Die Hirnnerven des Protopterns annectens. Morph. Arbeit, Bd. 4. I894.

Stannius, H.: Das peripherische Nervensystem der Fische, anatomisch und physiologisch untersucht. Rostock. I 849 .

Strong, O. S.: The Cranial Nerves of Amphibia. Jour. Morph., Vol. Io. I 895 . 
CHAPTER VII.

\section{SOMATIC AFFERENT DIVISION. SPECIAL CUTANEOUS SUBDIVISION.}

The typical sense organs of this system are the pit and canal organs which are found in rows on the head and along the lateral line of cyclostomes, fishes and aquatic amphibia. In Figure 6I are shown a large and a small organ of this type from a sucker embryo at about the time of hatching. The organ consists of high columnar supporting cells which form the whole thickness of the epidermis within the area of the organ, and of shorter thicker pear-shaped cells which do not reach the whole depth of the epidermis. The latter cells bear at their outer ends cuticular

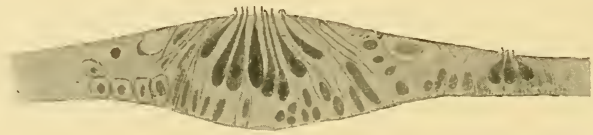

FIG. 6I.-A large and a small neuromast from a sucker (Catostomus) embryo at about the time of hatching.

hairs or bristles which project beyond the surface. These are the sense cells. Beneath the organ a few nerve fibers come up from a deeper lying nerve, lose their medullary sheaths as they reach the organ and penetrate between the cells. Here the fibers divide in a very complicated manner (Bunker) and end by very fine branches on the surface of the cells. In the typical pit organs the surrounding epidermis is much thicker and rises up as a wall on all sides, the bottom of the pit being formed by the sense organ. Organs of this type are found in fishes in a line along the lateral surface of the body, and in a supraorbital, an infraorbital and a hyomandibular row (Fig. 62). The organs of these typical rows in fishes are usually enclosed in canals in the manner described in the chapter on embryology, but in cyclostomes and amphibia 
they remain in the form of pit organs. In many cases accessory lines of pit organs, or even canals, are present and in selachians the total number of organs is very large. The number of organs found in the typical rows of the head varies greatly, as is indicated by the following examples: Amia, 40; Menidia, 37; Gadus, 28; Chimaera, 93. It has recently been shown by experiment that the function of the pit and canal organs is to take account of vibrations in the water of a frequency too low for the production of sound (between 6 and 100 per second).

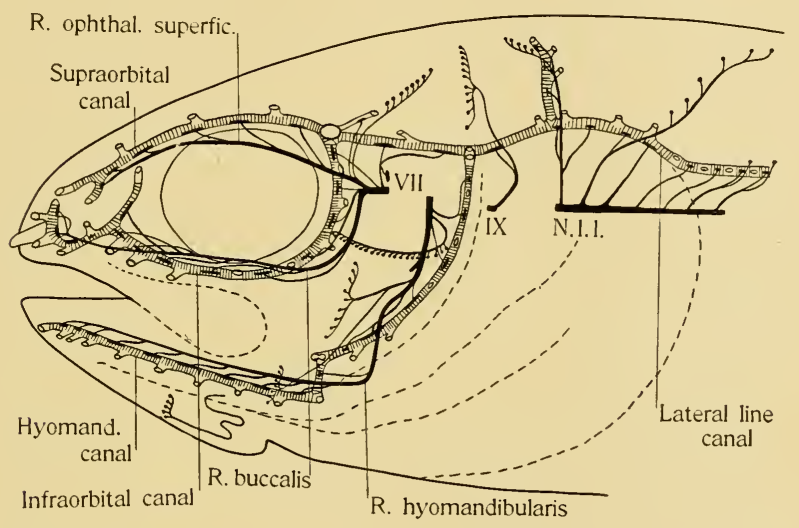

FIG. 62.-A diagram of the lateral line canals and nerves in the ganoid fish, A mia calva. After E. Phelps Allis.

In selachians there are found two other forms of sense organs which are histologically similar to the pit and canal organs and are also related to them in their nerve supply. These are the organs known as the ampullae of Lorenzini and the vesicles of Savi. The ampullae are found in groups including in some cases a large number of organs, imbedded in a soft gelatinous connective tissue in cavities about the skull or between other organs. The bodies which are imbedded in these groups, however, are only the enlarged ends of slender canals which after a longer or shorter course open on the surface. The development of the organs shows 
that the point at which the canal opens in the adult is the place from which the organ develops. Starting as pits at these points the tubes grow inward until they reach their final location. At the inner end of the tube there is developed a sense organ of the same type as the pit organ, but more complex in structure. The organs are supplied by branches of the nerves which supply the adjacent canals and are regarded as modified pit organs. The vesicles of Savi are small isolated sacs lying beneath the epidermis which contain pear-shaped hair cells and are also innervated by the same system of nerves as the canal organs. In ganoids also are similar organs called nerve sacs. Both are probably degenerated or at least modified organs of the same system with the canal and pit organs. All this system of organs has been commonly given the name of the lateral line system, because the lateral line canal is its most conspicuous part. Some years ago the term neuromasts was proposed by Wright for the organs whose sense cells are pear-shaped hair cells, as distinguished from the rodshaped cells found in the organs which are now known to be taste organs. This is a much more satisfactory name than the term lateral line organs.

It was shown in the chapter on embryology that the neuromast system derelops in close connection with the ear. An examination of the ear in all its relations has led to the conclusion that it is fundamentally a part of the same system of organs as the neuromasts. The evidence of this in part will be given in detail in the present chapter but may be summarized here as follows. (I) The sense cells in the ear of all vertebrates are hair cells similar to those of the canal organs. (2) The sense cells are enclosed in canals which during development sink in from the surface as do the sensory canals and remain open to the surface for some time by way of the ductus endolymphaticus. (3) The hair cells of both neuromasts and ear respond to vibrations in the fluid which fills the canals. The cells of the ear of many fishes and of higher vertebrates respond to vibrations of a more rapid rate (more than roo per second) than those to which the canal organs respond. (4) The sense cells of the ear are supplied by nerve fibers which in their development and their central endings 
correspond very closely to those of the canal organs. (5) The centers in which the nerves of the canal organs and ear end form one continuous structure whose histology and secondary connections in the different classes of vertebrates show that it has been derived from the general cutaneous centers.

The sense organs thus far spoken of lie in the semicircular canals and in the sacculus and utriculus and are the only sense organs of the ear in fishes. In addition to these there is developed in higher vertebrates the spiral-shaped cochlea with its complicated organ of Corti. The sense cells of this organ are also hair cells which respond to vibrations in fluid, of a still higher rate. Even this organ with its nerves and centers is so closely related to the rest of the ear that it must be regarded as a more highly specialized part of the same system of sense organs.

The function of the system as a whole seems to have been at first to aid an aquatic animal in directing its movements. Vibrations in the water caused by surface waves, by the movements of other animals, by its own movements,-all these were capable of stimulating these organs, and reactions to such stimuli constituted the means by which the animal directed many of its movements. Some of these organs becoming deeply imbedded in canals were not directly influenced by large slow waves, but only by the shorter quicker waves which could enter the canals. Some of the canals becoming completely enclosed and being filled by a denser fluid which responded more readily to waves of less amplitude and higher rate, enabled the animal to be influenced by a wider range of vibrations, including those of high enough rate to produce sound. In this way the open pits, the canal organs, and the organs of the ear came to be differentiated and to serve for a wide range of stimuli. Finally a still higher and higher rate of stimuli were provided for by the development of the cochlea, and as vertebrates ceased to live an aquatic life the pit and canal organs which responded to slow waves in water ceased to be of use and were lost.

The phenomenon of equilibration is a constant phase in the control of movements. Indeed, keeping the equilibrium is a necessary condition for all directed movement. It is probable 
that many factors enter into this, including all forms of somatic afferent impulses and the brain centers concerned with them. In simple animals without special sense organs the maintenance of equilibrium depends upon tactile stimuli from without and upon impulses aroused by changes of pressure due to movements of parts of the body upon one another. These factors are apparently sufficient for the purpose in these animals and they undoubtedly play an important role in equilibration in all animals. As special sense organs are developed all those whose impulses may affect bodily movements take part in the maintenance of equilibrium. When the eyes are well developed and much used they are important for equilibrium, as our own experience of dizziness and a stumbling gait after being long blindfolded, and the feeling of equilibriumweariness after walking or riding a bicycle in extreme darkness, give evidence. In fishes the neuromasts must be of great importance directly or indirectly, because of their wide distribution over the body which enables them to receive stimuli from many directions, and because they are sensitive to vibratory stimuli to which the general cutaneous endings do not respond. Finally, the structure of the ear with its semicircular canals and contained sense organs is such as to make it the especial organ of equilibration. In case of the ear it is just the change of position of the animal's own body which arouses the vibrations that serve as the appropriate stimuli to the sense organs. Since the control of equilibrium in response to stimuli aroused from within is the most direct and effective, the ears have become the dominant factors in equilibration. It will appear below that the portion of the ear concerned with equilibration is measurably separate from that concerned with sound, and this separation extends to the brain centers.

The nerves which innervate the neuromasts are connected with the dorso-lateral surface of the medulla oblongata by three chief roots, one of which may be subdivided into two. As already stated (p. 20) the caudal root is distributed to the organs of the lateral line, the middle root supplies the organs of the ear, and the cephalic root, which may be double, innervates the three canals of the head. On their way to their areas of distribution the fibers 
usually run with fibers of other kinds and so form components

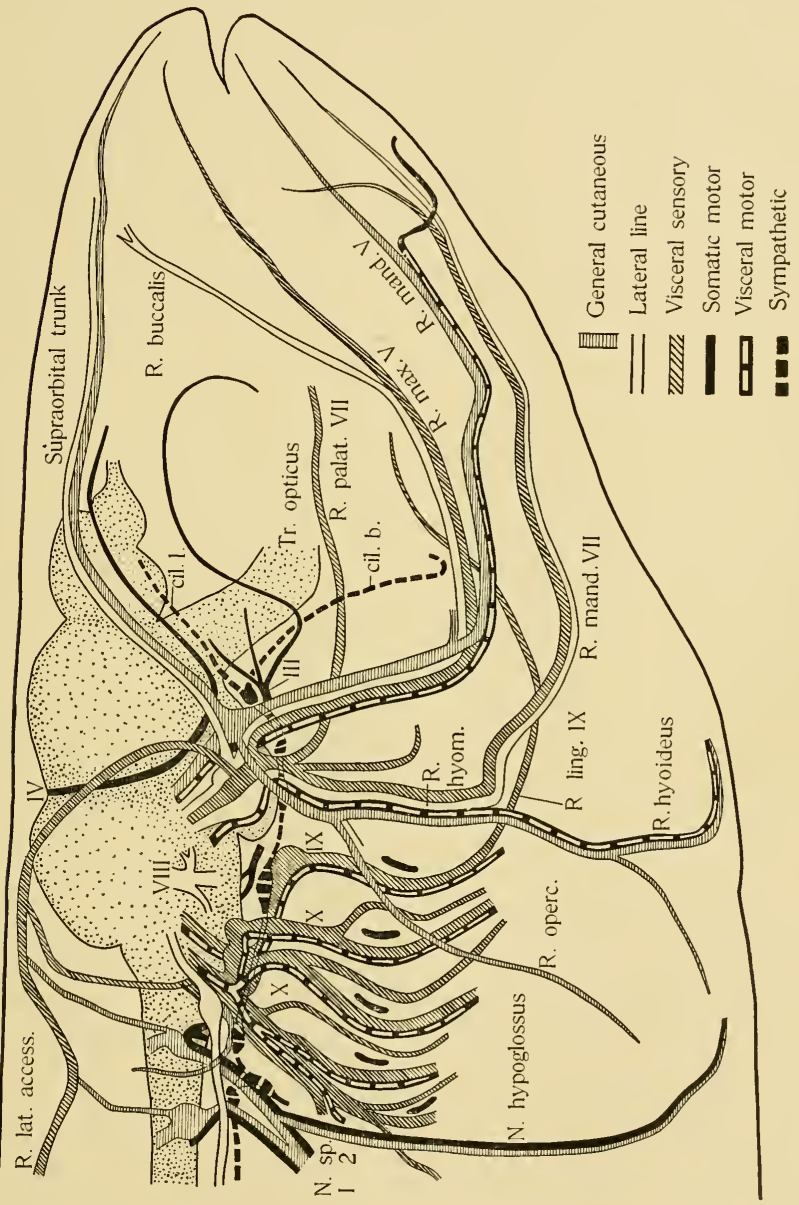

FIG. 63.-A reconstruction of the chief rami of the cranial nerves of a bony fish, Menidia, to show the arrangement of the several systems of components. After C. Judson Herrick. 
of various nerve trunks. This will be clear from an examination of Figs. 62 and 63 . In the former the canals of the head are shown with the nerves which innervate them but without the accompanying components of the other kinds. In Figure 63 the various components which constitute the cranial nerves of Menidia are shown as they are combined in nerve trunks. The neuromast components are shown in outline but the canals themselves are omitted on account of the complexity of the figure. The root and ganglion of the lateral line nerve is closely related to those of the vagus, as is nearly always the case. In many fishes also fibers from this root go into the IX nerve in which they run for some distance to reach their sense organs. In Menidia the fibers to the supraorbital canal, forming the ramus ophthalmicus superfacialis VII, run with the general cutaneous fibers which form the ranuus ophthalmicus superfacialis $V$, the two constituting a supraorbital trunk. This is the most common arrangement in other fishes also. The fibers for the infraorbital canal in Menidia run with general cutaneous and general visceral fibers in the maxillary trunk. The fibers to the infraorbital row of sense organs are known as the ramus buccalis VII and in most fishes are independent of other components for the greater part of their course. The fibers destined to the hyomandibular canal form a component of the ramus hyomandibularis, which contains also general cutaneous, visceral sensory and visceral motor fibers. It will be seen immediately that all the neuromast fibers, no matter in what rami they run, have the same central connections as well as the same type of peripheral organs, and are therefore justly considered as a single system of nerve components. The distribution of these components in the cyclostomes (Fig. 5I) and in amphibia (Fig. 79) should be compared with that in Menidia (Fig. 63).

Special cutaneous centers.-In the brain of cyclostomes the neuromast fibers are intimately associated with the general cutaneous fibers and end in the same slightly specialized centers. (See previous chapter.) In the brain of a selachian or ganoid fish although the general and special cutaneous fibers are still almost as intimately associated, a higher development of the centers has taken place and the special cutaneous fibers end chiefly 
in the more highly developed portions. This can be illustrated best by describing the cutaneous centers with their roots and secondary connections in some detail. As stated above (p. II 5 ) the general cutaneous fibers on entering the brain go in part by the spinal $\mathrm{V}$ tract to the nucleus of the dorsal funiculus and in part spread widely through the acusticum and cerebellum. The neuromast components also spread widely through the acusticum and cerebellum but only a small part of them go to the nucleus funiculi or to a small nucleus adjoining it. Thus the greater part of the nucleus funiculi, and, especially in higher vertebrates,

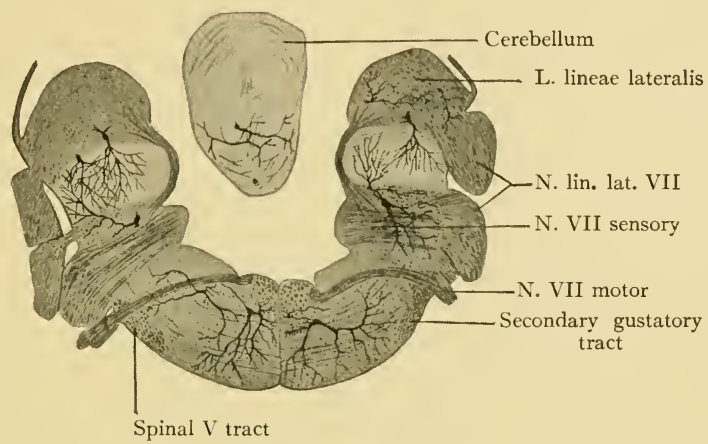

FIG. 64.-A transverse section of the brain of the sturgeon at the level of the VII and VIJI nerves.

cells accompanying the spinal $\mathrm{V}$ tract are related to general cutaneous components alone, while in the acusticum and cerebellum both general and special cutaneous fibers intermingle and presumably end in relation with the same cells. The intermingling of these components will be seen by reference to Figs. 64 and 65 .

In the acusticum and cerebellum there is to be noticed a great increase in size in true fishes as compared with cyclostomes and the presence of much more prominent granular and molecular layers. The outer portion of the cerebellum is composed of a dense layer of very fine fibers, interspersed with few cells, which continues caudally over the dorsal or lateral surface of the acus- 
ticum and forms what is known as the cerebellar crest. This corresponds to the molecular layer of the cerebellum of higher forms. The inner portion of both cerebellum and acusticum is composed of large and small cells and corresponds to the combined granular and Purkinje cell layer of higher forms.

The small cells are vastly more numerous in the cerebellum than in the acusticum and the small bodies of the cells closely packed together suggest the names gramule cells and gramular layer. The great majority of these cells are very small, have from one to three short dendrites with small claw-like branches and give rise to extremely fine neurites. These are the granule cells

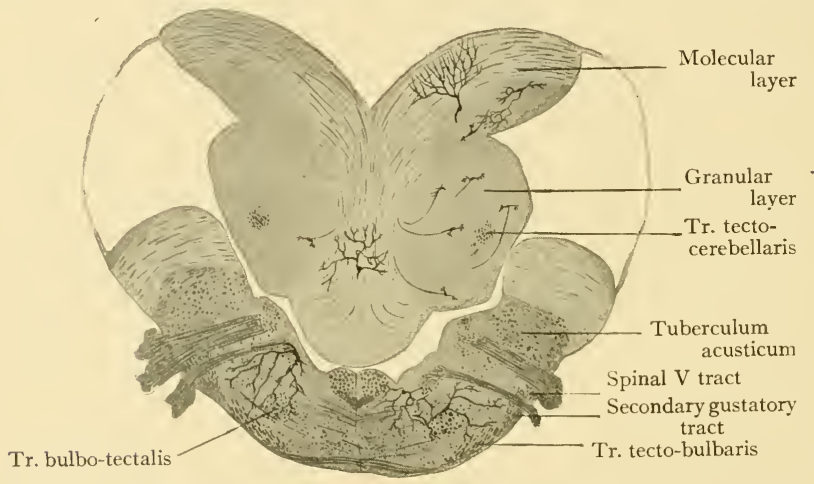

FIG. 65.-A transverse section of the brain of the sturgeon at the level of the $\mathrm{V}$ nerve.

in a strict sense. Their neurites turn toward the outer surface of the cerebellum or acusticum, as the case may be, and run parallel with the surface, forming the molecular layer. In most forms these fibers bifurcate on entering the molecular layer, one branch running forward and one backward. A considerable part of the neurites of granule cells in the cerebellum pass to the opposite side through the roof, forming the superior commissure of the cerebellum. The larger part of the molecular layer fibers end within the cerebellum; the smaller part, consisting of both crossed and uncrossed fibers, pass caudally in the cerebellar crest 
which grows gradually smaller and dwindles away toward the caudal end of the acusticum. The smaller number of small cells in the cerebellum and acusticum are of the form known as cells of type II, whose neurites divide into terminal branches in the near vicinity of the cell. A single granule cell is shown in Fig. 39, and in Figs. 64 and 65 are shown the relations of the granular and molecular layers in the brain of the sturgeon. In cyclostomes the molecular layer extends along the lateral surface

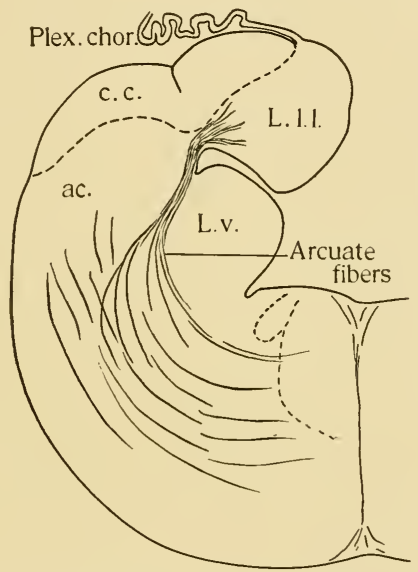

Fig. 66.-A transverse section of the medulla oblongata of Scyllium to show the folding of the cerebellar crest and tuberculum acusticum. $a c$, tuberculum acusticum; c.c., cerebellar crest; L.l.l., lobus lineae lateralis; L.v., lobus vagi.

of the acusticum. In selachians there is a folding of the acusticum in such a way that the molecular layer forms the floor of a longitudinal groove on the lateral surface (Fig. 66) and in the sturgeon this folding has gone so far that the groove has been closed up by the fusion of the opposed surfaces of the molecular layer. That part of the acusticum which lies above the fold is the lobus lineae lateralis (Fig. 3) and in the sturgeon it is almost separated from the rest of the acusticum by the cerebellar crest. The large cells in the acusticum and cerebellum may be described 
as of two main types with intermediate forms. The first type consists of cells with large bodies and rather coarse dendrites whose many branches spread widely through the granular layer. These cells show no special arrangement and no great peculiarities; they are most like the large cells in the dorsal horn of the cord or in the nucleus funiculi. Their neurites go as internal arcuate fibers to join the tractus bulbo-tectalis of the opposite

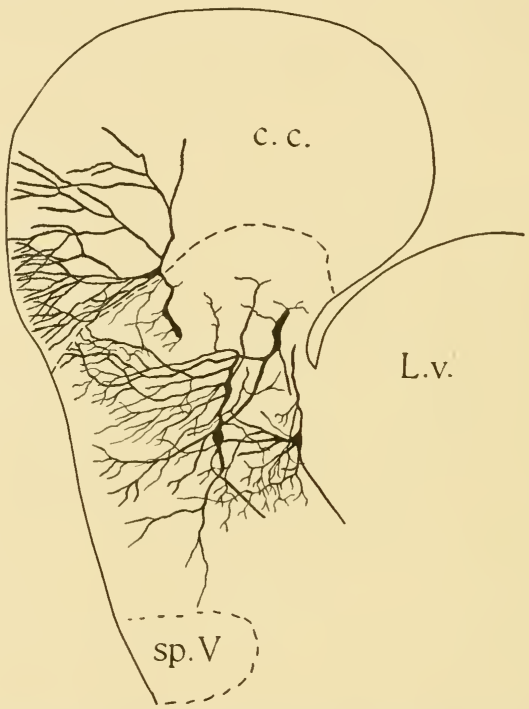

FIG. 67.-Transverse section of the acusticum of the sturgeon to show acusticum cells and a Purkinje cell. c.c., cerebellar crest; L.v., lobus vagi.

side of the brain. These cells will be referred to as acusticum cells. Such cells are shown in Fig. $58 \mathrm{~A}$, from the acusticum of a cyclostome and in Fig. 67 from the sturgeon.

The cells of the second type are also large but they differ from the first in having both a special arrangement and a special form differentiation. The cell-bodies stand in the granular layer next to the molecular layer and are somewhat elongated vertically 
to the surface. The dendrites arise from the end of the cell next to the molecular layer and spread in that layer. The dendrites are noticeably straight, have a stiff appearance, and all their branches in the molecular layer are provided with great numbers of little spine-like projections. The possession of such dendrites brings these cells into the same category with the Purkinje cells of the human cerebellum. Since the dendrites are imbedded in the myriads of fine fibers of the molecular layer it is probable that the small spines serve for contact or perhaps a closer connection with the fine fibers. A single Purkinje cell is shown in Fig. 39 and one is drawn in the upper part of Fig. 67. From the inner end of the cell-body, which is frequently slender and pointed, arises the neurite which may take one of three courses. Some of them go ventro-mesially close beneath the floor of the fourth ventricle and either make connections with the motor nuclei of the cranial nerves of the same region or enter the longitudinal fiber tracts closely related to those nuclei and go to nuclei of more distant nerves. The fibers from the cerebellum which have this destination form two or more bundles which curve down over the inner face of the acusticum and reach the motor column in the region of the trochlearis and abducens nuclei. All these fibers may be referred to as the short motor connections of the acusticum and cerebellum. Other fibers from the Purkinje cells, especially in the acusticum, go as internal arcuate fibers to join the tractus bulbo-tectalis. Still other fibers from Purkinje cells in the acusticum go as arcuate fibers on the outer surface of the brain todestinations which are as yet little understood. Some may go to a nucleus comparable with the lower olive of human anatomy, others go to the cerebellum. The latter would correspond to the external arcuate fibers of man. The desti ration of the larger part of the neurites of Perkinje cells in the cerebellum of lower forms is not known. In mammals (p. 245) the neurites of Purkinje cells are very widely distributed to distant parts of the brain and spinal cord and it is an interesting problem to know how low in the scale of rertebrates this condition makes its appearance.

The cells in the acusticum intermediate between these two types are equally large but have not such definite form and arrange- 
ment as the Purkinje cells (Fig. 68). The difference lies chiefly in the form and position of the dendrites. A part of the dendrites ramify in the granular layer and a part in the molecular layer. Those which lie in the granular layer are like those of the first class of cells, but any dendrites which enter the molecular layer

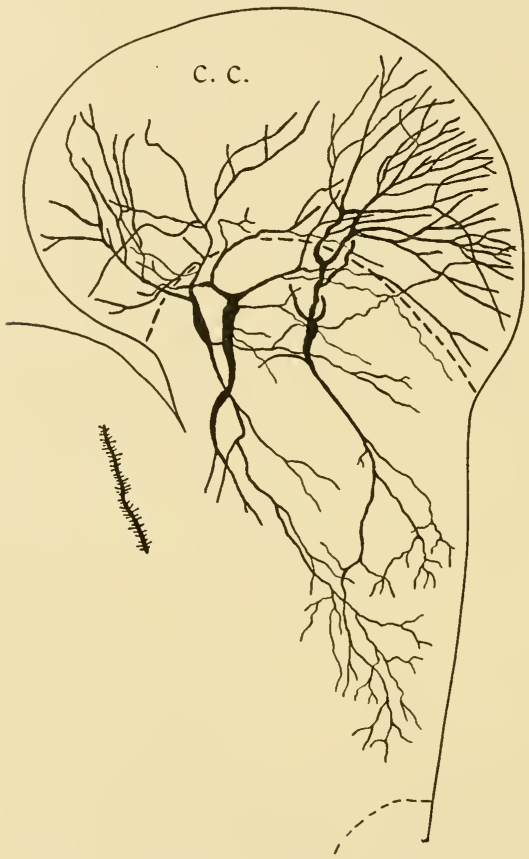

FIG. 68.-A section through the same region as in Fig. 67, to show cell forms intermediate between acusticum and Purkinje cells.

take on the characters of Purkinje cell dendrites. In these intermediate forms every gradation is found between the acusticum and Purkinje cells. The number of the acusticum and intermediate cells is much greater in the acusticum, that of the Purkinje cells much greater in the cerebellum. 
These facts lead to the conclusion that all these cells have been derived by modification from the simple large cells of the general cutaneous nuclei. The modification is due directly to the influence of the fine fibers of the molecular layer and in the cerebellum, where the granule cells are collected in greatest numbers and the fine fibers are most numerous, the large cells are nearly all specialized into Purkinje cells. The presence of great numbers of granule cells, of cells of type II and of highly developed Purkinje cells marks the cercbellum as the most highly specialized part of the special cutaneous nuclei. The specialization of both cerebellum and acusticum is to be attributed to the influence of the special cutaneous system of sense organs. In higher vertebrates these centers no longer receive many general cutaneous fibers, but undergo a still higher specialization, in part as the centers for the ear and in part as an apparatus for controlling bodily movements.

It is necessary now to follow the tractus bulbo-tectalis which receives the greater part of the secondary fibers from the special cutaneous nuclei, and see its relations in the mesencephalon. The roof of the mesencephalon in the fishes begins to show a differentiation into two parts, a median somewhat dome-shaped, bi-lobed tectum opticum and a lateral thicker mass forming a semicircular border about the tectum on either side. These lateral masses are known as the colliculi or the lateral mesencephalic nuclei. The origin and significance of these parts are more fully treated in Chapter XVI. A process of differentiation is seen in this region analogous to that which has been described in the cutaneous centers of the medulla oblongata. In the simplest condition in vertebrates the fibers which pass from the cutaneous center in the hindbrain to the midbrain (tractus bulbo-tectalis) end indiscriminately in all parts of the roof of the midbrain. When the colliculi are well developed it is noticed that the greater part of the tract ends in them, not in the tectum opticum. From these nuclei in bony fishes tertiary tracts go to the tectum opticum, as well as to the inferior lobes and the motor centers of the medulla oblongata. From the tectum opticum in fishes an important tract goes to the cerebellum. The presence of this tract is one 
of the first evidences of the development of coordinating functions on the part of the cerebellum, which was originally a simple general cutaneous center.

The distribution of the root fibers of the acustico-lateral system of nerves to the-special cutaneous nuclei in the medulla oblongata and cerebellum of fishes is shown in Fig. 69. This figure should be compared with that for the general cutaneous centers (Fig. 59). The central tracts from the special cutaneous centers in fishes are identical with those from the general cutaneous centers. In aquatic amphibia and in the tadpoles of land forms the

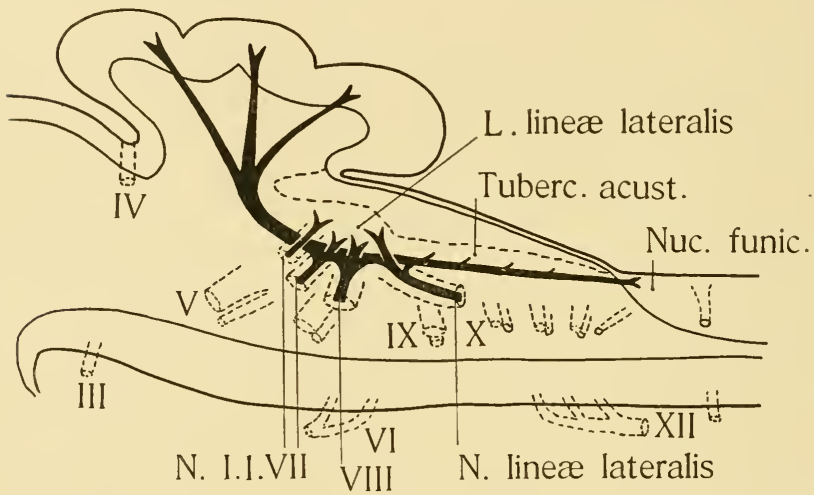

FIG. 69.--A diagram to show the central endings of the special cutaneous components in fishes.

acustico-lateral system has essentially the same relations as in fishes. In terrestrial forms, however, the pit organs disappear because they are serviceable only in the water. Only the enclosed canals of the ear with their sense organs persist. In reptiles, birds and mammals also, the inner ear is the only representative of this system of sense organs which holds so prominent a place in fishes. In mammals the VIII nerve is divided into two parts, the $N$. vestibularis and the $N$. cochlearis, and for these nerves two sets of nerve centers have been developed from the acusticum of fishes. The restibular nerve supplies the sense organs in 
the vestibule and semicircular canals which represent nearly the whole of the ear of lower vertebrates, and its centers retain in gencral the form and position of the acusticum in fishes. For the detailed description of these nuclei the student must be referred to the larger text-books on the human brain, but the following general summary is in place here. The fibers upon entering the brain bifurcate into small ascending and larger descending branches. The bundles of the large descending root are surrounded by and interspersed with cells which constitute its end-nucleus. Mesially this is continuous with a broad nucleus beneath the ventricle, called the mesial nucleus of the vestibular nerve. The two together correspond to the acusticum of fishes caudal to the VIII root. The anterior portion of the mesial nucleus is especially important and lateral to it is the lateral nucleus usually known as Deiter's nucleus, which is closely related to the bifurcation of the vestibular fibers and to the first portion of the descending branches. The ascending branches pass upward in a tortuous course toward the cerebellum. Many of them end in the superior nucleus of the vestibular nerve, dorsal to the lateral nucleus, and the rest enter the region of the nucleus tecti of the cerebellum. These ascending branches with their nuclei are the equivalent of the ascending VIII fibers and the continuous gray matter of the acusticum and cerebellum in fishes.

From these several nuclei the following chief tracts arise (Fig. 70): (I) fibers from the nucleus of the descending root to the cerebellum; (2) fibers from the same nucleus which go as internal arcuate fibers to the opposite side and then either ascend in the medial lemniscus (p. 258) or descend into the spinal cord; (3) fibers from Deiter's nucleus, some of which go to the cerebellum, but most of which go to the opposite side to run forward or backward in two or more bundles. The larger part of the fibers which cross to the opposite side run in the fasciculus longitudinalis medialis and may correspond to the "short motor connections" of the acusticum in fishes. Although there is greater complexity, the central apparatus of the vestibular nerve in mammals corresponds in a striking manner to that of the acustico-lateral system in fishes. 
It is usually stated that the cochlear nerve includes a branch to the macula acustica of the sacculus in addition to the fibers to the organ of Corti. Recent studies on the human embryo show, however, that the branch in question belongs to the vestibular nerve and is quite independent of the cochlear nerve (Streeter). The fibers of the cochlear nerve bifurcate on entering the medulla oblongata and end for the most part in two nuclei, the ventral and dorsal cochlear nuclei, which lie lateral and dorsal to the vestibular nuclei. Two important things are to be noticed in

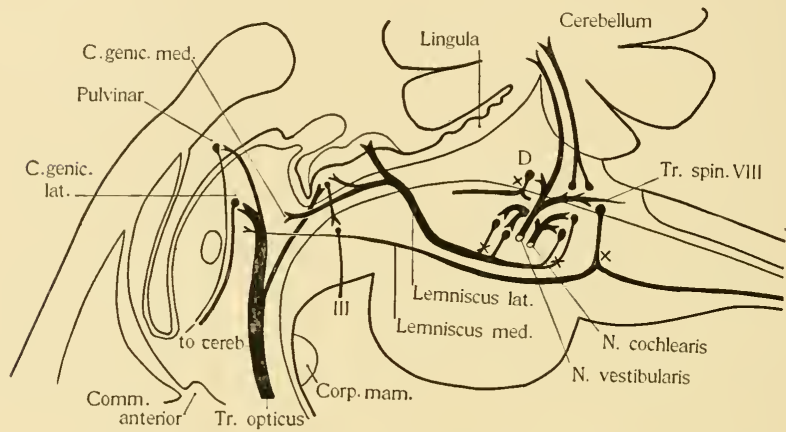

FIG. 70.-A diagram to show the central endings of the vestibular and cochlear nerves and of the optic tract in man and the chief secondary tracts related to them. Compare Fig. 6o.

regard to the centers for the cochlea. The first is that these nuclei are superficial with respect to the vestibular nuclei. In this they offer a clear illustration of the general law that the more highly specialized structures in the brain, and hence those which have appeared later in the phylogeny, are placed toward the outer surface with respect to older structures to which they are related. It is probable that these nuclei have been developed from the acusticum of lower vertebrates and have taken up the superficial position as they developed. The second point is that no cochlear fibers go to the cerebellum. Apparently the development of the cochlea has come so late as compared with the evolution of the brain that the cerebellum had already assumed functions of 
correlation inconsistent with its serving primary sensory nerves. On the other hand, some fibers of the cochlear nerve go beyond its primary nuclei, by way of the corpus trapezoideum and the secondary tracts, to higher centers. The fibers arising in the two cochlear nuclei go by a direct or indirect course chiefly to the lateral lemniscus of the same or opposite side (p. 258). The main facts with regard to the central connections of the cochlear and vestibular nerves are shown in the most diagrammatic form in Fig. 70 , in order to facilitate comparison with the arrangements in lower vertebrates (Fig. 69). The further consideration of the central relations will be more appropriate in the chapter on the correlating centers.

\section{DEMONSTRATION OR LABORATORY WORK.}

I. Dissect the lateral line system and ear and their nerves in the dogfish or skate.

2. Study sections of lateral line organs from a selachian or from teleost embryos, stained with iron haematoxylin or prepared by a special nerve method.

3. Review the dissection of the selachian and teleost brain (Chapter II, No. 2 and Chapter V, No. 2) with reference to the great development of the acusticum and cerebellum in selachians, and the correlation with the large number of acustico-lateral organs.

4. Study the roots of the acustico-lateral system of nerves in the brain of a selachian or ganoid fish in Weigert or Golgi sections.

5. In Golgi sections of a fish brain study cells of acusticum and cerebellum to follow the evolution of the Purkinje cells. Notice the granules and cells of type II.

6. In Weigert or Golgi sections of a fish brain note the internal arcuate fibers to the lemniscus system.

\section{LITERATURE.}

Allis, E. P., jr.: Lateral Line System in Amia. Jour. Morp., Vol. 2. r889. Ayers, H.: Vertebrate Cephalogenesis II. A Contribution to the Morphology of the Vertebrate Ear, with a Reconsideration of its Functions. Jour. Morph., Vol. 6. I892.

Barker, L. F.: The Nervous System and its Constituent Neurones. 1899.

Beard, J.: On the Segmental Sense Organs of the Lateral Line and the Morphology of the Vertebrate Auditory Organ. Zool. Anz.. Jahrg. 7. I884.

Brauer, A.: Beiträge zur Kenntniss der Entwickelung und Anatomie der Gymnophionen. Zool. Jahrb., Suppl. 7. 1904. 
Bunker, F. S.: On the Structure of the Sense Organs of the Lateral Line of Ameiurus nebulosus Le. S., Anat. Anz., Bd. 13. 1897.

Coggi, A.: Sviluppo degli organi di senso laterale, della ampolle di Lorenzini e loro nervi rispettivi in Torpedo. Archivio Zool., Vol. I. I902.

Coggi, A.: Su lo sviluppo e la morphologia della ampolle di Lorenzini e loro nervi. Archivio Zool., Vol. 2. I905.

Cole, F. J.: Cranial Nerves of Chimaera monstrosa. Proc. Roy. Soc. Edinb., Vol. 38. r 895.

Cole, F. J.: Cranial Nerves of Gadus. Trans. Linn. Soc. London. Ser. 2, Zool. 7. I898.

Ewart, J. C.: The Sensory Canals of Laemargus. Trans. Roy. Soc. Edinb., Vol. 37. I893.

Ewart, J. C. and Mitchell, J. C.: The Sensory Canals of the Common Skate (Raia batis). Trans. Roy. Soc. Edinb., Vol. 37. I893.

Herrick, C. Judson: The Cranial Nerves of Menidia. Jour. Conıp. Neur. Vol. 9. I899.

Herrick, C. Judson: Cranial Nerves of Siluroid Fishes, Jour. Comp. Neur., Vol. I I. I9or.

Johnston, J. B.: The Brain of Acipenser. Zool. Jahrb., Abth. f. Anat. u, Ontog., Bd. I5. I901.

Johnston, J. B.: The Brain of Petromyzon. Jour. Comp. Neur., Vol. I2 I902.

Koltzoff, N. K.: Entwickelungsgeschichte des Kopfes von Petromyzon planeri. Bull. Soc. Imper. Natural de Moscou, Annee Igor, No. 3-4. I902.

Leydig, Franz: Ueber die Schleimcanäle der Knochenfische. Arch. f. Anat., Physiol. u. wiss. Med. I850.

Leydig, F.: Ueber Organe eines sechsten Sinnes. Dresden. I868.

Mayser, P.: Vergleichend-anatomische Studien über das Gehirn der Knochenfische mit besonderer Berüchtigung der Cyprinoiden. Zeit. f. wiss. Zool., Bd. 36. I88r.

Merkel, Fr.: Ueber die Endigungen der sensiblen Nerven in der Haut der Wirbelthiere. Rostock. I880.

Mitrophonow, Paul: Etude embryogenique sur les Selaciens. Arch. de Zool. Exper., Tome I. I893.

Parker, G. H.: Hearing and allied Senses in Fishes. Contr. Biol. Lab. U. S. F. C., Woods Hole, Mass. I903.

Parker, G. H.: The Functions of the Lateral Line Organs in Fishes. Bull. Bureau of Fisheries. Vol. 24. I904.

Streeter, G. L.: Concerning the Development of the Acoustic Ganglion in the Human Embryo. Verh. anat. Ges. I9. Vers. 1905.

Wilson, H. V.: The Embryology of the Sea Bass. Bull. U. S. Fish Com., Vol. 9. I891.

Wright, R. Ramsay: On the Skin and Cutaneous Sense Organs of Ameiurus. Proc. Canadian Inst. Toronto, N. S. Vol. 2. I884. 


\section{CHAPTER VIII.}

\section{SOMATIC AFFERENT DIVISION. THE VISUAL APPARATUS.}

The general and special cutaneous systems serve for the reception of stimuli from the external world due to mechanical contact or pressure or to vibrations in fluids. Another set of stimuli of the greatest importance to the vertebrate animal, namely those given by light, seem to common observation not to affect these cutaneous organs. As a matter of fact, it has been shown that light stimuli do affect the endings of general cutaneous nerves in such a way as to produce characteristic reactions. If a light of suitable intensity be allowed to fall upon a frog whose eyes have been removed, the animal will turn its head toward the source of light and jump toward it. If the frog's skin also be covered from the light no such reaction takes place. Other amphibia, some fishes and reptiles are influenced by light which falls on the skin alone. In the case of ammocoetes, which lives buried in the mud, the skin of the tail is more sensitive to light than any other part of the body, including the eyes. This condition is useful to the animal, since it burrows head foremost and the sensitiveness of the tail ensures that it shall completely bury itself.

While light must be reckoned as one of the most important factors in the external world influencing the organism, it is evident that the free nerve endings in the skin are not an adequate means for the perception of light. It is beyond the province of this work to inquire how light has influenced the organism so as to produce an organ for its perception. It is, however, the business of comparative morphology to consider whether the organism responded to external influences by producing an entirely new structure or whether the organ produced was a modification of some structure already existing, and if the latter, what was its probable mode or course of evolution. The attempt to answer 


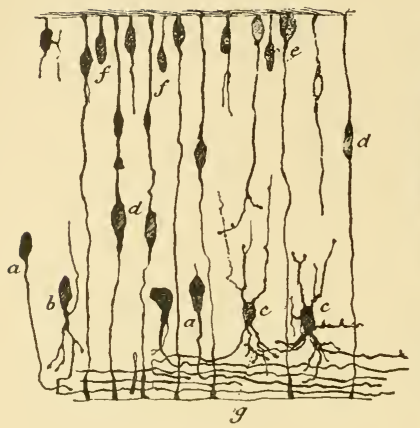

A

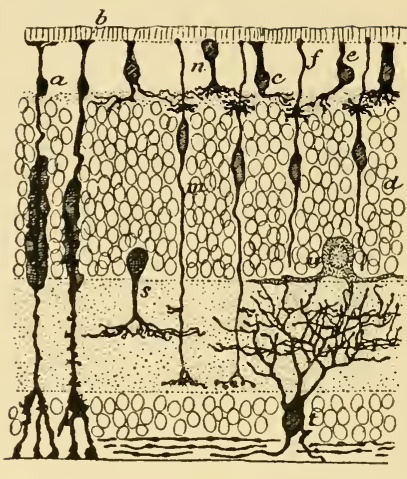

B

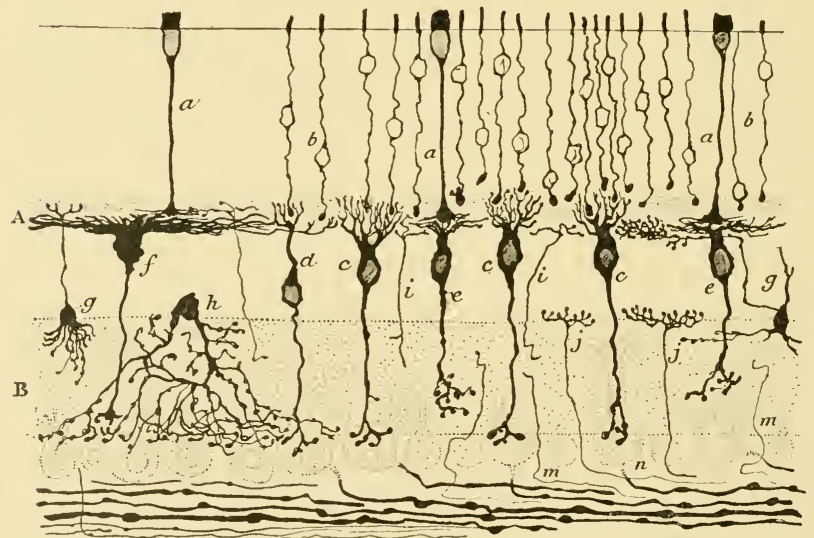

C

FIG. 7I.-Histogenesis and structure of the retina. From Cajal. (Die Retina der Wirbelthiere.)

A, a section through the retina of a mouse embryo of $\mathrm{I}_{5} \mathrm{~mm}$. $a, b, c$, neuroblasts; $d, e$, epithelial (Müllerian) cells; $f$, nucleus of rod cell.

$\mathrm{B}$, a section through the retina of a chick embryo of fourteen days. $a, b$, epithelial cells; $c$, rod cell; $d$, deep granule; $e, n$, cone cells; $m$, bipolar cell; $s, u$, amacrine cells.

$\mathrm{C}$, a section of the retina of a dog. $a$, cones; $b$, rods; $c$ and $e$, bipolar cells related respectively to rods and cones; $f$, giant bipolar cell; $h$, amacrine cell; $j$, centrifugal fiber; $n$, layer of ganglion cells. 
these theoretical questions should add interest to the study of the development and nerve connections of the visual apparatus.

It was shown in an earlier chapter that the lateral eyes are developed as a pair of vesicles from the dorso-lateral wall of the brain in about the region of the second neuromere (Figs. I8-22). Each vesicle comes to be attached to the ventral wall of the brain by a hollow stalk. There now appears in the ectoderm a thickening which sinks in to form a pit and finally separates from the ectoderm as a closed sac. This then develops into the lens of the eye. Meanwhile the optic vesicle becomes cupshaped toward the outside, enclosing the lens, and the wall of the concave side thickens to form the retina, while the convex wall remains thin. For the further development and adult relations of the eye-ball and accessory structures the reader must be referred to the larger text-books of embryology and anatomy. The histogenesis of the retina proceeds in a manner similar to that of the spinal cord or brain. Supporting structures are formed (the so-called Müllerian fibers) which are to be compared with the spongioblasts of the brain, and among these are found neuroblasts which give rise to the nerve cells of the retina (Fig. 7 I A). On the inner surface of the retina, that is next to the portion of the brain ventricle which extends into the optic vesicle, there are formed spindle-shaped cells whose one process extends to the ventricular surface and ends in a rod-shaped or cone-shaped structure, and whose other process runs deeper into the

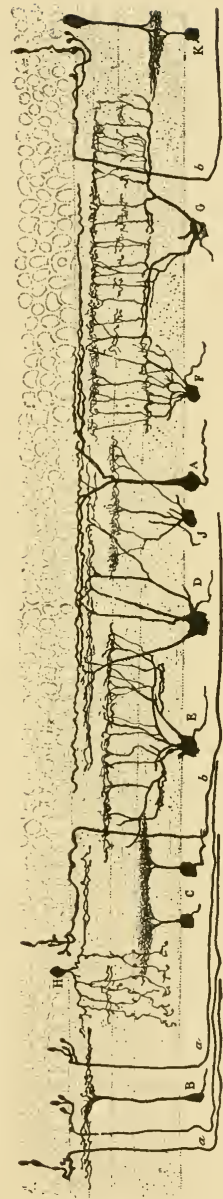

FIG. 72.-Cells from the retina of the chicken. From Cajal. $a, b$, centrifugal fibers. 
retina and branches in relation with the dendrites of cells forming the inner nuclear layer (Figs. 71, 72). These cells in turn set up connections with the elements of the ganglionic cell layer. The fibers from the ganglionic cells form a fiber layer on the outer, concave surface of the retina. The fibers collect toward a point near the center of the retina, dip into its substance and pierce it to its inner surface. From this surface of the retina the fibers pass along the optic stalk to the brain. This arrangement is brought about during development by a change of form of the retina and shifting of position of the stalk. At first the stalk is at the ventral border of the retina and the fibers run to the ventral border and thence to the brain in the stalk. Later the retina grows in such a way as to bring the attachment of the optic tract nearer its center. Finally, in all vertebrates except cyclostomes and some fishes and urodule amphibia, the hollow stalk degenerates and leaves the optic tract as the only connection of the retina with the brain. It should be noticed now that this optic tract, although commonly called the optic nerve, differs from all peripheral nerves in several ways. (I) The cells from which its fibers arise are derived from the wall of the brain. (2) They form part of a many-layered nervous structure whose development and histology suggest comparison with the brain wall. (3) Although the fibers carry afferent impulses they enter the ventral wall of the brain. Indeed, it has long been recognized that this is not a peripheral nerve but a central nerve tract and that the retina is a part of the brain wall.

When the optic tracts arrive at the ventral wall of the diencephalon (or before in bony fishes) they decussate, forming the optic chiasma. As a general rule the fibers from one retina pass to the opposite side of the brain, but in mammals a complete decussation of the optic tracts is rare. In different mammals a variable part of the fibers remain uncrossed and in man approximately one-third enter the same side of the brain as the eye from which they come. In vertebrates below the mammals most authors agree that the decussation is total. The beginnings of partial decussation are seen, however, in fishes. Golgi preparations of the chiasma of the sturgeon show a considerable number of fibers 
of the optic tracts giving off thick collaterals which enter the thalamus of the same side. The number of uncrossed fibers in any animal seems to depend upon the position of the eye. When the eyes are laterally placed as in most submammalian orders the uncrossed fibers are at a minimum. Among mammals, those whose eyes are lateral, so that the fields of vision do not overlap, have few uncrossed fibers; while those (apes, man) whose fields of vision largely overlap have a large part of the optic tracts uncrossed. The uncrossed fibers in man arise chiefly from the temporal part of the retina and run in a fairly well isolated bundle in the optic tracts and chiasma. Beyond the chiasma the optic tracts

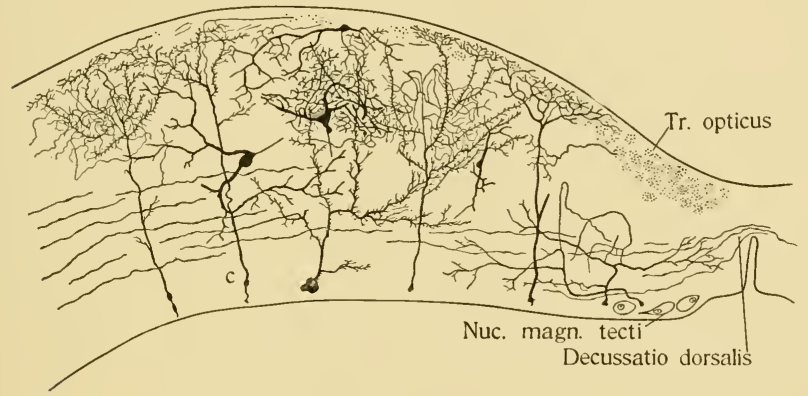

FIG. 73.-Part of a section of the tectum opticum of the sturgeon, schematic.

run up in the lateral part of the thalamus and end in the dorsal part of the thalamus and in the tectum opticum.

Structure of the tectum opticum.-In the lower fishes the tectum contains a large number of cells of several forms, most of which lie near the ventricle. The outer portion of the tectum is composed of fiber layers. Cells of both type I and type II are present. The cells of type II (Figs. 39 and 73) are slender spindle-shaped elements vertically placed near the ventricle, whose single thick dendrites rise toward the surface and branch profusely in the outer layers of the tectum. The neurite arises from some point of this dendrite far removed from the cell-body 
and branches very richly in the middle layers of the tectum in the immediate vicinity of the cell. All the other cells of the tectum may be described as cells of type I whose dendrites spread more widely and do not reach the outer surface of the tectum. Some of these cells have vertical spindle-shaped bodies and one or more branching dendrites, others have stellate bodies with several dendrites diverging widely, and still others are spindle-shaped but are placed tangentially and have two dendrites running parallel with the surface of the tectum. The neurites may arise from the cell-bodies or from any part of the dendrites, even from the tip of one of the tangential dendrites. The neurites arising from the cells of type I have various courses and destinations. (I) They cross to the opposite side, forming the dorsal decussation of the tectum. Whether any or all of these fibers leave the tectum after crossing is not known. (2) They enter the tractus tectobulbaris et spinalis and go either to the same or opposite side of the medulla oblongata and spinal cord. (3) They go down through the lateral wall of the mesencephalon or diencephalon to end in the inferior lobes, the tractus tecto-lobaris. Part of these fibers cross to the opposite side in the ansulate commissure in the ventral wall of the mesencephalon or in the postoptic decussation, or in both. (4) They go along the lateral border of the tectum to enter the cerebellum, the tractus tecto-cerebellaris. (5) They go out in the optic tract to end in the retina (Fig. 72). The last are called centrifugal fibers. The elements in the optic lobe of birds are shown in Fig. 74 .

A special apparatus is described in connection with the tectum opticum of all classes of vertebrates which is supposed to serve at least in early life for direct and prompt reflexes in response to optic impulses. In the mesial part of the tectum is found a nucleus consisting of a variable number of cells which are usually of extraordinary size. This is known as the roof nucleus or mucleus magnocellularis tecti. The neurites of these cells are said to enter the ventricle and form the structure known as Reissner's fiber, which makes connections with cells in the gray matter of the spinal cord. By means of this apparatus it is supposed that aquatic animals are able to avoid obstacles and danger by move- 
ments more prompt than those which are directed by the more complex brain tracts.

In cyclostomes all the optic tract fibers end in the tectum opticum

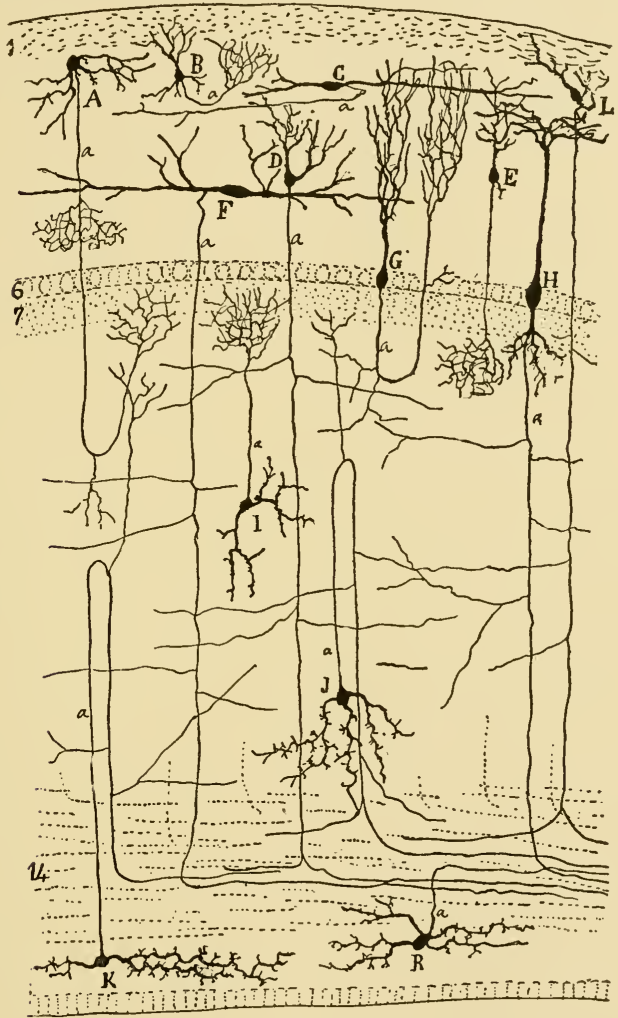

Fig. 74.-A section of the optic lobe of a bird. From Cajal (Textura, etc.). The letters refer to extended descriptions in Cajal's text.

but in selachians a part of the tract ends in the diencephalon and in all higher forms an increasingly large part of the tract has this ending. The chief nucleus in which the fibers end is 
situated in the lateral wall of the thalamus and is known as the corpus geniculatum laterale. The morphology of the thalamic and midbrain optic centers and their tertiary connections in higher vertebrates will be discussed in a later chapter (Chap. XVI).

The question of the origin of the eye and of its relation to other sensory systems may now be reviewed. Obviously a close relation would not be expected between the eye and the nerves or organs of visceral sensation. Is the eye, then, related to cutaneous sense organs and has it been formed by modification of any preexisting organ, or is it a wholly new structure? The facts show a remarkable similarity between the eye and the general cutaneous structures of other segments. The retina is derived from the dorso-lateral wall of the second neuromere. It therefore represents a dorso-lateral nucleus and as such corresponds to the cutaneous nuclei in the hindbrain and spinal cord. The optic tract which arises in the retina is a secondary brain tract for which the tectum opticum is the secondary nucleus. The secondary tract decussates in the rentral wall of the brain as do the secondary tracts from the cutaneous nuclei, and ends in the same center with those tracts, the tectum opticum. The tectum itself is a primary cutaneous center, since in several classes of vertebrates it receives a part of the sensory trigeminus nerve, and in the embryos of lower vertebrates the ophthalmicus profundus nerve arises from the roof of the midbrain. In lower vertebrates the mode of formation of the optic vesicle bears a significant resemblance to the mode of formation of the general cutaneous ganglia. In selachians, for example, both are formed as hollow outgrowths from the dorso-lateral wall of the neural tube.

If to these facts there be added now the physiological facts with which this chapter was begun, a remarkably strong body of evidence is presented for a relationship between the eye and the general cutaneous sensory system. The general cutaneous nerves are susceptible to light stimulation and the impulses carried to the brain produce reactions which correspond to those produced when the eyes are the vehicles of light perception. Whether the frog has the use of its eyes or only of its skin it turns its head toward the light and jumps toward it. Not only are the cutaneous nerves 
and retina both affected by light waves, but the nerve centers of the two are in part identical, so that the impulses arriving in the brain from either source produce the same reflexes.

From these facts it must be supposed that the general ectoderm was originally sensitive to light and that in ancestral vertebrates the sensitiveness became greatest in an area favorably situated on the top of the head. The sensitive elements in the skin are the free endings of the dendrites of nerve cells. When the central nervous system sank below the surface the cells whose dendrites were distributed to the skin were in part enclosed within the neural
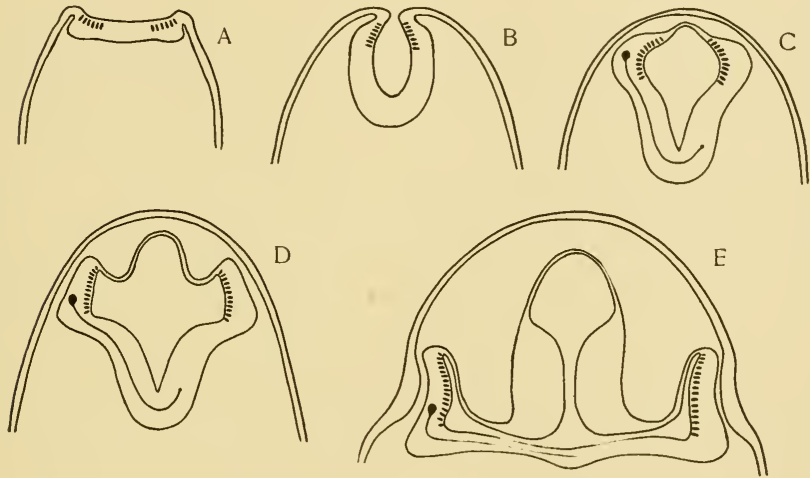

Fig. 75.-A series of diagrams intended to illusirate the origin and mode of formation of the optic vesicle in vertebrates.

tube (p. 37). The greater part formed the neural crest. In connection with the front part of the brain no neural crest is formed and it must be supposed that in this region the whole of the nervous ectoderm was included in the neural tube. In this area then the cells which were especially sensitive to light became the rod and cone cells of the retina. Each of these is a bipolar cell whose two processes are comparable respectively with the dendrites and neurite of a typical nerve cell or with the peripheral and central processes of a spinal ganglion cell. With the growing thickness and opacity of the muscles and skeleton overlying the 
brain tube it became necessary for the retinal area to project toward the skin in order to receive light stimuli. This area contained both primary receptive cells and brain centers. As it was carried out from the brain and the optic vesicle was formed, the stalk of the vesicle consisted chiefly of the fibers of the optic tract. Since these fibers were destined to decussate in the ventral wall of the brain, it was advantageous for the stalk to shift ventrad and so allow the tract to become shorter. This is illustrated in an accompanying diagram (Fig. 75). Although this special visual organ has been developed, the general cutaneous endings retain their sensitiveness to light in varying degrees.

In Amphioxus special light percipient cells are contained in the front end of the brain and throughout the spinal cord. These have been shown to be similar to the light percipient cells in the

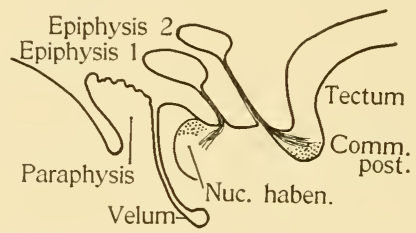

FIG. 76.-A sketch showing the relations of the two epiphyses in vertebrates.

ganglia of certain worms. Whether there is any relation between the light percipient cells of Amphioxus and the lateral eyes of vertebrates is uncertain.

In addition to the lateral eyes two other organs of light perception are present in vertebrates, the degenerate or reduced pineal eyes. Although in most vertebrates only one of these structures is present, at least in the adult, both are present in adult cyclostomes, and in some reptiles one in front of the other. The position and innervation of the organ found in other classes of vertebrates show that sometimes it is the anterior and sometimes the posterior organ which is present. The anterior organ sends its nerve fibers into the nucleus habenulae or adjacent center. Those from the posterior organ go to the region of the posterior commissure and probably enter the tectum opticum. 
These relations are illustrated by Figure 76 . Although degenerate in all vertebrates, yet one or the other of these organs is capable of light perception, at least in cyclostomes and some reptiles, and perhaps in some fishes and amphibia. The structure of the organ is apparently much simpler than that of the retina, but in some forms the presence of rods or cones has been described. There is evidence that the pineal eyes are not median structures. The organ is never quite median in its adult form and in the embryo paired organs begin to develop and only one persists. In selachians there have been described in early stages a series of "accessory optic vesicles" following the true optic vesicles. The pineal eyes were probably originally paired organs serially homologous with the lateral eyes, and the three pairs represent the cutaneous sensory system in those segments of the head in which the cutaneous nerves and ganglia are wanting (p. 6r).

\section{DEMONSTRATION OR LABORATORY WORK.}

I. Study the development of the optic vesicle, lens and optic tract in some vertebrate embryos. Compare the histogenesis of the retina with that of the brain wall.

2. Histology of the retina in Golgi preparations.

3. Trace the course of the optic tracts and compare the chiasma with the decussation of internal arcuate fibers in the medulla oblongata

4. Study the structure of the tectum opticum in Golgi sections of the brain of a fish and the frog.

5. In Golgi or Weigert sections study the tracts arising in the tectum and colliculus.

\section{LITERATURE.}

Barker, L. F.: The Nervous System and its Constituent Neurones. New York. I899. Chapter LIII especially.

Boveri, T.: Ueber die phylogenetische Bedeutung der Sehorgan des Amphioxus. Zool. Jahrb., Suppl. Bd. 7. I904.

Cajal, S. R.: Die Retina der Wirbelthiere. Wiesbaden. I894.

Eycleshymer, A. C.: The Development of the Optic Vesicles in Amphibia Jour. Morph., Vol. 8. I8go.

Froriep, A.: Die Entwickelung des Auges der Wirbelthiere. Hertwig's Handbuch der Entwickelungslehre. I905.

Hesse, R.: Die Sehorgane des Amphioxus. Zeit. f. wiss. Zool., Bd. 63. 1898 . 
Johnston, J. B.: Das Gehirn und die Cranialnerven der Anamnier. Merkel u. Bonnet's Ergebnisse, Bd. II. I902.

Johnston, J. B.: The Morphology of the Vertebrate Head. Jour. Comp. Neur., Vol. I5. I905.

Johnston, J. B.: The Radix mesencephalica trigemini. Anat. Anz., Bd. 26. I905.

Kerr, J. Graham: The Development of Lepidosiren paradoxa. Part 3. The Development of the Skin and its Derivatives. Quart. Jour. Mic. Sci., Vol. 46. I902.

Locy, W. A.: Contribution to the Structure and Development of the Vertebrate Head. Jour. Morph., Vol. I I. I 895.

Parker, G. H.: The Skin and Eyes as Receptive Organs in the Reactions of Frogs to Light. Amer. Jour. of Physiol., Vol. Io. I903.

Parker, G. H.: The Stimulation of the Integumentary Nerves of Fishes by Light. Amer. Jour. of Physiol., Vol. I4. I905.

Sargent, Porter E.: The Optic Reflex Apparatus of Vertebrates for Short-circuit Transmission of Motor Reflexes through Reissner's Fiber. Part r. Fish-like Vertebrates. Bull. Mus. Comp. Zool. Harvard Coll., Vol. 45. I9O4. 
CHAPTER IX.

\section{THE VISCERAL AFFERENT DIVISION. General Visceral Subdivision.}

The visceral afferent fibers bring impulses from the viscera to the central nervous system. They are distributed to the mucous surfaces in much the same way as the general cutaneous fibers to the skin. In the absence of special knowledge as to their appropriate stimuli it may be supposed that the fiber endings are stimulated by pressure as are the general cutaneous endings. Although it would be confusing to apply the term tactile to visceral

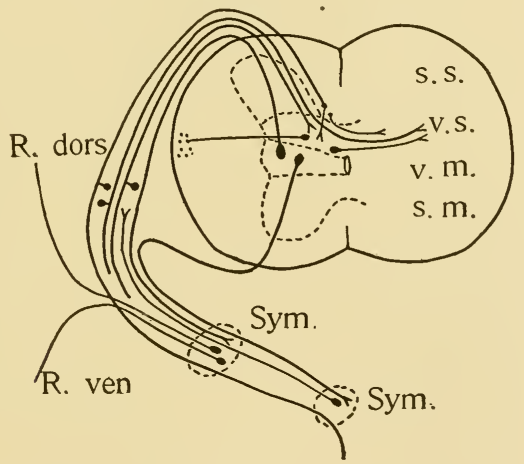

FIG. 77.-A diagrammatic representation of the general visceral sensory components in a trunk segment.

impulses, it is probable that there is a close analogy between the two. The difference between cutaneous and visceral sensory apparatus is not in the form of the endings or the mode of stimulation, but in the connections of the two kinds of fibers in the central nervous system.

The visceral afferent fibers form a component of each of the 
dorsal nerves of the trunk and head with the exception, in most vertebrates, of the trigeminus and ophthalmicus profundus nerves. In the trunk (Fig. 77) the fibers have their ganglion cells in the spinal ganglia and go by way of the white rami communicantes through one of the ganglia of the sympathetic chain, and by way

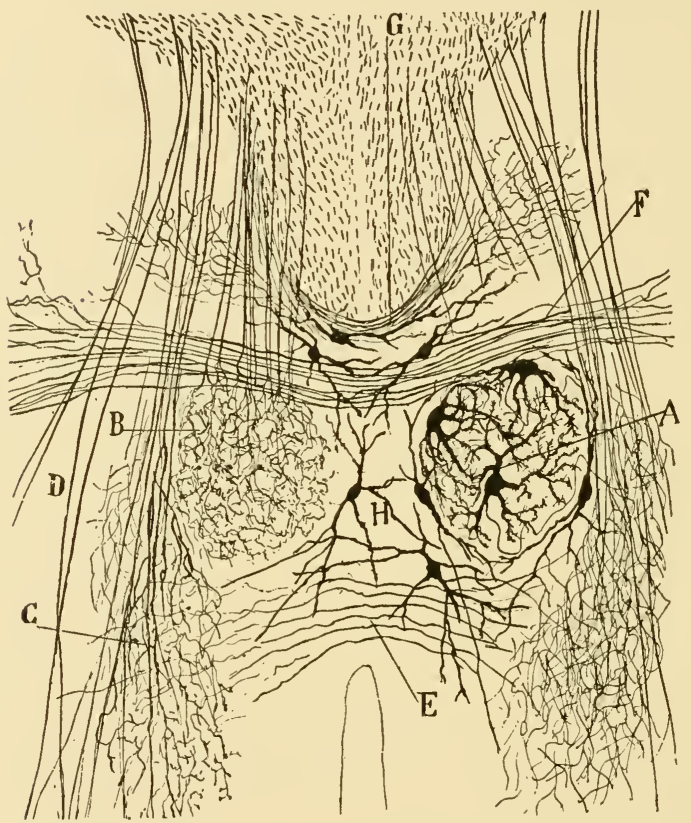

FIG. 78. - A transverse section through the region of Clarke's column of the thoracic cord of a new-born dog. From Cajal (Textura, etc.). A, Clarke's column; $B$, ending of collaterals in it; $C$, collaterals ending in the intermediate nucleus; $D$, reflex-motor collaterals; $E$, ventral commissure; $F$, middle commissure; $G$, dorsal commissure; $H$, cells of the dorsal commissure.

of sympathetic nerves to some of the organs of the viscera. In the spinal cord these fibers have their central endings in a part of the gray matter lying at the base of the dorsal horn, known as Clarke's column, and perhaps in connection with other cells 
which lie near the median plane dorsal to the central canal (Fig. 78). This column of cells and its central relations have long been known in man and mammals but it is only in recent years that its function as the center for sensory fibers of the sympathetic system has been proved. The neurites from the cells of Clarke's column go laterad to the surface of the cord and there turn cephalad to form a well defined tract known as the direct cerebellar tract, since it enters the cerebellum of the same side. As compared with the cutaneous sensory system the visceral afferent system in the trunk is very small.

In the head, on the other hand, the visceral sensory surface is greatly increased on account of the gills and there are present special organs of the sense of taste whose fibers run in the same nerves as the general visceral afferent fibers. The relation of these organs and their fibers to the general visceral fibers is so close that they may be spoken of as special visceral sensory structures. Because of the extensive branchial surface and the great number of gustatory organs in the head, the combined visceral systems may be larger than the cutaneous. The visceral afferent fibers form usually the largest component of the X, IX and VII nerves. They are distributed to the gills and the lining of the pharynx and also to the mouth and the surface of the head and body wherever taste organs are found. In fishes the ganglion cells of this component in the vagus and glossopharyngeus are situated in the epibranchial ganglia and the peripheral fibers reach their destination by way of the branchial and pharyngeal rami and the ramus intestinalis vagi. In the VII nerve the visceral ganglion cells form a ganglion which in different classes of vertebrates may be more or less closely in contact with the ganglion of the VIII, the lateral line or the V nerve. The fibers enter the ramus palatinus and other rami of the facialis which reach the mucosa of the mouth and the gill of the spiracular cleft when that is present. In cyclostomes this component of the VII nerve is very small and its distribution has probably not been completely made out. The general arrangement of these components in the cranial nerves is shown in Figs. 51, 63, 79, 80 .

In amphibia and all higher vertebrates owing to the disappear- 
ance of the gills this component is much smaller than in fishes. In mammals it runs in the following rami: chorda tympani, great

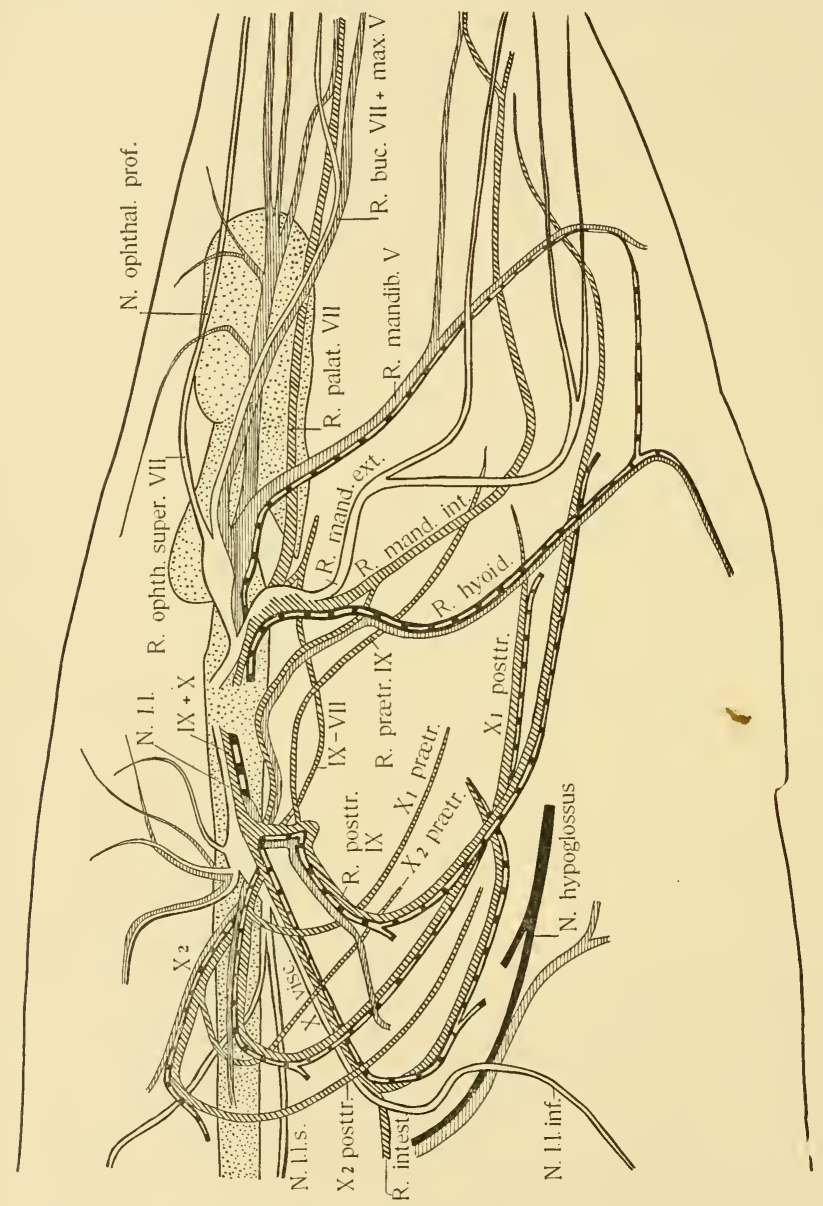

FIG. 79.-A reconstruction of the cranial nerve components in a tailed amphibian, Amblystoma. After Coghill. 
superficial petrosal and main trunk of VII; pharyngeal and lingual rami of IX; and pharyngeal, superior laryngeal, pulmonary, oesophageal, gastric and sympathetic branches of the $\mathrm{X}$ nerve. Possibly other branches also, such as the vidian nerve, carry fibers of this component.

VISCERAL SENSORY CENTERS. - The brain centers in which the visceral afferent fibers end in cyclostomes, ganoids, bony fishes, amphibia and mammals have been found to be directly continuous with the region of Clarke's column, namely, a column occupying the mesial portion of the base of the dorsal horn. In all cases these columns become greatly enlarged at about the junction of the spinal cord and medulla oblongata, rise dorsally mesial to the dorsal horns and join to form a median dorsal nucleus, the mucleus

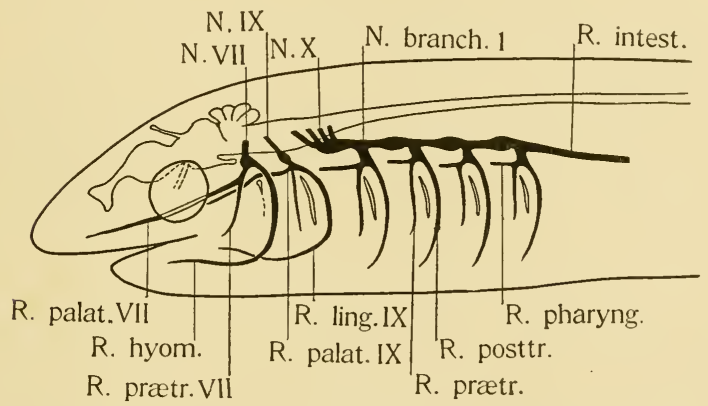

FIG. 8o.-A simple diagram of the visceral nerves of the head in fishes.

commissuralis, first described by Cajal in the mouse. The cells of the nucleus commissuralis lie imbedded among the fibers of a commissure which has been known in fishes as the commissura infima. Just cephalad of this nucleus and commissure the lateral walls of the brain spread apart and are connected dorsally only by the choroid plexus of the fourth ventricle. The visceral columns now appear as more or less prominent ridges continuing forward in the lateral walls of the fourth ventricle, which have been described as including the vagal and facial lobes.

As the visceral fibers in the $\mathrm{X}, \mathrm{IX}$ and VII nerves enter these 
lobes many of them divide into terminal branches inmmediately, and in many fishes the visceral lobe is strongly thickened opposite each nerve root so that it appears somewhat like a string of beads (Figs. 2, 3, II). The bifurcation of the fibers and the formation of a longitudinal tract are not such prominent features in the visceral system as in the cutaneous. A part of the fibers, however, do turn caudad and in fishes form a diffuse bundle which extends to the nucleus commissuralis, where a part of the fibers cross

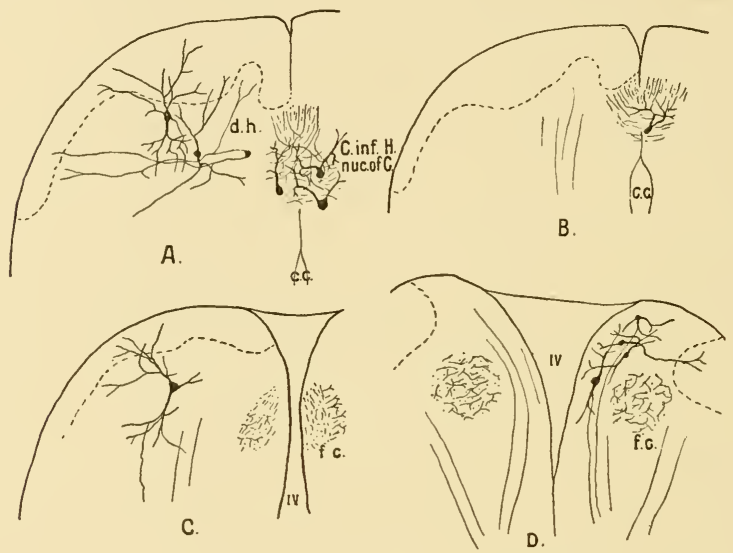

FIG. 8r.-Four transverse sections through the medulla oblongata of the frog to show the position and ending of the fasciculus communis and the nucleus commissuralis. C. inf. H., commissura infima; nuc. of C., nucleus commissuralis; $f . c$., fasciculus communis; $d$. h., dorsal horn.

to the opposite side in the commissura infima. In amphibia (Fig. 8I) these fibers form a well defined bundle which on account of its relation to the three nerves, VII, IX and $\mathrm{X}$ has been given the name fasciculus communis. In terrestrial vertebrates the loss of the gills has led to a great reduction in size of this system, and the centers no longer form conspicuous ridges projecting into the ventricle. Instead, there is in mammals only a small, sharply defined longitudinal bundle of fibers comparable to the fasciculus communis, which is known as the fasciculus solitarius, and a 
small column of cells accompanying this bundle. In the mouse (Figs. 82, 83), as in fishes and amphibia, the descending fibers enter the nucleus commissuralis and help to form the commissure. In all classes a part of the fibers continue caudad beyond the commissura infima in the visceral column of the cord.

In fishes, where these centers are best known, their structure is relatively simple. The terminal branches of the afferent fibers are short but very profusely subdivided and the dendrites of the cells often have the same characteristics, so that sections of this

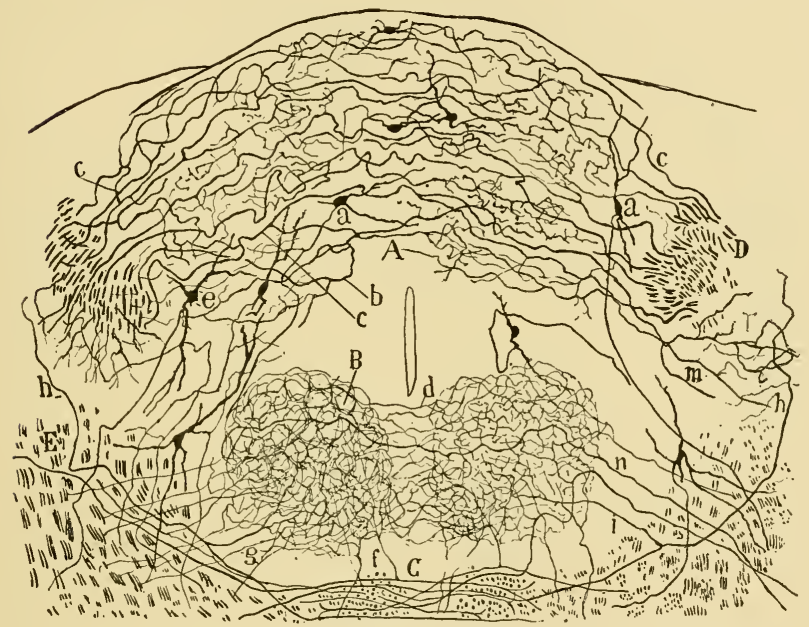

FIG. 82.-Transverse section through the medulla oblongata of the mouse at the level of the nucleus commissuralis. From Cajal (Beiträge u. s. w.). A, nucleus commissuralis; $B$, nucleus of hypoglossus; $C$, decussation of lemniscus; $D$, fasciculus solitarius; $b, c$, endings of fibers of $\mathrm{IX}$ and $\mathrm{X}$ nerves.

center prepared by the Golgi method show dense brushes of intricately interwoven fibers which have as a whole a very furry appearance (Fig. 84). Many of the cells are of type II whose neurites terminate within the lobe. In fishes whose gustatory apparatus is largely developed these intrinsic neurones are very numerous. Other cells send their neurites out of the sensory 
nucleus to end in the neighboring motor column, from which arise the viscero-motor nerves. These fibers constitute what may be called short viscero-motor connections. The remaining cells are cells of moderate size whose neurites go directly lateroventrad and near the surface of the medulla either bifurcate into

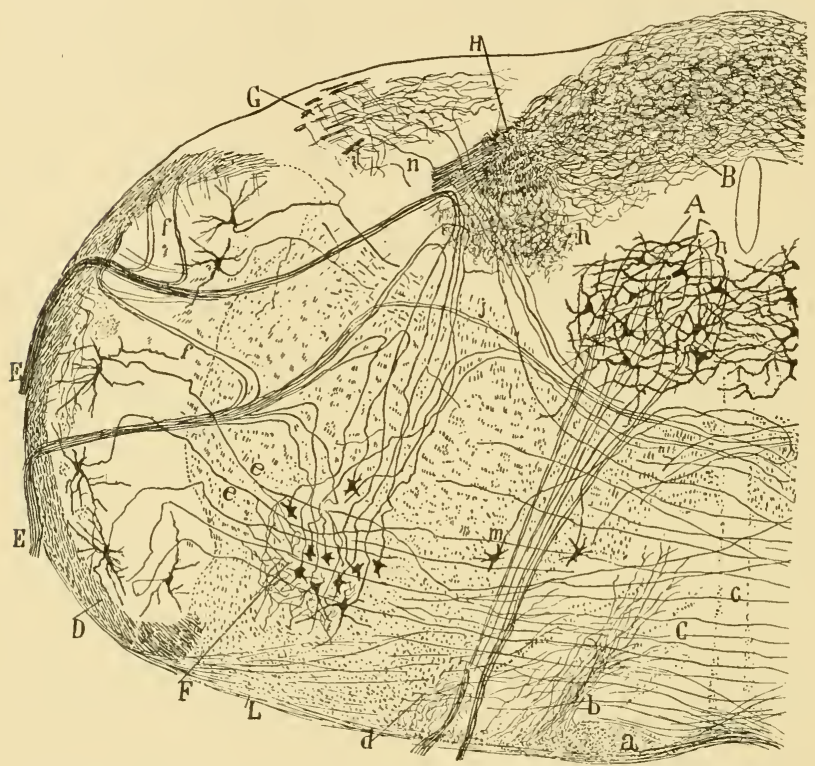

Fig. 83.-Transverse section through the medulla oblongata of a mouse four days old. From Cajal (Beiträge u. s. w.). A, hypoglossal nucleus; $B$, nucleus commissuralis; $C$, olive; $D$, spinal $\mathrm{V}$ tract; $E$, motor roots of $\mathrm{IX}$ and $\mathrm{X} ; F$, nucleus ambiguus; $G$, caudal portion of the nucleus of the descending root of the nervus vestibularis; $H$, fasciculus solitarius; $a$, pyramids; $f$, general cutaneous components in IX and $\mathrm{X}(?) ; h$, collaterals of fasciculus solitarius ending in its accompanying nucleus.

cephalic and caudal branches or run forward or backward without dividing. The descending fibers form a diffuse bundle which, after giving part of its fibers to a nucleus adjacent to the nucleus commissuralis (bony fishes), grows smaller caudally and is lost 
to view in the cervical cord. The greater part of the fibers turn forward and form in the myelencephalon a diffuse bundle which runs parallel with and ventro-mesial to the spinal $\mathrm{V}$ tract. The bundle continues to receive fibers from all parts of the visceral column, runs on forward past the roots of the trigeminus and enters a large nucleus lying in the lateral wall of the metencephalon

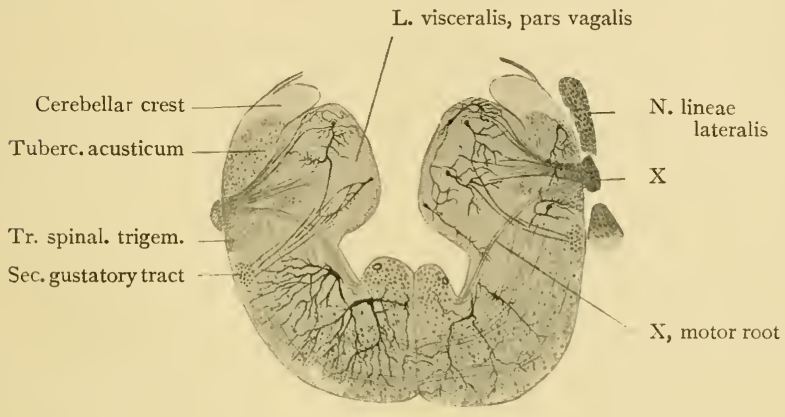

A

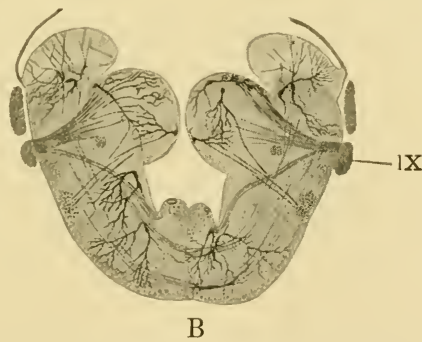

FIG. 84.-Transverse sections through the medulla oblongata of the sturgeon; $\mathrm{A}$, at the level of the $\mathrm{X}$ nerve; $\mathrm{B}$, at the level of the IX nerve. A is at a higher magnification than $\mathrm{B}$.

(Figs. 89, 92). This bundle has been called the secondary vagus tract in those fishes in which the vagal part of the visceral lobe is especially developed, but it is evidently a secondary visceral tract and the nucleus in which it ends, a secondary visceral nucleus. There is reason to believe that this tract and nucleus correspond 
to the direct cerebellar tract and its nucleus in man, but it is very desirable that the structures should be worked out in intermediate classes, especially reptiles and lower mammals.

Since the visceral centers are most highly developed in those forms in which the gustatory organs are most numerous, the further description of the secondary visceral nuclei will be given in the following section.

\section{Special Visceral or Gustatory System.}

In fishes, as already stated (p. 22), the gustatory organs have a much wider distribution than in higher vertebrates. As far as is at present known the distribution of taste organs in the different classes of vertebrates is as follows. In cyclostome larval forms they have been found only in the pharynx, on the inner surface of the branchial arches. In adults they are also irregularly distributed over the surface of the head and branchial region of the body. Whether they occur in the trunk and tail region has not been ascertained. In ganoids they are present in the mouth and pharynx and in considerable numbers over the surface of the head. In embryos of bony fishes they are found in the pharynx, oesophagus and mouth. In adults they reach their greatest development both as to number and distribution, being found also on the surface of the head and in many forms on the fins and practically over the whole body. In amphibia they are found on the tongue and mucosa of the mouth, being especially numerous on the papillae of the tongue. The so-called multicellular glands in the roof of the pharynx of tadpoles are probably taste organs. In man they are found in small numbers on the general surface of the tongue, more numerous along the sides of the tongue, and most numerous on and around the circumvallate papillae and on a region at the back of the tongue corresponding to the papillae foliatae of some mammals. They are also numerous on the anterior surface of the soft palate and on the posterior surface of the epiglottis.

The following facts show that the taste organs have their origin in the entoderm. (I) They arise in the lining of the pharynx in Ammocoetes, and are not found in the skin during larval life. 
(2) In ganoids and bony fishes (Amia, Catostomus) they arise in the entodermal lining of the pharynx, oesophagus and mouth. After the time of hatching, the mucosa pushes out over the lips and taste organs appear in the spreading entoderm. (3) In amphibians (Amblystoma punctatum, Rana) the taste buds arise and remain throughout life in the entodermal area of the pharynx and mouth. Although the limits of ectoderm and entoderm have not been determined in reptiles, birds and mammals, the most rea-

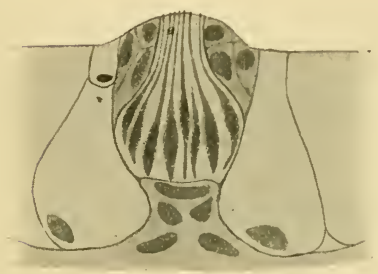

A

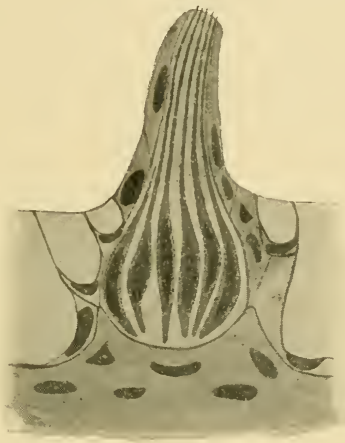

B

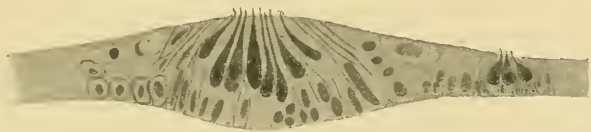

C

FIG. 85.-Sense organs of bony fishes. A, a taste bud from the oesophagus of Catostomus at the time of hatching; $\mathrm{B}$, a taste bud from the pharynx of the same embryo; C, two neuromasts from the skin of the same embryo.

sonable inference from the position of the organs is that they lie in entodermal territory.

The taste organs differ from the pit and canal organs: (I) in being surface organs not sunken in pits but sometimes projecting above the surface as hillocks; and (2) in that the sense cells are long, slender and rod-shaped and extend the full depth of the 
epidermis. Each sense cell terminates at the surface by a rodlike or hair-like projection which is much shorter than the sense hairs of the neuromast organs. Since the taste organs are stimulated by chemical changes they do not need the long sense hairs which adapt the neuromasts to stimulation by vibrations in fluids. Beneath the organ nerve fibers penetrate the dermis, lose their sheaths and end by fine branches in contact with the sense cells. A more intimate union between the cells and terminal branches of the fibers has not been seen. To facilitate comparison between neuromasts and taste organs there are shown in Fig. 85 two taste organs and two neuromasts from the same embryo of a bony fish. The tall form of taste organ is taken from the lining of one of the"gill" arches and represents the prevailing form in the

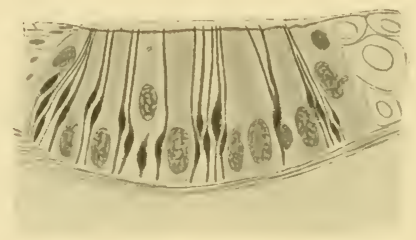

Fig. 86.-A taste organ from the pharynx of the ammocoetes of Petromyzon dorsatus.

pharynx, where the organs are best developed. The lower organ is taken from the oesophagus near the opening of the duct of the swim bladder and is of the same form as those in the mouth. The sharp contrast between the sense cells in these and in the neuromasts requires no comment. In Fig. 86 is drawn a taste organ from the pharynx of the larva of a cyclostome and in Fig. 87 a taste organ from the skin of an adult of another species. The great difference in form of the two organs suggests a profound influence of the surrounding structures, but both organs have the same type of sense cells as are in the taste organs of all vertebrates.

The innervation of the taste organs is as follows. Those in the pharynx are innervated by the visceral branches of the vagus 
and glossopharyngeus nerves. Those in the mouth are supplied by the palatine and hyomandibular rami of the facialis, by the pharyngeal ramus of IX which extends into the roof of the mouth, and by the ramus lingualis of the IX nerve. Those on the surface of the head and body in ganoids and bony fishes are supplied by components of the ophthalmic and maxillary rami and by a great system of superficial nerves which have been known under the name of ramus lateralis accessorius (or nerve of Weber). The name is unfortunate because it is likely to suggest some relation with the lateral line nerve, with which this nerve is to be sharply contrasted. The present nerve (Figs. 63, 88) arises from the visceral afferent root of VII and sometimes in smaller part from

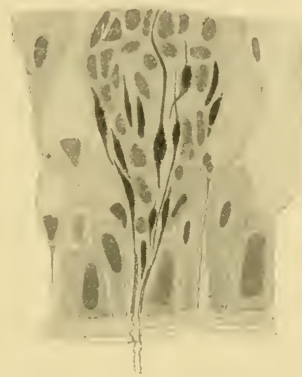

FIG. 87.-A taste organ from the skin of an adult Lampetra.

the corresponding root of $\mathrm{X}$, passes up through the cranium to the dorsal surface of the head and is distributed to the back, the tail and the fins, wherever taste buds are found. It has been definitely shown that taste buds, wherever they are situated, are always innervated by fibers derived from the visceral afferent roots of the VII, IX and $\mathrm{X}$ nerves and ending centrally in the visceral lobe. Where the taste buds are very numerous in the skin they are always innervated from the root of the facialis nerve and there is developed a special pars facialis of the visceral lobe.

The innervation of the taste buds in man is still somewhat in doubt. It was long supposed that fibers were supplied to 
taste buds by three nerves, the ramus lingualis IX, the chorda tympani and the ramus lingualis $\mathrm{V}$. In certain cases in which the Gasserian ganglion was removed and in which the clinical observations were continued for an unusually long time, it was clearly shown that taste was not at all impaired and that the trigeminus provided only for tactile sensation. This is in agreement with the conditions in lower vertebrates, but it is still possible that taste fibers run in the trigeminus in exceptional cases. The homology of the chorda tympani has been in doubt because it was not certainly known whether the chorda of mammals is a pretrematic or posttrematic ramus. It seems clear now that it

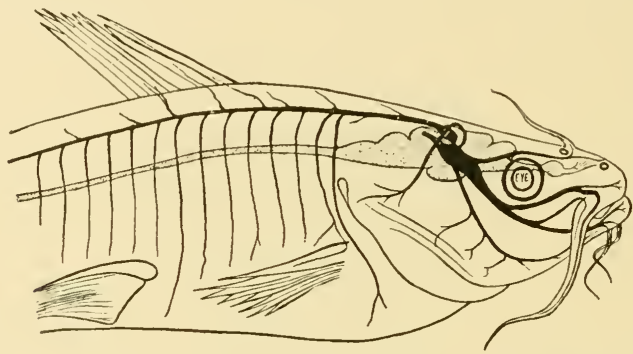

FIG. 88.-A projection of the cutaneous branches of the communis root of the right facial nerve in a bony fish, Ameiurus. From C. Judson Herrick. All the branches drawn are gustatory in function. Those which supply taste buds within the mouth are not shown.

is a posttrematic nerve and that the ramus mandibularis VII as seen in the frog tadpole and in fishes is its homologue. The ramus lingualis IX is the homologue of the posttrematic ramus of the IX nerve in fishes and amphibia, which is prolonged into the tongue.

The taste fibers enter the same centers with the general visceral fibers and no means has yet been discovered of distinguishing between the two. However it is probable that of the two sorts of secondary fibers mentioned in the last section, one serves general visceral and the other chiefly gustatory functions. Those which make direct connections with the motor nuclei of the cranial nerves carry only impulses from the visceral surfaces analogous 
to tactile impulses from the skin and give rise to reflex contractions of the branchial muscles controlling the respiratory movements. It is inherently probable that a part of the fibers of the long tract to the metencephalic nucleus have general visceral functions, especially as such a tract is present in mammals coming forward from the trunk, where taste organs are out of the question. We must at present suppose that when taste buds were first developed in vertebrates they came to be innervated by the general visceral fibers which already supplied the area in which the taste buds appeared. As the gustatory system came to be more important the long secondary tracts came especially into its service for the reason that these long tracts make possible more complex reflexes adapted to the capturing of food.

It is in the bony fishes, where the gustatory apparatus has reached an enormous development, that the secondary and tertiary connections of the taste center have been most fully worked out (Figs. 89, 90). Here the secondary visceral tract has the same general arrangement as has been described above. As the gustatory elements greatly preponderate in it, we may call it the secondary gustatory tract. Caudally a part of this tract extends into the spinal cord and a part ends in an inferior secondary gustatory nulceus adjoining the nucleus commissuralis. Complex relations between this and the adjacent nucleus funiculi (cutaneous center) perhaps enable the animal to correlate tactile with gustatory impulses in the control of movements for the capture of food. Cephalad the tract ends in the metencephalic nucleus, which Herrick calls the superior secondary gustatory nucleus. Part of the fibers end in the nucleus of the same side and part cross to the opposite side in a commissure which may be called the inferior cerebellar commissure. This commissure contains also fibers arising from the cells of the secondary nucleus. The nucleus is an enlargement of the gray matter bounding the fourth ventricle laterally and is very rich in cells and in terminal ramifications of fibers. From this nucleus, in addition to the commissural fibers, arises a tract which runs to the inferior lobes of the diencephalon. Other fibers from the secondary gustatory nucleus seem to go into the cerebellum and the tectum mesen- 


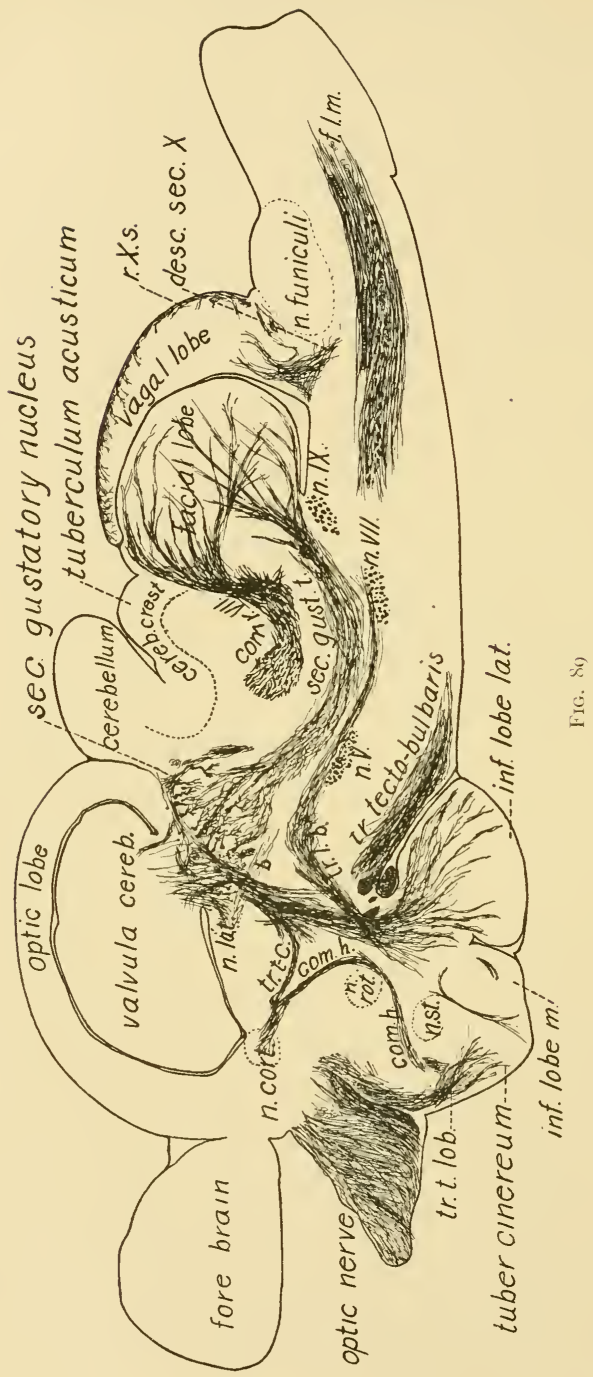


cephali. These may serve the more fully to bring about correlations with the somatic muscles in addition to the connections in the funicular region. From the inferior lobes two tracts already well known in lower vertebrates may forward the gustatory impulses. One of these is the tractus lobo-bulbaris which runs back through the myelencephalon and makes connections with the motor nuclei of the cranial nerves. The second tract is the tractus lobo-epistriaticus which carries impulses to that large coordinating center of the forebrain (epistriatum) which is primarily a part of the olfactory apparatus and in amphibia, reptiles and mammals develops into the hippocampal lobe and adjacent parts of the true olfactory cortex. (See Chapter XVIII.) It is possible that this tract is retained in higher vertebrates and serves as the path of gustatory sensations in the true sense. The chief central gustatory connections are shown in Figs. 89 and 90.

The arrangement of the secondary gustatory tracts and nuclei in selachians throws light on certain important structures peculiar to the brain of ganoids and teleosts. In both these classes the superior secondary gustatory nucleus is large, lies in the lateral wall of the metencephalon and sends its commissure through a

FIG. 89.-A parasagittal section through the brain of the spotted sucker, Minytrema melanops, to show the gustatory centers and tracts. From C. Judson Herrick.

The sketch is designed to illustrate the course of the ascending secondary gustatory tract and the connections of its terminal nucleus. The plane of the section is slightly oblique so that the caudal end and the ventral side are nearer the median line than are the cephalic and dorsal borders. The figure is a composite, made by outlining one section with the camera lucida and filling in the details from this section and the three sections of the same series on each side immediately adjacent, omitting irrelevant detail. The features introduced are schematized as little as possible. The whole course of the ascending secondary gustatory tract from the facial lobe is shown. The origin of the tract from the vagal lobe lies farther lateral.

$b$., tract between secondary gustatory nucleus and n. lateralis valvulae; com.h., commissura horizontalis, FrITSCH; com. $r$. VII, communis (gustatory) root of the facialis; desc.sec. $X$, descending secondary gustatory tract from the vagal lobe; f.l.m., fasciculus longitudinalis medialis; inf.lob.lat., lateral lobule of inferior lobe (hypoaria, C. L. HerRICK); inf.lob.m., median lobule of inferior lobe (mammillare, C. L. Herrick); n.cort., nucleus corticalis, FrITSCH; n.IX, motor nucleus of the glossopharyngeus; n.lat., nucleus lateralis valvulae; n.rot., nucleus rotundus, FrITSCH; n.st., nucleus subthalamicus, C. L. HERRICK; $n . V$, motor nucleus of the trigeminus; $n . V I I$, motor nucleus of the facialis; r.X.s., sensory root fibers of the vagus; sec.gust.t., ascending secondary gustatory tract from the facial and vagal lobes; $t r . l . b .$, tractus lobo-bulbaris; $t r . t$-c., tractus tecto-cerebellaris; $t r . t-l o b .$, tractus tecto-lobaris, JoHNSTON (commissura ventralis, C. L. HERRICK). The area marked n.funiculi contains also the inferior secondary gustatory nucleus. 
part of the cerebellum which projects into and largely fills up the ventricle of the mesencephalon,- the valvula cerebelli. In selachians no valvula is present. The cerebellum corresponds to that part of the cerebellum of bony fishes which is folded upward and outward. This will be clear from a comparison of Fig. 9I, which represents a sagittal section of the cerebellum of a newly hatched bony fish, with Fig. I I, representing a sagittal section of a selachian brain. The superior secondary gustatory nuclei in selachians are situated higher in the dorso-lateral wall of the metencephalon than in bony fishes and their commissure crosses in the roof of

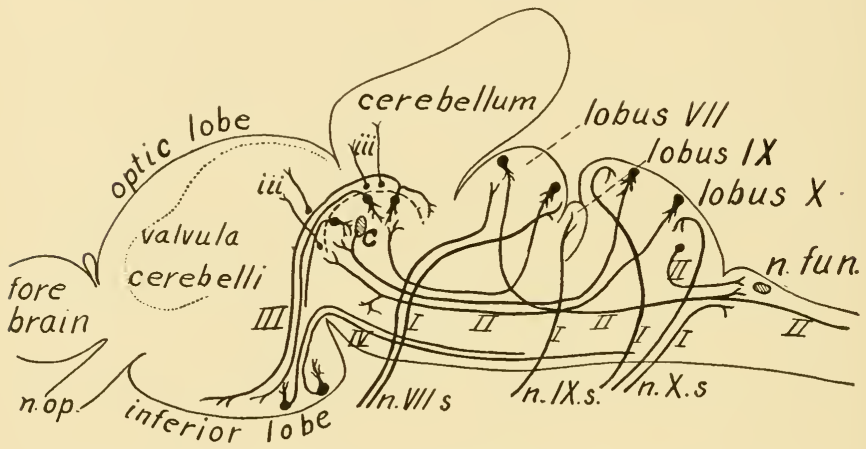

Fig. 90.-A diagram of the gustatory paths in the brain of the carp as seen from the left side. From C. Judson Herrick.

n.VII.s., n.IX.s., and n.X.s., represent the sensory root fibers of the facialis, glossopharyngeus and vagus respectively, or gustatory neurones of the first order $(I)$. The secondary tracts, both ascending and descending, are marked $I I$. The tertiary path to the inferior lobe is marked $I I I$; the path to the cerebellum and valvula, iii. The return path from the inferior lobe to the motor nuclei of the oblongata (tractus lobo-bulbaris) is marked $I V$. The commissures of the inferior and superior secondary nuclei are indicated by shaded areas (the latter marked $c$ ). $n . o p$., the optic nerve. The area marked $n$.fun. includes the funicular nucleus and the inferior secondary gustatory nucleus.

the brain at the junction of the tectum opticum and cerebellum. This commissure has been described in selachians and amphibia as the decussation of the velum medullare anterius. It is obvious that it is homologous with the inferior cerebellar commissure which passes through the valvula of bony fishes. Hence it must 
be supposed that the valvula has been formed by a growth and folding inward of the velum of selachians. The cause for the growth of this large structure is to be found in the great increase in the gustatory system in ganoids and bony fishes.

In selachians a part of the secondary fibers from the visceral lobe cross to the opposite side as do the internal arcuate fibers from the cutaneous nuclei. The tertiary tract from the superior secondary gustatory nucleus goes as in bony fishes to the inferior lobes. Apparently in the more primitive brains the inferior lobes as a whole were related to both gustatory and olfactory systems (cf. Chap. XVII). The relations in selachians are taken as the basis for the general diagram of visceral sensory structures, Figure 92. Figures $\mathrm{II}_{2-\mathrm{II} 7}$ in Chapter XV may also be consulted.

The taste buds are evidently unable to persist on the surface

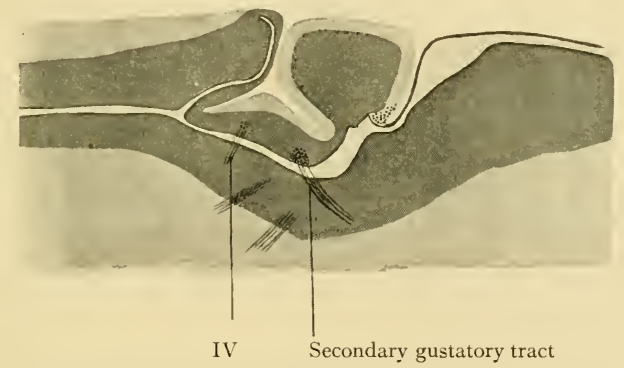

Fig. 9I.-Part of a sagittal section of the brain of a newly hatched bony fish, Catostomus, to show the relations of the secondary gustatory tract and the valvula cerebelli.

of the body in terrestrial animals, and in amphibia, reptiles, birds and mammals they are confined to the mouth cavity. Besides the great modification in structure of the gustatory system which this change entailed, a great change in function has been brought about. In primitive fishes the taste organs in mouth and pharynx detected indications of food brought by the respiratory water current. In fishes where the taste buds are situated on the surface of the body they serve to detect the presence of food, and 
frequently special organs such as the barblets about the mouth, or the fins, are richly provided with taste buds and are dragged about on the bottom or otherwise used in the active search for food. In short, the function of the taste organs of fish-like vertebrates is to detect food and to discover its location. In terrestrial animals, on the other hand, the taste organs in the mouth can rarely be used in the search for food. Their only service is to test the food after it is taken into the mouth to discover if it is desirable to eat. Terrestrial vertebrates depend chiefly on the senses of smell and sight for finding food. This explains the relatively

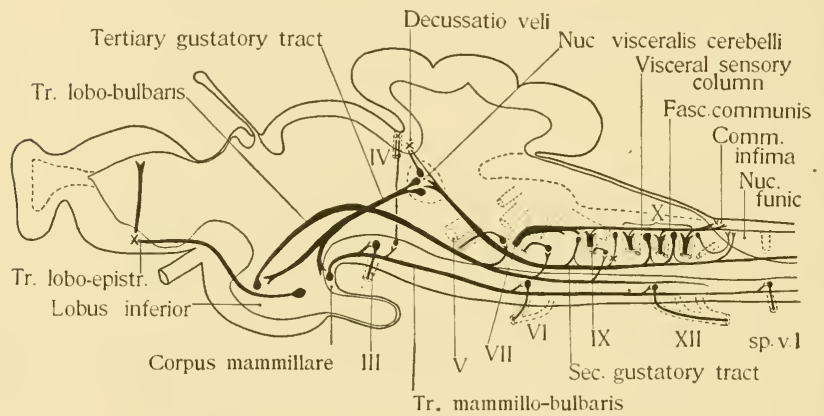

FIG. 92.-A diagram representing the centers and tracts related to the visceral sensory components in fishes.

slight importance of the sense of taste and the small size of its apparatus in higher vertebrates. At the same time, in higher vertebrates the general visceral system has been reduced in the head by the loss of the gills and more highly developed in the trunk in connection with the sympathetic system.

A comparison of the diagram for the visceral and gustatory apparatus with those for the general and special cutaneous apparatus will show how widely these divisions of the nervous system differ from one another. The student should now turn to the tabular definition of the two divisions (on p. Ior) and review this in connection with the figures in this and previous chapters. 


\section{DEMONSTRATION OR LABORATORY WORK.}

I. Review the dissections called for in Chapter V, Nos. I and 2 with reference to the visceral nerves and the visceral lobe in the brain.

2. Study the taste buds in sections of young fry of bony fishes, in frog tadpoles, and in the mammalian tongue.

3. In haematoxylin or Weigert sections of the brain of a bony fish, selachian or frog, study the sensory roots of the X, IX and VII nerves and the formation and course of the fasciculus communis.

4. Study the endings of visceral sensory fibers and the types of cells in the vagal and facial lobes in sections of the fish brain prepared by the method of Golgi.

5. The secondary and tertiary gustatory tracts and the secondary nuclei are best studied in Golgi and Weigert sections in the brains of teleosts, ganoids or selachians.

\section{LITERATURE.}

Cajal, S. R.: Beiträge zum Studium der Medulla oblongata. Leipzig. x896.

Cushing: The Taste Buds and their Independence of the N. trigeminus. Johns Hopkins Hospital Bulletin, Vol. I4. I903.

Dohrn, Anton: Studien zur Urgeschichte des Wirbelthierkörpers. No. XIII. Mitth. Zool. Sta. zu Neapel. I888.

Gaskell, W. H.: On the Structure, Distribution and Functions of the Nerves which innervate the Viscera and Vascular Systems. Jour. of Physiol., Vol. 7. I886.

Herrick, C. Judson: The Cranial Nerves and Cutaneous Sense Organs of North American Siluroid Fishes. Jour. Comp. Neur., Vol. II. Igor.

Herrick, C. Judson: The Organ and Sense of Taste in Fishes. Bull. U. S. F. C. 1902.

Herrick, C. Judson: On the Phylogeny and Morphological Position of the Terminal Buds of Fishes. Jour. Comp. Neur., Vol, I3. I903.

Herrick, C. Judson: The Central Gustatory Paths in the Brains of Bony Fishes. Jour. Comp. Neur. and Psych., Vol. 15. 1905.

Johnston, J B.: The Brain of Petromyzon. Jour. Comp. Neur., Vol. I2. I902.

Johnston, J. B.: The Cranial Nerve Components of Petromyzon. Morph. Jahrb., Bd. 34. 1905.

Johnston, J. B.: The Radix mesencephalica trigemini. Ganglion isthmi. Anat. Anz., Bd. 26. 1905.

Onuf and Collins: Experimental Researches on the Central Localization of the Sympathetic with a Critical Review of its Anatomy and Physiology. Arch. Neur. and Psychopath., Vol. 3. rgoo.

Schaffer, Jos.: Ueber das Fpithel des Kiemendarms von Ammocoetes nebst Bemerkungen über intraepitheliale Drüsen. Arch. f. mik. Anat. Bd. 45. I895. 


\section{CHAPTER X.}

\section{THE OLFACTORY APPARATUS.}

The olfactory apparatus is treated here because of the physiological relationship between it and the gustatory apparatus. Whether a morphological relationship exists or not has yet to be determined.

The peripheral organ of smell consists of a sensory epithelium situated at the extreme anterior end of the head. It arises in all vertebrates as a pair of thickenings of the ectoderm one at either side of the lower or anterior border of the neuropore. The thickenings are therefore formed from ectoderm which lies close at the border of the neural plate before it rolls up into the neural tube. While the brain and optic vesicles are developing and the secondary divisions of the brain are taking form, the two epithelial thickenings become depressed and sink into the angle between the cephalic surface of the optic vesicles and the brain, and eventually form deep pits or sacs each with an external opening. At the same time that these nasal pits are forming there appears below and between them a single invagination which has been described as the hypophysis (p. 66). The hypophysis is the remnant of the ancient mouth and in some forms still has a connection with the archenteron for a short time during development. It appears that the olfactory organ was originally situated in the roof of the mouth or in front of it. In this position the organ must have been useful both in finding and selecting food. When the hypophysis ceased to serve as mouth and a new mouth was formed from a pair of gill slits the olfactory organ was farther removed from the mouth but still in front of it. Finally, in air-breathing vertebrates the olfactory sac comes to have a connection with the pharynx and to serve as a passage for air in respiration. In this position the organ is favorably placed for detecting odors and so for finding food.

In the wall of the nasal sac a part of the cells develop into sense 
cells, the remainder act as supporting cells. The sense cells differ from those in any other sense organs of vertebrates and resemble a common type of sense cells in invertebrates. Each is a slender spindle-shaped cell from the inner end of which a nerve fiber arises and runs toward the brain (Fig. 93). The fibers grow out from the olfactory cells during development and enter the olfactory bulbs of the forebrain, where they end in a manner to be described below. These fibers constitute the olfactory nerve. They never have myelin sheaths.

The OLFACTORY CENTERS. In fishes the greater part of the forebrain is related exclusively to olfactory impulses. The primary

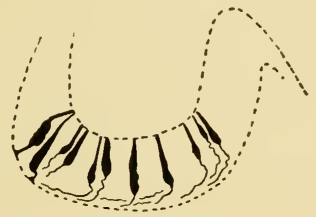

FIG. 93.-A section of the olfactory epithelium of a bony fish at the time of hatching, to show the origin of the fibers of the olfactory nerve.

center for olfactory fibers is the olfactory bulb. In cyclostomes the bulb consists of several layers of cells surrounding the ventricle and of a superficial zone of fibers (Fig. 94). Nearly all the cells are either spindle-shaped and provided with a single dendrite vertically placed in the wall of the bulb or are stellate and have two or more dendrites which run obliquely toward the surface. The final branches of the dendrites are intermingled with the end-branches of olfactory fibers near the surface of the bulb. The olfactory fibers run in bundles as they enter the bulb and as the individual fibers divide and subdivide the bundles form larger or smaller cylindrical masses of interwoven nerve fibrils. Into each of these masses the dendrites of numerous cells penetrate and so receive impulses from the olfactory fibers. The combined mass of fibers and dendrites is a glomerulus. There is noobservable difference in the relations of the various nerve cells of different sizes and shapes to these glomeruli. There is to be seen, however, the beginning of a special type of cells which come to pre- 
dominate in higher vertebrates. In the outer portion of the cell layer are seen a few cells of relatively large size whose dendrites are short and thick and more profusely branched than are those of other cells, and enter only one or two glomeruli. Although

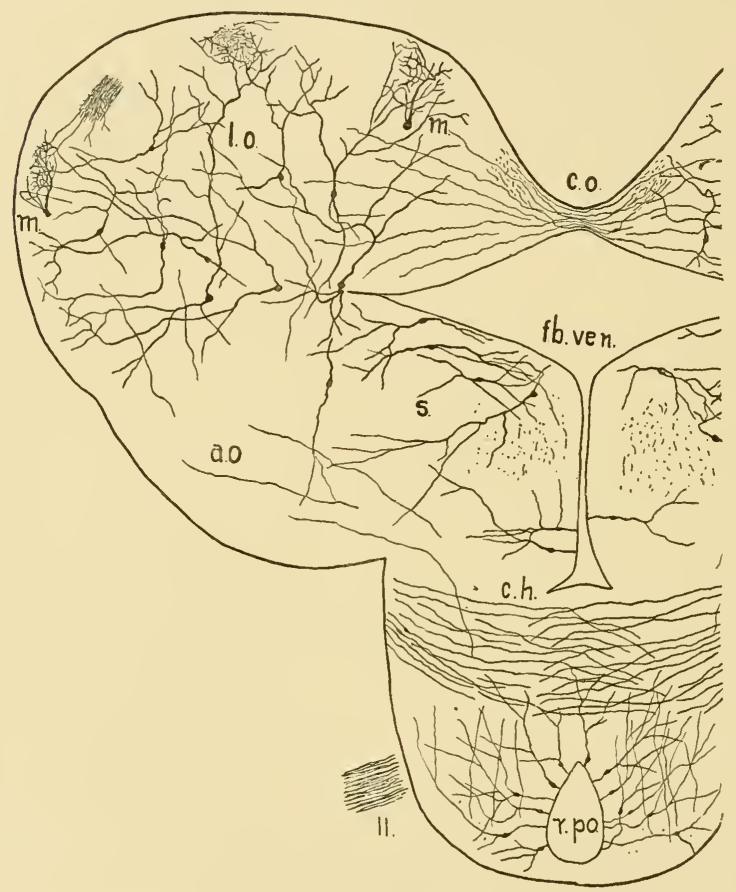

Frg. 94.-An oblique section of the forebrain of Lampetra, passing through the optic chiasma and the olfactory commissure. $a . o$, olfactory lobe; $c . h$., optic chiasma; $c . o$., olfactory commissure; $f . b$. ven., fore brain ventricle; $l$. $o$. olfactory bulb; $m$, mitral cells; $r$. po., recessus postopticus; $s$, striatum; II, optic tract.

these cells are not highly specialized in cyclostomes they can be recognized as the forerunners of the so-called mitral cells.

In true fishes and amphibia the structure of the bulb is much the same as in cyclostomes but there is a growing specialization 
among the cells. The structure of the bulb in the sturgeon, which is shown in Fig. 95, may be taken as typical for fishes and amphibia. There are a great number of stellate and spindleshaped cells which enter into functional relations with the olfactory fibers as in cyclostomes. The mitral cells also are well developed and show essentially the same character as in higher

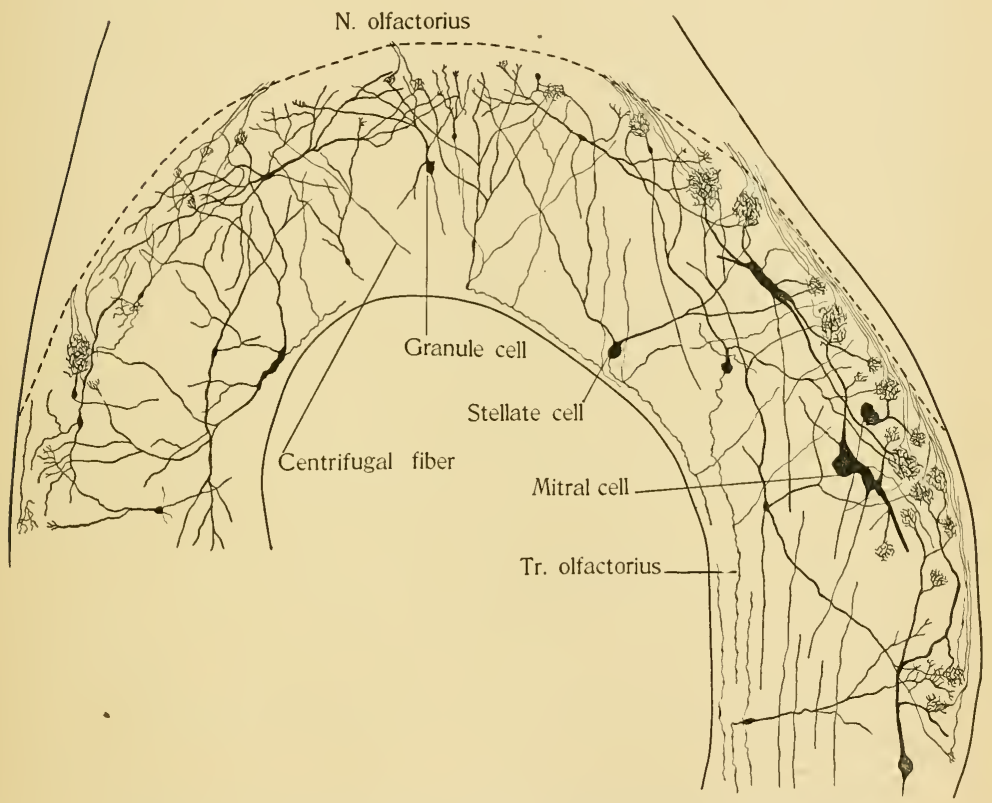

FIG. 95.-A horizontal section through the olfactory bulb of the sturgeon.

vertebrates. They are very large cells lying in the fiber zone which have thick dendrites with a comparatively small number of branches. Each of these branches enters a glomerulus where it divides into a very complex bush of end twigs. There also end in the glomerulus the branches of a number of olfactory fibers. These may subdivide repeatedly and bend back and forth, so 
that the glomerulus becomes an exceedingly complex interlacing of dendrites and olfactory fibers. The glomeruli also receive the dendrites of stellate and spindle cells (Figs. 96, 97) and some small glomeruli are formed by the dendrites of these cells alone. The transition from this to the condition found in mammals could probably be found in reptiles but has not yet been studied.

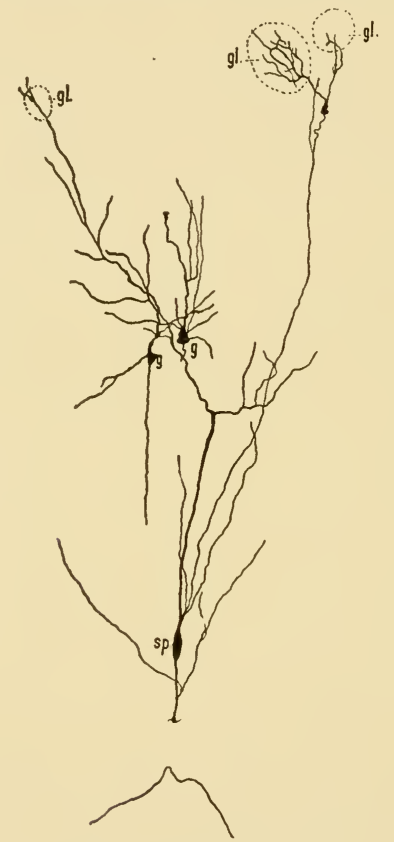

FIG. 96.-A spindle cell and two granules from the olfactory bulb of the sturgeon. $g$, granules; $g l$., glomeruli; sp., spindle cell.

In mammals the mitral cells are very highly developed and there are in addition to them numerous cells with short neurites. (Fig. 98) In the deeper parts of the bulb are a great number of small cells which seem to have no neurites, and whose dendrites rise toward the glomerular zone without entering the glomeruli. These are 
known as granule cells and probably represent the greater number of spindle and stellate cells of lower forms. It is supposed that in the course of evolution the mitral cells became predominant while the smaller and less efficient cells lost their function and now exist only as vestigeal structures, the granule cells. By some authors, however, the granule cells are described as of two kinds; one possessed of short neurites ending within the bulb, the other giving rise to excessively fine neurites which run in the olfactory tract to the forebrain nuclei. Mention must be made

\section{Olfactory fibers.}

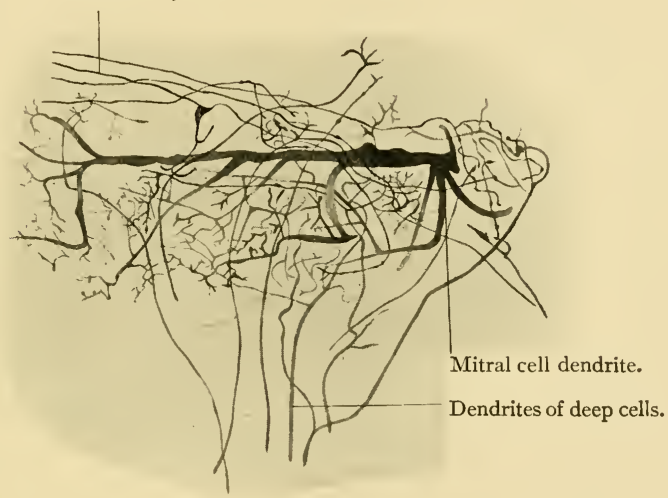

Frg. 97.-An olfactory glomerulus from the brain of the sturgeon to show the part taken by the dendrites of deep cells in forming the glomeruli.

of centrifugal fibers which come forward from the forebrain in the olfactory tract and end in the olfactory bulb. It is probable that these are commissural fibers coming from the bulb of the other side.

In all vertebrates the cells whose dendrites help to form the glomeruli send their neurites inward toward the ventricle and backward toward the forebrain, and there is no evidence that the neurites from the different types of cells have any different destinations or behavior. The whole number of fibers arising 
in the olfactory bulb (or ending in it from behind) form the olfactory tract. In many fishes and some reptiles the olfactory bulbs are drawn forward some distance from the forebrain so that the olfactory tract is a long cylindrical structure which contains a slender continuation of the forebrain ventricle. In cyclostomes, amphibia and mammals the bulb is closely applied to the fore-

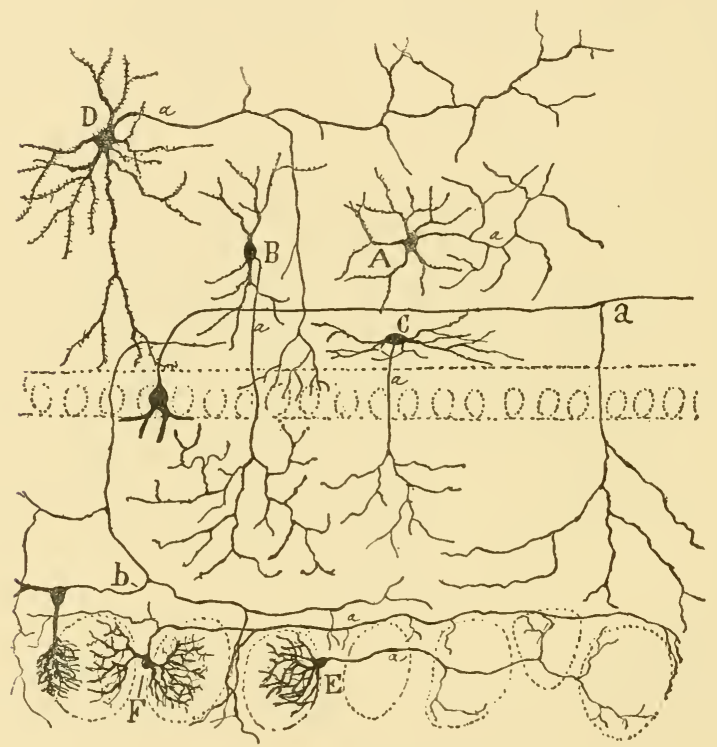

FIG. 98.-Cells with short neurites in the olfactory bulb of mammals. Schematic figure from Cajal. $A$, Golgi cell; $B$, cell with peripheral neurite; $C$, horizontal fusiform cell of the internal plexiform layer; $D$, cell with horizontal neurite; $E$ and $F$, periglc merular corpuscles; $a$, collateral of mitral cell neurite; $b$, collateral of a small brush cell.

brain so that the olfactory tract does not run for any considerable distance free from surrounding gray matter. In all cases the fibers of the olfactory tract enter one or other of several groups of cells which collectively should be called the olfactory lobe or area. 
The olfactory tract is the secondary central tract of the olfactory apparatus; the nuclei of the olfactory lobe are the secondary nuclei.

These secondary nuclei form a larger or smaller part of the forebrain in different vertebrates according to the importance of the olfactory organ. In cyclostomes the lateral lobes of the forebrain are divided by a vertical groove into anterior and posterior halves. The anterior half is the olfactory bulb; the posterior half is mostly occupied by the lobe, which is not divided into nuclei but is a continuous mass. In selachians the bulb is distinct from the lobe and a longer or shorter olfactory tract is present. The olfactory lobes occupy the anterior, the lateral and a larger or smaller part of the dorsal wall of the forebrain. The olfactory organ is very important in selachians and the large development of the olfactory centers accounts for the relatively great size of the forebrain in those fishes. In bony fishes the olfactory organ is much less important and the centers are correspondingly small, being confined to the lateral and ventral part of the forebrain. The caudo-lateral part becomes éspecially differentiated and is known as the nucleus thaeniae. In amphibia and reptiles the olfactory lobe has a similar extent. In mammals, owing to the great development of the cerebral hemispheres, the olfactory lobe is relatively very small. It includes the tuberculum olfactorium and praecommissural body occupying a small area on the ventral and mesial aspect of the hemisphere in front of the commissures, and the pyriform lobe which extends along the ventral surface of the corpus striatum at the junction with the lateral cortex.

The olfactory lobe may be divided into cephalic and lateral portions. The cephalic portion occupies the front wall of the forebrain, in front of the commissures. In lower vertebrates it includes two or more collections of cells which have been called the (median, lateral and dorsal) postolfactory nuclei. The lateral portion is an extensive nucleus covering the outer surface of the corpus striatum, a part of which is the nucleus thaeniae.

The cells of all of these nuclei are irregular stellate or spindle cells which show no definite orientation. The fibers which end in these nuclei are all olfactory tract fibers which come from the 
bulb of the same side or from that of the opposite side, crossing in the anterior commissure. The fibers which arise from the nuclei form two main tracts, the tractus olfacto-hypothalamicus and the tractus olfacto-habenularis. The fibers of the former tract arise from the cells of both portions, run backward through the lateral and ventral parts of the corpus striatum and at the junction of the forebrain and thalamus appear in a medial and a lateral bundle. These enter the diencephalon and end in the hypothalamus. The tractus olfacto-habenularis is smaller. It arises chiefly from the nucleus thaeniae and sometimes from the other olfactory nuclei including the nucleus pracopticus in the walls of the preoptic recess, and runs upward and backward through the epistriatum to the dorsal part of the diencephalon. There each tract wholly or partially crosses to the opposite side,

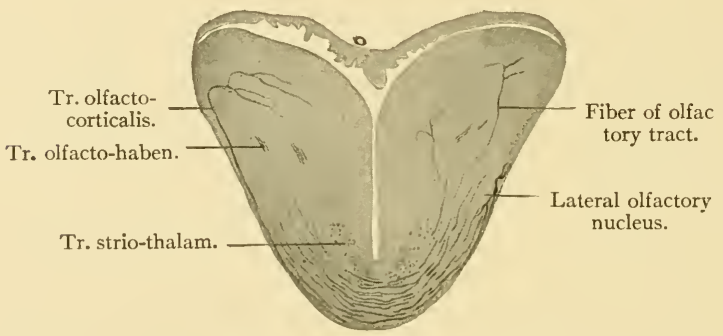

FIG. 99.-A transverse section of the brain of the sturgeon at the level of the anterior commissure.

the decussation of the two tracts forming what is known as the superior or habenular commissure. The tracts end in the nuclei habenulae. These two tracts are tertiary olfactory tracts.

Another secondary nucleus in the forebrain is to be described. The central gray matter surrounding the forebrain ventricle, bounded in front by the postolfactory nuclei and covered laterally and ventrally by the lateral olfactory nucleus and the corpus striatum, is known as the epistriatum. The epistriatum is composed of pyramidal cells arranged in rows, the cell-bodies being near the ventricle and the dendrites directed toward the surface. 
A large number of fibers of the olfactory tract which decussate in the anterior commissure end in the epistriatum. As has been mentioned. (p. I8I), the epistriatum receives also fibers from the hypothalamus, which probably in large part or wholly carry gustatory impulses. The epistriatum is thus related to both the sense organs which are concerned with the food relations of the organism. A large part of the epistriatum cells have short neurites which end in the underlying corpus striatum (Fig. 149) from which the tractus strio-thalamicus goes backward. This constitutes a third path by which olfactory impulses may reach the diencephalon. As the result of the distribution of these three tracts the greater part of the gray matter surrounding the third ventricle is brought into the service of the olfactory organ.

In selachians, where the olfactory apparatus reaches an unus-

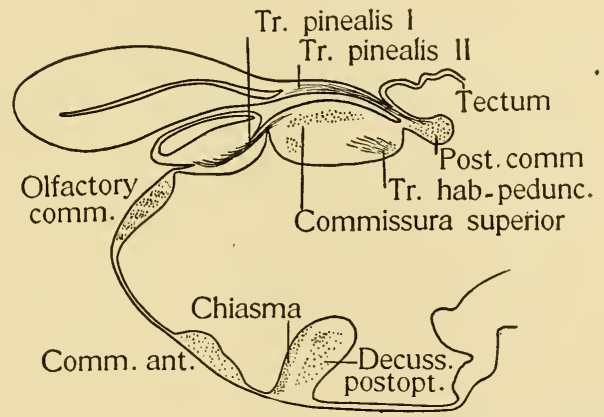

FIG. I0o.-An outline of the median sagittal section of the forebrain of Lampetra.

ually great development, the nuclei and commissures require some explanation. In all lower vertebrates the olfactory portion of the anterior commissure is more or less distinct from the portion which is formed of fibers coming forward from the hypothalamus. In Petromyzon the olfactory commissure is quite separate and is situated farther forward and upward on the front end of the forebrain (Fig. IOO). In selachians the dorsal and lateral olfactory nuclei extend up from the front and side walls to form the thick nervous roof of the forebrain which has been mentioned. No 
olfactory commissure has been seen in selachians but a large tract arises from the dorsal olfactory nucleus on either side and passes to the opposite side in the roof of the forebrain to end in the epistriatum. The decussation of these tracts seems to take the place of the larger part of the anterior commissure of other fishes, since the anterior commissure proper in selachians is very small. It should be noticed that this is a tertiary olfactory tract and that it forms a decussation and not a true commissure. In some other fishes similar fibers are found which run from the olfactory nuclei on one side through the anterior commissure to the epistriatum of the other side. The peculiarities in selachians are the large size of the olfactory nuclei and of the tertiary tract and the consequent shifting forward of this tract (cf. further Chap. XVIII).

The olfactory apparatus of fish-like vertebrates may be summarized as follows. The fibers of the olfactory nerve arise from the sense cells and end in the glomeruli of the olfactory bulb. The fibers from the cells of the bulb constitute the (secondary) olfactory tract which is distributed to the olfactory lobe and the epistriatum. A part of the fibers of the olfactory tract, including probably all those to the epistriatum, cross to the opposite side of the brain in a special part of the anterior commissure. From the nuclei of the lobe tertiary tracts go to the epistriatum through the anterior commissure, to the nuclei habenulae through the habenular commissure and to the hypothalamus for the most part without crossing. The epistriatum gives its fibers to the striatum which in turn sends a tract to the thalamus. From the thalamus and hypothalamus tracts are sent to the medulla oblongata and cerebellum where they make direct and indirect connections with the motor nuclei. From the nuclei habenulae a tract goes to the corpus interpedunculare and adjacent nuclei in the base of the mesencephalon, from which further connections with motor nuclei are-made. See Figure Ior and the figures in Chapter XVIII.

In amphibia, reptiles, birds and mammals the olfactory apparatus differs from that described for fishes chiefly in the greater development of the tertiary centers within the forebrain which constitute the olfactory cortex of the cerebral hemispheres. The 
relations and homologies can be treated best in a separate chapter dealing with the hemispheres (Chapter XVIII).

The primary relations of the olfactory apparatus to the rest of the nervous system is one of the most difficult problems before us. It has appeared in previous chapters that all the parts of the nervous system concerned with the reception of stimuliaffecting the bodily welfare of the organism in its surroundings are morphologically as well as physiologically related. The stimuli to which the sense organs respond are physical vibrations of some

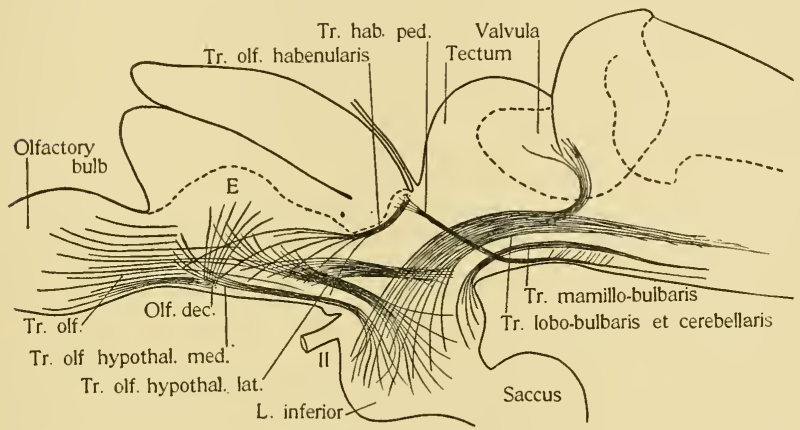

FIc. IOI.-A diagram of the olfactory conduction paths in the sturgeon. $E$, epitriatum. The tractus strio-thalamicus is not lettered. It is placed horizontally in the center of the figure.

form (changes of pressure, sound-vibrations, light-vibrations), and all of the peripheral and central organs have probably been developed out of the general cutaneous nerves and centers as a common fundament. On the other hand, the gustatory system of nerves and centers is almost inextricably bound up with the general visceral. This condition is readily understood if it be true (p. I64) that the taste buds first appeared in the entodermal lining of the pharynx to which the general visceral fibers were already distributed.

The olfactory organ is closely related in function with the gustatory. The stimuli affecting both are changes in the chemical character of the substances present in the indifferent water by 
which the organs are constantly bathed. In both cases the nerve impulse is probably aroused by the entrance into the sense cell of a small modicum of the stimulating substance. Since there is this similarity in the stimuli and in the purpose which the gustatory and olfactory organs serve, the question whether there is any morphological relation between the two becomes of considerable interest.

A direct comparison of the olfactory organ and the taste buds is impossible, for the reason that the sense cells of the olfactory organ themselves give rise to the fibers which carry their impulses to the central nervous system, while the fibers which carry taste impulses arise from ganglion cells situated in the cranial nerve ganglia. The olfactory sense cells are to be grouped together with the ganglion cells of general visceral and gustatory fibers as primary visceral receptive cells, while the rod and cone cells of the retina and the ganglion cells of the general cutaneous and acusticolateral fibers are primary somatic receptive cells. The cells of the two categories are broadly homologous, as primary receptive cells possessing neurites. The taste cells and neuromast cells are accessory sense cells without neurities. Turning to the central nervous system, a certain connection between the gustatory and olfactory apparatus is at once evident since the chief tertiary tracts of both systems enter the hypothalamus. When the structural relations of the correlating centers of the brain are examined in the following chapters, evidence will appear that all of the gustatory and olfactory centers belong to a continuous zone of the brain of which the visceral lobe in the medulla oblongata is a part. It is necessary that organs which function as visceral sensory organs should be related to the same set of central nuclei.

\section{DEMONSTRATION OR LABORATORY WORK.}

I. Study the development and histology of the olfactory organ in fish, amphibian or chick embryos by the method of Golgi.

2. Study the histology of the olfactory bulb in the brain of a fish or frog. Golgi method.

3. Study the arrangement of the secondary nuclei and tracts in dissections of the brains of a selachian and a frog and in serial sections by the Weigert and Golgi methods. 


\section{LITERATURE.}

Cajal, S. R.: Origen y terminacion de las fibras nerviosas olfactorias. Gac. san. de Barcelona. I89o.

Cajal, S. R.: Textura del sistema nervioso del Hombre y los Vertebrados. Madrid 1904. Tomo II, segunda parte.

Catois, E. H.: Recherches sur l'histologie et l'anatomie microscopique de l'encephale chez les poissons. Bull. sci. de la France et de la Belgique, Tome 36. 1901.

Disse, J.: Riechschleimhaut u. Riechnerv u. s. w. Merkel u. Bonnet's Ergebnisse, Bd. II. I901.

Edinger, L.: Untersuchungen über die vergleichende Anatomine des Gehirns. I. Das Vorderhirn. Frankfurt a. M. I888. III. Neue Studien über das Vorderhirn der Reptilien. I896.

Van Gehuchten, A.: Contribution a l'etude de la muqueuse olfactive chez les mammiferes. La Cellule, I8gr.

Goldstein, Kurt: Untersuchungen über das Vorderhirn und Zwischenhirn einiger Knochenfische, nebst einigen Beiträgen über Mittelhirn und Kleinhirn derselben. Arch. f. mik. Anat., Bd. 66. I905.

Johnston, J. B.: The Olfactory Lobes, Forebrain and Habenular Tracts of Acipenser. Z.ool. Bull., Vol. ז. I898.

Johnston, J. B.: The Brain of Petromyzon. Jour. Comp. Neur., Vol. I2. 1902.

Kappers, C. U. A.: The Structure of the Teleostean and Selachian Brain. Jour. Comp. Neur. and Psych., Vol. 16. rgo6.

Koelliker, A.: Gewebelehre. 6te Aufl., Bd. 2.

Rubashkin, W.: Ueber die Beziehungen des Nervus Trigeminus zur Riechschleimhaut. Anat. Anz., Bd. 22. 1903.

Schultze, M.: Untersuchungen über den Bau der Nasenschleimhaut, namentlich die Struktur und Endigungsweise der Geruchsnerven beim Menschen und den Wirbelthieren. Abhandl. d. Naturf. Gesellsch. zu Halle, Bd. 7. 1862 . 


\section{CHAPTER XI.}

\section{THE SOMATIC MOTOR DIVISION.}

This division of the nervous system directly controls the actions of the typical body muscles; namely, those derived from the dorsal mesoderm or somites. It would be expected that each segment of the body which has such muscles would have a pair of somatic motor nerves. Inasmuch as several somites in the occipital region degenerate in most vertebrates without producing muscle, these nerves are wanting in those segments. Somites $\mathrm{I}, 2$ and 3 produce the eye muscles and these are innervated by the cranial nerves numbered III, IV and VI. Between these and the first somatic motor nerve of the spinal or trunk region is a gap owing to the absence of a variable number of postotic myotomes. In cyclostomes, where the postotic somites all develop into myotomes, one or more nerves are absent (Petromyzon), apparently because one or two somites only partially develop. In one cyclostome (Bdellostoma) it is now known that a complete series of somatic motor nerves is present in this region, one nerve for each postotic myotome. In the adult of this animal, however, the eye muscle nerves are wholly lacking. Finally, it is to be mentioned that one rudimentary somite is known in selachians anterior to those which produce the eye muscles. It is probable that the segment to which this somite belonged possessed muscles in primitive or ancestral vertebrates. The somatic motor division is to be thought of as incomplete owing to the loss, in various segments, of the muscles which it should innervate. Otherwise this division is the simplest and least modified of the four functional divisions of the nervous system.

In the trunk region (Fig. I02) the somatic motor nerve fibers arise from the cells of the ventral horn of the spinal cord and make their exit from the ventral surface of the cord as the ventral roots of the spinal nerves. In cyclostomes these ventral nerres arise 
opposite the middle of the myotomes, pass through the membranous skeleton and divide into dorsal and ventral rami. The rami of each nerve run upon the inner face of the myotome to which they belong and twigs from them penetrate the myotome to end in relation with the muscle fibers. These ventral nerves make no connection with the dorsal nerves, which lie in the spaces between each two myotomes. In all higher classes each ventral nerve unites with an adjacent dorsal nerve to form a composite structure called a spinal nerve. The union takes place at or near the distal end of the ganglion of the dorsal nerve and the composite nerve immediately divides into dorsal and ventral rami. At

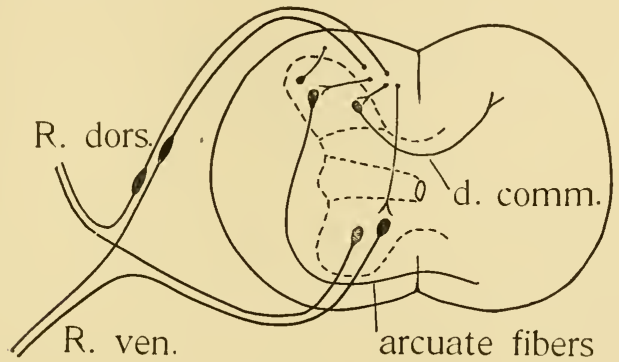

Fig. 102.-A diagrammatic representation of the somatic motor components of a trunk segment.

about the same point, or from the ventral ramus, the ramus communicans is given off to the sympathetic ganglion. (See p. 200.) In urodeles (Bardeen) where the trunk muscles have the same simple segmental arrangement as in fishes, the spinal nerve lies in a myoseptum between two muscle segments. The sensory fibers are distributed to the skin both before and behind this septum, and the motor fibers enter both the adjacent muscle segments and innervate the muscle fibers at their ends. Each nerve therefore helps to innervate two muscle segments and any muscle fiber may be innervated from two spinal nerves. These facts seem to have an important bearing on the question of metamerism in the vertebrate body and also" upon the problems of 
histogenesis of motor nerves (cf. p. 63). In higher vertebrates when the myotomes lose their simple segmental arrangement and become divided into special muscles, the relations of the nerves to the muscle segments become more obscure.

The greatest modifications affecting the ventral nerves occur in connection with the innervation of the limbs. The limbs are innervated by rami going out from plexuses formed by the union of the ventral rami of several spinal nerves. Two such plexuses are formed, the brachial for the fore limb, the lumbar plexus for the hind limb. The presence of such plexuses is explained by the mode of origin and evolution of the vertebrate limbs. The limbs first arose as folds of skin and muscle extending along the

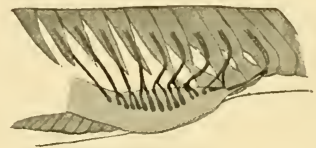

FIG. 103.-An early stage in the formation of the pectoral fin and brachial plexus in a selachian, Spinax. The muscle buds are in dark shading, the nerves in black.

side of the body. These long limb folds are formed in the embryos of lower vertebrates by outgrowths or buds from a number of myotomes together with mesenchyme (Fig. I03). The myotome buds form the muscles of the limb; the mesenchyme gives rise to the skeleton and the connective tissue into which the blood vessels and nerves grow as the development of the limb proceeds. As many nerves are involved in the innervation of the limb muscles as there are myotomes involved in the limb fold. In higher vertebrates (and in later stages in the growth of the individual), as the limb grows in length it comes to have a shorter base where it is attached to the trunk. At the same time the nerves in order to reach their muscles which have shifted out into the limb, must converge to enter the narrow base of the limb. This together with various modifications of position due to the formation of the special muscles of the limbs have caused the nerves to unite into intricate plexuses. 
The most cephalic of the ventral spinal nerves form the so-called cervical plexus. This is closely related to the brachial plexus, some nerves usually contributing to both. The rami arising from the cervical plexus go to innervate muscles extending between the pectoral girdle and the region of the tongue, commonly called the tongue musculature. This musculature is formed by buds from a number of myotomes in the cervical region, and, in vertebrates which possess gills, these muscles are separated from the dorsal muscles and from the place of origin of the nerves by the expansion and shifting backward of the gill apparatus. In consequence, the nerves destined to the tongue muscles must run around behind and forward beneath the gills. As the more

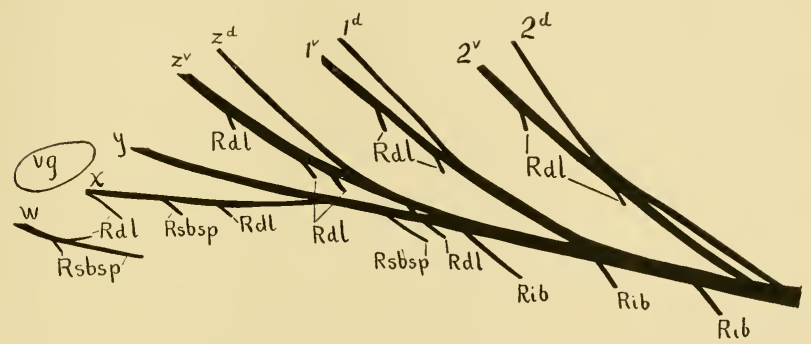

FIG. I04.-The constitution of the cervical plexus in a selachian, Hexanchus. After Fürbringer. $v g$. , vagus; $w, x, y, z$, spino-occipital nerve roots; I and 2 , spinal nerves; the letters $d$ and $v$ indicate respectively the dorsal and ventral roots; $R d l$, rami for the dorso-lateral trunk muscles; Rsbsp, rami for the subspinal muscles; $R i b$, rami for the interbasal muscles.

anterior nerves run back to get around the gills they unite with the more caudal ones and so give rise to the cervical plexus (Fig. 104). In higher vertebrates this plexus becomes somewhat modified. The anterior part of it, consisting of nerve roots arising in the occipital region and innervating the muscles of the tongue, becomes relatively independent of the plexus and is known as the hypoglossal nerve. The remainder of the plexus gives rise to rami supplying various muscles of the neck and is even connected with the spinal accessory nerve which belongs to the visceral motor system. 
The number and segmental position of the roots represented by the hypoglossus varies in different vertebrates, owing to the difference in the number of gills and to the extent caudally of the branchial apparatus. The tongue musculature arises from myotomes situated immediately behind the gills, and in fishes and higher vertebrates possessing five or four gills it is probable that one or two more anterior myotomes may enter into the tongue muscles than in forms like the cyclostomes where there are seven or more gills. In all higher vertebrates the hypoglossal roots include the first ventral roots following the eye muscle nerves. In cyclostomes, however, and to a less extent in selachians, a number of myotomes are preserved anterior to those which contribute to the tongue muscles and to supply these muscles ventral nerves are present anterior to the hypoglossal roots. In Petromyzon all the myotomes behind the ear form permanent muscles, while the first myotome to contribute to the tongue muscles is the seventh behind the ear (myotome Io). However, from one to three nerves are absent in different species of Petromyzon in spite of the presence of permanent muscles formed from their myotomes, and there remain from three to five nerves anterior to those which enter into the formation of the hypoglossus. The most anterior ventral root present in Petromyzon dorsatus belongs to the same segment as the vagus (Fig. 5I). The segment of the glossopharyngeus also has a somatic motor nerve in Bdellostoma, so that, as noted above, the series of somatic motor roots in this animal is complete from the segment of the glossopharyngeus backward.

The eye muscles are developed from the first, second and third somites. From the first somite are derived the rectus superior and inferior, the rectus internus and the obliquus inferior. From the second somite comes the obliquus superior, and from the third comes the rectus externus. The nerve which innervates the rectus externus muscle is the VI or abducens. It is the ventral motor nerve of the third somite and is comparable in every way with a ventral spinal nerve. In Petromyzon there is no VI nerve. The muscle which is usually regarded as the homologue of the rectus externus is innervated by a branch from the trigeminus ganglion 
which probably arises from the trigeminus motor nucleus. The source of the muscle--whether from dorsal or lateral mesodermis uncertain. The nerve innervating the obliquus superior muscle is the IV or trochlearis, which is the ventral nerve of somite 2. This also is comparable with a ventral spinal nerve except that its root starting from a ventral motor nucleus runs upward in the brain wall, decussates with its fellow in the roof of the brain and emerges from the dorsal or lateral surface between the cerebellum and tectum mesencephali. No satisfactory explanation has yet been found for the curious course of this nerve. The

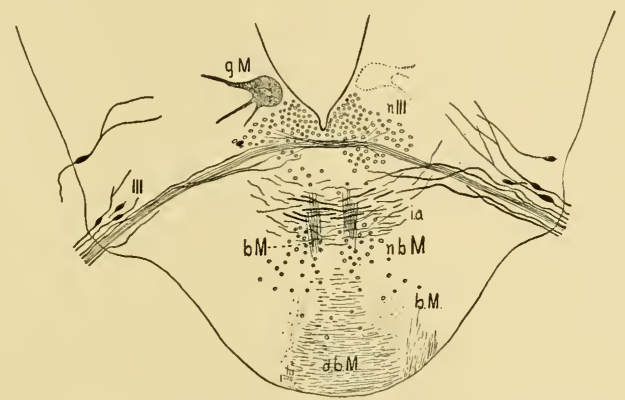

FIG. I05.-A transverse section through the nucleus of origin of the III nerve in a cyclostome, Lampetra. n.III, nucleus of III nerve; b.M., bundle of Meynert (tractus habenulo-peduncularis); $d . b . M$., decussation of the same; $n . b . M$., endnucleus of the same; g.M., one of the giant cells of Mauthner.

nerve which innervates the four muscles derived from the first somite is the III or oculomotorius, which arises from a ventral motor nucleus in the base of the mesencephalon. It is a noticeable peculiarity in the origin of this nerve that a large part of its fibers arise from the nucleus of one side and cross to enter the root of the opposite side (Fig. I05). The same arrangement is found in the roots of other ventral nerves but to a much less degree.

All the somatic motor nerves arise from a portion of the gray matter which lies latero-ventral to the central canal or ventricle. In the brain region it is usually marked by a pair of special grooves or furrows in the floor of the ventricle, one at either side of the 
mid-ventral furrow (Figs. 3, 46, etc.). The motor cells are large and have large dendrites whose branches spread widely through the latero-ventral part of the brain or cord. The neurites from the cells which lie in the immediate vicinity of a nerve root may pass out in that root, but most neurites must run forward or backward in order to reach their nerve roots. Indeed, it is probable that the neurites do not all enter the nerve root which lies nearest to their cells of origin but that many neurites run through one or more complete segments before going out of the brain or cord as fibers of a ventral nerve. The neurites which run from segment to segment lie mesial to the motor nuclei, where they run in a definite bundle at either side of the mid-ventral groove of the ventricle. The large bundle of coarse fibers in this position is known as the fasciculus longitudinalis medialis (dorsalis or posterior), and forms one of the most conspicuous landmarks in the brain of any vertebrate. This contains, however, other fibers in addition to those here mentioned. That portion of it which is made up of motor fibers on their way to become fibers of ventral nerves may be called the somatic motor fasciculus. The motor cells together with this fasciculus make up the somatic motor column or zone of the spinal cord and brain. In those segments of the brain which have no ventral nerves the somatic motor cells are wanting and the column is represented only by the somatic motor fasciculus. This fasciculus continues forward beyond the oculomotor nerve and its fibers take their origin from the cells of a special nucleus cephalad from the nucleus of the III nerve in the ventral part of the central gray of the thalamus. This nucleus is frequently considered to have some relation to the fibers of the posterior commissure (cf. p. 265 and Fig. I34, p. 272).

Owing to the importance of bodily movement in nearly all the activities of the animal, the connections of the somatic motor centers with the rest of the nervous system are numerous and varied in character. Necessarily the motor neurones form a link in every reflex chain which leads to a bodily movement, whatever the source and character of the exciting stimulus. Some of the chief classes of impulses and the tracts which bring them to the motor centers will be mentioned here. The simplest case is that 
of tactile impulses which are brought into the spinal cord by the cutaneous fibers of the dorsal roots. Collateral branches of these fibers carry the impulses directly to the motor cells. A somewhat more complex course for similar impulses is illustrated in the relations of the acusticum and cerebellum to the motor centers. Impulses from the skin, the lateral line organs and the ear are given directly or indirectly to the large cells of the acusticum and cerebellum. The neurites from a part of these cells form bundles which have been described as going down close to the ventricle, to the somatic motor column (p. I35). Such bundles have been seen in selachians going to the nucleus of each of the eye-muscle nerves. A part of the fibers enter the fasciculus longitudinalis medialis and may go to the segments of the somatic motor column in the spinal cord which control the movements of the body and limbs. A third and more complex course for such impulses is that by way of the roof of the mesencephalon (cf. p. II 7). The fibers descending from the tectum form the tractus tectobulbaris. The end branches of these fibers make direct or indirect connections with the motor centers in the medulla oblongata and spinal cord. Finally, when in a mammal or man such impulses are carried up to the cerebral cortex and give rise to a sensation, there may follow a voluntary motor impulse which descends over the fibers of the pyramidal tract and reaches the motor centers of the spinal cord. The simpler courses for tactile impulses from the cutaneous to the somatic motor nerves are indicated in Figure 59, p. I 8 . The student should construct similar diagrams to illustrate the course of impulses from the ear and the eye.

It is not yet certainly known whether visceral sensory impulses (from the general visceral surfaces, from taste organs or the olfactory organs) go directly to the somatic motor nuclei. Further study of the central gustatory apparatus may be expected to throw light on this question. Until such investigations are made it can only be said that in general the connections between the visceral sensory and somatic motor nerves are much more indirect than. those between the cutaneous and somatic motor nerves. Some of the indirect paths of taste impulses leading to somatic motor centers are shown in Figure 92, p. I74. 


\section{DEMONSTRAIION OR LABORATORY WORE.}

I. Reriem the dissections of spinal and cranial nertes alreads made. with especial reference to the position of the rentral rooss and the relation oi the rami to the muscle segments. Dissect the brachial and cervical plexuses of a selachian.

2. Eramine carefulls the somatic motur cranial nerres, noting their segmental arrangement with reiereace to the dorsal nocts and the number and position of the "hyparglossal routs" present. Selachian brains are especialls useful for this. Small roots mbich mould crdinarily he orerlooked can be broughi sharply to riem br paintirg the dissection with a oze percent. solurion of oswic acid which is well washed awar with water as soon as the nerres are blackened.

3. In sections br the Weigert or Golgi method studs the sumatic motor nuclei and the formation of the rentral roots. Selachian of irog.

4. Upou the basis of the descriptions given in previous chapters consiruci diagrams representing the course of impulses-the centers and tracts involved-in somatic motor reteres anoused br culanevus, auditory, optic and oliactory stimuli.

\section{IITERATURE.}

Bardeen. C. R. The Bimeric Distribution of the Spinal Venes in Elasmobranchii and Trodela. Amer. Tour. of Acat. Vol s Ioce

Fübritger. M.: Teber die spinowncipitalen Verren der Selachier: $\$$ w. Gegenbaur's Festatriti. Bd. 3. IN

Jobnston. I. B.: The Cracial Terte Compunents of Petromrana. Merpt. Jahrb.. Bd. 3i. ross.

KoltzoE. .. K. Entwickelungsgasuichte des Koptes ron Petnmyzon

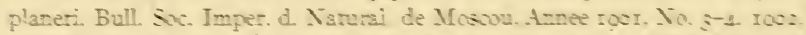

Neal. H. Y.: The Derelopment of the Hrooglosus Mustalarure in Petromyon and Squalus Anat Anz. Bd. Is. IS:

Veal. H. V: The Derelopmeer of the Ventral Veres in Selachii. I. The Spinal Nenes. Mark Anniversary Volume Ioos.

ran WTike. I. W.: Ceber die Mesdermsegmente und die Entwickelung de: Verven des Selacbierinopies Amste-dam Is:

Wothingon. Tulia: The Descrintive Anatomr of the Brain and Crazial Veres of Bdellnstoma Domberi Cuar. Jour. Mre Sci. Vol. 20. Ioc: 
CHAPTER III.

\section{THE VISCERAL EFFERENT DIVISION.}

The risceral efferent division controls the smooth muscles in the viswera and elserrhere in the batr, the muscles of the heart and blood ressels certain suriated mustes derired from the lateral mesoderm, and the glands of the bodr. In higher rertebrates at leasin the smooth muscle and flands donot receire impulses direcily from the central nerrous srstem, but the symparhetic system offers intermediate neuromes by which cerebso-spinal

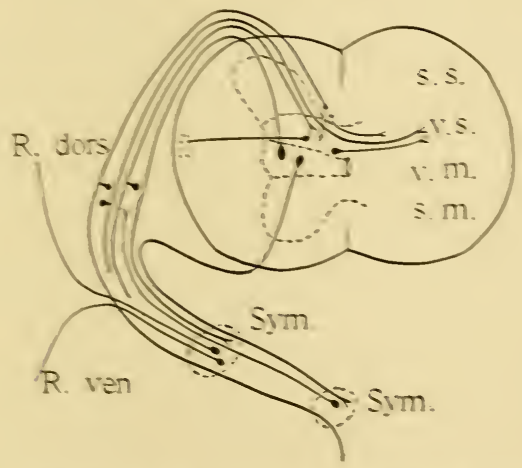

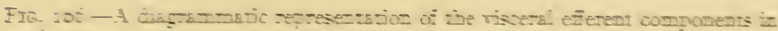
a zati sermen:

impulies are cartied sef followinz chepter. In the lower vertebra:es where the sympathetic stsiem is poodr dereloped. it is probable that some of the functions performed by it in higher forms are periormed br the risceral eferen: netres and centers. As it is not possible at present to distinguish the excito-glandular from the excito-moto: cells in the cearal zerrous sistem, the 
nuclei and nerve components may be described under the general name of visceral efferent structures.

The visceral efferent nuclei in the spinal cord occupy a position dorsal to the ventral horn, between it and the visceral afferent column (Fig. I06). The visceral efferent nuclei in the higher vertebrates and man form here a lateral projection of the gray matter known as the lateral horn. The neurites from the cells of this column pass out of the cord in the dorsal nerve roots in lower vertebrates. In higher vertebrates a part of these fibers, and in some cases all of them, pass out by way of the ventral roots. The fibers then go through the white rami communicantes into the ganglia of the sympathetic chain. Their further relations will be given in the next chapter.

In lower vertebrates the visceral efferent column of the cord is continued forward as a column in the brain constituting the nuclei of origin of the efferent roots of the X, IX, VII and V nerves. In fishes, where the voluminous musculature of the gill apparatus is to be innervated, this is a large and important column of gray matter at either side of the ventricle as far forward as the cerebellar segment. In higher vertebrates, where the gills have been lost, the column becomes less important and is divided into dorsal and ventral portions. The former is the dorsal vago-glossopharyngeal nucleus, and gives rise to efferent sympathetic fibers. The ventral portion consists of discontinuous masses known as the nucleus ambiguus, and gives rise to fibers which innervate striped muscles (Fig. I07). The neurites from the cells of this column form the visceral efferent component of the X, IX, VII and V nerves in all vertebrates. In the gill breathing forms (Figs. 5 $1,63,79$ ) these components run in the posttrematic ramus of each of the branchial nerves. This ramus runs down along the anterior side of each branchial arch and hence behind the gill slit. The fibers in question are distributed to the muscles which control the gill arches in respiratory movements. The component in the trigeminus supplies more specialized muscle in all vertebrates. In fishes this component runs in the mandibular ramus of the trigeminus which holds the same relation to the mandibular arch and mouth that the posttrematic rami of the branchial nerves hold 
to the gill arches and slits. The motor fibers of the trigeminus supply the muscles which move the mandibular arch, i.e. the chief muscles of mastication. In all gnathostome vertebrates the muscles of mastication are supplied in this way; with the exception of the posterior belly of the digastric, which is supplied by the corresponding component in the VII nerve. In higher vertebrates the motor component of the facial nerve also controls highly specialized muscles which move the skin of the face, of the

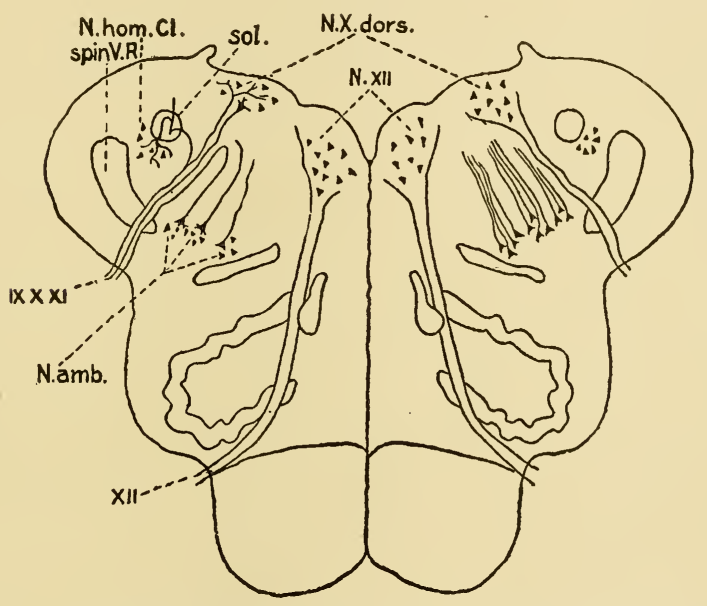

FIG. I07.-Diagram to show the central relations of the IX, X and XI nerves in mammals. From Onuf and Collins. N.X.dors., dorsal vagus or vago-glossopharyngeal nucleus, $=$ nucleus for the visceral or vegetative (sympathetic) efferent fibers; N.amb., nucleus ambiguus, = nucleus for the striped muscle innervated by the IX, X and XI nerves; sol., fasciculus solitarius; $N$.homol.Cl., nucleus homologous with Clarke's column; N.XII, nucleus of hypoglossus; spin.V.R., spinal V tract.

scalp and ears, the muscles of expression. This mode of innervation indicates that these muscles are derivatives of the branchial muscles of the hyoid segment which have spread forward to their present position, whither the motor branches of the facial nerve have followed them. This is one example of the way in which 
terms ill-adapted to the comparative description of the nervous system of vertebrates have come into use. The nerve is named the facial from the distribution of its larger branches in man, but the comparative anatomy shows that this distribution has been secondarily acquired and only in higher vertebrates. The facial nerve is really the nerve of the hyoid segment.

As in the case of the somatic motor nuclei the course of the neurites of the visceral motor cells is not always simple. Not only do the fibers run longitudinally in the brain for longer or shorter distances before going out in their nerve roots, but there have occurred shiftings of segmental relations which are at first sight difficult to understand. In the case of the trigeminus, a part of the nucleus of origin of its motor component lies in all vertebrates caudal to the root, and the fibers from this part of the nucleus run forward lateral to, or in the lateral part of, the fasciculus longitudinalis medialis to join the remainder of the root. In the case of the facialis the entire nucleus always lies caudal to the plane of exit of the root and the fibers run forward as a distinct bundle in the fasciculus longitudinalis medialis and turn laterad to form the root. In man this is known as the geniculated root of the facialis. The roots and nuclei of the IX and $\mathrm{X}$ nerves are arranged in much the same way as those of the $\mathrm{V}$ nerve. This condition is more pronounced in the vagus and the fibers do not all unite into one root but the vagus has a number of motor as well as of sensory rootlets. This is explained by the fact that the vagus has gathered into it all the branchial nerves of the segments following that of the glossopharyngeus. The roots of the more caudal branchial nerves have gradually shifted forward until they have united with that of the vagus, but the union is not complete in any class of vertebrates. In some fishes the number of rootlets approaches twenty and they are scattered for a considerable distance along the side of the medulla oblongata (Figs. $2,3,7,12)$. The fibers of the most caudal of these motor rootlets in fishes go to supply certain muscles connected with the pectoral arch which are homologized with a part of the trapezius musculature in mammals. In higher vertebrates the nuclei of these more caudal rootlets apparently extend farther back in the spinal 
cord and the roots take their exit from the dorso-lateral surface of the cord between the dorsal and ventral roots of the spinal nerves, run forward along the side of the medulla oblongata and join the trunk of the vagus (Figs. 20, 32). These roots have the name of the spinal accessory or XI cranial nerve. In mammals the nucleus and roots of this nerve extend farther caudad than in other classes, are more variable in position and show a greater tendency to a segmental arrangement and a closer relation with the dorsal roots of the spinal nerves. The more caudal roots are smaller, more nearly segmental and are placed nearer the dorsal roots (Lubosch). It seems that above the amphibia the increasing importance of the trapezius muscles have been correlated with an increase in the extent of the accessorius nucleus.

The fact that skeletal muscles important in the movements of the fore limb are innervated by nerves arising from the visceral motor column requires a word of explanation. All other muscles involved in general bodily movements are derived from the dorsal mesoderm and are innervated by nerves from the ventral motor column. A somewhat similar anomaly is seen in the muscles of mastication. Although these are derived from the lateral mesoderm and are innervated by visceral motor fibers they are voluntary muscles which move skeletal parts whose functions are much more than merely visceral functions. Although primarily all muscles derived from the lateral mesoderm may have been related solely to the walls of the alimentary canal and have been involuntary in their action, it is evident that neither of these characters are retained by all such muscles. What is found to be constant is that muscles derived from the lateral mesoderm are innervated by nerves arising from the visceral motor column. The chief question regarding the trapezius musculature, then, is how it comes to be attached to the skeleton of the arm. The only probable explanation is that the shoulder girdle or pectoral arch did not have its origin as a part of the skeleton of a limb, but existed as a branchial arch before the limb was formed. It is believed that primitive vertebrates possessed a considerably larger number of gills than are now found in most vertebrates and it is supposed that the skeleton of one or more branchial 
arches has been retained as a girdle for the attachment of the fore limb. The muscles which moved this branchial arch, or perhaps those of several arches, have in part been preserved as muscles of the limb girdle. These muscles and their nerves were of course visceral muscles and nerves like those of other branchial arches, and they have secondarily acquired somatic functions. This interpretation is supported by the following facts: (I) The position of the brachial plexus in mammals shows that the shoulder girdle has shifted backward from its primitive position. (2) The most primitive vertebrates now possess a large number of gills, as many as thirty-five (Price). (3) There are in amphibian embryos signs of gill slits extending back into the trunk region caudal to the position of the fore limb (Platt).

As pointed out in the last chapter, the somatic and visceral efferent nuclei differ in the source of the impulses which come to them and in the tracts which bring them. Tracts from higher . brain centers bring impulses to both sets of motor nuclei, but much remains to be done in order to explain the mechanisms by which somatic and visceral activities are correlated.

Collaterals from afferent visceral fibers directly to the visceral efferent nuclei are probably present in mammals (see Figs. 52 and 78 ). The short viscero-motor connections described in a previous chapter (p. I62) form a two linked chain between the visceral sensory and the visceral motor apparatus. The tertiary connections of the inferior secondary gustatory center are not known. From the superior secondary gustatory center a large tract goes to the inferior lobes of the diencephalon, from which tracts go to the cerebellum and medulla oblongata. The greater part of the tract to the medulla oblongata ends in the region of the visceral motor nuclei and it is undoubtedly chiefly these nuclei which receive the impulses. Olfactory impulses also may come over the same tract to the visceral motor nuclei. It is probable that even in fishes tracts from other correlating centers, such as the cerebellum or the mesencephalic nuclei, bring impulses to the visceral motor nuclei for the control of some of the more complex movements, especially for the coordination of somatic and visceral muscles in the act of seizing food. 


\section{DEMONSTRATION OR LABORATORY WORK.}

I. Review the dissections already made, with especial reference to the viscero-motor rami of the cranial nerves.

2. Study the spinal accessory nerve in a mammal, either by dissection or in embryos such as the pig. Compare the arrangement of the $\mathrm{X}$ and $\mathrm{XI}$ roots in a $\mathrm{I} 2 \mathrm{~mm}$. pig embryo with that in a selachian or the frog.

3. In Golgi or Weigert sections of fish or frog brain study the origin of the viscero-motor roots of the cranial nerves.

\section{LITERATURE.}

Coghill, G. E.: The Cranial Nerves of Amblystoma. Jour. Comp. Neur., Vol. 12. 1902 .

Fürbringer, M.: Spino-occipitalen Nerven der Selachier u. s. w. Gegenbaur's Festschrift, Bd. 3. I897.

Herrick, C. Judson: The Cranial and First Spinal Nerves of Menidia. Jour. Comp. Neur., Vol. 9. I899.

Johnston, J. B.: The Morphology of the Vertebrate Head, etc. Jour. Comp. Neur. and Psych., Vol. 15. 1905.

Lubosch: Vergleichend-anatomische Untersuchungen über den Ursprung und die Phylogenese des N. Accessorius Willisii. Arch. f. mik. Anat., Bd. 54. I899.

Osborn, H. F.: A Contribution to the Internal Structure of the Amphibian Brain. Jour. Morph., Vol, 2. I888.

Platt, Julia B.: Ontogenetische Differenzirung des Ektoderms in Necturus. Arch. f. mik. Anat., Bd. 43. I896.

Price, G. C.: Some Points in the Development of a Myxinoid (Bdellostoma Stouti L.) Verhdl. Anat. Ges. ro. Vers. Berlin. I8g6.

Stannius, H.: Das peripherische Nervensystem der Fische, u. s. w. Rostock. I849.

Streeter, G. L.: The Development of the Cranial and Spinal Nerves in the Occipital Region of the Human Embryo. Amer. Jour. Anat., Vol. 4. I904.

Strong, O. S.: The Cranial Nerves of Amphibia. Jour. Morph., Vol. ro. I 895 .

See also the list at the close of the following chapter. 


\section{CHAPTER XIII.}

\section{THE SYMPATHETIC SYSTEM.}

To understand the sympathetic system it is necessary to begin with the study of its development. At a time when the spinal ganglia and the dorsal and ventral nerve roots are formed there is noticed on the mesial side of the composite ventral ramus of each nerve a collection of ganglion cells which later forms the sympathetic ganglion. A stage a little earlier than this has been recognized in mammals. The beginning of the development of the sympathetic is the outgrowth of fibers from the ventral root and also from the dorsal root ganglion, in the direction of the aorta. Then . cells from the spinal ganglion are seen to migrate along these fibers. These constitute the group of cells first mentioned. As development proceeds the group of cells moves away from the spinal ganglion toward the aorta, but remains connected with the spinal nerve by the strand of fibers which grew out first. There are thus formed a pair of ganglia in each segment, lying below the notochord and lateral to the aorta, and connected with the spinal nerves by the rami communicantes. The ganglia are those known as the ganglia of the chain but at this stage they are not yet connected longitudinally into a chain.

The process of growth of fibers and the migration of cells along them continues beyond these chain ganglia and results on the one hand in joining the ganglia together by longitudinal cords, and on the other hand in the formation of additional ganglia. The cells which migrate from the chain ganglia form first certain median prevertebral ganglia or plexuses. These are in man the cardiac, solar and hypogastric plexuses. Further migration of cells carries them to or even among the tissues of several of the organs innervated by the sympathetic, where peripheral ganglia are formed. Examples of these are the small ganglia in the heart, the plexuses of Auerbach and Meissner in the wall of the digestive 
canal, etc. While the sympathetic elements are migrating in this way to their definitive positions, some of the cells of the chain ganglia and perhaps of other ganglia send fibers back along the rami communicantes into the spinal ganglia or the rami of the spinal nerves. The fibers which grow out from the spinal nerves acquire myelin sheaths and so become white fibers, and the part of each ramus communicans formed by them is known as the white ramus communicans. The fibers which grow from the sympathetic cells back into the spinal ganglion or nerve form the gray ramus communicans.

In selachians a pair of chain ganglia is formed in each segment in the trunk and for some distance into the tail. The anterior six pairs of trunk ganglia disappear during development. This Hoffmann attributes to the shifting backward of the heart and other organs with reference to the spinal column and nerves. In man the three cervical ganglia which are found in the adult are supposed to be formed by the fusion of a larger number of primary segmental ganglia of the chain. It is important to notice that there is not a complete segmental series of white rami communicantes in mammals. In the cervical segments from which the spinal accessory nerve roots take their origin there are few or no myelinated fibers in the rami communicantes, while in the segments immediately following the last root of the accessory nerve there appears suddenly a great increase in the number of such fibers. A second increase in these fibers begins at the caudal border of the brachial plexus and extends to the beginning of the lumbar plexus. The fibers of the white rami are small myelinated fibers which are excito-motor or excito-glandular in function and are in a broad way serially homologous with the efferent fibers of the vagus and spinal accessory nerves. The question of this homology will be taken up again a little later (p. 215).

The development of the sympathetic system in the head has not been well studied. Some indications as to its source can be obtained by considering the character of the cranial nerves from which it is derived, and from its structure in the most primitive vertebrates. In selachians the development of the ciliary ganglion has been repeatedly described but it is still imperfectly understood. 
It seems to be formed in part from the ganglionic anlage known as the Nervus thalamicus, and early comes into relation with the ophthalmicus and oculomotorius nerves. In the chick it is derived in part from the neural tube and in part from the most anterior portion of the ganglion of the ophthalmicus profundus nerve. The development of the other sympathetic ganglia of the head has not been directly followed. Ganglia are present in bony fishes in connection with each of the dorsal cranial nerves, from which presumably they are derived during development. As these nerves have no somatic motor component it is evident that this component does not enter into the head sympathetic. It is therefore probable that the fibers which grow out from the ventral spinal nerves to help form the sympathetic are not somatic motor fibers. Indeed, it is known from the adult structure in mammals that the fibers which go by the ventral spinal roots to the sympathetic take their origin from cells in the visceral motor column of the cord. In cyclostomes the only connections of the sympathetic with the cranial nerves are with the visceral portions of the facialis and vagus. Indeed, from what we know of the development and structure of the sympathetic system in lower vertebrates, the general conclusion must be drawn that it is an outgrowth from the visceral nerves, including efferent fibers and ganglion cells. The formation of a relatively distinct system is due primarily to the migration of ganglion cells along the primitive nerves of the riscera toward the areas supplied by them.

In describing the structure of the sympathetic system four types of nerve elements must be considered: (I) sensory fibers whose ganglion cells are in the spinal ganglia; (2) efferent fibers whose cells of origin are in the spinal cord or brain; (3) sympathetic excitatory cells; and (4) sympathetic sensory cells. The description of these elements will be more clear if Fig. I08 is consulted in connection with the text.

(I) Sensory fibers whose ganglion cells are in the spinal ganglia. These fibers are the visceral sensory fibers already described in a previous chapter ( $\mathrm{p} . \mathrm{I}_{5} 6$ ). They are the largest of the myelinated fibers running in the sympathetic nerves and may be seen to pass through one or more of the sympathetic ganglia without forming 


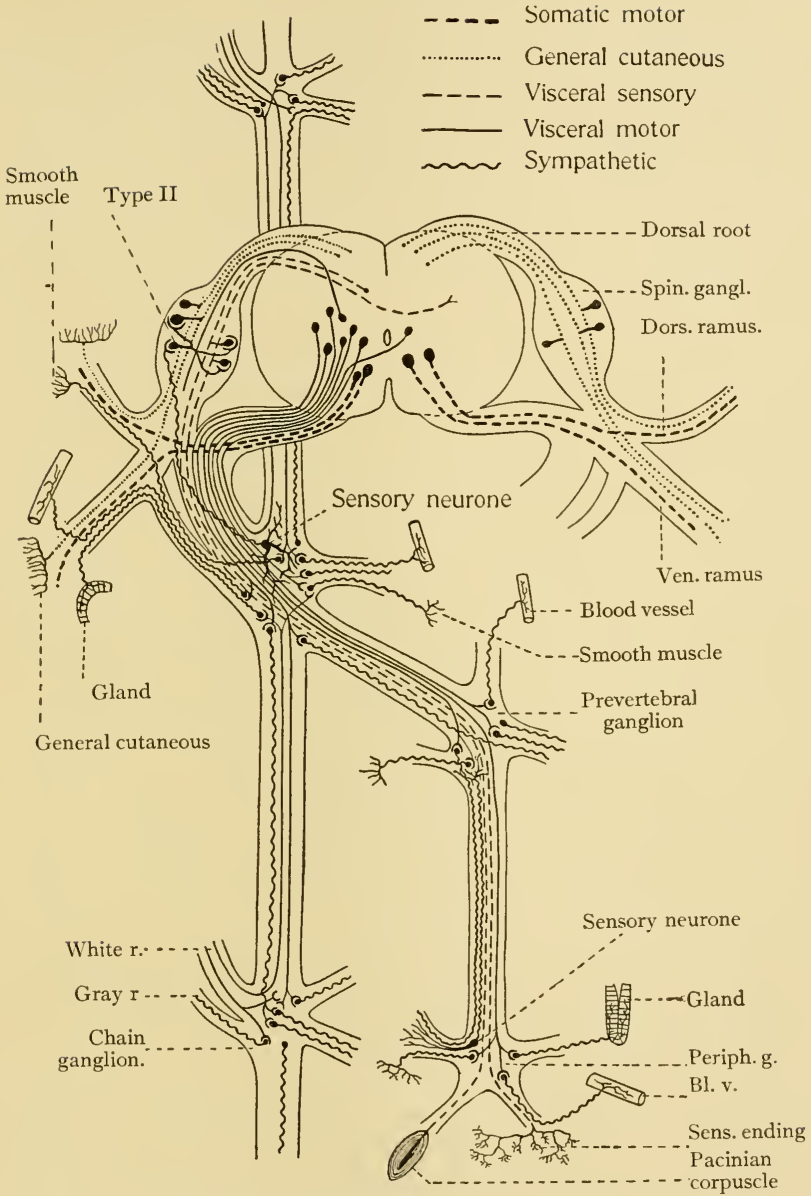

Fig. 108.-A diagram of the sympathetic system and the arrangement of its neurones in a mammal. On the left are shown the typical elements of a trunk segment including the sympathetic system. On the right are shown only the somatic afferent and efferent neurones of the spinal nerve. Of the sympathetic system are shown the white and gray rami, three ganglia of the chain, one prevertebral ganglion and one peripheral ganglion. The symbols used are explained in the figure. In most respects the diagram follows one of Huber's figures. 
any connection with the sympathetic cells. The fibers are finally distributed by widespread branches to the mucosa of the viscera. Some of these fibers also enter the Pacinian corpuscles as the fibers of those sense organs. The distribution of these fibers and their lack of histological connection with the sympathetic ganglia show that they do not belong properly to the sympathetic system. The truth is rather that they are older than the

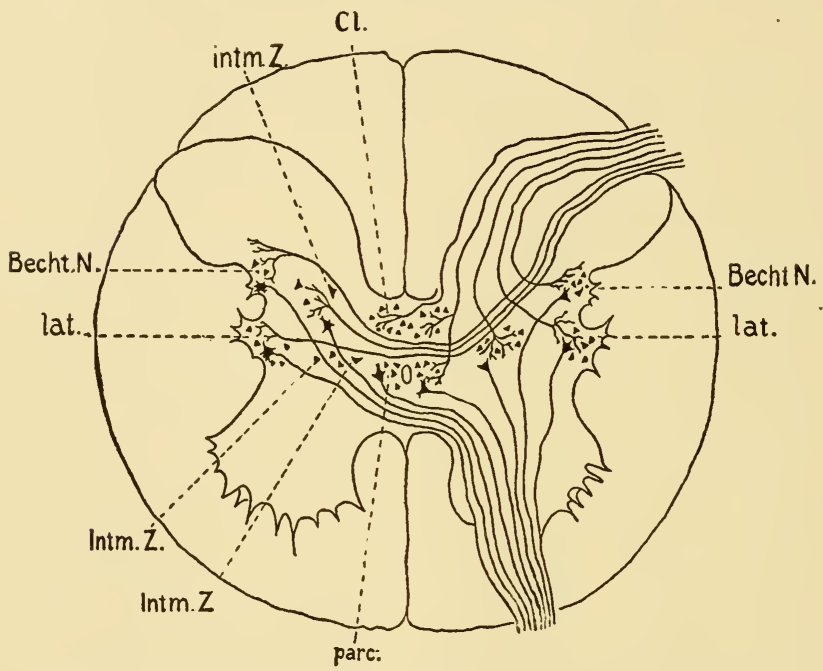

Fig. Iog.-Diagram illustrating the spinal representation of the sympathetic nerves in a mammal. From Onuf and Collins. $\mathrm{Cl}$. Clarke's column; intm. Z., intermediate zone; Becht. N., Bechterew's nucleus; lat., lateral horn cell-group; parc., paracentral cell-group.

sympathetic system and that the sympathetic ganglia are placed along the course of these primitive visceral sensory fibers. Centrally, these fibers enter the visceral sensory column of the cord or brain as already described.

(2) Efferent fibers whose cells of origin are in the spinal cord or brain. The location of the cells of origin of these fibers has been determined with accuracy in the spinal cord of the cat. As indi- 
cated in Fig. Io9 they are located in a zone of the gray matter between the dorsal and ventral horns and extending from the central canal to the lateral horn and the base of the dorsal horn. This is the portion of the gray matter which has previously been called the visceral efferent column (p. 200). As already stated, the fibers from this column in lower vertebrates pass out through the dorsal roots, but in the mammals which have been most used for the study of the sympathetic they pass out by way of the ventral roots.

The fibers are small myelinated fibers, usually less than $4 \mu$ in diameter, which enter the ganglia of the chain and find endings in relation with the cells of these or other sympathetic ganglia. They may (a) end in the chain ganglion first entered, (b) run through it to end in another ganglion of the chain, (c) end in one of the prevertebral ganglia, or (d) in one of the peripheral ganglia. During their course the fibers may give collaterals to one ganglion and pass on to end in another. The method of ending of these fibers is important. They pierce the capsule of the sympathetic cells and their branches interlace to form more or less complex plexuses or baskets immediately in contact with the sympathetic cells. By means of these pericellular baskets the impulses sent out from the central nervous system are transferred to the sympathetic excitatory cells. Such endings are found in the prevertebral and peripheral ganglia as well as in the ganglia of the chain, and it is believed that the great majority if not all of the excitatory cells of the sympathetic are thus brought under the direct influence of the central nervous system.

(3) Sympathetic excitatory cells. The sympathetic cells have in general the same forms as cells in other parts of the nervous system. They may have a single process which is a neurite, or a neurite and one dendrite, or a neurite and several dendrites. The last is the rule for the great majority of cells, at least in mammals. The cell-body is surrounded by a nucleated capsule which is pierced by the dendrites. Outside the capsule the dendrites divide and subdivide into very delicate branches which interlace with those of other cells to form a rich plexus. In most cases the dendrites end within the ganglion in which the cell lies, 
but it has been shown that occasional dendrites pass along a sympathetic nerve and reach another ganglion, in which they break up into end-branches. It appears that the dendrites of sympathetic cells play a minor part in the reception of impulses and it is not clear that either the pericellular plexuses of dendrites or the passage of dendrites from one ganglion to another has any functional significance. The neurite of the sympathetic cell arises either from the cell-body or from a dendrite and may or may not become myelinated. When it is myelinated it is so fine as still to be distinguished from the smallest fibers of cerebrospinal origin and the myelin sheath may extend for a longer or shorter part of the course of the fiber. The neurites, after a longer or shorter course in the splanchnic nerves or by way of the gray rami communicantes and one of the peripheral rami of the spinal or cranial nerves, end in (a) involuntary muscle, (b) heart muscle, (c) glands, or (d) other sympathetic ganglia. All smooth muscle, whether in the wall of the alimentary canal, in the ducts of glands, in the urinogenital system, in blood ressels, the skin or the eye is innervated by neurites from sympathetic cells. The ending is by means of simple branches often with small knobs or enlargements. The heart muscle is innervated by neurites from the cells in the intrinsic sympathetic ganglia of the heart. The endings may be more complex, somewhat like those in striated muscle. The secreting cells of glands are innervated by simple endings of sympathetic neurites which enter the glands along the ducts or blood vessels or which come from neurones situated in the glands themselves. The ending of the neurites of sympathetic cells in other sympathetic ganglia is still a matter of dispute. Histologists have described the endings of neurites upon the dendrites of sympathetic cells, but physiologists have obtained no functional evidence to corroborate the supposition that these are the endings of neurites arising from sympathetic neurones. Inasmuch as the efferent cerebro-spinal fibers are universally believed to end in the pericellular baskets within the capsules of sympathetic cells, it is probable that the endings in connection with the dendrites come from sympathetic cells and that suitable forms of experiment for determining their functions have not yet been 
devised. It is also uncertain as yet whether these fibers run from one of the chain ganglia to a more peripheral ganglion or from a more peripheral to a more proximal ganglion. The important question regarding these endings is whether the visceral excitatory chain consists of more than two links. The physiologists claim that only one sympathetic cell intervenes in any case between the efferent cerebro-spinal fiber and the muscle or gland innervated. The existence of sympathetic endings in sympathetic ganglia, if clearly established, would seem to show that in some cases two such neurones enter into the excitatory chain.

(4) Sympathetic sensory cells. Certain cells in the peripheral ganglia, as in Auerbach's plexus, have longer dendrites than those of ordinary sympathetic cells and these dendrites are supposed to be distributed to the mucosae and to serve as sensory fibers. The neurites of these cells pass through one or more sympathetic ganglia to which they give branches. These branches

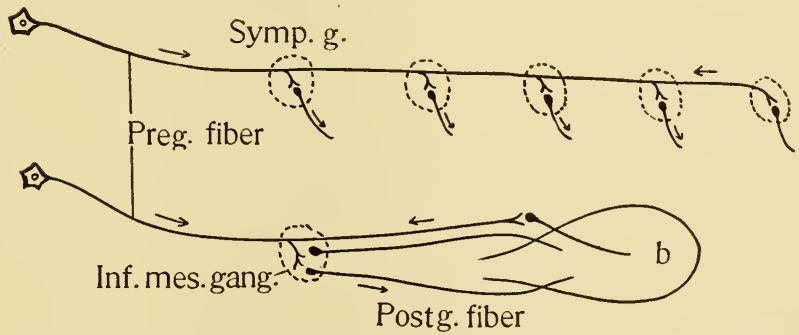

Fig. I I0.-A diagram to illustrate Langley's "axone reflex". After Langley. Preg. fiber, preganglionic fiber; Postg. fiber, postganglionic fibers; Inf. mes. gang., inferior mesenteric ganglion; $b$, bladder.

enter into the plexus of dendrites in the ganglion and may serve to arouse peripheral reflexes by stimulating the excitatory cells in the ganglion. It is stated as probable (Dogiel) that these neurites run on through the gray rami communicantes and form the pericellular endings which are known to occur in the spinal ganglia of several classes of vertebrates. These are complex endings immediately around the bodies of certain spinal ganglion cells which are described as cells of type II. These second type 
cells have neurites which break up into branches within the spinal ganglion and form pericellular baskets about the bodies of ordinary spinal ganglion cells. The functions and the structural arrangement of the sensory sympathetic cells and their supposed connection with the spinal ganglion cells require further study.

The statement is made (Onuf) that fibers which enter the visceral sensory column of the spinal cord are caused to degenerate by cutting the rami communicantes of the sympathetic. This would indicate that sensory cells situated in the sympathetic system send their neurites directly into the spinal cord. Such cells and fibers are not shown in Figure 108.

Another form of peripheral reflex has been suggested in which the branches of a single neurone only would be involved. It is supposed that an impulse may travel from a peripheral ganglion back along an efferent fiber and go out from it along a collateral to stimulate a sympathetic excitatory cell. This form of reflex . is illustrated in Figure 1 Io. It must be said that this hypothesis seems very improbable in view of what we know of the polarity of neurones in other parts of the nervous system, and that there is little direct evidence in its support.

The essential feature of the sympathetic system is that in the visceral reflexes governing smooth muscle, heart muscle and glands, there is interpolated in the efferent limb of the reflex chain a peripheral neurone between the cerebro-spinal fiber and the organ innervated. There may be two such neurones interpolated and the sympathetic may carry out peripheral reflexes without the aid of cerebro-spinal elements, but these things are still uncertain, as are also the sensory sympathetic neurones. The sympathetic system does not to any great extent carry on independent or automatic functions. The great majority of its actions are directly aroused by efferent impulses coming from the brain or spinal cord and in response to the stimulation of visceral sensory fibers which run through, but have no connection with, the sympathetic ganglia. In a strict sense the sympathetic consists solely of the neurones whose cell-bodies lie in the various ganglia, the excitatory and sensory sympathetic cells above described. The afferent and efferent neurones whose cell-bodies lie respectively in the 
cranial or spinal ganglia and in the brain or cord belong properly to the cerebro-spinal system and not to the sympathetic.

The efferent cerebro-spinal fibers which end in sympathetic ganglia were given in the last chapter (p. 200) as the visceral efferent fibers of the spinal nerves. Similar fibers occur in the cranial nerves in all vertebrates in which the sympathetic is developed in the head region. Where the head sympathetic is not developed the functions of the sympathetic, if performed at all, are probably performed by efferent visceral fibers in the cranial nerves without the intervention of peripheral neurones. There is, of course, the further alternative that there may exist peripheral ganglia which are not developed from the cranial ganglia in the typical manner. If in the lower fishes the head sympathetic is wanting there can scarcely be any sharp distinction drawn between the fibers which innervate smooth muscle and glands and those which innervate the striated muscles of the gill arches. Wherever the sympathetic is developed, however, such a distinction is very clear, since in the one case a peripheral neurone is interpolated in the reflex chain, in the other case not. The two sorts of fibers take their origin from the same zone in the brain and spinal cord but it happens that all the fibers which innervate striated muscle are confined to the cranial nerves, including the spinal accessory, while the sympathetic system extends through both head and trunk. The nuclei of origin for fibers which innervate striated muscle have probably become distinct from the nuclei of origin of sympathetic efferent fibers (see Figure 107). An explanation of this condition may be offered as follows. In primitive vertebrates all visceral muscles were presumably non-striated and the visceral reflex chain consisted of simple afferent and efferent limbs without peripheral neurones. The more active branchial muscles became striated and retained their direct innervation. For the innervation of the non-striated muscle and glands neurones migrated from the cranial and spinal ganglia and came to be interpolated in the efferent pathway. As to the morphological status of these migrated neurones of the sympathetic ganglia no sufficient explanation can at present be given. As to the sensory neurones, it would be not at all surprising that ganglion cells should migrate 
toward their innervation territory, from the spinal ganglia into the viscera, but it is just these sensory cells whose existence and arrangement are in dispute. The excitatory neurones in the sympathetic system belong to a special category. They seem to have had their origin from neural crest material, but whether as modified spinal ganglion cells or directly from indifferent ectodermal cells there is no evidence. The double origin of the ciliary ganglion in the chick is of interest in this connection.

Regardless of these unsettled theoretical questions it should be held clearly in mind that the sympathetic system is an offshoot or subsidiary portion of the visceral afferent and efferent divisions of the nervous system which has come to have a special structure and arrangement owing to the conditions of visceral activities.

\section{DEMONSTRATION OR LABORATORY WORK.}

I. Dissect the sympathetic system of a frog and a mammal.

2. Study sections of sympathetic ganglia prepared by the Golgi or methylene blue method.

\section{LITERATURE.}

Balfour, F. M.: Monograph on the Development of Elasmobranch Fishes. I 878 .

Balfour, F. M.: Comparative Embryology. Vol. 2. 1885.

Cajal, S. R.: Textura del sistema nervioso del Hombre y de los Vertebrados. Tomo II, segunda parte.

Dogiel, A. S.: Zur Frage über den feineren Bau des sympathischen Nervensystems bei den Saugethieren. Arch.f.mik.Anat., Bd. 46. 1895.

Gaskell, W. H.: On the Structure, Distribution and Function of the Nerves which innervate the Visceral and Vascular Systems. Jour. of Physiol., Vol. 7. 1886 .

Van Gehuchten, A.: Les cellules nerveuses du sympathique. La Cellule, Tome 8. I 892 .

Herrick, C. Judson: The Cranial Nerves of Menidia. Jour. Comp. Neur., Vol. 9. 1899 .

His, W., jr.: Die Entwickelung des Herznervensystems bei Wirbelthieren. Abhdl. Math.-physischen Classe d. Königl. Sächsischen Gesell.d.Wiss., Bd. 8. Leipzig. I89r.

Hoffmann, C. K.: Zur Entwickelungsgeschichte des Sympathicus. I. Die Entwickelung des Sympathicus bei den Selachiern (Acanthias vulgaris). Verhandl. K. Acad. Wetensch. Amsterdam. 1900. 2. Die Entwickelungsgeschichte des Sympathicus bei den Urodelen. lbid. Ig02. 
Huber, G. C.: Lectures on the Sympathetic Nervous System. Jour. Comp. Neur., Vol. 7. I897.

Huber, G. C.: A contribution on the Minute Anatomy of the Sympathetic Ganglia of the Different Classes of Vertebrates. Jour. Morph., Vol. I6. I8g9. Johnston, J. B.: The Cranial Nerve Components of Petromyzon. Jour. Comp. Neur. and Psych., Vol. 15. 1905.

Langley, J. N.: The Arrangement of the Sympathetic Nervous System based chiefly on Observations on Pilo-motor Nerves. Jour. of Physiol., Vol. 15. I893. Langley, J. N.: A Short Account of the Sympathetic System. Pamphlet Physiol. Congress Berne. 1895.

Langley, J. N.: The Sympathetic and other related systems of nerves. Text-book of Physiology. Edited by Schäfer. Vol. 2. I900.

Langley, J. N.: The Autonomic Nervous System. Brain. Vol. 26. I9०3. Langley, J. N.: Das Sympathische und verwandte nervöse Systeme der Wirbelthiere (autonomes nervöses System). Asher u. Spiro's Ergebnisse. II. Jahrg., II. Abtheil. I903.

Onuf and Collins: Experimental Researches on the Central Localization of the Sympathetic with a Critical Review of its Anatomy and Physiology. Arch. Neur. and Psychopath., Vol. 3. 1900. 


\section{CHAPTER XIV.}

\section{CENTERS OF CORRELATION.}

The whole nervous system has been treated thus far as consisting of four main divisions, each of which is connected with a special set of functions. For a review and summary of these functional divisions the student should turn to the outline given in Chapter V. The central portions of the functional divisions constitute four longitudinal zones of the brain and spinal cord. The four zones lie in the same relative position throughout the whole length of the central nervous system, except in certain segments of the brain where one or other zone is largely or wholly wanting. It may be supposed that the specialization of these four zones has taken place within a relatively undifferentiated neural tube which was possessed by the remote ancestors of vertebrates and that in all existing vertebrates the functional divisions are quite distinct from one another. The process of specialization of the functional divisions has left over, so to speak, a certain amount of material which has come to serve the purpose of connecting the functional divisions with one another and the centers of one segment with those of another. The elements which properly belong to the primary functional divisions as described in previous chapters may be summarized as follows. (I) In the afferent or sensory columns: (a) receptive neurones, which receive the end-branches of afferent fibers; (b) intrinsic neurones, whose neurites whether long or short are confined to the given column; and (c) extrinsic neurones, whose neurites go beyond the given column to carry impulses to other centers. These other centers are primarily located in the same column from which the neurites spring but they fall under the category of the centers of correlation which are here under consideration. The neurones (b) and (c) may both be at the same time receptive neurones. (2) In the efferent columns: motor or excito-glandular neurones whose neurites go to the periphery as fibers of efferent nerves. 
Neurones which do not properly belong to any one division are at first scattered through all four divisions and in the spinal cord this condition is maintained, so that the material in question appears as cells scattered throughout the whole gray area. These cells have come to be known as homolateral and heterolateral tract cells (Fig. III). In the brain a large part of the corresponding material is retained in its embryonic position adjacent to the ventricle. The term central gray matter has been applied to this circum-ventricular zone of cells. Since many of the cells of the primary sensory and motor centers lie in this central gray,

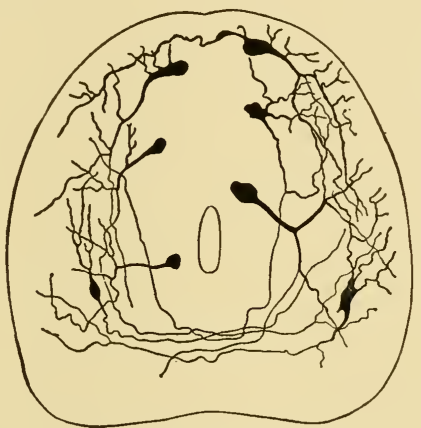

Fig. IIr.-Tract cells in the spinal cord of the trout. Combined from two figures by Van Gehuchten.

especially in lower vertebrates, it is necessary to use some other term to designate the material which serves functions of correlation. Whether these cells are situated adjacent to the ventricle or are scattered through the wall of the brain, their dendrites intermingle with the fiber tracts which form a large part of the brain wall. These areas consisting of mingled fiber tracts, cells and dendrites may be called the substantia reticularis. The portion in which the fiber tracts predominate is the substantia reticularis alba; that which is composed chiefly of cells is the substantia reticularis grisea.

The tract cells in the spinal cord illustrate best the functions which this unspecialized material first served. Since these cells 
are widely scattered through the cord, some of them may receive impulses from one source, some from another. Their neurites enter the lateral tracts of the cord and run forward or backward for a longer or shorter distance, ending in relation with motor cells. There has been observed anatomically no order or system about these cells and their fibers. They seem to offer opportunities for the wide spread of all kinds of impulses from segment to segment of the cord. The heterolateral cells add the possibility of impulses reaching the opposite side of the cord. Whether any regularity in the relations of these neurones is constant in the species and is inherited from generation to generation is unknown. It seems more probable that these neurones offer a relatively indifferent material in the embryo, providing for the diffusion of impulses from segment to segment and from one side to the other, and that definite paths for impulses are set up chiefly as the result of the experience of the individual. If impulses traveling through certain cells and fibers serve for the performance of an act efficiently, the success attending the act will lead the young child to repeat the attempt. The repetition will render the impulse-pathway more easy for succeeding impulses to follow. Thus a habitual pathway is set up, while other possible pathways offered by the indifferent tissue of the embryonic nervous system become after a time unavailable through lack of use. So in the early life of the child it is probable that certain orderly sets of connections are established by way of these indifferent tract cells by means of which complex reflexes are carried out, and the actions of two divisions of the nervous system correlated. It is indeed just this development of orderly connections in the central nervous system which is going on during and as a result of the aimless movements of the infant in the first few months of its life.

In the brain the same kind of processes have been at work but the indifferent material is proportionately greater in amount and in certain regions special brain centers have been formed. In order to understand these it is necessary to look at them from the genetic point of view, especially as regards their relations to the functional divisions. Strictly speaking, no fast line of division can be drawn between the elements of the functional divisions 
proper and these of the substantia reticularis. Not only are the neurones of the reticularis scattered throughout the four longitudinal zones, but in the brain region at least, the reticularis neurones are especially related to the functional division in which they lie. In all segments of the brain cephalad from the VII nerve one or other of the primary functional divisions is either greatly reduced or wholly wanting. Throughout this region of the brain special centers are formed which in most cases clearly lie within the bounds of one of the primary longitudinal zones. Whether neurones belonging primarily to the functional divisions have entered into the formation of special centers, and to what extent this may havehappened are questions which cannot now be decided. For the present the following practical criterion may be applied; where the structure of centers and the disposition of their tracts do not follow the typical arrangement of centers and tracts in one of the functional divisions, the centers in question are treated as centers of correlation. Since these centers are at least largely derived from the substantia reticularis it may be stated that the most fundamental difference between the brain and spinal cord is the presence in the former of a relatively larger volume of this indifferent material for the formation of correlating centers. It will be the purpose of this and the following chapters to give in a broad and general way an account of the phylogenetic history, morphology and functional relations of these special brain centers.

The reason for the use of the term centers of correlation is very simple. As has already been shown (p. 8I), simple reflexes are mediated by direct connections between sensory and motor nuclei. Even large movements of a vague and ill-directed sort may be carried out in this way. But when complex movements involving the action of many muscles directed to a definite end are called forth by a stimulus, the intervention of secondary and tertiary centers with their fiber paths is necessary for the control of the muscles as to the time, extent and force of contraction. The experiments with the brainless frog (p. 82) show that for movements of short duration up to a certain grade of complexity the tract cells of the spinal cord serve the purpose of correlating centers, but for the direction of movements for a longer period 
of time involving adjustment and readjustment of muscles with reference to some whole act destined to reach a given end, the better organized brain centers are necessary. It is the function of relating several simple actions with reference to some common end, the co-relation of activities, which these brain centers serve.

The degree of complexity of the activities controlled by the centers of correlation in various animals is directly paralleled by the complexity of the brain itself. The efforts at escape made by a normal frog when seized are much more complex and long continued than those of a frog whose brain has been destroyed. To the human observer, however, the efforts of the normal frog are very simple. The frog has no cerebral hemispheres related to somatic sensation and somatic movement. The efforts of a mammal with its cerebral cortex are enormously more complex and may involve keen observation, connected effort through relatively long periods, employment of indirect means, etc.

In the lowest vertebrates, cyclostomes, a large part of the substantia reticularis of the brain remains in its primitive indifferent condition; few special nuclei are developed and the activities of the animals are correspondingly simple. To any stimulus that may come the animal can respond only in a very limited number of ways. To two similar stimuli little or no difference in response is to be expected. In the whole hindbrain region no special nuclei in the substantia reticularis have been found. Even the secondary gustatory nuclei are so little developed that they have not yet been seen. The cerebellum is wholly unspecialized. The tectum opticum and the nucleus of the tractus habenulo-peduncularis in the mesencephalon, the nucleus habenulae, the nucleus of the posterior commissure and the inferior lobes in the diencephalon, and the striatum and epistriatum in the telencephalon probably comprise all the special nuclei at present known in the cyclostome brain. These will be considered in connection with the brain of true fishes below.

In the different classes of vertebrates the process of differentiation of many of the special centers which are well marked in the mammals is seen in various stages of completeness. In some selachians and ganoids parts of the brain are little more 
highly specialized than in cyclostomes. Other parts of the brain, however, as the olfactory centers in selachians and the gustatory centers in some bony fishes, are very largely developed and appear more complex than in other fishes. The cerebellum also is extremely large in many selachians and bony fishes. The study of these structures in those forms in which they are highly developed has led to some results which could not be so well attained from the study of any other forms. In bony fishes the development of special centers from the indifferent gray substance has gone farther than in other lower vertebrates. There has been a collecting and sorting of elements which are more diffusely placed in ganoids and selachians. This fact makes the brain of the teleost an especially rich field for the study of the centers and fiber tracts constituting the apparatus for the performance of specific functions. Since the study of less specialized brains has given the fundamental plan of structure of the vertebrate brain, the brain of the teleost should now be subjected to careful and detailed study in order to determine the early form of the central apparatus which directs known activities. Herrick has just done this for the gustatory apparatus, and it is much to be desired that the centers and fiber paths involved in other functions should be worked out in the same way. Generally speaking, any vertebrate in which any system of organs is unusually highly developed presents special opportunities for the study of the central apparatus of that system and also of the process and method of brain differentiation in general.

Although much remains to be done in the way of rendering our knowledge of the special centers and their relation to the main functional divisions complete and exact, the description of these centers will be given as far as possible in the form of an account of the functional system of neurones of which they form parts.

First there are to be mentioned a number of neurones which seem to be a vestige of invertebrate structures which are quite lost in higher vertebrates. These are the Müllerian cells and fibers of cyclostomes and the cells of Mauthner of fishes and amphibia. There are in the brain of Petromyzon over twenty gigantic cells lying in the somatic and visceral motor columns 
in the region of the cranial nerve roots. Their neurites run back into the spinal cord. In other fishes a pair of such cells lies adjacent to the motor root of the VII nerve, whose neurites cross and run back into the spinal cord. These elements remind one of the large cells and thick fibers characteristically found in the nervous system of invertebrates and the fact that they are found only in lower vertebrates and most numerous in the cyclostomes, suggests that they are very archaic elements which are not to be counted among the typical elements of the vertebrate nervous system.

In the region of the myelencephalon the substantia reticularis has on the whole the same relations as in the spinal cord. In lower vertebrates the formation of special nuclei from this material has not proceeded far, but it is probable that further study will show a tendency even in fishes for the segregation of the neurones related to somatic centers from those related to visceral centers. Especially is this to be expected in any forms in which one system, such as the acustico-lateral in selachians or the gustatory in bony fishes, is greatly developed. Indeed it seems clear that the inferior and superior secondary gustatory nuclei, which have already been described, are specially developed parts of the substantia reticularis which were primitively closely related to the visceral sensory column.

At the caudal end of the myelencephalon in fishes a collection of substantia reticularis cells about the roots of the first ventral spinal nerves (hypoglossus) forms the inferior olive. This nucleus becomes of great size and complexity in mammals but its functional relations are not yet well understood in any vertebrate.

In the ventral part of the cerebellar segment occurs a collection of several nuclei which in mammals causes the large protuberance known as the pons. These nuclei are highly developed only in the mammals, where they are related to the pyramidal tracts and the cerebellum. A part of them receive numerous collaterals and terminal branches from the pyramidal tracts and are believed to send fibers to the motor centers of the spinal cord and to the cerebellum. These pontial nuclei are thus interpolated in the direct pathway between the cerebral hemisphere and the 
spinal cord and also in the indirect path by way of the pons and the cerebellum. The mesial part of the pontial nuclei receives collaterals from the lemniscus and hence is related to the somatic sensory apparatus.

\section{DEMONSTRATION OR LABORATORY WORK.}

I. Study the tract cells of the spinal cord in Golgi sections of young fish fry, frog tadpoles or chick embryos of the fifth to eighth day of incubation.

2. Study the lower olive and pontial nuclei in Golgi sections of the brain of the mouse or other small mammal.

3. Study the tract cells of the spinal cord of a fish or amphibian and the cells and their relations to the four primary columns in the medulla oblongata.

\section{LITERATURE.}

Cajal, S. R.: Beiträge zum Studium der Medulla oblongata. Leipzig I896.

Cajal, S. R.: Textura del sistema nervioso del Hombre y de los Vertebrados. Madrid I904.

Van Gehuchten, A.: La moelle epiniere de la truite (Trutta fario). La Cellule, Tome II. I 895 . 


\section{CHAPTER XV.}

\section{THE CEREBELLUM.}

In the most primitive existing vertebrates the cerebellar segment shows little or no higher organization than any segment of the medulla oblongata. In man the cerebellum is, next to the cerebral hemispheres, the most complex part of the brain and is connected by a great number of tracts with nearly all parts of the nervous

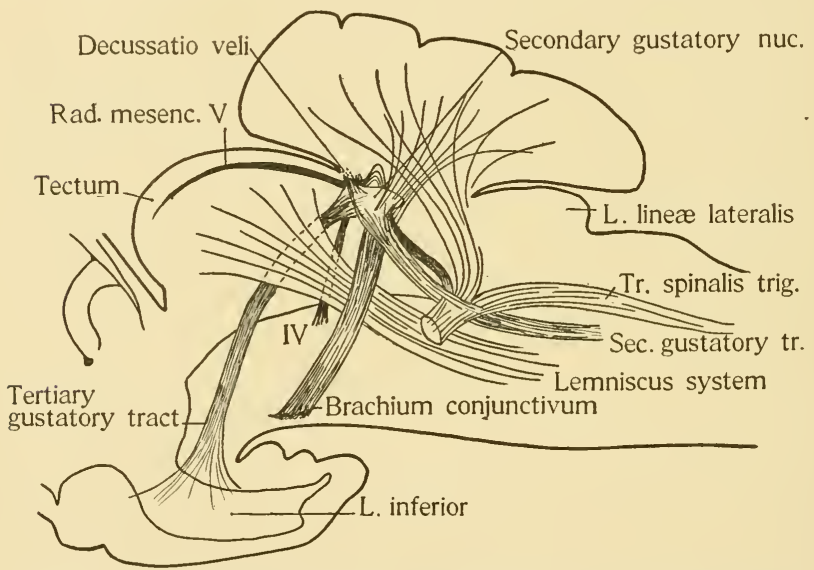

FIG. I I2.-The relations of the cerebellum, brachium conjunctivum and gustatory tracts in selachians (Scyllium). Projection upon the median sagittal plane.

system. The chief facts in the evolution of this complex organ and its relationship will be dealt with in this chapter.

In primitive vertebrates the cerebellar segment differs from those following it chiefly in the absence of visceral nerve roots and their primary sensory and motor nuclei. The dorsal part 
of the segment belongs to the somatic sensory column (cf. p. I I5) and receives general and special cutaneous nerve fibers. The cutaneous centers arch over the ventricle and are connected dorsally by a commissure. In the lateral wall, at least in true fishes, the visceral sensory column is represented by the secondary gustatory nucleus. In the ventral wall is the somatic motor nucleus of the trochlearis nerve. The central gray and the superficial zone of longitudinal fiber tracts with a decussation in the central raphe complete the structure of the cerebellar segment.

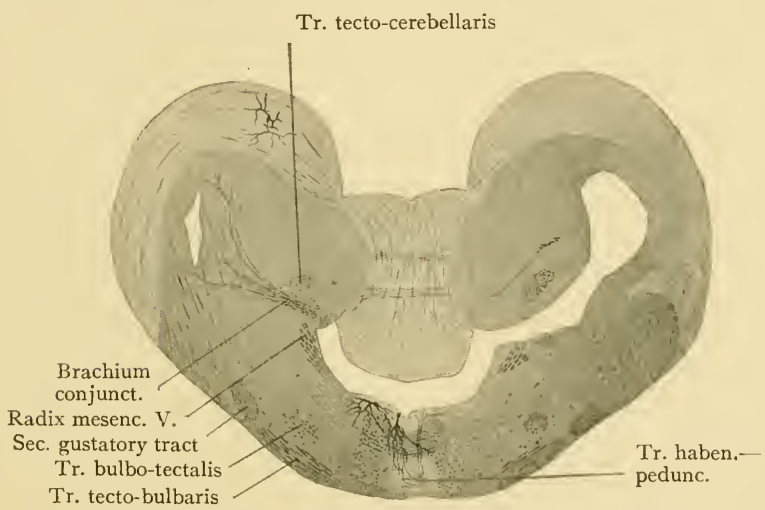

FIG. II 3.-Transverse section through the cerebellum of the sturgeon.

In cyclostomes the central gray matter presents nothing of special interest and the visceral sensory structures are as yet not studied. The somatic sensory centers consist of large and small cells. The small cells give rise to neurites of fine caliber which form a superficial fiber zone and a part of which cross to the opposite side, forming a dorsal commissure. The neurites of the large cells take the characteristic course for secondary cutaneous fibers, decussating in the ventral wall of the mesencephalon. Whether they run to the tectum mesencephali or to some other center is not certainly known. They may represent 
the fibers in the brachium conjunctivum of higher vertebrates which arise from the nucleus dentatus and run to the optic thalami.

In selachians the somatic sensory portion is greatly increased in size and complexity. It forms a large, sometimes enormous, arched and folded roof to the metencephalon, in which histological specialization has gone much farther than in the cerebellum of cyclostomes. The increased volume is due to a much greater volume of small cells and to a larger size and greater number of the large cells. The small cells constitute the granular layer and are known as granule cells. Their neurites constitute the greater part of the molecular layer and form the commissure

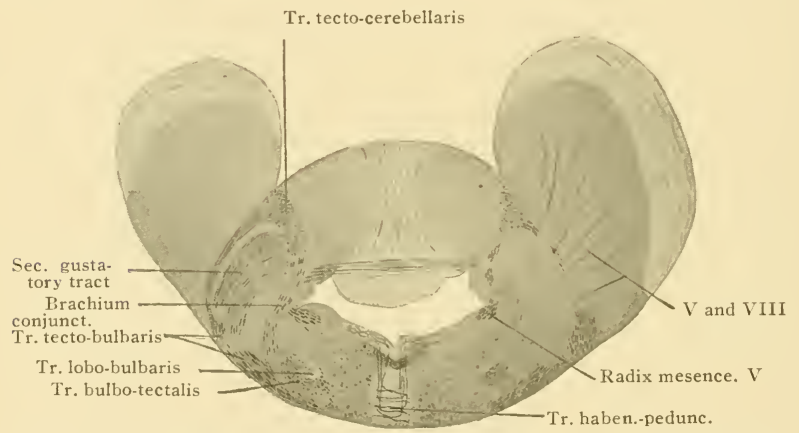

FIG. I I4.-Transverse section through the cerebellum and secondary.gustatory nucleus of the sturgeon.

of the cerebellum and the so-called cerebellar crest over the acusticum (cf. Chap. VII). The large cells are definitely arranged on the border between the granular and molecular layers and their dendrites, which expand in the molecular layer, have the characteristic appearance of Purkinje cell dendrites. This portion of the cerebellum receives in addition to somatic sensory root fibers secondary tracts from somatic sensory centers, including one from the tectum opticum. This shows that it serves both as a primary somatic sensory center and as a center of correlation for 
activities called forth by impulses from different organs of somatic sensation. A well developed brachium conjunctivum is present and probably consists in larger part of fibers arising in the cerebellum (Fig. I24, A, B).

In the lateral walls of the metencephalon in selachians lie the secondary visceral sensory nuclei (p. 172 above). These nuclei receive the secondary visceral or gustatory tracts and give rise to a commissure which crosses dorsally at the junction of the cerebellum and optic lobes, in the velum medullare anterius. This is known as the decussatio veli and lies in close relation with the decussation of the IV nerve. The secondary gustatory nucleus

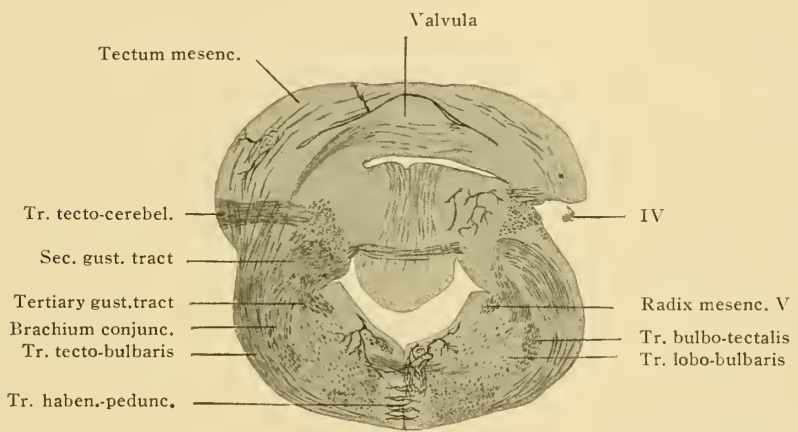

FIG. I I 5.-Transverse section of the brain of the sturgeon at the junction of the cerebellum and midbrain.

also sends a large tract forward and downward to the inferior lobe, the tertiary gustatory tract (p. I73). The arrangement of the brachium conjunctivum and the tracts related to the secondary gustatory nucleus is shown in Fig. II2.

In ganoids and bony fishes the somatic sensory portion of the metencephalon is not essentially different from that in selachians. It is not so large but the secondary tracts from other somatic sensory centers-external arcuate fibers and tractus tecto-cerebellaris-are more highly developed. The connections of the cerebellum with the secondary centers for the skin, ear and eye 
become more important relative to its primary connections than in lower fishes. The visceral nuclei (Figs. II4, II5) are situated somewhat farther ventrally and are both actually and relatively much larger than in selachians owing to the greater development of the gustatory organs. The position of the commissure between the gustatory nuclei is very different from that in selachians. Instead of lying in the roof it lies deeply imbedded in a massive median structure-the valvula cerebelli-which largely fills up the ventricle of the cerebellar and mesencephalic segments. The position of the commissure is shown in Figure 9I, which represents

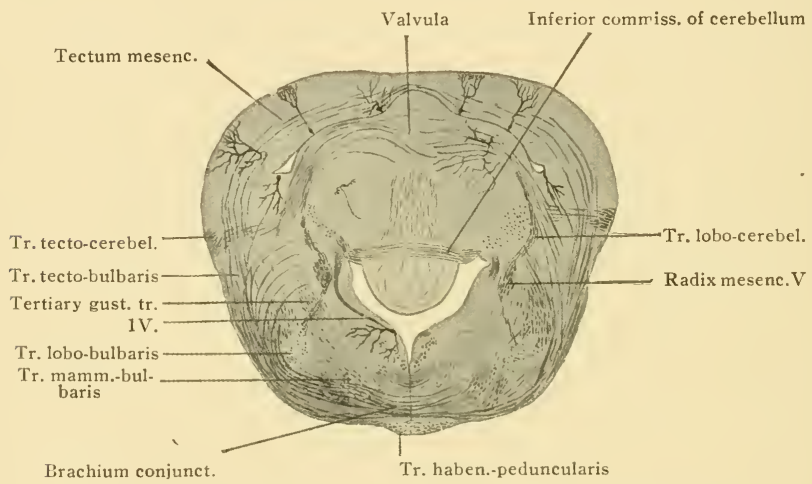

FIG. II6.-Transverse section through the midbrain of the sturgeon.

a sagittal section of the brain of a teleost a few days after hatching (see also Figs. II 5 and II6). The form of the adult cerebellum of teleosts is essentially the same as this. The place of crossing of the commissure and of the IV nerve is homologous with the velum in selachians and it is clear that the valvula has been formed by an infolding of the roof in the region of the velum. Since the structure of the valvula is essentially that of the cerebellum it may be assumed that the typical layers of the cerebellum have spread forward into the valvula. The infolding of the roof, however, came about undoubtedly on account of the great size of the second- 
ary gustatory nucleus and it is probable that the nucleus has invaded the valvula along the commissure. The dorsal limb of the valvula is thin and belongs to the tectum mesencephali. The arrangement of tracts related to the gustatory nucleus in a ganoid is shown in Figure II 7 .

The cerebellum in the higher classes of vertebrates does not continue to increase in size and complexity as it does through the several classes of fishes. On the contrary, in amphibia and reptiles it is relatively very small, owing to the comparatively

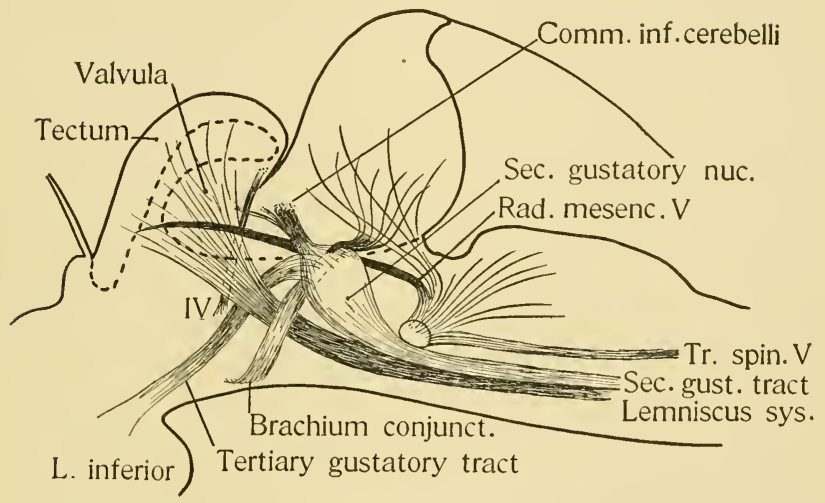

FIG. II 7.-The relations of the cerebellum, brachium conjunctivum and gustatory tracts in a ganoid fish (Acipenser). Projection on the median plane.

sluggish habits of these animals and the consequent reduction in the number of cutaneous and gustatory sense organs. The reduction of the cerebellum in amphibia as compared with selachians is chiefly a decrease in size only. The somatic sensory portion constitutes lateral lobes which are simply arched over the ventricle, not folded, but in these the typical granular and molecular layers and Purkinje cells are as clearly marked as in selachians. Similarly the secondary visceral nuclei are present in the lateral walls but no valvula is developed. The size of the cerebellum isclosely related to the degree of activity of the animals. In active forms 
such as the frog and crocodile the somatic sensory lateral lobes are greatly increased in size. This increased size is not due chiefly to a greater number of sense organs or to a richer cutaneous innervation, but to an increase in the secondary tracts from the cutaneous, auditory and optic centers to the cerebellum, and to a greater number of Purkinje cells whose fibers go to motor nuclei. In other words, the cerebellum in the more highly organized amphibia and reptiles shows an increase in the correlating mechanisms in comparison with the primary sensory apparatus.

The further steps in the development of the correlating mechanism in birds and mammals are not well understood for lack of comparative studies. A careful study of the structure and fiber

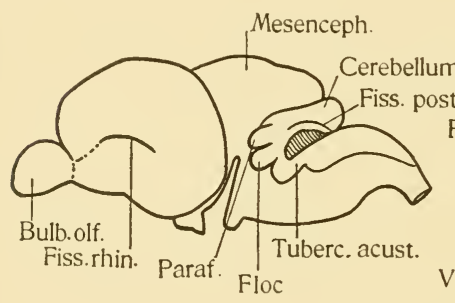

A

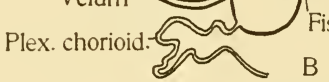

Fig. II8.-A, the left lateral aspect of the brain of a pouch specimen of Dasyurus viverrinus; $\mathrm{B}$, median sagittal section of the cerebellum of the same brain. After G. Elliot Smith. Fiss. praec., fissura praeculminis; Fiss. postn, fissura postnodularis; Fiss. sec., fissura secunda; Floc., flocculus; Parafloc., paraflocculus.

connections of the cerebellum in a series of forms including representatives of monotremes, marsupials, bats, rodents and carnivores is much needed in order to show the course of evolution of the extremely complex cerebellum of man. No connected account of this can be given at present, but it is evident that a larger number of specialized centers come into relation with the cerebellum in man than in fishes. At the same time the structure of the cerebellum itself has become more complex. This complexity of structure and of anatomical connections indicates the 
number and variety of functional relationships into which the cerebellum enters. The cerebellum has become in man a great center concerned with correlated movements in response to impulses from many sources. A brief review of the human and mammalian cerebellum will illustrate this.

In order to understand the mammalian cerebellum it is necessary first to discard the cumbersome and meaningless description of lobes and surface divisions based upon the adult appearances, which is found in text-books of anatomy. The simpler method of dividing the cerebellum based upon the developmental history is much to be preferred, but even this gains its significance only when it is combined with a consideration of the centers and tracts within. First of all must be pointed out the fallacy of the common statement that the cerebellar hemispheres of mammals are new formations, not found in sub-mammalian classes. The hemispheres are formed first. The outline of the brain of a young marsupial given in Fig. II8 shows that in these forms the cerebellar hemispheres correspond closely to those of reptiles, amphibia or even of fishes (compare Figs. 2, 3, 7). The tuberculum acusticum occupies the same position as in lower vertebrates, at the dorsal border of the medulla oblongata immediately behind the cerebellum, and in front of it the border of the cerebellar hemisphere is formed of the flocculus and paraflocculus and these are continued upward by the middle lobe as the arch of thecerebellum. In the early human embryo after the cerebellar arch has been formed by the massive walls fusing in the roof, the lateral lobes are more prominent than the middle portion and the whole cerebellum has the same form as in lower vertebrates. The vermis is formed later than the hemispheres, not earlier. So in the phylogenetic history: the lateral lobes are constant in the vertebrate series, the vermis is formed only in birds and mammals. What does happen in the higher mammals to produce a cerebellum which seems to differ greatly from that of lower vertebrates is: (I) a great growth of the median or keystone region of the arched cerebellum to form the vermis; (2) a great growth of that part of the hemispheres which lies in front of the floccular lobe, to form what is commonly known as the hemispheres; and (3) an arrest 
of growth of the flocculus and paraflocculus, together with the submersion of a part of the lateral lobes of lower vertebrates to form the nucleus dentatus.

Those portions of the cerebellum which become large and important in mammals are subdivided by variously placed fissures which are merely the result of mechanical conditions of growth and most of which are of no importance except as they may serve as land-

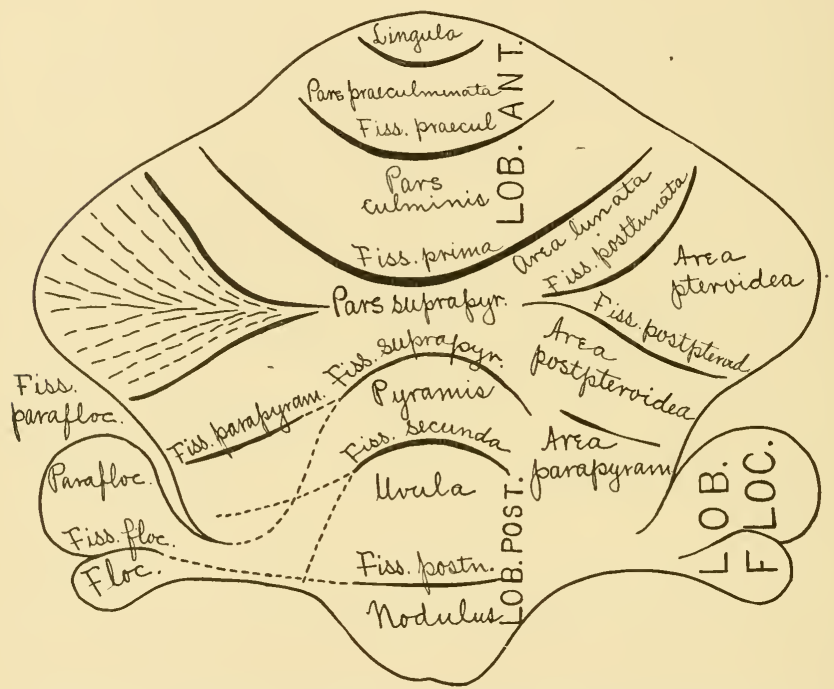

Fig. Irg.-A diagram representing the more fundamental and constant fissures of the mammalian cerebellum spread out in one plane. After G Elliot Smith.

marks in practical work. Those fissures which develop earlier in all mammals may be regarded as the more primitive and important and may be taken as the boundary lines of the chief divisions of the cerebellum. Upon this basis the cerebellum may be divided into (A) the floccular lobe, including the flocculus and paraflocculus; and (B) the rest of the cerebellum; which is subdivided 
by two transverse fissures into (a) anterior, (b) middle and (c) posterior lobes. The transverse fissures are named the fissura prima and fissura secunda. These divisions are shown in a median sagittal section of the marsupial cerebellum in Fig. II 8 and in a diagrammatic dorsal view of the higher mammalian brain in Fig. I I9. The anterior and posterior lobes do not expand laterally but are formed from the region adjacent to the middorsal line. They become divided by later fissures into subsidiary lobules which are of no importance in the present connection. The anterior lobe includes at its cephalic border the lingula which is connected by means of the valve of Vieussens with the corpora quadrigemina. This region therefore corresponds in position to the velum medullare anterius of the selachian brain and the valvula cerebelli of the brain of ganoids and teleosts. The posterior lobe includes the two transverse folds known as the uvula and nodulus, to the latter of which is attached the membranous roof of the fourth ventricle. The nodulus therefore corresponds to the meso-caudal border of the cerebellum to which the choroid plexus is attached in all vertebrates. (Compare Figs. I $8 \mathrm{~B}$ and $\mathrm{I20}$.) The middle lobe in the embryo extends laterally and connects with the extreme lateral portions which form the floccular lobe. The middle lobe is divided into a median portion or vermis and lateral lobes, each of which is further divided by subsidiary transverse fissures. The anterior lobe corresponds to the larger part of the superior vermis of anatomists, while the inferior vermis includes the posterior lobe and most of the median portion of the middle lobe.

This brief survey of the surface characters of the cerebellum gains in significance when the structure and arrangement of its deeper parts are considered. Throughout the whole cerebellum except the anterior lobe it consists of the following layers from without inward. (I) Molecular layer, consisting of (a) cells, (b) non-myelinated fibers derived from the granule cells, and (c) the dendrites of Purkinje cells. (2) Layer of Purkinje cellbodies. (3) Granular layer consisting chiefly of granule cells. (4) Layer of myelinated fibers. This layer is very voluminous and its subdivision to the various lobes gives rise to the well known arbor vitae. In the region of the anterior lobe the structure is 


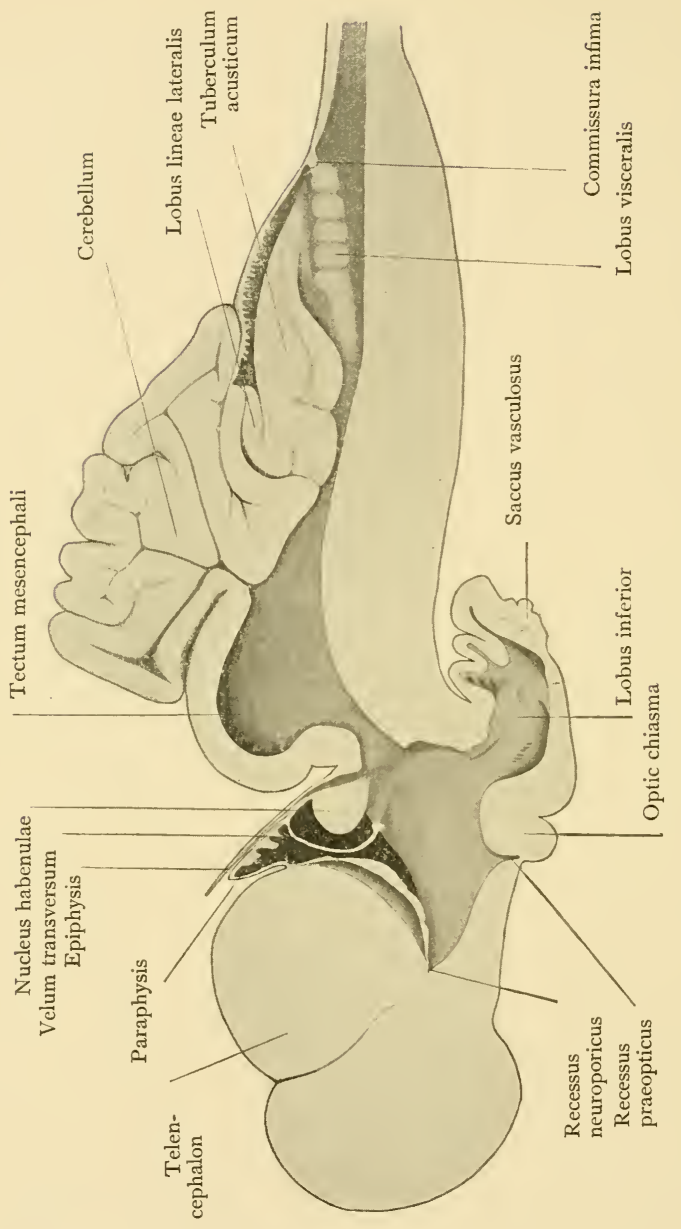

Fig. 120.-The mesial surface of the right half of the brain of Squalus acanthias. 
the same as elsewhere except that the fourth or fiber layer is largely occupied by a number of gray masses or nuclei. These gray masses form the roof of the fourth ventricle at its anterior end. In this region are recognized near the median line the paired muclei tecti or fastigii; lateral to them on either side the smaller nucleus globosus and nucleus emboliformis; and farther laterally the large mucleus dentatus which in man is convoluted like the lower olive but in lower mammals has a simple compact form. In the region of these nuclei is the commissure of the deep or white layer of the cerebellum.

The general features of the vertebrate cerebellum may now be summarized. It consists in all classes of the dorso-lateral walls of the metencephalic segment which are arched over and connected above the ventricle, where there is a commissure of molecular layer fibers. In most vertebrates the lateral walls bulge outward and forward as the auricular lobes, the floccular lobes in man. In selachians the cerebellum contains a part of the fourth ventricle which extends up into all the folds (Fig. I20). In mammals the great increase of the white layer has obliterated the cavity in the several cerebellar folds and its position is indicated only by the branches of the arbor vitae. In median sagittal section the roof of the fourth ventricle extends up into the cerebellum in the form of an inverted letter $\mathrm{V}$. The apex of the $\Lambda$ enters the base of the arbor vitae and separates the gray masses beneath the anterior lobe from the nodulus. The position of these deep gray masses and the commissure which passes through them corresponds fully to that of the velum medullare anterius and neighboring parts in selachians. The nodulus, floccular lobe and the acustic nuclei bear the same relations in mammals as do the caudal border of the cerebellum, auricular lobe and tuberculum acusticum in selachians. The mammalian vermis is formed by a great thickening of what corresponds to the mid-dorsal region of the cerebellum of any lower vertebrate. The hemispheres correspond to the dorso-cephalic wall of the lateral lobes in lower vertebrates. At the base of the lateral walls in fishes lie the secondary gustatory nuclei whose commissure crosses through the velum. In mammals in the region corresponding to the velum 
there is a deep commissure accompanied by nuclei which will be described below. In all vertebrates the cerebellum has two brachia, a posterior and an anterior. The posterior brachium contains primarily fibers belonging to both somatic and visceral sensory systems. As already described, primary root fibers of the

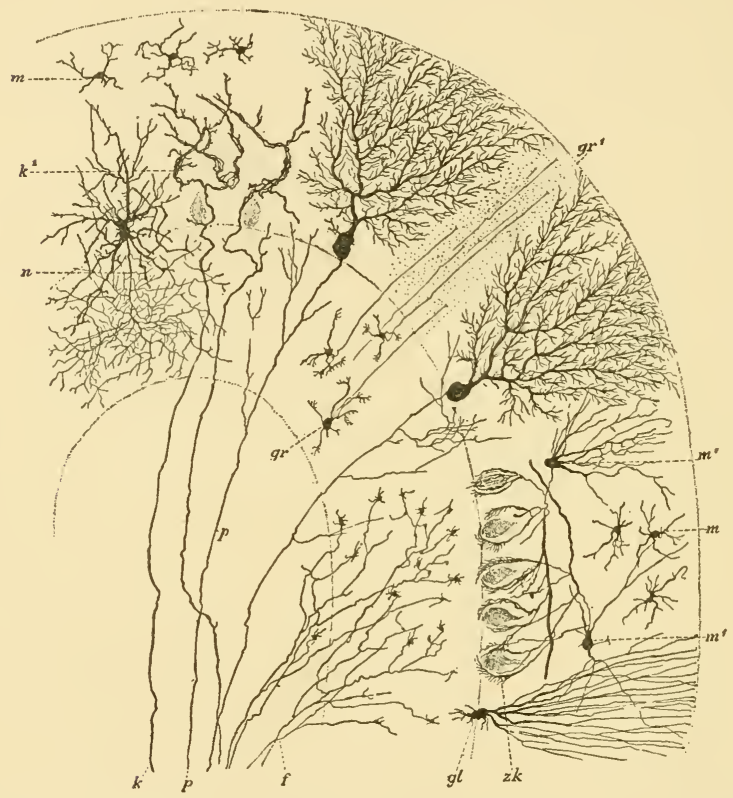

Fig. I2I.-A diagrammatic transverse section of one fold of the cerebellum. From Koelliker. f, moss fibers; $g l$, glia cells; $g r$, granules; $g r$, neurites of granules seen in the molecular layer; $k$, net-like fibers; $k^{\prime}$, endings of the same; $m$, small cells of the molecular layer; $m^{\prime}$, basket cell; $z k$, pericellular basket of the same; $n$, short neurite of large granule.

somatic sensory nerves and external arcuate (secondary sensory) fibers enter the cerebellum in all vertebrates. In lower vertebrates the secondary gustatory tract runs ventral to and parallel with the somatic sensory tracts and ends in the secondary gustatory 
nucleus. In mammals the direct cerebellar tract, which is the secondary visceral sensory tract from the spinal cord, runs lateral to the somatic sensory tracts and both are included in the corpus restiforme. The anterior brachium, brachium conjunctivum, in lower vertebrates (Figs. II2, II 7 ) runs from the lateral lobe partly through and partly beneath the secondary gustatory nucleus and passes diagonally downward and forward to the base of the mesencephalon. In mammals (Fig. 126) it is enormously larger and has made room for itself by shifting other structures to one side. In all vertebrates the anterior and posterior brachia cross one another as they enter the cerebellum like the two limbs of a letter $\mathrm{X}$, the anterior brachium passing mesially to the posterior. In mammals a third brachium is added, the brachium pontis, which goes vertically downward between the diverging anterior and posterior brachia.

Structure OF THE CEREBEllar CORTEX.-The most conspicuous elements in the cerebellum are the Purkinje cells. These differ from those in lower vertebrates chiefly in the mode and regularity of their arrangement. The cell-bodies are situated between the molecular and granular layers and the dendrites spread in the molecular layer. The arrangement is such that in any fold of the cerebellum the dendrites of each Purkinje cell spread like a fan across the fold (Fig. I2J). The dendrites are provided with small lateral spines. From the deeper end of the cell-body arises the neurite which penetrates the white layer. In the first part of its course it gives off several collateral branches which rise toward the surface and end in the granular or molecular layer. The neurites then become myelinated and proceed as constituent fibers of the white fiber layer.

The granular layer contains both granule cells and cells of Golgi's type II. The granule cells are very numerous and closely packed together and, like those of lower vertebrates, have short dendrites which end in claw-like tufts of small branches. The neurites are exceedingly fine, rise directly into the molecular layer and divide in $\mathrm{T}$-form into two branches which run parallel with the surface of the folds of the cortex. Among these fine fibers of the molecular layer are imbedded the dendrites of the Purkinje 
cells, the small spines of which apparently serve for connections with the fine fibers. The cells of the second type are much larger than the granule cells, their dendrites spread in both granular and molecular layers, and their neurites branch immediately and profusely in the granular layer.

The molecular layer contains two chief types of cells. In the deeper part of the layer are numerous cells the behavior of whose neurites has given them the name of basket cells. The neurites begin as slender fibers which grow thicker as they run parallel with the Purkinje cell layer. At intervals they give off collateral branches which run down and branch to form basket-like networks around the bodies of the Purkinje cells. Although such cells have been seen in rare cases in the cerebellum of fishes, they are not highly developed or numerous below the mammals. In the outer part of the layer are numerous small cortical cells whose neurites are short and either branch repeatedly close to the cell or have a longer or shorter horizontal course before ending.

Fiber tracts OF THE CEREBELlum.-The fibers connecting the cerebellar cortex with other parts of the brain in part arise in the cerebellum, in part end in it. Since the structure of the cortex and the arrangement of the fiber endings are everywhere the same, it follows that all three peduncles of the cerebellum carry both in-coming and out-going fibers. The in-coming fibers are of two forms: moss fibers, which bear peculiar bundles of short branches in their course and at their ends, and fibers which end by complex net-like end-branches. The moss fibers occasionally bifurcate and give off frequent collaterals, so that the terminal branches are widely distributed. The peculiar small tufts of end-branches stand in relation with the similar branches of the dendrites of the granule cells. The second kind of fibers rise through the granular layer, apply themselves to the surface of the Purkinje cell dendrites and ramify upon the branches of these dendrites (Fig. I22). There is a remarkable uniformity in the character and arrangement of the nerve cells and in-coming fibers in all parts of the cerebellar cortex in mammals. The incoming fibers in mammals are very different from those in lower vertebrates. In fishes the great majority of in-coming fibers are somatic 
sensory fibers which end in the granular layer. In mammals somatic sensory root fibers are still received from the spinal nerves by way of the dorsal funiculi and the corpus restiforme, from the vestibular nerve and from the trigeminus, but the number

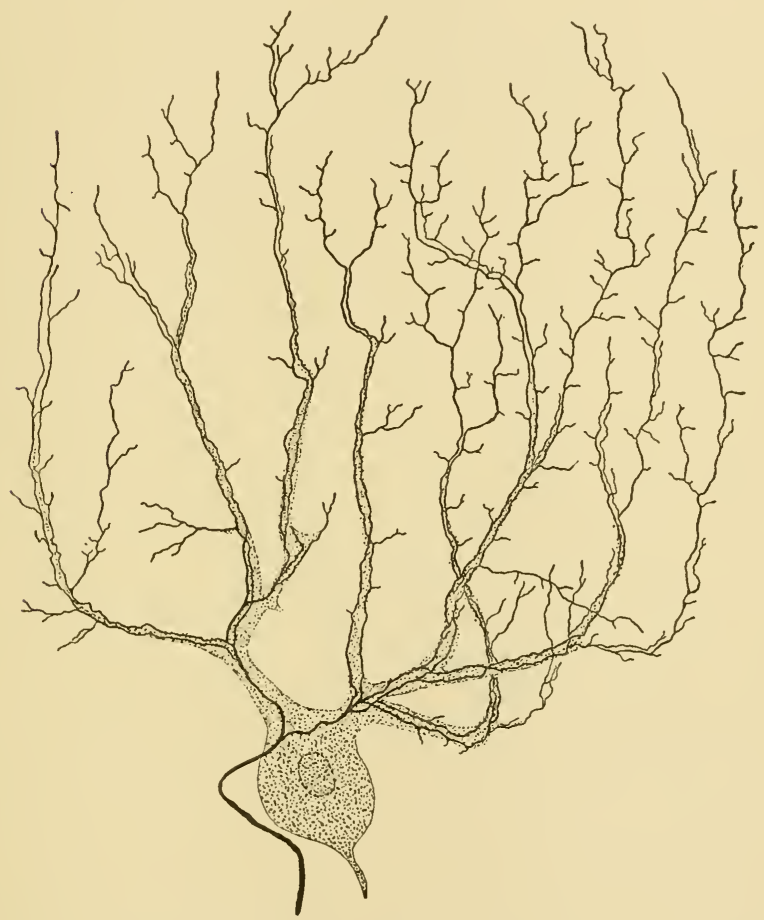

Fig. 122.-Ending of a net-like fiber in the cerebellum of man. After Cajal.

of such fibers is very small in comparison with the number of fibers coming to the cerebellum from other brain centers. In spite of this great change in the character of the incoming fibers the mode of receiving impulses in the cerebellum has remained essen- 
tially unchanged. The fibers from other brain centers have conformed to the plan of structure of the cerebellum, and deliver
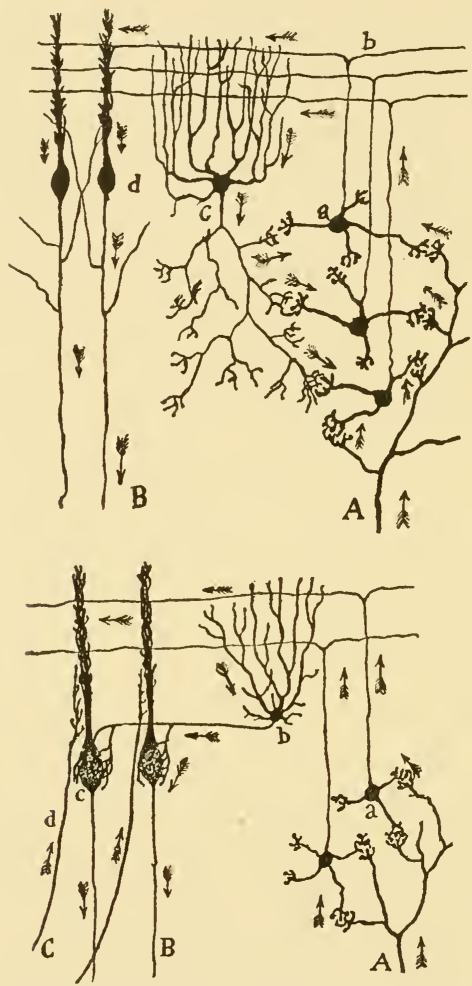

Fig. I23.-Two schemes to show the course of impulses in the cerebellar cortex. After Cajal. In the upper figure: $A$, moss fibers; $B$, neurites of Purkinje cells; $a$, granules; $b$, fibers of molecular layer; $c$, cell of type II; $d$, Purkinje cell. In the lower figure: $b$, basket cell; $c$, Purkinje cell; $d$, net-like fiber.

their impulses either to the granule cells or directly to the Purkinje cells. All impulses received by the granules are transferred to the Purkinje cells through the molecular layer, 
either directly or by means of basket cells or other cells with short neurites as indicated in the accompanying schemes (Fig. I23).

Recent experimental work on the cerebellum of the rabbit has led Van Gehuchten to the conclusion that the in-coming fibers enter the cerebellum in the corpus restiforme and brachium pontis, while the out-going fibers go by way of the brachium conjunctivum.

The fibers which enter the cerebellar cortex may be grouped under the following categories:

a. Primary somatic sensory fibers from the roots of the spinal, vestibular and trigeminal nerves.

b. Secondary somatic sensory fibers. These arise from the cells of the nuclei of the dorsal funiculi and from the superior and lateral nuclei of the vestibular nerve. The fibers from the nuclei of the funiculi run in part in the corpus restiforme of the same side, in part as external arcuate fibers in the corpus restiforme of the opposite side.

c. Fibers from the gray matter of the cord of the same and opposite side which run up in the fasciculus spino-cerebellaris ventralis (tract of Gowers) and enter the cerebellum in part by way of the brachium conjunctivum and in part by the corpus restiforme, to end in the superior vermis and hemispheres.

d. Tractus olivo-cerebellaris, from the lower olive to the cerebellar cortex.

e. Fibers from the nuclei of the pons. Some of these constitute with Purkinje cell neurites a two-linked commissure between the two hemispheres of the cerebellum. Others forward impulses which are brought to the pons from the cerebral hemispheres by way of the pyramids.

f. Fibers from the nucleus ruber to the cerebellum by way of the brachium conjunctivum (Edinger's tractus tegmento-cerebellaris). Recent researches render the existence of such fibers very doubtful.

g. Fibers from the nucleus of the lateral lemniscus and the posterior colliculus of the corpora quadrigemina. These are secondary nuclei of the auditory paths. 


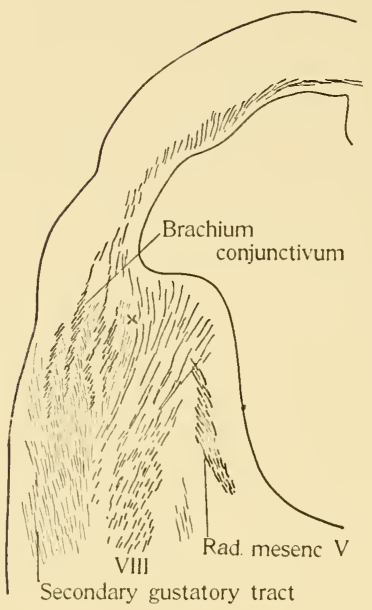

A

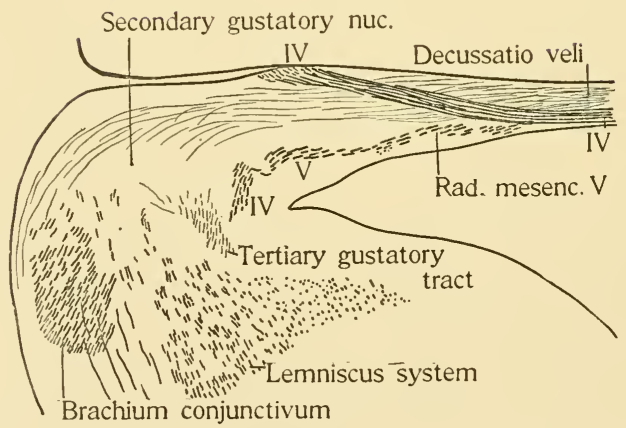

B

FIG. I24.-Two transverse sections through the cerebellum of Scyllium. A, a section at the extreme caudal end of the secondary gustatory nucleus, the position of which is marked by the cross; $\mathrm{B}$, through the secondary gustatory nucleus, the decussatio veli and the origin of the tertiary gustatory tract. The secondary gustatory nucleus lies between the brachium conjunctivum and the velum. 
h. Secondary visceral sensory fibers. These are the fibers of the direct cerebellar tract from Clarke's column in the cord. Most authors state that this tract ends in the deep gray nuclei but it is sometimes described as ending in the cortex of the vermis.

The fibers which go out from the cerebellum are all neurites of Purkinje cells. They go to the spinal cord, the lower olive, Deiter's nucleus, nuclei of the pons and perhaps to other centers. By way of these various paths the cerebellum may exercise control over both somatic and visceral motor nerves. A part of the fibers which go through the middle peduncle to the pons go directly to the spinal cord to connect with the somatic motor column. Other fibers end in the nuclei of the pons, from which fibers go to the opposite cerebellar cortex or to the cerebral cortex. Many Purkinje cell neurites may end in the nucleus dentatus, from which the large brachium conjunctivum goes to the optic thalami. By this path and the tractus thalamo-spinalis the cerebellum may gain a widespread connection with motor nerves.

There is no one fact more striking in the study of the human brain than the great complexity of structure and fiber connections of the cerebellar cortex and the great increase in the number of relationships of the cerebellum from lower to higher vertebrates. Much remains to be done, especially on the course of Purkinje cell neurites, in order to gain an exact knowledge of these relationships.

Nucleus Dentatus. - The nucleus dentatus is taken up separately from the other deep gray masses because of its apparent closer relation with the cortex. The peculiar form of the nucleus which gives it its name in man is not seen in lower mammals. In these it is a simple gray body which lies nearer to the surface of the brain and nearer the junction of the cerebellum with the medulla oblongata. The fibers which enter the nucleus dentatus are not fully understood but they seem to include external arcuate fibers from the nuclei of the dorsal funiculi, fibers from some of the nuclei of the vestibular nerve and fibers of Purkinje cells of the cortex. The neurites arising in the nucleus dentatus go mostly or wholly into the brachium conjunctivum which is composed almost exclusively of such fibers (Van Gehuchten). The 
brachium decussates in the ventral wall of the mesencephalon, passes through the nucleus ruber and ends in the optic thalami. The nucleus dentatus is concerned chiefly with somatic sensory impulses and is more closely related to the cortex than to the deep nuclei. This indicates a correspondence between this submerged and folded nucleus of the human cerebellum and the portion of

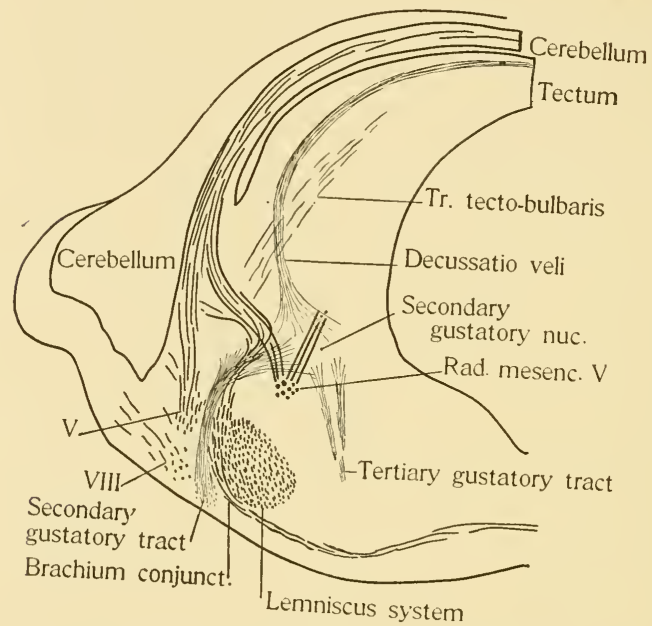

FIG. I25.-A transverse section through the cerebellum of Necturus. The figure is somewhat diagrammatic in that the whole course of the decussatio veli as drawn does not fall in the same section with the other structures. The actual section from which the outline was drawn inclined forward somewhat, so that it passed through the tectum in front of the velum. The word Cerebellum at the left is 'placed in the part of the fourth ventricle which extends into the auricular lobe.

the selachian cerebellum with which the brachium conjunctivum is connected. In selachians the brachium conjunctivum enters the latero-ventral part of the cerebellum close to the junction with the tuberculum acusticum, a region which is wholly concerned with primary sensory and external arcuate fibers. It seems probable that in the evolution of the cerebellum this nu- 
cleus has lost its superficial position and been overgrown by the greatly expanded hemispheres. The course and destination of the brachium in mammals and. Petromyzon (p. II 7 ) suggests comparison with the ascending fibers of the lemniscus system (cf. p. 258).

NUClei TECTI, GLOBOSUS AND EMBOLIFORMIS.-The fiber connections of these nuclei are not well understood. The nucleus tecti is known to receive part of the fibers of the vestibular nerve and of the external arcuate fibers from the nuclei of the dorsal funiculi. A connection between the nucleus tecti and the superior olive of the pons has been described. The conflicting descrip-

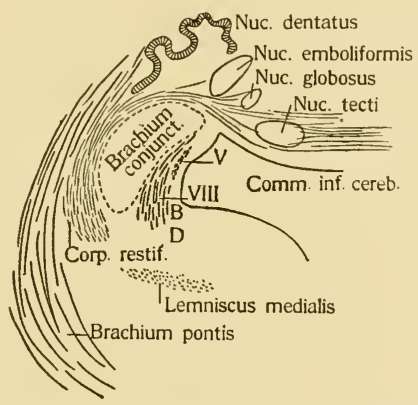

FIG. I 26.-A transverse section through the deep gray nuclei of the cerebellum of man. $V$, the radix mesancephalica $V ; V I I I$, root fibers of the vestibular nerve going to the cerebellum; $B$, the position of Bechterew's nucleus; $D$, the position of Deiter's nucleus.

tions of the direct cerebellar tract do not allow us to decide whether it is confined to the deep gray or extends also to the overlying cortex of the anterior lobe. It seems certain, however, that the nucleus globosus and nucleus emboliformis are related to this tract and that the commissure which runs through these nuclei is formed either by the fibers of this tract or by neurites arising from these nuclei. It seems probable that these nuclei may represent the secondary gustatory nucleus of the cerebellum of lower vertebrates. Nothing is certainly known about gustatory 
paths in man but it is to be expected that the gustatory nucleus will be found related to the nucleus of ending of the direct cerebellar tract (secondary visceral sensory tract).

In Figures 124, I25 and 126 are drawn transverse sections through corresponding regions in the brain of a selachian, an amphibian and man. With these may be compared Figures II 2, II5, II6 and II7. In all these forms, although they differ widely in many respects, the relations of the brachium conjunctivum mesencephalic root of $\mathrm{V}$, the primary and secondary somatic sensory tracts and the cerebellum are essentially the same. If the direct cerebellar tract has its ending in one of the deep nuclei of the cerebellum it would correspond to the gustatory tracts of lower forms. It appears that the nuclei in the roof have been pushed up from the lateral wall on account of the great size of the brachium conjunctivum. This appears the more probable if the brachium conjunctivum in mammals is related solely to the nucleus dentatus as Van Gehuchten's recent studies indicate.

The evolution of the structure and function of the cerebellum may be summarized as follows. In fishes the cerebellum consists of a large dorsal somatic sensory nucleus and of a secondary visceral (gustatory) nucleus ventral to it. The gustatory nucleus has a dorsal commissure through the cephalic border of the cerebellum. The presence of this commissure leads to extensive changes in the form of the cerebellum when the gustatory nucleus is large. Nothing further can be said regarding the visceral portion of the cerebellum until the center for the direct cerebellar tract in mammals is more fully studied and the question of its homology with the gustatory nucleus of fishes is settled.

The somatic sensory portion is not only very large in fishes but shows a higher specialization of structure than would be called for by its purely sensory function. Its great size is directly accounted for by the great development of the acustico-lateral system of sense organs. Its structure, however, differs from that of the tuberculum acusticum, which also serves as the center for the same system, in the presence of a greater number of granule cells and the higher development of the Purkinje cells. In addition, the cerebellum receives a fiber tract from the tectum opticum 
which serves to bring optic stimuli into relation with cutaneous. The cerebellum is no longer a purely cutaneous center, but impulses may be sent out from it in response to retinal stimuli also. The development of special functions has not gone far in the selachians, for removal of the cerebellum alone in the dogfish does not produce visible effects on locomotion (Bethe). In combined operations on the cerebellum and other parts of the brain, however, it is shown that the cerebellum plays some part in the coordination of movement.

With the disappearance of lateral line organs in land amphibia the cerebellum is greatly reduced in size. The reduction affects chiefly the primary sensory center, and from the amphibia onward the relations of the cerebellum with other brain centers increase. The fibers from other brain centers end chiefly in the dorso-median and cephalic regions of the cerebellum and in higher vertebrates the vermis and adjacent parts of the hemispheres are developed from these regions. Fibers come to these parts from the primary and secondary nuclei of the cutaneous, vestibular and cochlear nerves, and from the inferior olive, the nuclei of the pons and perhaps other sources. The fibers which go out from the cerebellum make direct or indirect connections with nearly the whole range of motor nuclei, probably both somatic and visceral.

It is reasonable to suppose that the presence of the somatic pallium in mammals has influenced the evolution of function of the cerebellum. In fishes and perhaps in amphibia and reptiles the cerebellum and the roof of the mesencephalon share between them the functions of higher centers to which somatic sensory impulses of the second and third orders are sent and from which impulses go out to control complex motor responses. In mammals these impulses are carried to the neopallium, which has taken on the direction of all voluntary movement. What then is the function of the cerebellar cortex? Disease of the cerebellum in man and its extirpation in animals always resultsindisturbances of voluntary muscular action. Animals from which one hemisphere or the whole cerebellum has been removed are unable to stand or walk until they have learned to make compensatory efforts. Does the cerebellum have the special function of main- 
taining the equilibrium, or is it necessary for the coordination of muscular contractions with reference to definite movements? In the results of experimental investigations on mammals the function of the cerebellum which stands out most prominently is different from either of these. Dogs which have lost one cerebellar hemisphere, although they are unable to stand or walk, can swim well in water (which supports their body weight), both coordinating their movements and maintaining their equilibrium. Such animals learn after a time to compensate for the loss of the cerebellum by certain voluntary modifications of their movements; e.g., curving the spine so as to bring the center of gravity over the sound legs, spreading the feet wide apart, etc. They can then stand and walk. These and other facts show that the loss of the cerebellum does not involve loss of the power of equilibration nor of cutaneous or muscle sense on which the power of coordinated movements depends, but does result in weakness of muscular action on the injured side. It seems, therefore, that the cerebro-spinal mechanisms are sufficient to carry out all voluntary movements without the aid of the cerebellum, but the movements are lacking in strength, precision and regularity. The cerebellum is not shown to be a necessary link in the nervous mechanisms which control muscular action but it seems to add something to the voluntary movement. According to Luciani the function of the cerebellum is to maintain the tone of muscles during rest, to increase the energy of contraction when called forth by voluntary impulses and to determine the rhythm of motor impulses. In this way the imperfect actions of the dog deprived of its cerebellum would be perfected into normal movements. Whether the cerebellar cortex actually serves other functions, such as the coordination of specific movements, remains for further investigation to decide.

The fact that the cerebellum receives fibers from so many and various sources is important in this connection. It would seem that the maintenance of tone is not an abstract thing which is unrelated to present activity or sensory stimuli. If the function of the cerebellum is to maintain the tone of muscles, it is evident that it sends out the necessary impulses in response to impulses brought to it from related sensory areas or special sense organs. 
Thus coordinated movements in response to sensory impulses are directed by the mesencephalic and cerebral apparatus to be described in future chapters, while the side circuit through the cerebellum furnishes the means of maintaining the requisite tone.

It is erident that the cerebellum has changed its functions in the course of vertebrate history but the indications are that the broad functional relationships of its main parts have been retained. The somatic sensory part has come in mammals to play a special role in the senso-motor functions. It is still concerned chiefly with the reactions of the organism toward the external world by means of its somatic muscles. It is to be hoped that future experimental studies will be directed toward discovering the structural and functional relationships of the deep nuclei of the anterior lobe. The suggestion that some of these are homologous with the gustatory nucleus of fishes will be justified if it stimulate investigation in this direction.

\section{DEMONSTRATION OR LABORATORY WORK.}

I. Review the laboratory work on the somatic sensory relations and the structure of the cerebellum in fishes given in Chapters VI and VII.

2. Study the structure of the cerebellar cortex in a mammal in Golgi sections.

3. Examine by dissections and by sections in various planes the relations of the several parts of the cerebellum in fishes and mammals. Verify the comparisons made above, especially the constancy of the hemispheres in the vertebrate series.

4. Examine in the same way the relations of the cerebellar peduncles and of the secondary gustatory nuclei and the velum.

\section{LITERATURE.}

Bianchi, Arturo: Sulle vie di connessione del cervelletto. Archivio di Anat. e di Embriol., Vol. 2. 1903 .

Barker, L. F.: The Nervous System.

Bethe, A.: Die Locomotion des Haifisches u.s.w. Arch. f. d. ges. Physiol., Bd. 76. 1899 .

Cajal, S. R.: Textura del sistema nervioso del Hombre, etc. Madrid. I9०4.

Catois, E. H.: Recherches sur l'histologie et l'anatomie microscopique de l'encephale chez les poissons. Bull. Sci. de la France. Tome 36. Igor.

Edinger $u$. Wallenberg: Untersuchungen über den Gehirn der Tauben. Anat. Anz., Bd. 15. 1899.

Van Gehuchten, A.: Le corps restiforme et les connexions bulbo-cerebeleuses. Le Nevraxe, Tome 6. rgo4. 
Van Gehuchten, A.: Les pedoncules cerebelleuses superieurs. Le Nevraxe, Tome 7. I905.

Johnston, J. B.: The Brain of Acipenser. Zool. Jahrb., Bd. I5. I90I. Johnston, J. B.: The Brain of Petromyzon. Jour. Comp. Neur., Vol. I2. I902.

Kappers, C. U. A.: The Structure of the Teleostean and Selachian Brain. Jour. Comp. Neur. and Psych., Vol. ı6. Igo6.

Koelliker, A.: Gewebelehre. 6te. Aufl. Bd. 2. I896.

Luciani, L.: Das Kleinhirn. Asher u. Spiro's Ergebnisse. III. Jahrg., II. Abth. I904.

Ramon, P.: Investigaciones micrograficas en ed encefalo de los batracios y reptiles. Zaragossa, I894.

Schaper, A.: Zur feineren Anatomie des Kleinhirns der Teleostier. Anat. Anz., Bd. 8. r893.

Schaper, A.: Die morphologische und histologische Entwickelung des Kleinhirns der Teleostier. Morph. Jahrb., Bd. 2I. I894.

Smith, G. Elliot: On the Morphology of the Brain in the Mammalia. Trans. Linn. Soc. London, Ser. 2, Zool. 8. I903.

Smith, G. Elliot: Further Observations on the Natural Mode of Subdivision of the Mammalian Cerebellum. Anat. Anz., Bd. 23. I9o3.

Stroud, B. B.: The Mammalian Cerebellum. The Development of the Cerebellum in Man and the Cat. Jour. Comp. Neur., Vol. 5. I895.

The literature of the mammalian cerebellum will be found in the general works cited above. 
CHAPTER XVI.

\section{CENTERS OF CORRELATION (Continued). THE MESEN- CEPHALON AND DIENCEPHALON.}

\section{THE CUTANEOUS APPARATUS.}

In describing the centers and fiber tracts connected with the general and special cutaneous nerves (Chapters VI and VII) it was shown that the largest secondary tract from the primary centers goes in the form of internal arcuate fibers to the opposite side of the brain and passes forward to end in the roof of the mesencephalon. This tract is called in lower vertebrates the tractus bulbo-tectalis, in mammals the lemniscus. The tract has a wider distribution in the mesencephalon and diencephalon in mammals than in lower vertebrates. All the fibers which have this general course may be known as the lemniscus system. The evolution of this system and of its end nuclei will be considered here.

The first important point to notice is that the lemniscus system in mammals is divided into two chief parts, the medial and the lateral lemniscus. Each of these parts is believed to contain descending fibers in addition to the ascending ones. It must be emphasized that the ascending fibers alone are of interest in the present connection. The medial lemniscus arises in small part from the dorsal horns of the cord and chiefly from the nuclei of the dorsal funiculi and from the nucleus of the spinal $\mathrm{V}$ tract. It is therefore a general cutaneous conduction path. Some ascending fibers from the nuclei of the vestibular nerve probably join the medial lemniscus and others probably run separately to similar destinations in the diencephalon. The lateral lemniscus arises from the various nuclei of the cochlear nerve and is therefore an auditory conduction path. The chief place of ending of the lateral lemniscus is the posterior corpora quadrigemina, that of 
the medial lemniscus is the anterior corpora quadrigemina and certain nuclei in the thalamus. The separation of the lemniscus system into two parts is the result of a differentiation in the mesencephalon and diencephalon the main features of which can be outlined, but the details of which offer most interesting subjects for investigation.

The mesencephalon in primitive vertebrates was a segment of simple tubular form comprising two primary neuromeres similar to the cerebellar neuromere or even to a segment of the spinal cord. In typical fishes the roof of the mesencephalon is greatly enlarged and is as highly specialized as the cerebellum. This is due to the entrance into the mesencephalic roof of secondary tracts (I) from the general and special cutaneous centers of the medulla oblongata and spinal cord, and (2) from the retina. These tracts (tractus bulbo-tectalis and tractus opticus) have been described and their morphology discussed in previous. chapters. In lowly fishes the centers for these tracts are not isolated but are more or less confused or intermingled in the brain roof. Indeed the differentiation of special centers within an indifferent region is in progress in existing fishes.

In typical fishes the midbrain roof is an arch whose bases rest on the ventro-lateral walls of the brain and whose keystone is formed by a thin lamina (roof plate of His) traversed by the dorsal decussation. Enlargement of the centers in the roof is secured by the widening of the arch and expansion of the ventricle. The thickness of the walls varies much less in different fishes than the extent of the roof. In most fishes there is formed in this way a dorsal expansion of the iter known as the optic ventricle or optocoele. In Fig. 127 are shown outline sections through the tectum of a cyclostome, a selachian, a bony fish, an amphibian and a mammal to illustrate the changes of form which this region undergoes. The first important fact is that the expansion of the optic ventricle takes place by bulging the side walls of the arch without separating its bases. From this it results that the ventro-lateral part of the tectum remains beneath the side of the expanded optic ventricle and is overhung by the bulging dorso-lateral portion of the tectum. The portion of the original roof which now lies beneath the optic 
ventricle is much thicker than the rest and is known as the collicular region. The portion which roofs over the optic ventricle
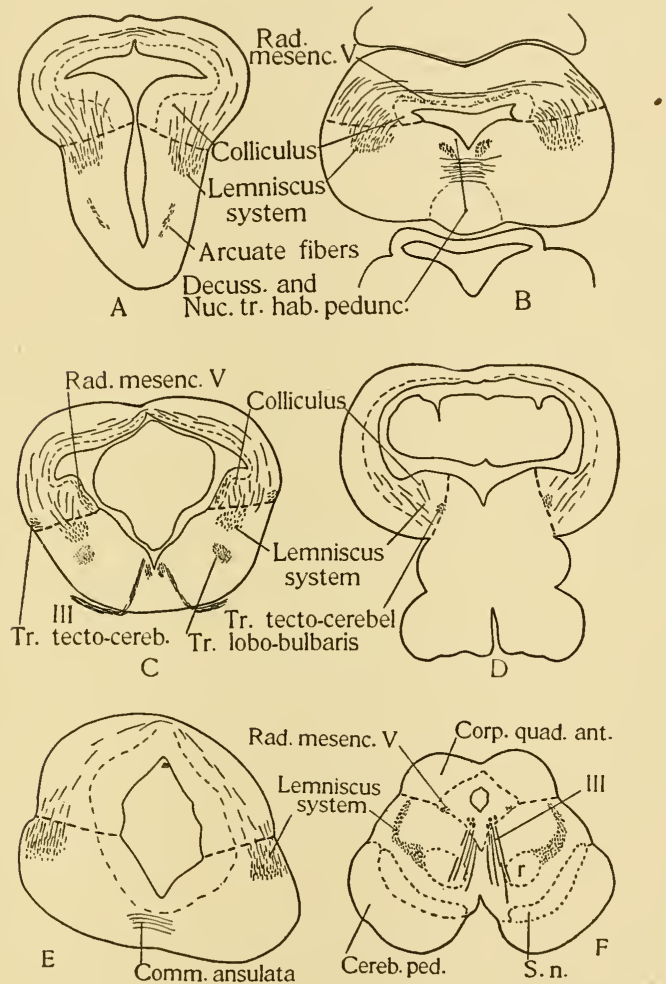

Fig. 127.-Outline transverse sections through the mesencephalon of various vertebrates to illustrate the changes of form of the tectal region. A, a cyclostome; $\mathrm{B}$, a selachian; C, a ganoid; D, a bony fish; $\mathrm{E}$, an amphibian; F, man (after Koelliker). $r$, nucleus ruber; $S$. $n$., substantia nigra.

is known as the tectum opticum. (It must be remembered always that the tectum opticum is only a part of the tectum mesencephali.) 
Although differentiation between these centers is not complete in fishes it may be said in general that the optic tract predominates in the tectum opticum, while the collicular region is especially related to the tractus bulbo-tectalis. That the specialization of these centers is not complete is clear from the fact that in blind fishes and those from which the eye has been experimentally removed, the tectum opticum is not atrophied but only certain layers of its cells disappear (Ramsey). Evidently the secondary cutaneous tracts enter the tectum opticum as well as the colliculus, but the optic tract is more nearly confined to the tectum opticum. The descending fibers from both the tectum opticum and the colliculus run in the same tracts so that they are all grouped under the name of tractus tecto-bulbaris.

In the amphibia a marked change in the form of the mesencephalon is seen (Fig. I $27 \mathrm{E}$ ). The form of the transverse section is more nearly that of a simple tube. The wall is relatively thick and there is only a slight indication of a special optic ventricle. In selachians, ganoids and bony fishes there is an increasing expansion of the tectum opticum and thickening of the massive colliculus. The size of the tectum opticum is directly affected by the size and importance of the eyes, while the great volume of the colliculus is due to the great development of the acustico-lateral system. In amphibia the reduction of the roof is due to a decrease in both optic and cutaneous tracts which end in it. In most amphibia the eyes are less important than in most fishes and the number of optic fibers which enter the tectum is much farther reduced by the greater development of the optic centers in the thalamus. On the other hand, the cutaneous tracts are greatly reduced by the complete disappearance of the lateral line organs in the adult. The amphibia are believed to have descended from fish-like ancestors whose affinities are with the lower orders of existing fishes. The amphibian brain shows resemblances to that of both selachians and cyclostomes. The reduction of the midbrain roof has left it in a primitive form. There is no clear distinction between tectum opticum and colliculus, but the greater thickness of the wall in the caudal part of the roof indicates the beginning of formation of the posterior 
corpora quadrigemina. It is probable that the roof in amphibia is an indifferent center for cutaneous, auditory and optic stimuli in which special centers for optic and auditory tracts are beginning

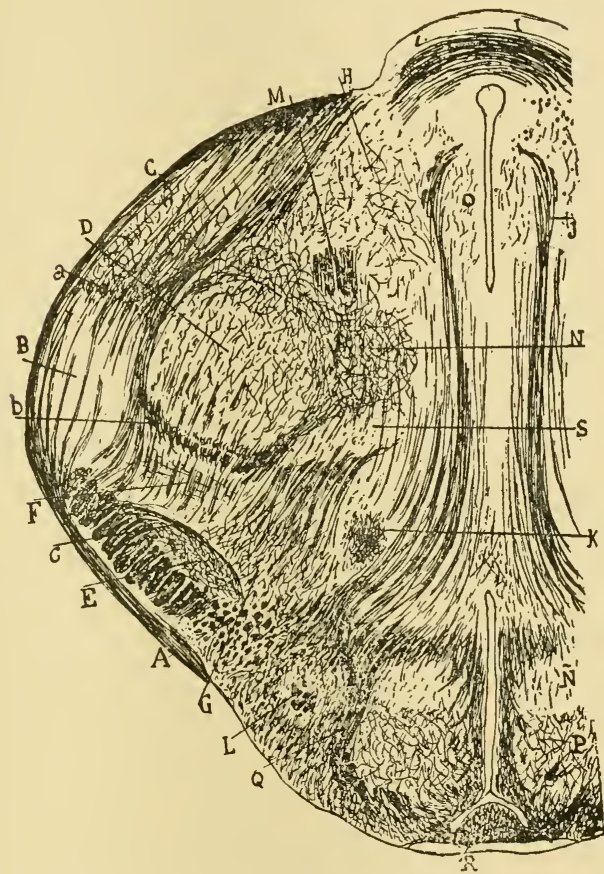

Fig. I28.- - Transverse section of the diencephalon of the rat at the level of the body of Luys. From Cajal (Textura, etc.). $A$, optic tract; $B$ and $C$, nuclei of the corpus geniculatum laterale; $D$, sensory nucleus (end nucleus of lemniscus); $E$, nucleus of Luys; $F$, zona incerta; $I$, posterior commissure; $N$, nucleus triangularis.

to be formed. In its caudal part the roof is comparable to the colliculus of fishes rather than to the tectum opticum; in its cephalic part the reverse is true.

The form of the midbrain roof in reptiles and mammals is in 
essentials similar to that in amphibia. The wall has thickened and the anterior and posterior corpora quadrigemina have differentiated. The anterior corpus quadrigeminum serves as the place of ending of optic and secondary cutaneous tracts and is comparable to the cephalic part of both tectum opticum and colliculus in fishes. The posterior corpus quadrigeminum serves as the chief place of ending of the secondary auditory paths and is roughly comparable to the caudal part of the colliculus in fishes. In birds a large tectum opticum has been developed on account of the large size of the eyes and the mesencephalon of birds is more like that of bony fishes than that of other lower vertebrates.

The lateral lemniscus arises, as has been said, from the nuclei of the cochlear nerve. A large part of the fibers come as internal arcuate fibers from the nuclei of the opposite side, the remainder as direct fibers from the nuclei of the same side. The lateral lemniscus passes forward into the mesencephalon, bends upward and separates from the medial lemniscus, and the greater part of it enters the posterior corpus quadrigeminum. A part of the fibers pass forward to end in the anterior quadrigeminum and a part go on to end in the medial corpus geniculatum or adjacent nuclei in the thalamus. From the posterior corpus quadrigeminum fibers go to the medial corpus geniculatum and from this center auditory impulses are forwarded to the cerebral hemispheres. From the posterior quadrigeminum other fibers go down through the lateral lemniscus to end in the various cochlear nuclei (recurrent fibers).

The medial lemniscus consists of both crossed and uncrossed fibers from the centers for cutaneous nerves. The tract receives fibers also from many other sources not related to the cutaneous nerves. As the tract passes forward fibers go from it to end in the gray matter of the medulla oblongata, pons, isthmus, midbrain and hypothalamus. It is shown, however, that the great majority of the fibers which arise in the cutaneous nuclei pass forward to the thalamus and it is believed that the other fibers which enter and leave the tract do not belong to the lemniscus system proper. The secondary cutaneous fibers end in the so-called nucleus ventralis of the thalamus. It must be noticed that this nucleus 
is by no means situated in the ventral part of the thalamus (as often stated) but lies mesial to the corpus geniculatum laterale in the dorsal half of the thalamus (Fig. I28). It would be better to call it as Cajal does the sensory mucleus of the thalamus, especially as the term nucleus ventralis is used for a different center in fishes. From this sensory nucleus impulses are forwarded to the cerebral cortex and descending fibers from the cortex also end in this nucleus. In the cat (Tschermak) a part of the fibers of the me-

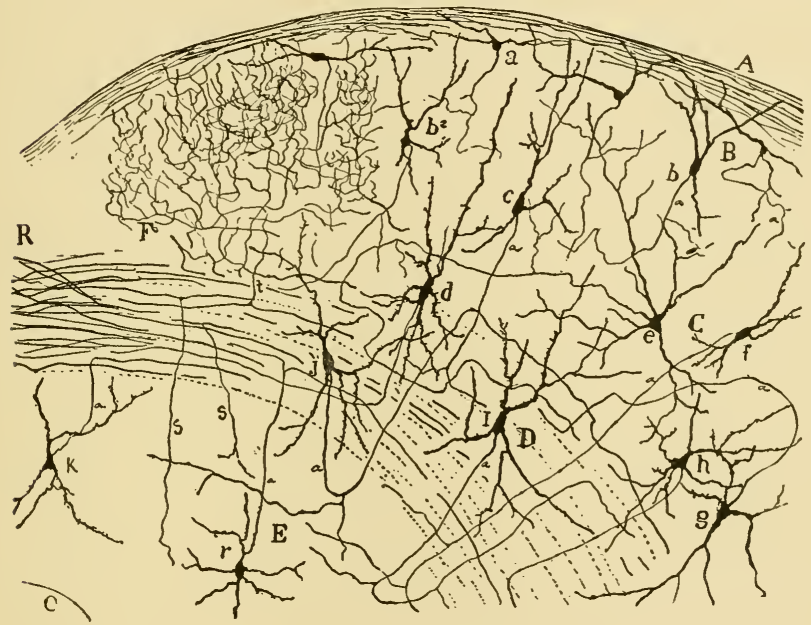

Fig. 129.-Transverse section of the dorso-mesial portion of the posterior corpus quadrigeminum of the newborn dog. From Cajal (Textura, etc.). A, peripheral fiber layer; $B$, cells of the second layer; $C$, stellate and fusiform cells of the third layer; $D$, fibro-cellular layer; $E$, central gray matter; $R$, commissure; $F$, plexus of second and third layers.

dial lemniscus are found by the degeneration method going through the thalamus to reach the cortex directly. There is some evidence that such bulbo-pallial fibers exist also in man. In view of the ending of secondary cutaneous fibers in the midbrain in lower vertebrate sit may be expected that some of the fibers of the 
medial lemniscus in mammals should stop in the corpora quadrigemina. The large branch of the medial lemniscus which runs to the anterior quadrigemina may be made up of such fibers. The structure of the corpora quadrigemina is shown in Figures I 29 and I 30 .

The lemniscus system in lower vertebrates is related to an

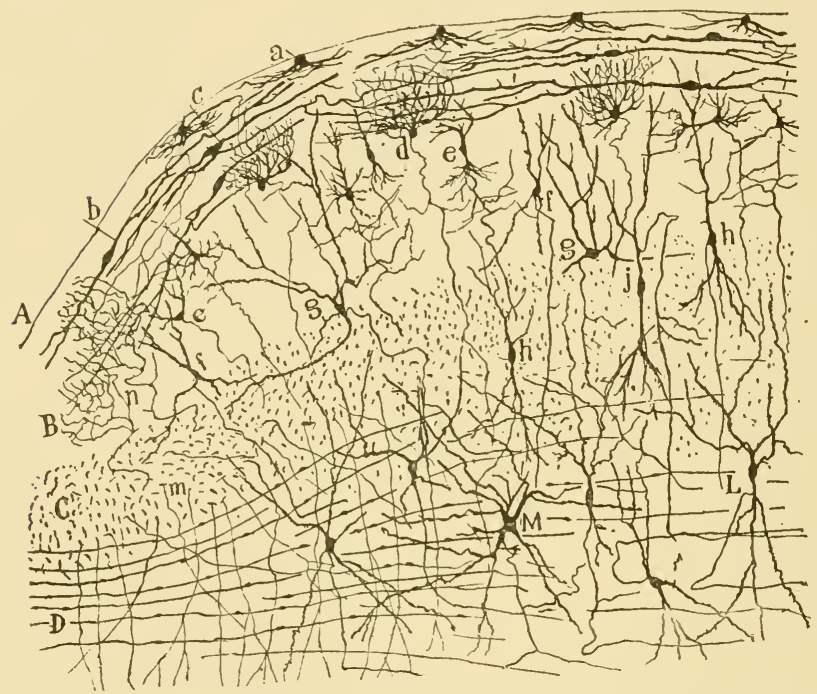

Fig. I30.-Transverse section of the anterior corpus quadrigeminum of the rabbit of eight days. From Cajal (Beiträge u.s.w.). $A$, surface at the median line; $B$, superficial gray layer; $C$, layer of opticus fibers; $D$, transverse fiber layer; $a$, border cells; $b$ and $c$, horizontal spindle cells; $e$, vertical spindle cells; $f, g$, various cell types of the gray layer; $h, j$, spindle cells of the opticus layer; $M, L$, cells of the fiber layer; $n$, ending of opticus fiber.

indifferent tectum mesencephali. It has been differentiated into a medial general cutaneous tract and a lateral auditory tract. The auditory tract has claimed the caudal portion of the tectal region. The cutaneous tract, while it is probably related to the 
anterior corpus quadrigeminum, has chiefly shifted its place of ending to the dorsal part of the thalamus. There is evidence that a few fibers of both auditory and cutaneous tracts may go directly to the cerebral hemisphere.

\section{THE VISUAL APPARATUS.}

It was seen in the last section that optic tract fibers in all vertebrates end in the tectum opticum. Although this is apparently the earliest place of ending of optic tract fibers a second important end nucleus appears as low as the selachians. This is the corpus geniculatum laterale situated in the lateral wall of the thalamus. This nucleus increases in importance in the series of vertebrates and forms the largest optic center in the mammalian and human brain. In addition, the pulvinar of the thalamus receives optic tract fibers in mammals. Some authors have described as places of ending of optic tract fibers a nucleus named by Edinger the corpus ectomammillare (reptiles, Edinger; teleosts, Goldstein) and the ganglion isthmi in birds. The relations of the ganglion isthmi of birds require further study. The nucleus in amphibia and fishes to which Edinger has given the same name is of a very different character. The identity of the corpus ectomammillare and the proof that optic fibers end in it are not clear from the descriptions that have been given.

In selachians the optic tracts after their decussation in the chiasma pass up on the lateral surface of the thalamus where they cover superficially a layer of cells which is homologous with the corpus geniculatum laterale of higher forms. Only collaterals of the optic fibers are said to end in this nucleus. The main body of the optic tract ends in the tectum opticum. In some bony fishes the corpus geniculatum is more highly developed and receives a larger number of optic fibers. This is true also in Amia (Fig. I4I). In some bony fishes and in the sturgeon the corresponding cells are closely related to the nucleus anterior thalami and receive the endings of a small part of the optic tract. In amphibia, reptiles and birds a well developed corpus geniculatum laterale is found and a large part of the optic tract ends in 
it. In birds on account of the large size and importance of the eyes both the tectum opticum and optic thalami are well developed.

In mammals and man the number of uncrossed fibers in the optic tract increases greatly. The corpus geniculatum laterale (Fig. I3I) becomes the most important center for optic impulses

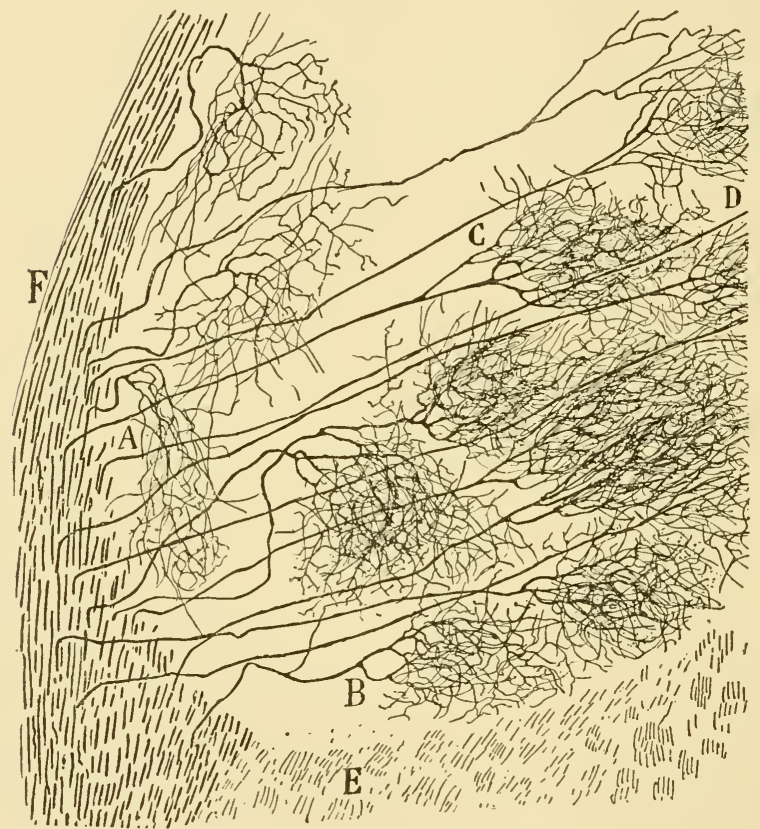

Fig. I3I.-Lower part of the corpus geniculatum laterale of the newborn cat. From Cajal (Beiträge u.s.w.). $A, B, C, D$, endings of opticus fibers.

and some fibers end in the center of similar structure situated in the pulvinar of the thalamus. The relations in mammals show that with the increasing size of the corpus geniculatum there has gone hand in hand a process of differentiation of function between 
it and the tectum opticum. In man the anterior corpus quadrigeminum is small and poorly developed as compared with that of lower animals. The descending tract from it is relatively small and represents only a part of the tractus tecto-bulbaris of lower vertebrates. The bundles of the two sides descend over the central gray of the midbrain and form a decussation in its ventral wall called by Forel the "fountain-like" decussation. As the tracts pass on toward the medulla oblongata they give collaterals and terminals to the nuclei of the eye muscle nerves. This is the chief connection of the tract going out from the anterior quadrigeminum and it shows that the chief function of that nucleus is to direct eye muscle reflexes to visual stimuli. The existence of fibers from the anterior quadrigemina to the cerebral cortex has not been clearly demonstrated and the complete loss of the anterior quadrigemina does not affect light or color vision.

The corpus geniculatum, on the other hand, sends a large tract to the occipital region of the cortex and the geniculatum is the chief intermediate center in visual perception. The connection of the geniculatum and pulvinar with the occipital cortex is clearly shown by the secondary degeneration of these nuclei after destruction of the visual cortical area. The tract has been followed clearly in animals by the method of Golgi (Cajal) and in the newborn babe the tract from the geniculatum to the cortex is medullated while adjacent tracts are not, so that Weigert staining gives a clear picture of this conduction path (Flechsig). There is evidence that in lower vertebrates fibers pass from the tectum opticum and the geniculatum to the forebrain and it is probable that this tract was one of the first to stimulate the development of the neopallium. Little is certainly known of the relations of the geniculatum in lower vertebrates, although connections with various parts of the brain have been described (Catois, Edinger).

The existence of the corpus geniculatum laterale in selachians shows that it is far from being a new or phylogenetically young optic center. It is equally true, however, that it does not become important relative to the tectum opticum until the cerebral hemispheres are developed. Through the vertebrate series there has been a gradual shifting cephalad of the endings of optic tract 
fibers. In fishes they are distributed throughout the whole length of the tectum mesencephali and a few end in the thalamus. In mammals the caudal half of the tectum no longer receives optic tract fibers and most of them (in man 80 per cent.) end in the thalamus. This shifting of optic tract fibers is part of the process of specialization of the mesencephalon described in the last section. The caudal part comes into the service of the secondary auditory tracts, the cephalic part becomes a visual reflex center for eye movements, while the conduction paths for general cutaneous and visual perception both leave the tectum mesencephali and end in thalamic nuclei. All these changes have resulted in greater compactness and directness in the arrangement of centers and tracts. Generally speaking, each conduction path in mammals is the shortest and most direct that could be evolved out of the unspecialized centers and tracts which already served the same set of functions in lower vertebrates. The caudal part of the tectum is claimed by the auditory paths which come from behind, the cephalic part by the optic path which comes from in front. The secondary general cutaneous path shifts from the tectum to the thalamic nuclei, which are nearer the cerebral cortex to which the impulses of general sensation are destined. Similarly the visual impulses destined for the occipital cortex are transferred to the corpus geniculatum instead of going to the more distant corpus quadrigeminum anterior. The shifting forward (prosencephalization) of visual centers is explained by the advantage of gaining shorter paths to the cerebral cortex, for the reason that visual impulses are significant in higher mammals chiefly for space and color perception of the surroundings. In fishes visual impulses arouse reflex movements of the body for the capture of food, avoidance of obstacles, etc. In mammals the reflexes which depend solely on visual impulses are few (lid reflex, etc.). Visual impulses are for the most part carried to the pallium where they are associated with impulses of other sorts (tactile, auditory) for the formation of a complex perception of the situation. Under the influence of this percept voluntary impulses arouse movements adapted to meet the situation. This may be taken as a characteristic illustration of the difference between the brain 
of man and that of a fish. Whereas the sensory impulses in a fish are correlated by the relatively slightly organized centers of the mesencephalon and call forth simple, direct and often very quick responses; the center for correlation in man is removed to the highly organized cerebral cortex and the responses lose something in quickness but gain vastly in precision and in the completeness with which they are adapted to the several factors of the situation.

There should be added to this account some mention of the centrifugal fibers in the optic tracts which end in the retina. The presence of such fibers is demonstrated by the Golgi method which shows their origin, course and their endings in the internal molecular layer of the retina (Figs. $7 \mathrm{I}, 72$.). Their presence and course is also shown by the methods of primary and secondary degeneration. In fishes in which one eye has long been lost the optic tract of the opposite side degenerates with the exception of these fibers, which persist and are stained by the Weigert method. In mammals, following section of the optic tract there occurs secondary degeneration of cells in the anterior quadrigeminum, and in the dorsal part of the geniculatum laterale and pulvinar. These findings in mammals agree with those in fishes by the Golgi and degeneration methods, where the centrifugal fibers arise from the tectum opticum and geniculatum (Catois). The significance of these fibers is not understood but their presence in all vertebrates seems to show that they have some constant function. It has been suggested that they are examples of fibers which pass forward from the cutaneous center of one segment to that of a center farther forward, and hence homologous with the fibers of the lemniscus system.

\section{CENTERs RELATED to THE POSTERIOR COMmisSURE.}

The posterior commissure, although it has long been used as one of the most prominent and constant landmarks in the brain, is still very imperfectly understood. In Petromyzon (Fig. I32) the fibers of the commissure arise from cells widely scattered through the dorso-caudal part of the thalamus and the cephalic part of the tectum opticum and the collicular region. The fibers 
are very fine until they approach the point of crossing, when they thicken into relatively coarse fibers. After crossing they bend ventro-caudally and spread widely through the wall of the midbrain, mingling with the fiber tracts descending to the medulla oblongata. In mammals the commissure arises from a nucleus situated at the cephalic border of the anterior corpora quadrigemina, between the tractus habenulo-peduncularis, the nucleus ruber and the root of the III nerve (Koelliker, p. 445). In other vertebrates the origin of the commissure has not been clearly distinguished. It is variously described as arising in, ending in or serving as a true commissure for a nucleus lying cephalad from the nucleus of origin of the III nerve. The same nucleus is described

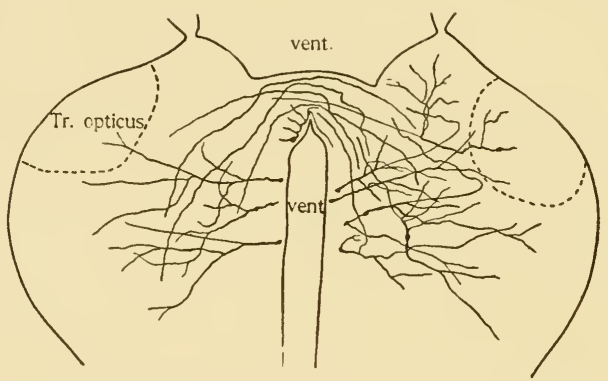

Fig. I32.-Nucleus of posterior commissure in Lampetra. vent., the aqueduct of Sylvius below, the optic ventricle above.

as the nucleus of origin of the fasciculus longitudinalis medialis, and the fibers of the posterior commissure itself are said to form that fasciculus. These vague and conflicting statements are due to imperfect methods. Those who have worked by the Weigert technique have been misled by the fact that the fibers of the commissure do not become myelinated until they approach the point of crossing. In Scyllium the fibers approach the median plane from the lateral direction just as in Petromyzon and presumably arise from a nucleus situated dorsally as in Petromyzon. The same is true in amphibia. The nucleus praetectalis of Edinger 
which has been described in fishes by various authors lies in the region of junction of thalamus and tectum mesencephali and probably is at least a part of the nucleus of the posterior commissure. After crossing, the limbs of the commissure bend downward and backward through the central gray more or less parallel with the tractus habenulo-peduncularis and are lost among the longitudinal and decussating tracts in the region of the III nucleus and the ansulate commissure. Most authors agree that the tract is related to the nucleus which gives rise to the fasciculus longitudinalis medialis and to the nuclei of the eye muscle nerves. The commissure contains many fibers which arise from or end in the tectum opticum and its whole nucleus of origin in fishes is closely related to the tectum. All the evidence goes to show that the system of the posterior commissure is closely related to the optic centers.

\section{DEMONSTRATION OR LABORATORY WORK.}

I. Trace the lemniscus systems in Weigert sections of the brain of a bony fish, frog and a mammal. Note especially the relations of the thalamic centers.

2. Study in Golgi sections the structure of the tectum mesencephali (corpora quadrigemina) and the corpus geniculatum laterale in the brain of a selachian, frog and the mouse or rat.

3. In the Golgi and Weigert sections used above search carefully for the origin and destination of the fibers of the posterior commissure.

\section{LITERATURE.}

Barker, L. F.: The Nervous System. Chapter LIII.

Cajal, S. R.: Beiträge zur Studium der Medulla oblongata. Leipzig. I8g6.

Cajal, S. R.: Textura del sistema nervioso del Hombre y de los vertebrados. Madrid. I904.

Catois, E. H.: Recherches sur l'histologie et l'anatomie microscopique de l'encephale chez les poissons, Bull. de Sci. de la France, Tome 3r. Igor.

Edinger, L.: Vorlesungen über den Bau der nervösen Centralorgane. Leipzig. I904.

Johnston, J. B.: The Radix mesencephalica trigemini. Ganglion isthmi. Anat. Anz., Bd. 26. I905.

Kappers, C. U. A.: Teleostean and Selachian Brain. Jour. Comp. Neur. and Psych., Vol. 16. I906.

Koelliker, A.: Gewebelehre, 6 Aufl. Bd. 2. 
Myers, B. D.: The Chiasma of the Toad and of some other Vertebrates Zeit. f. Morph. u. Anthrop. Bd. 3. I901.

Ramon, P.: Investigaciones sobre los centros ópticos, etc. Zaragoza. I89o.

Ramon, P.: El encéphalo de los reptiles. Zaragoza, I89ı.

Ramon, P.: El encéphalo del cameleón Rev. trim. micrografica, tomo I. I 896 .

Ramon, P.: Centros ópticos de las aves. Rev. trim. micrografica, tomo I. I 898 .

Ramsey, E.: The Optic Lobes and Optic Tracts of Amblyopsis speleus de Kay. Jour. Comp. Neur., Vol: I I. Igor.

Van Gehuchten, A.: La structure des lobes optiques chez l'embryon de poulet. La Cellule. I 892 . 
CHAPTER XVII.

\section{CORRELATING CENTERS IN THE DIENCEPHALON (Continued).}

\section{THE OLFACTORY AND GUSTATORY APPARATUS.}

The centers considered in the last chapter have to do with somatic sensory impulses and are all differentiated from the dorsal part of the mesencephalon and diencephalon. The centers now to be considered have to do with visceral sensory impulses and lie, with one exception, in the ventral part of the diencephalon. It was shown in Chapters IX and $\mathrm{X}$ that gustatory impulses are carried to the inferior lobes of the diencephalon by a tract from the superior gustatory nucleus and that olfactory impulses come to the same region in two or three isolated bundles of the tractus olfacto-hypothalamicus.

It is important to understand the exact limits of the hypothalamus in fishes and to determine the corresponding structures in higher vertebrates. In all fishes a pair of rounded lobes, the inferior lobes, containing a wide extension of the third ventricle project ventro-caudally behind the optic chiasma. In cyclostomes and selachians these lobes are relatively small and have a simple and primitive structure, but in ganoids and bony fishes they are greatly expanded and show a somewhat higher histological development. Caudo-ventrally the wall of the lobe is produced into a median thin-walled and vascular sac known as the saccus vasculosus. The caudal wall of the lobes above the opening of the saccus shows special characters and is known as the corpus mammillare. The relations of these structures may be seen in sagittal sections of the brain (Figs. 2, II, and Chap. XVIII).

The whole area which shows the structural characteristics of the inferior lobes and is related to olfactory and gustatory tracts may extend somewhat beyond the lobes proper, and the limits 
between this area and the thalamus have not been clearly appreciated. Thus, the nucleus of origin of the fasciculus longitudinalis medialis has been spoken of as lying in the hypothalamus (Edinger). If a section through the inferior lobes of the sturgeon brain be compared with one through the III nerve (Figs. I33, II6) it will be seen that the tectum mesencephali and lateral walls are the same in both, and also that the fasciculus longitudinalis medialis

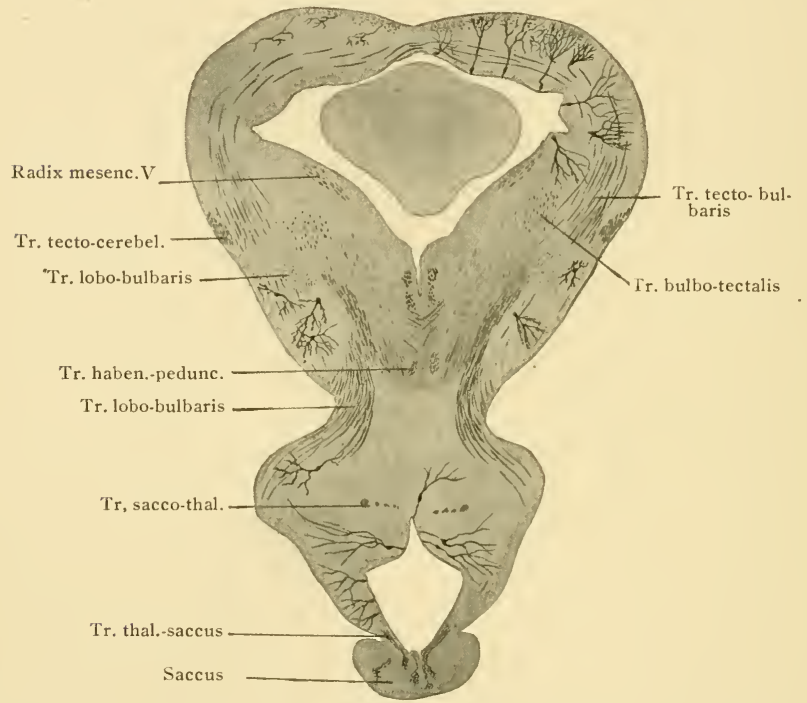

Fig. I33.- Transverse section through the corpora mammillaria of the sturgeon.

and the fundamental bundles of the lateral tracts extend forward into the thalamus. In front of the nucleus of the fasciculus longitudinalis medialis the nucleus of the tractus strio-thalamicus and the tract itself continue forward at about the same level. These several structures represent the brain base or stem. The greatly expanded inferior lobes ventral to them are anomalous structures. The characteristic structure of the inferior lobes extends up to 
the lateral border of the nucleus of the tractus strio-thalamicus, which belongs to the thalamus. The hypothalamic structure extends up lateral to this nucleus, however, upon the lateral surface of the thalamus and midbrain nearly to the ventral border of the tectum mesencephali (Figs. I33, I34, I35). This area is quite free from myelinated fiber tracts but is traversed by the myriads of fine fibers of the tractus lobo-bulbaris, to which it contributes additional fibers. The dorsal border of this area is defined by a dense bundle of this tract. In bony fishes the typical hypothalamic structure extends up in precisely the same way upon the lateral surface of the thalamus and midbrain and on account of the great size of the tectum mesencephali the base of the latter is crowded down into contact with this portion of the hypothalamus. In both the sturgeon and the bony fish the hypothalamic structure is sharply limited dorsally by a groove and a septum of connective tissue extending deep into the brain substance. The limit between the thalamus and hypothalamus (Fig. I34) runs from a point near the base of the tectum mesencephali to the lateral border of the nucleus of the tractus strio-thalamicus. The structure of the hypothalamus is uniform throughout and is remarkably constant in the series of vertebrates. The fiber tracts connected with the hypothalamus are quite different from those connected with the thalamus. To what extent the structure of the hypothalamus extends up on the lateral surface of the thalamus in other classes than ganoids and teleosts is not known.

Fortunately we have an account of the genetic relations of this hypothalamic structure which appears so anomalous in the adult brain. In early teleost embryos the brain consists of a number of ring-shaped neuromeres which have been described in Chapter III. As indicated in that chapter, the first neuromere gives rise to the forebrain, the second gives rise to the retina and comes to have the optic chiasma at its ventro-cephalic border (Chap. VIII). The third neuromere forms the thalamus, nucleus habenulae and epiphysis. The fourth and fifth neuromeres form the mesencephalon. One of the earliest differentiations of form to appear in the brain segments of bony fishes is an expansion of the ventral wall of the second neuromere, which begins to crowd 
back beneath the third neuromere (Fig. I9). This ventro-caudal projection from the second neuromere is the beginning of the hypothalamus. Its early appearance in the embryo is due both to its importance and to the fact that it is phylogenetically an old structure. The hypothalamic rudiment continues to expand until it forms the large inferior lobes beneath the third neuromere.

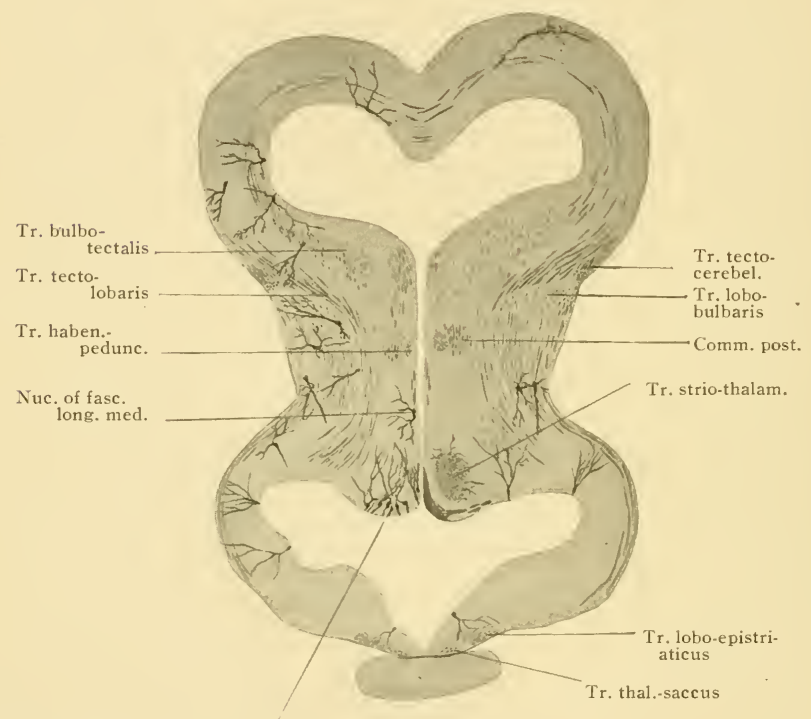

End nucleus of Tr. sacco-thalam.

Fig. I34--Transverse section through the inferior lobes of the sturgeon.

The ventricle of the second neuromere is carried back with the outgrowth and fuses with that of the third neuromere along the line meso-ventral to the tractus strio-thalamicus and its nucleus.

The diencephalon therefore consists of the third neuromere and a part of the second, the remainder of the second being carried 
out into the retina. The third neuromere gives rise to the greater part of the thalamus, the nucleus habenulae and an epiphysis. The second neuromere forms the anterior part of the thalamus and the hypothalamus. The recognition of the two main divisions of the diencephalon and their genetic history leads the way to an understanding of the morphological relations of its special nuclei.

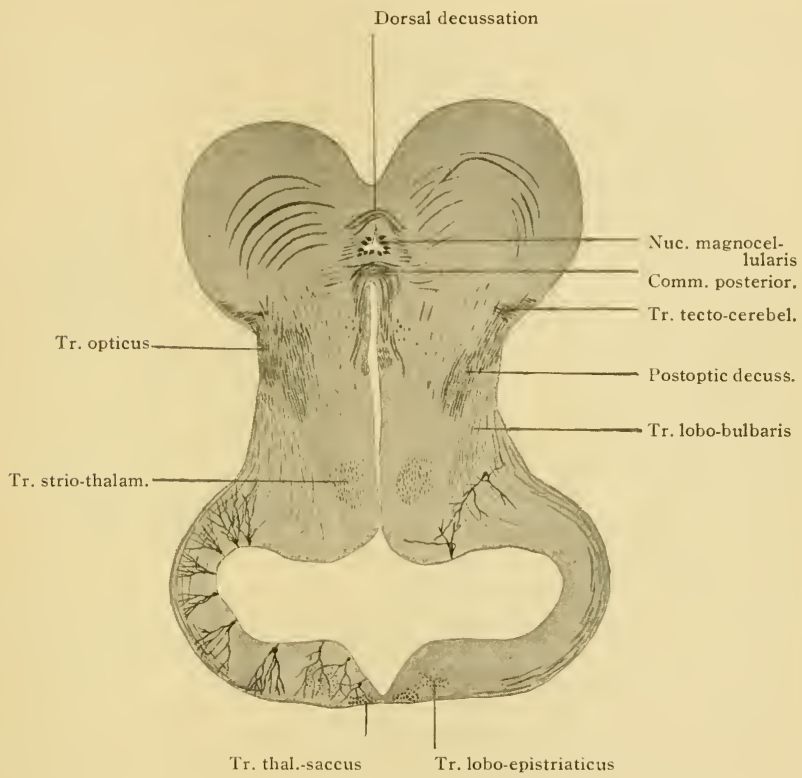

Fig. I35.-Transverse section through the posterior commissure of the sturgeon.

The gross relations of the hypothalamus being established it remains to discuss its functional relations as indicated by the fiber tracts connected with it. The tracts which bring impulses to the hypothalamus are primarily the gustatory and olfactory tracts of the third order. Although the gustatory tracts have only recently been demonstrated they are probably not less fundamental I8 
than the olfactory tracts which have long been known. The olfactory tracts in fishes come to the hypothalamus either isolated or mingled with the tractus strio-thalamicus. On account of the latter fact the view has been advocated by some that a part of the olfactory impulses were delivered to nuclei in the thalamus proper. This is probably incorrect. When the medial olfacto-

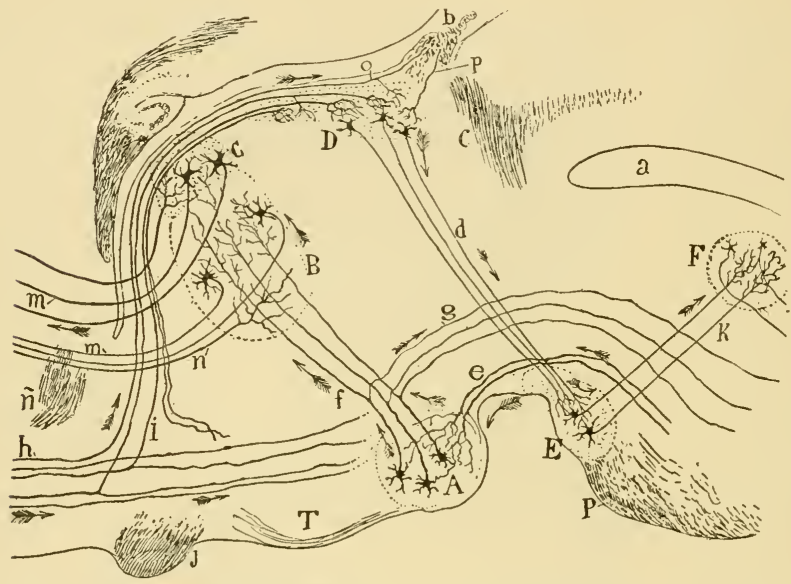

Fig. I36.-Scheme of the connections of the mammillary tracts, the nucleus habenulae, and the nucleus dorsalis thalami. From Cajal (Textura, etc.). $A$, corpus mammillare; $B$, nucleus dorsalis thalami; $C$, upper part of this nucleus; $D$, nucleus habenulae; $E$, corpus interpedunculare; $F$, dorsal nucleus of the tegmentum; $J$, optic chiasma; $a$, aqueduct of Sylvius; $b$, commissura habenularis; $c$, commissura posterior; $d$, tractus habenulo-peduncularis; $e$, peduncle of the corpus mammillare; $f$, bundle of Vicq d' Azyr; $g$, tractus mammillo-peduncularis; $h$, olfactory tract of projection (tractus olfacto-hypothalamicus); $i$, stria thalami (tractus olfacto-habenularis); $m$, thalamo-cortical fibers; $n$, cortico-thalamic fibers; $o, p$, fibers of the stria thalami which cross in the habenular commissure.

hypothalamic tract is mingled with the tractus strio-thalamicus there are always many fibers going ventrally from the latter tract into the inferior lobes and it is wholly probable that all olfactory impulses enter the hypothalamus (except those to the nucleus habenulae, see below). The tertiary gustatory tracts also enter 
the inferior lobes and both gustatory and olfactory tracts are widely distributed in the hypothalamus. In higher vertebrates nothing is known of the central gustatory tracts. The corpora mammillaria have long been known as the place of ending of the chief olfactory conduction path, the fornix. From the mammillary bodies the tractus mammillo-peduncularis goes caudally and is comparable with the tractus mammillo-bulbaris in fishes. Collateral branches from the fibers of this tract near their origin form the tractus mammillo-thalamicus to the nucleus dorsalis thalami (Fig. I36). The cephalic part of the hypothalamus, the tuber cinereum, has never been well understood in mammals.

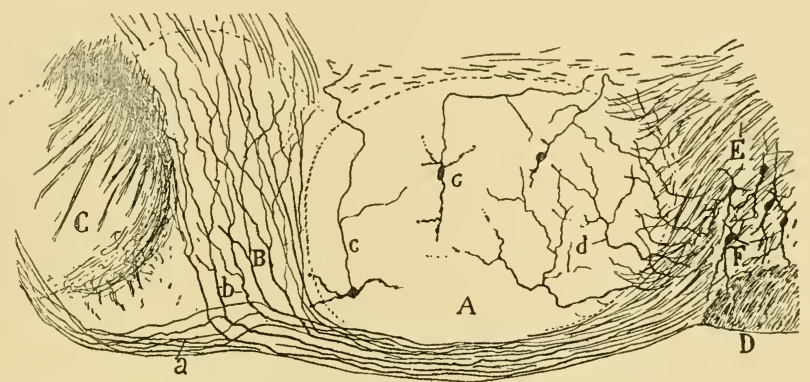

Fig. I37.-Sagittal section of the tuber cinereum of the newborn rat. From Cajal (Textura, etc.). $A$, anterior or chief nucleus; $B$, posterior nucleus; $C$, internal nucleus of the corpus mammillare; $D$, optic chiasma; $E$, afferent tract from the forebrain (tractus olfacto-hypothalamicus); $F$, nucleus supraopticus; $a$ and $b$, branches of bifurcation, and $d$, terminal branches of the afferent fibers.

The first important contribution toward a clear understanding of its relations has been made recently by Cajal. This author shows that the two nuclei of the tuber cinereum receive bundles of nonmyelinated and myelinated fibers which come from the septum pellucidum of the cerebrum, run close over the optic chiasma and end in these nuclei and in the mammillary bodies. These tracts are illustrated in Figures $\mathrm{I}_{37}$, I38, taken from Cajal's textbook. As the discussion in the next chapter will show, these fibers are homologous with the medial olfacto-hypothalamic tract 
of fishes and other vertebrates. They are tertiary olfactory fibers and it is evident that the whole hypothalamus receives such fibers in all vertebrates, although the caudal part, the corpora mammillaria, is especially developed as the end-nucleus of olfactory fibers of the fourth order, the fornix. Considering the conditions in fishes it is to be expected that a tertiary gustatory tract in mammals will be found ending in the tuber cinereum.

In fishes a tract from the tectum mesencephali enters the hypothalamus, the tractus tecto-lobaris. This tract would provide

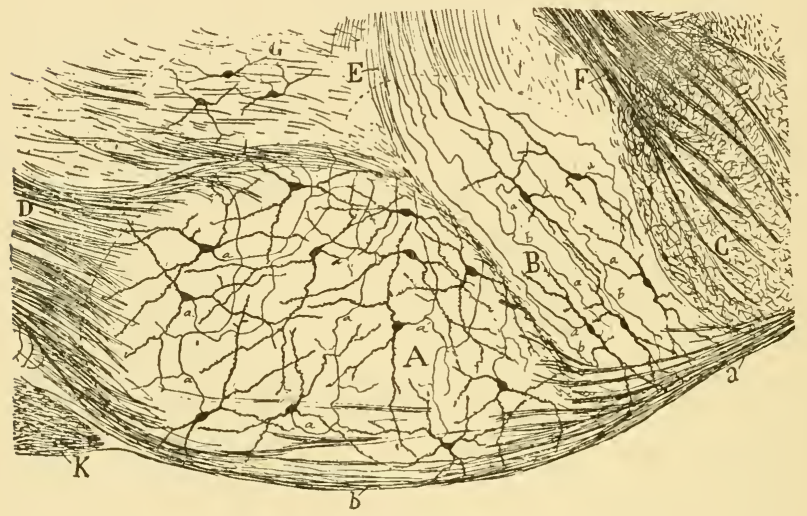

Fig. 138.-Sagittal section of the tuber cinereum of the rat of eight days. From Cajal (Textura, etc.). $A$, anterior or chief nucleus; $B$, posterior or accessory nucleus; $C$, internal nucleus of corpus mammillare; $D$, nerve tract coming from the septum pellucidum (tractus olfacto-hypothalamicus medialis); $E$, efferent fibers from the tuber which disappear in the central gray matter; $F$, efferent tract from the corpus mammillare; $G$, upper nucleus of the tuber; $K$, optic chiasma.

for the correlation of olfactory and visual or cutaneous impulses. The homologue of this tract in mammals has not been recognized, but it is known that fibers from other sources besides the olfactory systems described above end in the tuber cinereum.

The tract going out from the corpora mammillaria, as already mentioned, is the same in all vertebrates. Tracts going from the 
tuber cinereum have been followed only into the central gray of the thalamus (Fig. 137). This is the direction taken by the tr. lobo-bulbaris in lower vertebrates. Another tract from the hypothalamus which is not known in mammals and but poorly understood in lower vertebrates, is an ascending tract to the forebrain, the tractus lobo-epistriaticus.

A second olfactory conduction path, already described for fishes, is found in mammals; namely, that by way of the nucleus habenulae. The tract from the forebrain to the nucleus habenulae comes partly from the secondary olfactory nucleus, the nucleus thaeniae or nucleus amygdalae, and in part from the hippocampus. Those from the hippocampus are a part of the fornix system.

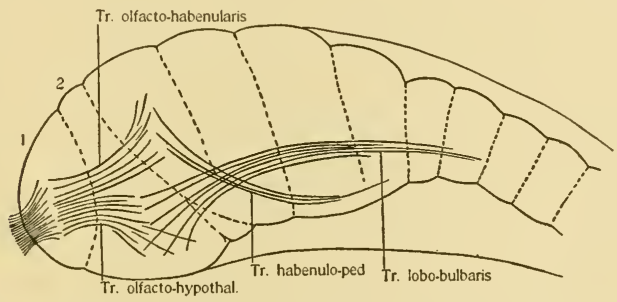

Fig. I 39.-A scheme to show the embryological relations of the nucleus habenulae and the inferior lobes in fishes. I 2, neuromeres.

The tract forms a part of the striae medullaris and enters the nucleus habenulae, where it contributes to the habenular commissure as in lower forms. From the nucleus habenulae the tractus habenulo-peduncularis descends to the base of the mesencephalon, where the paired tracts form an intricate decussation and end in the corpus interpedunclare.

The fact that the two olfactory conduction paths diverge so widely seems at first sight difficult to understand. The accompanying diagram will serve to show how this has come about. In Fig. IOI the olfactory paths are sketched into the outline of a sagittal section of a fish brain, and in Fig. I 39 a reconstruction is given in which the several centers are drawn in their embryonic 
position. It will be seen that while in the adult the hypothalamus lies in an extreme ventral position, somewhat caudal to the nucleus habenulae, its embryonic and presumably early phylogenetic position was one neuromere cephalad from the nucleus habenulae and not so far ventrad as in the adult. On the other hand, while the nucleus habenulae in the adult lies at the dorsal border of the brain wall it was overtopped in primitive vertebrates by the somatic sensory center. When it is considered that the large center for the tractus strio-thalamicus and the central gray have separated the hypothalamus and nucleus habenulae, that the hypothalamus

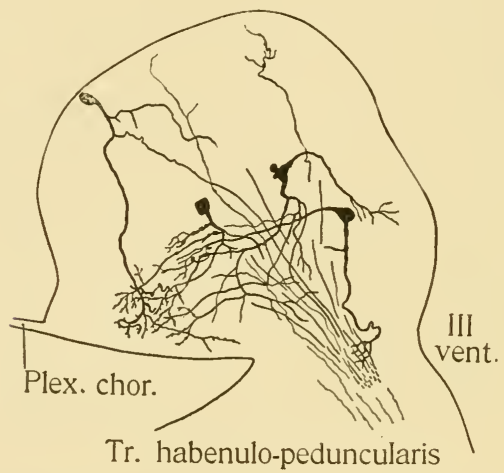

Fig. I40.-Transverse section of the nucleus habenulae of the sturgeon.

has protruded ventrally as the result of its expansion, and that the nuclei habenulae have been drawn dorsally by the habenular commissure connecting them, it becomes altogether probable that these two tertiary olfactory centers have been developed from the same column of indifferent material, namely, the substantia reticularis grisea of the second and third neuromeres. They are morphologically not dorsal and ventral structures, but represent the substantia reticularis of successive segments. Both receive identical tracts, including fornix fibers, which have been bifurcated by the mechanical shifting apart of their end-nuclei. 
An additional evidence in favor of this view is seen in the relation of the nucleus habenulae to the ventricle and the membranous roof. The nucleus habenulae in fishes (Fig. I40) is a lobe pro-
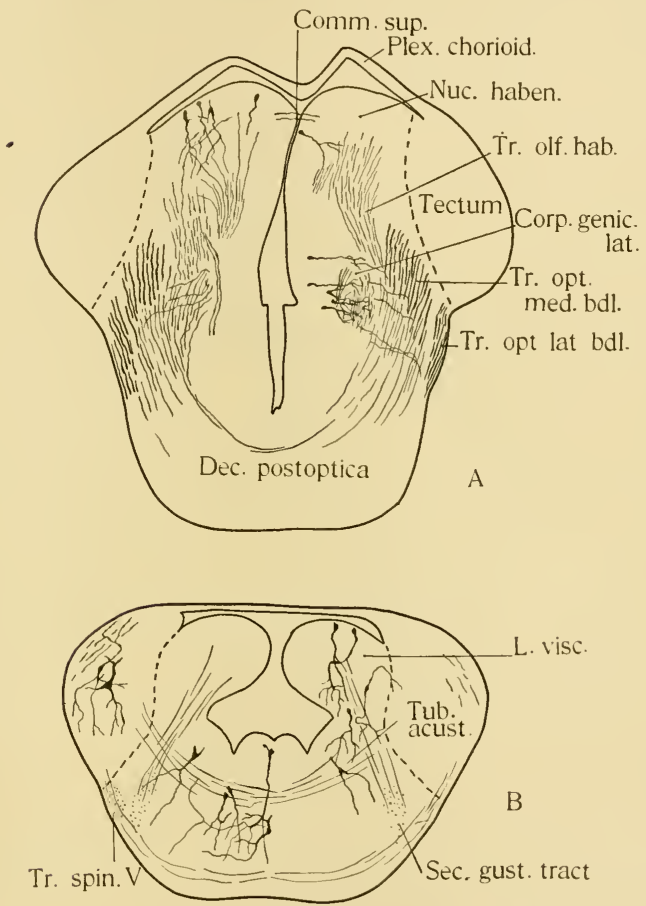

Fig. 14r.- Transverse sections through the brain of Amia at the level of the nucleus habenulae and of the facial lobe. Comm. sup. indicates the position in which the habenular commissure appears in the next adjacent section. The drawings were made from Golgi sections with the aid of the camera.

jecting into the ventricle, its cells either border upon the ventricle or are arranged in rows parallel with the ventricular surface, and the membranous roof passes beyond the nucleus habenulae and is 
attached to the dorsal border of the corpus geniculatum laterale. This shows clearly that the latter body forms the dorsal border of the brain wall. The nucleus habenulae has risen up mesial to it and pushed it outward. This will become clearer on comparison with the relations of the visceral and somatic sensory nuclei

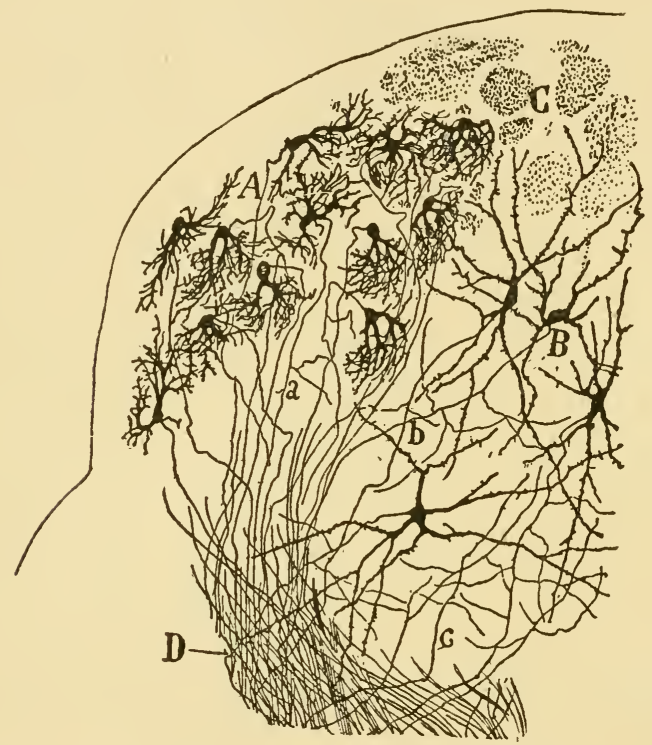

Fig. 142.-Transverse section of the habenular nuclei in the dog. From Cajal (Textura, etc.). $A$, internal nucleus; $B$, external nucleus; $C$, stria thalami; $D$, tractus habenulo-peduncularis. Only the internal nucleus corresponds to the nucleus habenulae in the sturgeon (Fig. I40).

in the medulla oblongata. In Figure I4I are drawn two sections from the brain of a young freshwater dogfish (Amia), one through the medulla oblongata and one through the nucleus habenulae. It will be seen that in both the somatic sensory centers, which are morphologically dorsal, are turned out to the side and are 
overtopped by the visceral lobe and the nucleus habenulae respectively. The position of the nucleus habenulae is in every way analogous to that of the vagal or facial lobe. In both cases a more median and ventral body has been hypertrophied and has pushed up until it has overtopped a more dorsal and lateral body. The nucleus habenulae has overtopped the geniculatum just as the vagal lobe or the facial lobe in bony fishes has overtopped the acusticum.

In mammals the nucleus habenulae is composed of a mesial portion similar in structure to the nucleus in fishes, and of a lateral portion which has a very different structure (Fig. I42). Two similar portions are to be recognized in the nucleus habenulae of some bony fishes also. Several fiber tracts are said to be connected with the nucleus habenulae in addition to those mentioned above but it is not known how the two portions of the nucleus are related to these tracts.

5. THE NUCLEUS OF THE TRACTUS STRIO-THALAMICUS AND THE SUBSTANTIA RETICULARIS THALAMI.

The large nucleus of the tractus strio-thalamicus, as already stated, lies in the stem region of the thalamus. In bony fishes it is divided into the two large muclei dorsalis and ventralis (nucleus rotundus Fritsch). From these nuclei arise the large tractus thalamo-bulbares et spinales which constitute an important part of the fundamental bundles in the medulla oblongata. It is to be noticed that the striatum is not a secondary olfactory nucleus, but is a correlation center for olfactory, gustatory and perhaps other impulses, and that the tractus strio-thalamicus is a descending tract or motor tract. The pathway is broken once in the thalamus and the fibers arising here probably make connection with widely separated motor nuclei in the brain and spinal cord. These functional relations emphasize the statement made above that these tracts represent the stem or base of the interbrain and forebrain. Essentially the same motor conduction path is found in all vertebrates, although its functional relations may be somewhat modified in mammals on account of the cerebral cortex.

In all vertebrates there remains surrounding the ventricle a 
mass of central gray and in more highly specialized forms (teleosts, birds, mammals) special nuclei are present in addition to those mentioned. The functional relations of these are not yet sufficiently understood. It must be noted that some of these nuclei which constitute correlating centers of a higher order than those described above, by some authors have been assigned without reason to the hypothalamus. Thus the nucleus rotundus and even the corpus interpedunculare of bony fishes have been included in the hypothalamus. Equally unfounded is the assignment of the corpus Luysii, the field of Forel and adjacent centers in mammals to the hypothalamus. The term hypothalamus should be strictly limited to the infundibular and mammillary regions which have secondarily bulged ventrally and which serve as centers related to olfactory conduction paths.

\section{THE SACCUS APPARATUS.}

In all lower vertebrates the saccus vasculosus is a wide sac, sometimes much branched, with epithelial lining and with an extremely rich blood supply in its walls. This outgrowth of the brain wall comes into very close relation with the vestige of the hypophysis, the branching tubes of the saccus often being interdigitated with the epithelial sacs of the hypophysis. This fact has led many authors to ascribe to the hypophysis nervous structures which really belong to the saccus.

The saccus is a part of the brain wall and is composed of elements characteristic of the brain wall. The vascular plexus is of course of mesodermal origin. Within this the saccus consists of a layer of nerve fibers and an epithelium bounding the cavity which is a part of the brain ventricle. The epithelial lining is made up of supporting cells and nerve cells. The supporting cells form an internal limiting membrane as in the rest of the brain and extend through the fiber layer in which they form a supporting meshwork. These cells are therefore comparable with the ependyma cells of the brain. The nerve cells have been described in several fishes both in embryonic and adult stages (Lundborg, Johnston). They are rather large spindle-shaped cells whose inner ends bear a tuft of cilia projecting into the ventricle. Such cells are already 
present in the floor of the brain ventricle in Amphioxus in a position corresponding to that of the saccus; a fact which indicates how ancient a structure the saccus is and that it functions in relation to the brain ventricle. In fishes the ciliated cells taper to a point at their outer ends and give rise to nerve fibers which help to form the fiber layer. These cells may be compared with typical primitive nerve cells elsewhere in the brain. The nerve fiber arises from the peripheral end of the cell as in the case of the neuroblasts in the embryo, and the cell-body retains the position in the epithelial lining which is characteristic of the

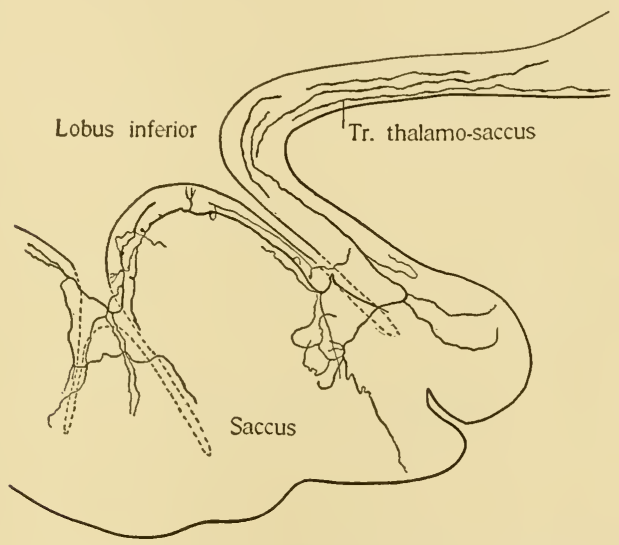

Fig. 143.- The efferent tract to the saccus vasculosus in the sturgeon. The drawing represents a sagittal section a little to one side of the median plane through the front part of the saccus and a part of the ventral wall of the inferior lobe. The course and main branches of three fibers are shown, from among the many impregnated in the section.

germinal cells and many neuroblasts. Well developed nerve cells which retain their epithelial position are very numerous in the brain of fishes (cf. p. 48). The saccus cells do not produce dendrites but instead bear cilia projecting into the ventricle. It must be supposed that these cells receive stimuli of some sort, whether vibratory or chemical, from the cerebro-spinal fluid. 
The impulses are carried by the neurites of the sense cells to the thalamus. The fibers form symmetrical tracts which in the sturgeon run up through the walls of the corpora mammillaria to end in a nucleus adjacent to the nucleus of the tractus striothalamicus in the extreme ventral part of the thalamus (Figs. I33, I34). In bony fishes the nucleus is situated lower down and a part of the tract decussates in the caudal wall of the corpora. mammillaria (Goldstein). The tract in teleosts also arises from the ciliated cells of the saccus (Johnston) and a similar tract is present in selachians. The tract does not arise in the dorsal part of the thalamus and end in the saccus as Edinger described it, but arises in the saccus. The secondary connections of the endnucleus of this tract are not clear, but in teleosts a secondary tract has been traced caudally over the ansulate commissure.

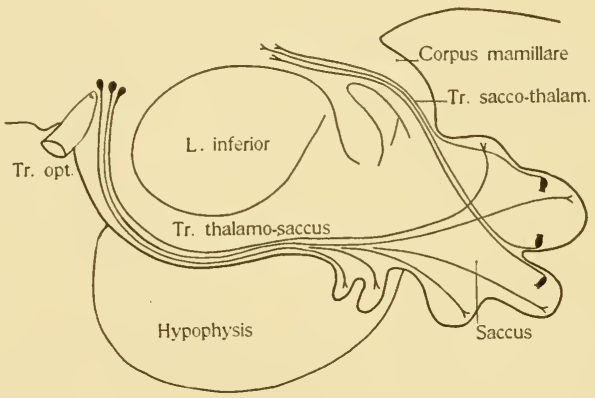

Fig. 144.-A general scheme of the saccus tracts as projected upon the median plane.

In addition to the tractus sacco-thalamicus a tract goes out from the hypothalamus to end in the saccus. This tract comes in the sturgeon from the region just behind the optic chiasma (Fig. I43) and in the salamander the origin of its fibers from cells in this position has been demonstrated (Bochenek). The fibers of this tract go to all parts of the saccus vasculosus and ramify richly among the cells of the epithelium. In the salamander 
the ciliated cells are said to be absent. A general scheme of the saccus apparatus is given in Fig. I44.

In mammals there is a sac with epithelial lining and dorsal to it a thick mass containing numerous cells of doubtful character and a rich plexus of nerve fibers (Berkeley, Cajal). From this plexus fibers pass into the epithelium to end freely among its cells (Cajal, Gemelli). The nerve plexus is connected with the brain by a large tract which runs along the raphe of the tuber cinereum. The tract takes origin from a nucleus situated directly over the optic chiasma. The tract and nucleus correspond in position to the efferent tract, and its nucleus in fishes. The epithelial sense cells and the tractus sacco-thalamicus have not been described in mammals.

In all classes of vertebrates this outgrowth of the brain wall is present and is provided with nervous elements. Although the structure has been very incompletely studied, enough is known from fishes, amphibia and mammals to indicate that the relations of the saccus are fairly constant in the vertebrate series. The only suggestion regarding its function is that it serves as an organ for controlling the character of the cerebro-spinal fluid. Its plentiful blood supply and its thin wall adapt it for secreting fluid into the brain ventricle. The existence of a double nerve supply, both centripetal and centrifugal, indicates that it does more than simply secrete. The ciliated cells must be regarded as sense cells and it is conceivable that they may be stimulated by changes of either pressure, density or chemical character in the cerebro-spinal fluid. In response to these stimuli the saccus may secrete some specific constituents of the ventricular fluid. The tract which ends in the saccus epithelium would arouse or control this secretive activity.

7. Mention may be made here of an epithelial structure resembling in some respects the saccus epithelium, which forms the base of the epiphysis in the roof of the diencephalon. This epithelium receives the free endings of nerve fibers and gives rise to fibers which go in various directions. Part of the in-coming and out-going fibers form a commissure over the base of the epiphysis (Holt, Johnston).

The fate of the four functional divisions in the midbrain and 
interbrain may now be reviewed in a few words. The motor columns are represented only by the nucleus of the III nerve and the thalamic nucleus of the fasciculus longitudinalis medialis, which belong to the somatic motor division. The presence of efferent sympathetic fibers in the III nerve in mammals indicates the presence in the midbrain of cells representing the visceral efferent column, but they have not yet been recognized as a definite column, unless the nucleus of origin of the mesencephalic root of the $\mathrm{V}$ nerve be that column. The somatic sensory division is represented by the tectum mesencephali, the corpus geniculatum laterale and mediale, and the nucleus of the medial lemniscus in the thalamus. With the exception of the mesencephalic root of the trigeminus, only secondary or tertiary tracts end in these nuclei. The tectum mesencephali is clearly the continuation forward of the primary cutaneous centers of the cord and medulla oblongata. It has been modified into a center which is chiefly secondary. In the diencephalon the corpora geniculata and the nucleus of the lemniscus are situated in the dorsal region and hold essentially the same relation to sensory tracts as do the several nuclei in the tectal region of the mesencephalon. In both midbrain and interbrain a relatively indifferent region has developed special nuclei for visual, cutaneous and auditory impulses. The fact is clear that the position of all the centers mentioned with relation to the axis of the brain and to other chief columns is the same as that of the somatic sensory columns in other segments, and the conduction paths in which these centers form stations are all somatic sensory conduction paths. The recent description of the brachium conjunctivum in mammals as a tract from the nucleus dentatus to the optic thalamus of the opposite side, brings the brachium into close comparison with the lemniscus system and adds an important fact to the grounds upon which the above interpretation of the diencephalon is based.

The visceral sensory division is not represented by any known special centers in the midbrain but in the interbrain it is largely developed and includes centers in gustatory pathways. The visceral sensory column (or the substantia reticularis belonging to it) has been distorted by the expansion and shifting of the 
centers lying in the two interbrain segments in such a way that a part of this column lies far dorsad (nucleus habenulae) and a part far ventrad (hypothalamus). This has been fully set forth above.

Finally, a considerable part of the adult midbrain and interbrain consists of substantia reticularis or nuclei derived from it, whose morphological and genetic relations to the primary functional divisions are unknown.

THE COMmissures OF THE BRAIN.-The facts regarding the chief brain commissures which have been scattered through the foregoing pages may be brought together here for convenience of reference. It should be noted at the start that the fibercrossings in the lower vertebrates are for the most part mere decussations. The dorsal decussation of the spinal cord in higher vertebrates contains visceral sensory (sympathetic) fibers, collaterals from cutaneous and visceral fibers, and secondary fibers from both somatic and visceral sensory columns. At the junction of the spinal cord and brain, i.e. just behind the choroid plexus of the ventricle, in all vertebrates this decussation is greatly enlarged. This enlarged portion, known as the commissura infima (Figs. 81, 82, 83, 90, 92), is due chiefly to an increase of the visceral sensory fibers from the roots of the VII, IX and X nerves and of secondary visceral fibers arising from the nuclei of those nerves. Other fibers in this commissure come from the cells of the nucleus funiculi. The dorsal decussation of the cord is therefore mixed somatic and visceral in character. These two components must be rigidly distinguished if the dorsal decussations of the brain are to be understood.

The dorsal decussation of the medulla oblongata is not obliterated on account of the non-nervous roof, but its elements are crowded forward or backward. Behind the choroid plexus the commissura infima contains the visceral sensory elements proper to the segments of the VII, IX and X nerves. It is probable that the course of the root fibers of these nerves within the brain has been influenced by the crowding backward of their decussation and median nucleus by the choroid plexus. It is further probable that those fibers which take this caudal course are the more 
primitive components of these nerves, namely the general visceral fibers as distinguished from taste fibers. The point of special interest is that the concentration of the visceral decussation for the VII, IX and $\mathrm{X}$ nerves behind the choroid plexus precludes the expectation that the visceral elements of the first order will be found in the dorsal decussations farther forward. There are no visceral nerves anterior to $\mathrm{N}$. VII.

The somatic sensory elements have behaved differently with reference to the IV ventricle. Instead of concentrating behind it they have concentrated in front of it. In those vertebrates in which the cerebellum is most primitive (Petromyzon, Protopterus, Urodeles) a decussation constitutes a prominent part of it. This decussation consists of axones of granule cells situated in the cerebellum destined to the somatic sensory nuclei of the medulla oblongata. This is therefore to be considered as the homologue of the somatic sensory portion of the dorsal decussation of the spinal cord. It is an important decussation in all lower vertebrates.

A second prominent cerebellar decussation is found in fishes. This is situated in the velum medullare anterius or in the enlarged equivalent of the velum, the valvula cerebelli of ganoids and bony fishes. Instead of connecting the dorsal portions or lateral lobes of the cerebellum, this commissure connects two nuclei which in fishes lie in the lateral walls distinctly rentral to the somatic sensory centers, the superior secondary gustatory nuclei. The fibers of the secondary gustatory tract coming from the visceral sensory column end in part in the secondary gustatory nucleus of the same side and in part cross to the opposite side. The remainder of the decussation is formed of the neurites of the cells of these nuclei. The destination of these fibers is not certainly known, so that it is uncertain whether a true commissure is present. It is evident, however, that the inferior cerebellar commissure belongs to the visceral sensory division of the nervous system.

The dorsal decussation of the tectum mesencephali must be regarded as a somatic sensory decussation comparable with the somatic sensory portion of the dorsal decussation in the spinal cord.

The posterior commissure has been discussed above (p. 265). 
In the roof of the diencephalon two decussations are present, the well-known superior or habenular commissure and a decussation closely related to the base of the epiphysis known only in a few forms. The habenular commissure contains decussating fibers from the olfactory nuclei of the forebrain (tractus olfacto-habenularis) and also probably true commissural fibers. It is to be compared with the inferior cerebellar commissure. Decussating fibers of the second and third order are present in each case and the nuclei in both cases are specialized parts of the substantia reticularis related to visceral functions.

The post-epiphysial decussation has been described only in ganoids (Johnston), bony fishes (Holt) and the horse (Favoro). It is poorly understood but deserves further study.

The anterior commissure, which will be described in the next chapter, is a dorsal decussation which, so far as at present known, is related in lower vertebrates to centers belonging to the visceral sensory system (olfactory and gustatory). In higher vertebrates two large commissures, one related to the olfactory cortex, the other to the somatic pallium, are developed from the anterior commissure.

The dorsal decussations may be summarized by saying that the mixed dorsal decussation of the cord has been differentiated in the brain into separate somatic and visceral sensory decussations. The commissura infima, the inferior commissure of the cerebellum, the habenular commissure and the anterior commissure represent the visceral portion. The superior commissure of the cerebellum, the dorsal decussation and posterior commissure in the mesencephalon (and the corpus callosum in the telencephalon) represent the somatic portion.

The ventral decussation of the spinal cord consists of internal arcuate fibers and of the neurites of heterolateral tract cells. It is in smaller part a decussation of secondary sensory tracts, in larger part belongs to the substantia reticularis. In the medulla oblongata the secondary sensory elements (lemniscus system) are more numerous and in the base of the mesencephalon a large number of fiber tracts decussate in the region of the nuclei of the III and IV nerves. These tracts are in part tertiary sensory tracts, in part descending tracts from somatic and visceral correlat- 
ing centers going to make motor connections in the medulla oblongata and spinal cord. The complexity of these decussations is very great and the region is by no means well understood. For attempts at the analysis of the midbrain decussations the student must be referred to the papers by Edinger, Johnston, and Goldstein. The great number of decussating fibers in this region is due to the projection ventrad of the inferior lobes, which has crowded back the decussations from the segment of the diencephalon.

At the cephalic border of the hypothalamus another collection of decussating fibers is due in part to the same cause. These constitute the postoptic decussations. The optic chiasma has already been compared to the fibers of the lemniscus system in the ventral decussation of the medulla oblongata. The postoptic decussations are to be compared in a broad way with the other elements of the ventral decussation. They belong chiefly to the substantia reticularis, either of the hypothalamus or of the nuclei in the collicular region of the mesencephalon. These decussations have not yet been fully analyzed and the comparison of those in fishes and mammals is especially difficult. For the most recent treatment of these decussations the reader is referred to the papers of Myers, Kappers, and Goldstein. In Petromyzon the tractus lobo-epistriaticus, and in selachians the tractus olfactohypothalamicus lateralis decussate in the postoptic region.

\section{DEMONSTRATION OR LABORATORY WORK.}

I. Study the general relations of the thalamus, hypothalamus, saccus and nucleus habenulae in haematoxylin preparations of the brain of a ganoid, bony fish or selachian, in the frog and in a mammal.

2. Study the cells and fibers in the hypothalamus and nucleus habenulae in a fish brain by the method of Golgi. Study the general course of the chief fiber tracts in Weigert sections of the same brain.

\section{LITERATURE.}

Berkeley: The Nerve Elements of the Pituitary Gland. Johns Hopkins Hospital Reports, Vol. 4. I 895 .

Bochenek, A.: Neue Beiträge zum Bau der Hypophysis cerebri bei Amphibien. Bull. internat. Akad. Sc. Cracovie. I902.

Boeke, J.: Die Bedeutung des Infundibulums in der Entwickelung der Knochenfische. Anat. Anz., Bd. 20. Igor. 
Boeke, J.: Ueber das Homologon des Infundibularorganes bei Amphioxus lanceolatus. Anat. Anz., Bd. 21. I902.

Cajal, S. R.: Textura del sistema nervioso del Hombre y de los vertebrados. Edinger, L.: Utersuchungen u.s.w. 2. Das Zwischenhirn. Abhdl. d. Senkenberg. Naturf.-Gesell. I888.

Edinger, L.: Untersuchungen u.s.w. 4. Studien über das Zwischenhirn der Reptilien. Ibid. I899.

Gemelli: Nuove Richerche sull Anatomia e sull Embriologia dell Ipofisis. Boll. della Soc. med.-chirurg. de Pavia. I903.

Goldstein, K.: Vorderhirn und Zwischenhirn einiger Knochenfische, u.s.w. Arch. f. mik. Anat., Bd. 66. I905.

Herrick, C. Judson: The Central Gustatory Paths in the Brains of Bony Fishes. Jour. Comp. Neur. and Psych., Vol. I5. I905.

Hill, Charles: Developmental History of the Primary Segments of the Vertebrate Head. Zool. Jahrb., Bd. I3. I899.

Holt, E. IW. L.: Observations on the Development of the Teleostean Brain with especial reference to that of Clupea harengus. Zool. Jahrb., Bd. 4. I89o.

Johnston, J. B.: The Brain of Acipenser. The Brain of Petromyzon.

Kappers, C. U. A.: The Structure of the Teleostean and Selachian Brain. Jour. Comp. Neur. and Psych., Vol. I6. Igo6.

Koelliker, A.: Gewebelehre. 6te. Aufl. Bd. 2.

Lundborg, H.: Die Entwickelung der Hypophysis und des Saccus vasculosus bei Knochenfischen und Amphibien. Zool. Jahrb., Bd. 7. I895. 


\section{CHAPTER XVIII.}

\section{THE EVOLUTION OF THE CEREBRAL HEMISPHERES.}

The cerebral hemispheres of man are the largest and most complex part of the nervous system. They are also proportionately larger and more complex than in animals. The degree of development of the cerebral hemispheres is correlated with the mode of life of the animal. The greater size and the complexity of internal structure of the hemispheres in man are a measure of the degree of organization of his activities, the perfection of his adjustment to the manifold aspects of his environment, and the correlation of experience which makes such adjustment possible. The cerebral hemispheres constitute a mechanism whose structure is determined by all the experience of the race and of the individual, and in the working of whose minute parts is found the means of directing every one of the more complex activities of the man. In order to understand this highly organized mechanism every means of study must be employed, and nowhere has the comparative method proved more useful than here. The differences between the human cerebrum and that of lower animals would seem at first sight to be so great as to make intelligent comparison impossible. In fact, as will appear below, the most fundamental parts of the cerebral hemispheres of man are present and have the same structure in all vertebrates, while for the study of the most highly specialized parts comparison with the various orders of mammals is very fruitful.

The hemispheres of man are divisible into three widely different parts. The part by which the hemispheres are directly connected with the rest of the brain is a thick bi-lobed mass consisting of collections of nerve cells pierced by numerous large bundles of fibers and is known as the basal ganglion or corpus striatum. It is by way of the corpus striatum that the chief fiber tracts connecting the hemispheres with the rest of the brain pass to or from the 
thalamus. Lying in front of and below the corpus striatum and forming part of the lower and mesial wall of the hemispheres at the anterior end are the olfactory bulb and olfactory lobe. On the ventral surface of the striatum is the mucleus amygdalae which is continuous caudally with the pyriform lobe and the hippocampus in the temporal region of the hemisphere. These several structures, together with the fornix and hippocampal commissure constitute the second main portion of the hemisphere, and may be spoken of collectively as the central olfactory apparatus. All the rest-much the greater part-of the cerebrum is concerned with sensory impulses from the external world which come from various parts of the body including the special sense organs of sight and hearing; with the correlation of these impulses with one another and with habitual tendencies produced by previous actions; with voluntary impulses sent out to arouse, direct or inhibit actions in response to stimuli; with sensations; and with thought processes. This portion of the cerebral hemispheres may be spoken of as the somatic pallium. The phylogenetic history of these three portions of the forebrain has formed one of the most obscure chapters of comparative morphology. If it is possible to frame a connected account of the evolution of these structures, it will render the study of the human cerebrum simpler and its relations more intelligible.

In order to gain a clear view of the vertebrate forebrain it will be necessary to begin with the lowest classes and give as concise an account as possible of the centers and fiber tracts and their functional relations in one class of vertebrates after-another, endeavoring to fix with as great certainty as possible the homology of the most important structures and to harmonize those inconsistencies which arise from differences of nomenclature or interpretation of known facts. In such a survey the guiding principle must be functional relationship. When a given center or fiber tract is clearly recognized anatomically, the questions must be asked, what is its function; with what other centers or fiber tracts is it related; with what kind of impulses is it concerned?

THE FOREBRAIN of CyCLOSTOMES consists of paired lateral lobes and of a mesial portion connected with the diencephalon. 
The lateral lobes are rounded and are divided into anterior and posterior portions by a slight groove on the lateral surface, nearly vertical in position. If the brain be cut into halves in the median sagittal plane and one half looked at from the mesial surface (Fig. 145) the relation of all the parts can be better seen. In such a hemisection there is seen in the dorsal wall of the dien-

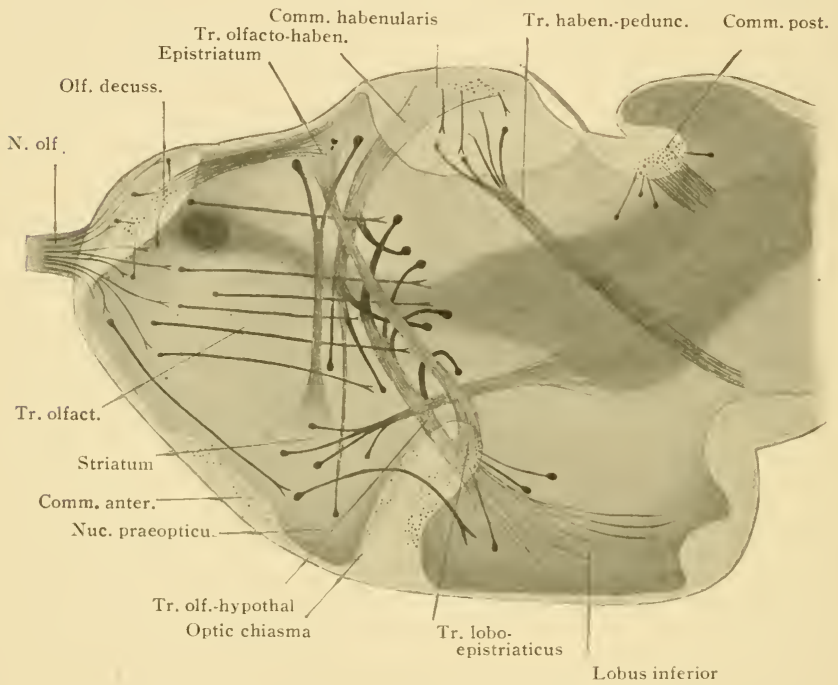

Fig. 145.-A diagram of the fiber tracts in the forebrain of a cyclostome, Lampetra Wilderi. The mesial surface of the right half of the forebrain and interbrain is drawn. The deeper shading indicates the wider parts of the ventricle and the dark oval opening is the foramen of Monro. The fiber tracts and parts of them which lie farthest laterad are drawn in the darkest shade.

cephalon the thick nucleus habenulae and opposite it ventrally the optic chiasma and the decussations of other tracts. Behind this is the depressed hypothalamus. The limit between the diencephalon and telencephalon is roughly indicated by a line drawn between the optic chiasma and the nucleus habenulae. In front 
of this line the median or third ventricle extends forward through the whole length of the telencephalon (cf. Fig. 8). It is bounded laterally by thick walls but dorsally and ventrally the walls are much thinner. Just in front of the optic chiasma the floor of the ventricle is suddenly depressed to form the preoptic recess. In front of this recess is the point corresponding to the lower edge of the neuropore in the embryo. From this point forward and upward the brain wall is formed by the closing of the neuropore in the median line. As this is regarded as the end of a closed tube the front wall of the median ventricle is called the lamina terminalis. The lower portion of the lamina terminalis is thickened by the anterior commissure, and the upper portion of it is also thickened by a transverse band of fibers known as the olfactory decussation. Immediately above the olfactory decussation is seen a short triangular projection of the ventricle which marks the point at which the neural tube remained longest in connection with the ectoderm. This was probably at the upper border of the neuropore and the little sac is called the recessus neuroporicus. From the recessus neuroporicus back to the nuclei habenulae the roof of the median ventricle is membranous. This is a part of the true brain roof and does not belong to the lamina terminalis. There is no such thing as a pars supraneuroporica of the lamina terminalis. In the front part of the forebrain the median ventricle expands laterally into the cavities of the lateral lobes. These cavities are the lateral ventricles and each has an anterior and a posterior branch corresponding to the two parts of the lateral lobes. These must not be confused with the anterior and posterior horns of the lateral ventricles in man, since both together correspond more nearly to the anterior horn in man. The connection of the median with the lateral ventricle of each side is known as the foramen of Monro.

Into the anterior half of each lateral lobe the olfactory nerve enters and its fibers are distributed to all parts of the anterior half of each lobe. This anterior part of the lateral lobe is therefore the olfactory bulb. It consists of a great number of slightly differentiated cells (Fig. 94) from which arise the fibers of the olfactory tract. These fibers pass back into the posterior portion 
of the lateral lobes, to the whole extent of which they are distributed. These are the olfactory lobes, including the equivalent of the mucleus thaeniae of higher forms. The vertical groove in the

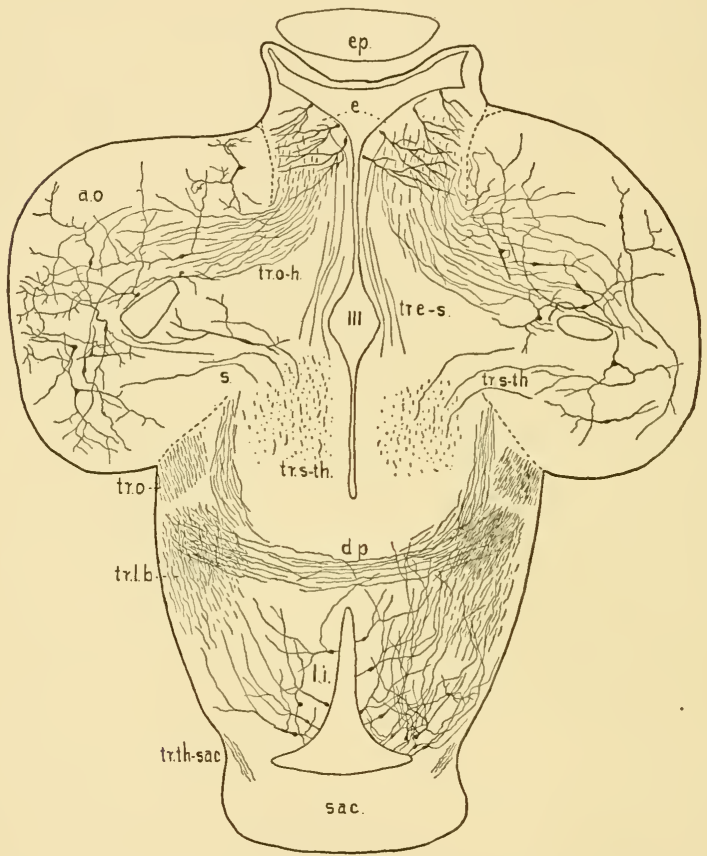

Fig. I46.-An oblique section through the inferior lobes and forebrain of Lampetra. III, median ventricle; $a . o$, , olfactory lobe; $d . p$., postoptic decussation; $e$, epistriatum; $e p$. , epiphysis; tr.e-s., neurites of epistriatum cells to striatum; $t r . l-b$., tractus lobo-bulbaris; tr.o., tractus opticus; tr.o-h., tractus olfacto-habenularis; tr.s-th., tractus strio-thalamicus; tr.th-sac., tractus thalamo-saccus; sac., saccus vasculosus.

lateral wall separating the olfactory lobes from the bulbs is the only external indication of the olfactory tract, which is usually recognizable externally in other vertebrates. A part of the olfac- 
tory tract fibers do not pass back on the same side but cross to the opposite side in the upper part of the lamina terminalis, forming the olfactory decussation. These fibers then enter the dorsal part of the wall of the median ventricle and do not go to the lateral lobes. This lateral wall of the ventricle is directly continuous caudally with the lateral wall of the diencephalon and through the foramen of Monro with the caudal wall of the olfactory lobe. The nucleus which occupies this area is the epistriatum (Fig. I46). The olfactory tract, then, goes in greater part to the olfactory lobe of the same side and in lesser part through a decussation in the lamina terminalis to the epistriatum of the other side.

From the olfactory lobe two tracts arise. One passes internal to the optic tracts and enters the inferior lobes of the diencephalon, the tractus olfacto-hypothalamicus. The other goes upward and backward through the epistriatum to the nucleus habenulae, where the larger part of its fibers cross to the opposite nucleus, forming the commissura habemularis. This is the tractus olfactohabemularis. In addition to fibers of the olfactory tract which end in the epistriatum an equally large tract comes to it from the hypothalamus by way of a decussation behind the chiasma. This is an important tract the equivalent of which is probably found in all vertebrates, usually in close relation with the tractus striothalamicus. It should be recognized as an independent tract under the name of the tractus lobo-epistriaticus. The epistriatum is characterized by pyramidal cells whose dendrites are studded with little knobbed spines. The cell-body lies next the ventricle and the neurite arises from the basal part of a dendrite and proceeds away from the ventricle. The neurites descend through the lateral wall of the median ventricle and end in the ventral half of the same wall, which constitutes the corpus striatum. The cells of the striatum are irregularly arranged bipolar or stellate cells whose neurites form the tractus strio-thalamicus, which ends in the central gray of the thalamus. Surrounding the preoptic recess is a layer of cells of very primitive character forming the nucleus praeopticus. The neurites from this nucleus in part run dorsad to enter the tractus olfacto-habenularis and in part run back over the chiasma into the hypothalamus. The 
fibers which constitute the anterior commissure have not been definitely traced.

This is the most primitive type of forebrain that has been studied. It is concerned with olfactory impulses and possibly with gustatory impulses which may reach the epistriatum by way of the hypothalamus. It will be seen as the account proceeds that the centers and fiber tracts which have been described are preserved in higher vertebrates.

THE SELACHIAN FOREBRAIN.-The forebrain of the primitive selachians (e.g. Heptanchus, Fig. 2) and of the Holocephali (Chimaera, Fig. 7) is rather slender and elongated. That of the more specialized forms (e.g. Squalus acanthias, Figs. II and I47, Scyllium, Raja, Torpedo, etc.) is much more massive and compact in form. The difference is chiefly a difference in size due to the greater development of certain parts of the brain in more specialized selachians. In both, the walls of the median ventricle are essen- . tially as in cyclostomes except that the ventro-cephalic and the front part of the lateral wall are enormously thickened. The foramen of Monro leads laterally from the front end of the median ventricle into the lateral ventricle which traverses the thick lateral mass and continues forward through a more or less elongated olfactory tract into the olfactory bulb (Fig. 8). This is the typical form for the olfactory bulb in vertebrates. In cyclostomes the bulb has been pushed out to the side and backward by pressure from the large buccal funnel, and the side wall of the forebrain (olfactory lobe) has been folded outward and backward so as to form a sort of posterior horn to the lateral ventricle which is quite peculiar to the cyclostomes.

The great mass at the front of the brain is composed of two parts the limits between which are readily seen in Figs. II and I47. Above and in front of the foramen of Monro the median ventricle is produced into a small pointed sac, the recessus neuroporicus. This meets a fibrous strand from the pia which descends through a narrow canal from the dorso-cephalic surface of the forebrain. This canal marks the dorsal border of the lamina terminalis and the mass lying in front of it is formed by a thickening of the lamina terminalis and of the adjacent wall, between the bases of the two 
olfactory tracts. As indicated in Figures $8 \mathrm{~B}$ and 9, the great growth of the front walls of the lateral lobes has resulted in their apposed mesial faces fusing together so as to give the appearance of an enormously thickened lamina terminalis. The preservation of the anterior branch of the lateral ventricle and of the canal from the dorsal surface serves to show the primary form of this region. At either side of the recessus neuroporicus in Figure 8

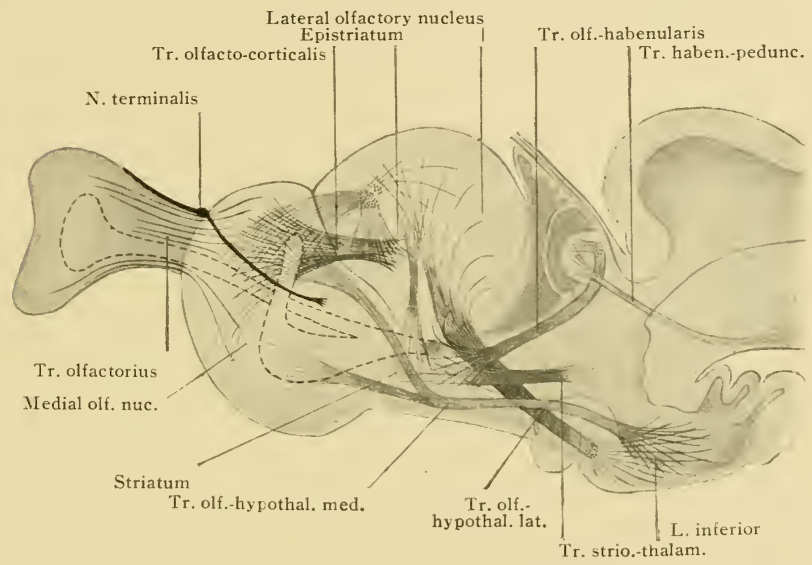

Fig. 147.-A diagram of the fiber tracts in the forebrain of a selachian. The mesial surface of the right half of the brain of Squalus acanthias is drawn and the fiber tracts projected upon it. The course of the tracts is taken chiefly from the description by Kappers, but the work of Catois, Edinger, Houser, Locy and others has been considered.

$\mathrm{B}$ is seen a ridge projecting into the lateral ventricle, the regio uncinata. This represents the front wall of the brain immediately adjacent to the lamina terminalis. The great mass which has been formed by the expansion, thickening and bending upward of the front walls of the brain between the olfactory bulbs will be called the mesial olfactory mucleus.

The lateral walls have also grown up, thickened enormously and fused together over the ventricle to form the massive roof 
seen in Figure 147 behind the canal leading to the recessus neuroporicus. The basal portion of the lateral wall is occupied by the corpus striatum. The outer layers of the lateral wall and of the thick roof constitute the lateral olfactory nucleus. The inner surface of both the striatum and the lateral olfactory nucleus is covered by a gray layer rich in small cells which bounds the ventricle both ventro-laterally and dorsally. This is the epistriatum.

The course of the fiber tracts will show the functional significance and homology of the various parts of the selachian brain. The olfactory tract spreads through the whole anterior and lateral wall and ends in the mesial and lateral olfactory nuclei. From each of these nuclei a tract runs to the hypothalamus. The first gathers from all parts of the mesial nucleus, curves downward and backward in the thick front wall, runs back near the mid-ventral line and joins the tractus strio-thalamicus. This tract should be called the tractus olfacto-hypothalamicus medialis. The second tract collects from the lateral olfactory nucleus, runs downward and backward through the lateral wall, passes over the optic chiasma, forms a decussation behind the chiasma and ends in the hypothalamus. This tract has usually been called the pallial tract because the nucleus from which it arises forms the roof of the forebrain. This nucleus, however, is the place of ending of olfactory tract fibers and is hence merely a part of the olfactory lobe. The tract in question should therefore be called the tractus olfacto-hypothalamicus lateralis. From the lateral part of the lateral olfactory nucleus another tract arises which runs along the dorsal border of the narrow lateral wall of the posterior part of the forebrain and enters the nucleus habenulae. Here the tract decussates with its fellow to form the habenular commissure and ends in the nucleus habenulae of the opposite side. This is the tractus olfacto-habenularis and corresponds to the tract of the same name in cyclostomes. That part of the lateral olfactory nucleus from which it arises may be called the mucleus thaeniae. The two tracts to the hypothalamus correspond to the one in cyclostomes, the existence of a separate medial tract in selachians being due to the extraordinary development of the olfactory apparatus. 
The commissures in the forebrain of selachians differ in some respects from those in other vertebrates. In the floor (lamina terminalis) in front of the recessus praeopticus is the anterior commissure which contains two sets of fibers: one coming from the tractus strio-thalamicus and the other from the lateral olfactory nucleus and both ending in the deeper parts of the lateral wall, the epistriatum. In the roof is a large commissure which contains two kinds of fibers. The greater part of it consists of a decussation which is said to be composed of fibers from the dorsal part of the mesial olfactory nucleus and not of olfactory tract fibers. The fibers of this decussation end in the regio uncinata and in the epistriatum. In addition to this a direct tract arises in the mesial nucleus and ends in the epistriatum of the same side. These tracts in the selachian brain are new as compared with the brain of cyclostomes. It must be held clearly in mind that these fibers form the third link in a chain of which the olfactory nerve and the olfactory tract form the first two links. These fibers therefore constitute a tractus olfacto-corticalis. The nucleus which receives these fibers is a center of the same grade as the olfactory cortex of higher vertebrates. That part of the epistriatum which forms this nucleus must be called the olfactory cortex or archi-pallium. The fibers which go out from this center are not well understood, but it is known that the neurites of cells in the epistriatum connect it with the striatum (tr. cortico-medialis). From this the tractus strio-thalamicus carries impulses to the thalamus. In the roof also is another fiber crossing which is said to be composed of true commissural fibers between the lateral olfactory nuclei. This commissure has no counterpart in other vertebrates; but an analogous commissure is seen in the medulla oblongata of some fishes. In some bony fishes the facial lobes are so largely developed as to fuse together over the ventricle and in the lobus impar so formed are found commissural fibers. So here, the lateral olfactory nuclei have arched over the ventricle and a large commissure is formed where they have fused together.

The scheme of the fiber tracts given in Figure 147 will make clear the general relations of the central olfactory apparatus. It should be noticed particularly that the tractus olfacto- 
hypothalamicus medialis curves down in front of the foramen of Monro.

In this figure there is shown also the root of the nervus terminalis which has its ending in the regio uncinata. The relations of the end nucleus of this nerve to the adjacent olfactory nuclei and the course of fibers arising in it have not yet been studied.

THE FOREBRAINS OF GANOIDS AND BONY FISHES can be treated together as they are much alike. The forebrain is elongated,

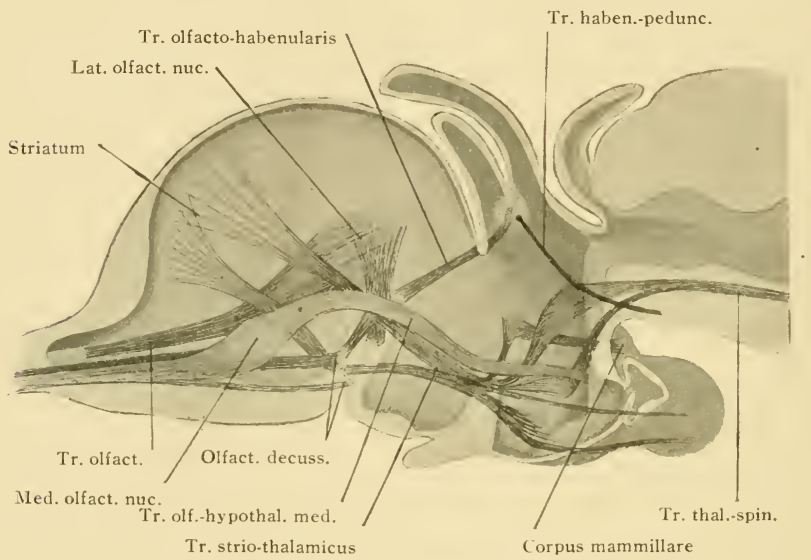

Fig. 148.-A diagram of the fiber tracts in the forebrain of a bony fish. The figure follows in the main a figure by Goldstein, and is drawn on the same plan as Figs. 146 and 147 .

the lamina terminalis is nearly horizontal, the lateral walls are thick but not high and the whole roof as far forward as the olfactory bulbs is membranous (Fig. I48). The median ventricle is large and spreads out wide under the membranous roof and at the cephalic end it bifurcates (foramina of Monro) into the rentricles of the olfactory bulbs. In the thick lateral walls are found nuclei corresponding to those in the selachian brain but much less well developed. The corpus striatum occupies the chief part of 
the basal and lateral wall and on its dorsal and internal surface is the epistriatum (Fig. I49). The olfactory lobe forms the whole thickness of the wall at the front part of the forebrain and covers the lateral surface of the striatum, but does not extend up into the roof. In the sturgeon a few nerve cells and fibers are found in the membranous roof which may be vestiges of the massive roof in selachians. In bony fishes the lateral olfactory nucleus is better developed than in ganoids and forms the nucleus thaeniae. The olfactory bulb lies forward as in selachians and is connected with the forebrain by a distinct olfactory tract. The

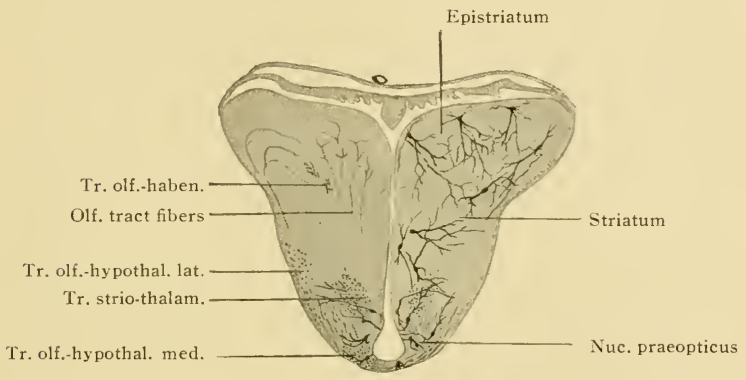

Fig. 149.-A transverse section of the brain of the sturgeon behind the anterior commissure. Compare Fig. 99

olfactory tract in ganoids (Fig. IOI) is distributed to all parts of the olfactory lobe and a part of it decussates in the cephalic part of the lamina terminalis to end in the epistriatum of the other side. In bony fishes the olfactory tract is in two bundles, a medial and a lateral. The lateral bundle ends in the lateral olfactory nucleus (nucleus thaeniae) and in some cases a part of it decussates in the anterior commissure. The medial bundle always decussates and is distributed to the lateral olfactory nucleus. In both ganoids and bony fishes there arises from the anterior part of the olfactory lobe a tractus olfacto-hypothalamicus medialis, and from the lateral part of the lobe (nucleus thaeniae) a tractus olfactohypothalamicus lateralis. From the nucleus thaeniae of bony 
fishes and from the whole olfactory lobe and nucleus praeopticus of ganoids arise the fibers of the tractus olfacto-habenularis which decussate in part in the habenular commissure and end in the nucleus habenularis. The epistriatum in the sturgeon receives a large tract of ascending fibers from the hypothalamus, the tractus lobo-epistriaticus, which decussates in the anterior commissure. This tract may bring gustatory impulses to the epistriatum. The neurites of the epistriatum cells in the sturgeon find endings in the striatum; in bony fishes they are said to go in the tractus strio-thalamicus to the thalamus. The anterior commissure contains fibers from the lateral olfactory nucleus to the epistriatum of the other side. From the nucleus praeopticus a tract goes back over the optic chiasma to the hypothalamus.

The scheme of fiber tracts given in Figure 148 shows that in essentials they agree with those of selachians. The olfactory lobe is smaller and does not extend up into the roof of the ventricle. The greater extent of the choroid plexus is due to the receding of the olfactory centers which in selachians help to form the roof. On this account there is no dorsal commissure but tertiary olfactory fibers cross in the anterior commissure and end in the epistriatum as in selachians. The primitive crossing of olfactory tract fibers which has not been seen in selachians is present in ganoids and bony fishes. The tracts to the hypothalamus and nucleus habenularis are essentially alike in all groups thus far described. The epistriatum of selachians is described as the place of ending of tertiary olfactory fibers only, while in ganoids it receives both secondary and tertiary olfactory tracts. Further investigation will probably show that the secondary olfactory fibers to the epistriatum are not absent in selachians. A prolonged discussion as to the nature of the pallium in bony fishes has been due especially to the elevation of the so-called pallium of selachians to the dignity of a true cortical center. Now that it is known that the pallium of selachians is a part of the olfactory lobe and that there is a close correspondence between the fiber tracts in selachians and bony fishes, it requires only the recognition of the slight development of the olfactory apparatus in bony fishes to explain the condition of the pallium. A greater or less part of the proper 
membranous roof has been displaced in selachians by the growing up, folding over and fusion of the lateral walls. In other fishes the corresponding part of the lateral wall is much smaller and the membranous roof is more extensive than in selachians. In

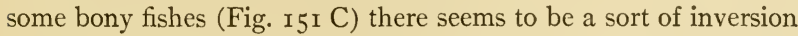
of the lateral wall, so that the striatum and epistriatum bulge high up in the ventricle and the pallium passes over them and is attached to the lateral wall on the ventro-lateral aspect of the brain. A membranous roof over the median ventricle is universally present in the forebrain of vertebrates. In the more specialized selachians the greater part of it is displaced by the upgrowth from the lateral walls; in bony fishes it is extraordinarily broad because of the reduction and receding of the lateral walls.

The nervus terminalis which is characteristic of selachian brains is found also in Amia, in Protopterus and in embryonic stages of Ceratodus, but nothing is known of its central connections.

THE FOREBRAIN OF AMPHIBIA presents two external peculiarities: first, the relatively great size and independence of the lateral lobes, and second, the fast that they extend forward far beyond the lamina terminalis. A glance at Figures 8 and 9 will show that the real difference between the amphibian and selachian brains in this regard is slight. In front of the lamina terminalis the lobes are separated by an open space known as the sagittal fissure. In the frog this fissure is bridged across by the fusion of the two olfactory bulbs, but remains open behind the bulbs. The internal structure of the amphibian forebrain has been puzzling chiefly because its fiber tracts and commissures are difficult to compare with those of other vertebrates. An understanding of the gross relations in one of the lower tailed forms, such as the hellbender (Cryptobranchus) or mud-puppy (Necturus), will help to make the finer structure intelligible. The median ventricle is relatively short (Fig. 150). Its floor in front of the optic chiasma is formed by the nucleus praeopticus and farther forward by the lamina terminalis, which is very greatly thickened by two commissures crossing one above the other in nearly the same plane. In front of the commissures the lamina terminalis is nearly vertical in position and becomes continuous with the membranous roof. This is 
folded into the ventricle to form the choroid plexus. The recessus neuroporicus is recognizable in the frog a little above and in front of the commissure as in Petromyzon. The caudal part of the roof is produced dorsally into a more or less branched sac, the paraphysis. The median ventricle is connected by wide foramina of Monro with the lateral ventricles, which extend forward into the olfactory bulbs and backward into the rounded posterior

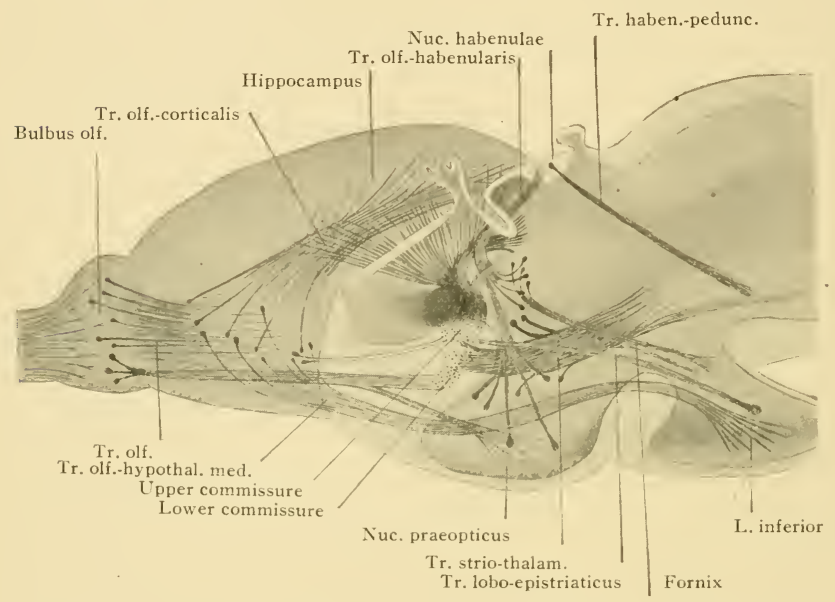

Fig. 150.-A diagram of the fiber tracts in the forebrain of a tailed amphibian, Necturus. The representation of the commissure is based wholly upon Weigert sections of the brain of Necturus. In drawing the other tracts the descriptions of P. Ramon, Van Gehuchten and Bochenek for other amphibia have been consulted. The tractus olfacto-hypothalamicus lateralis is represented as joining the tractus strio-thalamicus from above and going off from it to the inferior lobe.

part of the lateral lobes. For the purpose of describing centers and fiber tracts there may be distinguished in the lateral lobes a base or ventral wall, a lateral wall, a roof and a mesial wall. It will be convenient to anticipate the results of the following discussion and divide the mesial wall into a portion in front of the foramen of Monro called the septum (precommissural or parater- 
minal body), and a portion above the foramen of Monro which together with the adjacent dorsal and caudal parts of the hemisphere forms the hippocampus.

The fibers of the olfactory tract are distributed to the whole of the lateral wall and to the front part of the roof, base and septum and also to the nucleus praeopticus. A part of the olfactory tract decussates in the lower of the two commissures and goes to the lateral wall. As in selachians, then, the lateral and front walls of the hemispheres constitute the olfactory lobe. The base of the hemisphere is the corpus striatum. Fibers from the lateral wall pass back to the thalamus mingled with the tractus strio-thalamicus. They constitute a tractus olfacto-hypothalamicus lateralis, homologous with that in fishes. From the septum and part of the roof and base at the front end arise fibers which curve forward and downward and form a tract which runs backward near the mid-ventral line and enters the hypothalamus (tractus corticomedialis of P. Ramon in the frog). This corresponds to the tractus olfacto-hypothalamicus medialis in fishes. From the ventral and lateral part of the lateral wall, an area corresponding to the nucleus thaeniae in fishes, arises the tractus olfacto-habenularis which runs as in fishes. From the septum, which belongs to the olfactory lobe, fibers arise which run up and back and end in the caudal part of the mesial wall and roof, the tractus olfactorius septi of authors. This is a tertiary olfactory tract and corresponds to the tractus olfacto-corticalis in selachians, and should be given the same name.

The commissures are difficult to analyze and compare with those of other vertebrates. The lower commissure contains fibers of the tractus olfacto-hypothalamicus from the cephalic and lower half of the mesial wall (precommissural or paraterminal body, mesial olfactory nucleus), fibers of the tractus olfactorius which end in the recessus praeopticus, and fibers of the tractus striothalamicus. The lower commissure is placed in the base and lateral walls in very much the same position as the anterior commissure in fishes and it is usually called the anterior commissure proper. The upper commissure is very peculiar in its position and composition. It crosses from side to side in the lamina 
terminalis, causing a high ridge across the floor of the ventricle. At either side it rises up in the side walls just behind the foramen of Monro and bends forward over the foramen to be distributed to the upper half of the mesial wall and adjacent part of the roof. It also spreads back into the posterior part of the lateral lobe, into the part which is usually called the occipital pole. This name must not be taken to suggest any comparison with the occipital cortex of the human brain and would better be avoided.

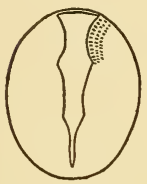

A

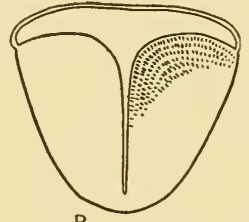

B
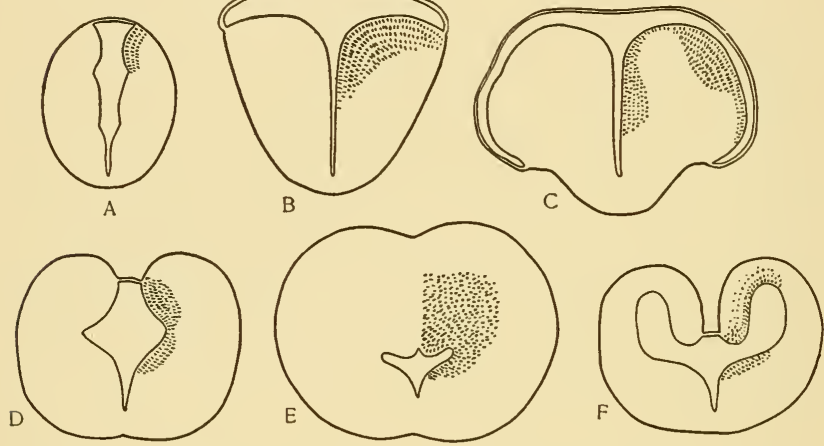

Fig. I51.-Simple diagrams to show the history of the epistriatum in fishes and amphibia. The epistriatum is represented by coarse dots adjoining the ventricle, and the figures indicate how it is involved in the changes of form of the forebrain and how there are developed from it the hippocampal formation and the epistriatum proper of the amphibian brain. A, Petromyzon; B, Acipenser; C, Teleost; D, Chimaera; E, Squalus acanthias; F, Necturus.

The upper commissure is usually described as a true commissure of the mesial and caudal regions just mentioned. It is, however, not so simple, for near its point of crossing it receives fibers from four other sources. First, fibers enter it from the lateral walls of the hemispheres; second, fibers from the medial olfactory nucleus; third, fibers from the tractus strio-thalamicus; and fourth, fibers which come directly from the hypothalamus and enter the commissure above the tractus strio-thalamicus. The commissure also has a third place of distribution in the dorsal 
part of the brain, namely, in the lateral wall of the median ventricle anterior to the central gray of the thalamus. The composition and distribution of the commissure is shown in Figure I5o. As it runs up behind the foramen of Monro it divides into two parts, the larger going into the medial wall of the hemisphere and the smaller turning into the lateral wall of the median ventricle. The latter bundle runs for a short distance ventral to and distinct from the tractus olfacto-habenularis and spreads out in the central gray cephalo-ventral to the nucleus habenulae. This region of central gray is clearly seen in Cryptobranchus, Necturus and in tadpoles of Amblystoma. It is a very compact body whose cells are arranged in rows next the ventricle and whose outer part is a fiber layer formed by the commissural bundle. In its structure, position and its relation to the tractus olfacto-habenularis, this body corresponds to the epistriatum of Petromyzon and to the caudal part of the epistriatum in Acipenser. As the cell layer is traced forward it curves through the foramen of Monro, forming the dorsal border of the foramen, and becomes continuous with the ventricular cell layer of the dorsal half of the mesial wall. Inasmuch as the commissure is distributed to both the lateral wall of the median ventricle and to the mesial wall of the lateral ventricle and as the ventricular cell layer is continuous throughout these regions, it is just to conclude that they form a structural and functional unit. The composition of the commissure gives further ground for regarding this whole region as homologous with the epistriatum in fishes, with which a part of it agrees in position. The epistriatum in fishes receives an ascending tract from the hypothalamus which decussates in the anterior commissure. Such a tract is not certainly found in the lower commissure in amphibia but is present in the upper commissure. These fibers presumably constitute the tractus lobo-epistriaticus and the area in which they end is the epistriatum. In selachians it has been noticed that the region called the epistriatum receives a tertiary olfactory tract from the mesial olfactory nucleus, the tractus olfacto-corticalis. In selachians and ganoids a part of this tract crosses to the opposite side. In amphibia the tractus olfactorius septi and the bundle which enters the upper commissure from 


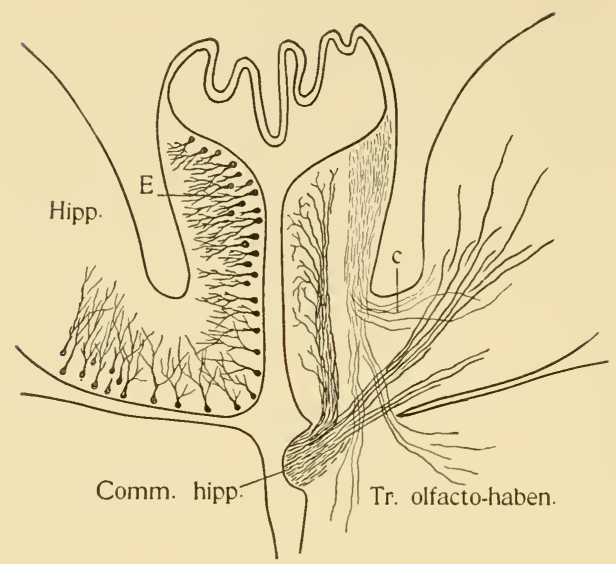

A

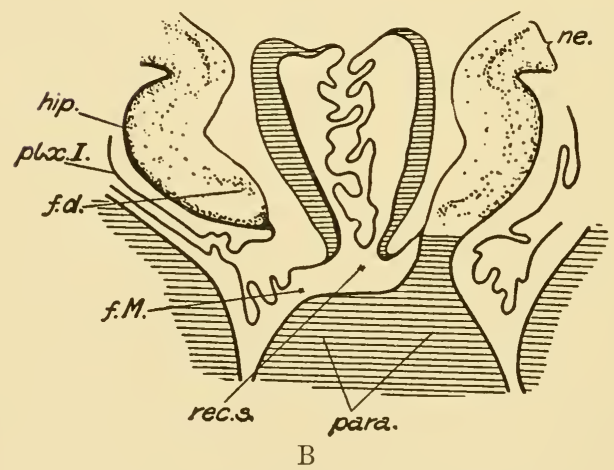

Fig. 152.- Sketches of transverse sections through (A) the caudal part of the epistriatum in amphibia and (B) the corresponding structure in Ornithorhynchus. $\mathrm{B}$ from G. Elliot Smith. In A the tracts are drawn from the brain of Necturus and the cells in the epistriatum $(E)$ are drawn schematically to show their disposition next the venticle and the continuity of the cell layer through the foramen of Monro with that of the hippocampal formation (Hipp.). c , the tractus cortico-habenularis. On the right side the section is supposed to pass just behind the foramen of Monro. In B: f.d., fascia dentata; f.m., foramen of Monro; hip., hippocampus; ne., neopallium; para., paraterminal body; plx.l., choroid plexus of the lateral ventricle; rec.s., recessus superior. The recessus superior extends dorsad between two vertical shaded lateral walls which correspond to the caudal part of the epistriatum in amphibia. This is erroneously called the paraphysis in mammals. 
the mesial olfactory nucleus are homologous with the tractus olfacto-corticalis, and the region to which the upper commissure is distributed must be considered as a part of the epistriatum. The part of the epistriatum which receives tertiary olfactory fibers is the olfactory cortex or hippocampus. A part of the epistriatum which does not receive such fibers covers the inner surface of the striatum and in all higher vertebrates is regarded as an integral part of that body.

The amphibian hemispheres differ in two chief ways from those of selachians. First, the secondary olfactory centers are less massive, the wall is thinner and the ventricle larger, and the epistriatum is relatively larger. Second, there is a more complete folding of the lateral wall than in selachians. In selachians the lateral walls rose up, arched over and fused. In amphibia the lateral walls rose up and folded over without fusing with one another. The result is to form on each side a lateral hemisphere whose ventricle is a continuation of the primitive lateral or olfactory ventricle and whose dorso-mesial wall was primitively the dorsal part of the lateral wall of the median ventricle. The lateral ventricle of the hemisphere is not completely surrounded by nervous walls as is the primitive olfactory ventricle. In amphibia the mesial wall of each hemisphere is connected with its fellow over the median ventricle by a membranous roof, which is homologous with that in fishes. The diagrams in Figure ${ }^{5}{ }^{1}$ will show how the amphibian hemispheres have been formed by folding over of the lateral walls, and also the history of the epistriatum in fishes and amphibia. The epistriatum is in reality no more or less than the central gray matter of the forebrain in fishes. The dorsal part of this central gray in selachians receives olfactory fibers of the third order and in consequence becomes differentiated as the olfactory cortex. This region first becomes distinct in the amphibian brain as the result of the folding described. The caudal portion of the forebrain wall has not been folded into the lateral hemisphere and the epistriatum retains the position which it has in the caudal part of the forebrain in fishes. In higher forms this body becomes reduced but is still recognizable in mammals 
a short distance in front of the nucleus habenulae. Its nervous nature is evident in embryos but in the adult it has been confused with an entirely different structure under the name of paraphysis. In the accompanying Figure $\mathrm{I}_{52}$ the relations of the so-called paraphysis of a monotreme (Ornithorhynchus) are compared with those of the caudal part of the epistriatum in a tailed amphib-

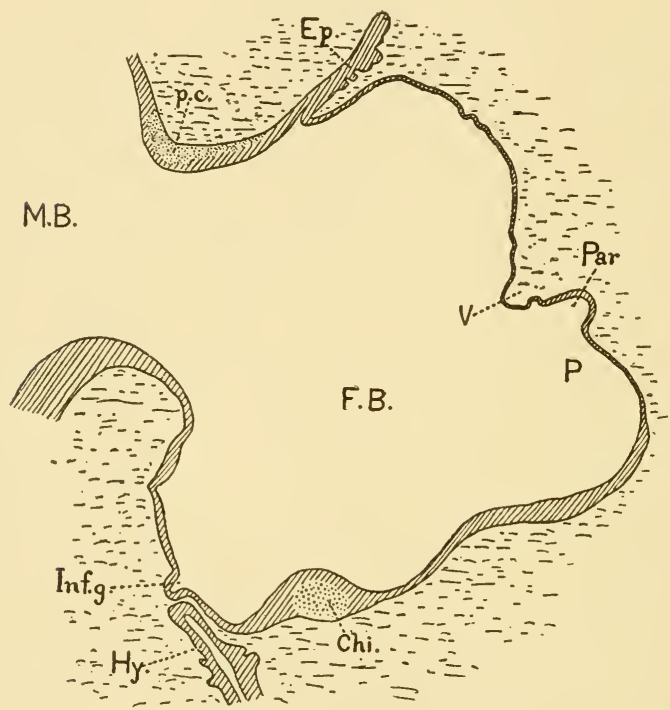

Fig. 153.-A sagittal section of the forebrain and interbrain of a chick embryo of 7.0 days. From Minot. F.B., forebrain; M.B., midbrain; chi., optic chiasma; $e p$. ., epiphysis; hy., hypophysis; Inf.g., infundibular gland (saccus vasculosus); $P$., paraphysial arch; Par., paraphysis; p.c., posterior commissure; $V$, velum.

ian (Necturus). The structure which is properly known as the paraphysis is in lower vertebrates an outgrowth from the membranous roof of the forebrain in front of the velum transversum (Figs. 36, I47 and I53).

The limits of the secondary and tertiary olfactory centers in amphibia are not clear but the dorso-medial and dorsocaudal 
parts of the hemisphere are at least chiefly tertiary. The internal structure of this region is more complex than in fishes. In addition to the pyramidal cells characteristic of the epistriatum of fishes there are many cells of type II and tangential cells present. It is clearly evident that this region constitutes an olfactory cortex

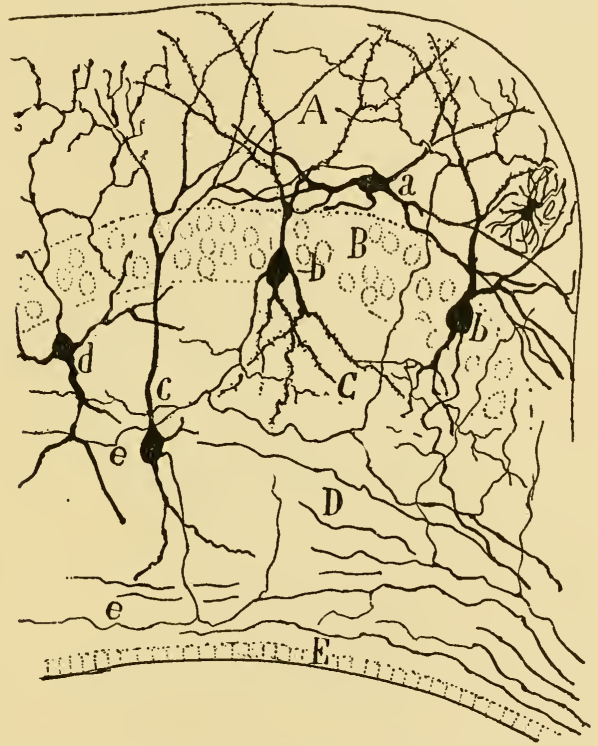

Fig. 154--Part of a transverse section of the cortex of a chameleon. After Cajal (Textura, etc.). $A$, superficial plexiform layer; $B$, layer of pyramids; $C$, deep plexiform layer; $D$, white substance; $E$, ependyma.

and corresponds to the hippocampal formation in the mammalian brain. The commissure of this region must therefore be compared functionally with the hippocampal commissure. Anatomically, however, the commissure in amphibia is not the same as that in mammals. The upper commissure in amphibia lies beneath the median ventricle and behind the foramen of Monro and could not 
by any process of shifting be brought bodily into the position occupied by the hippocampal commissure in mammals. Moreover, the presence in this commissure of the ascending tract from the hypothalamus marks it as a part of the anterior commissure. In amphibia, then, the commissural fibers of the hippocampal formation run by way of the anterior commissure, in which they constitute a large bundle nearly separate from the rest of the commissure. The presence of the tract from the hypothalamus

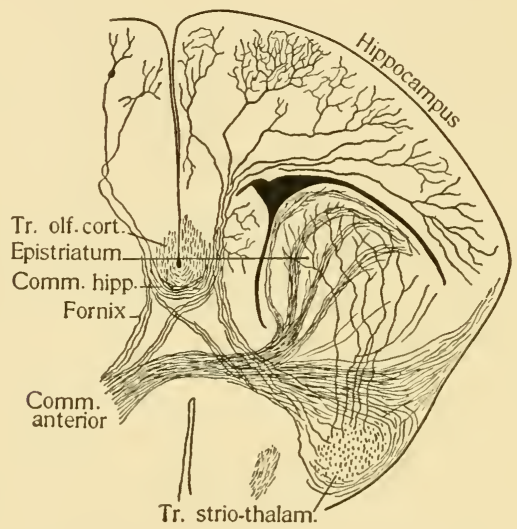

Fig. 155.-Transverse section through the forebrain of Lacerta at the level of the anterior commissure. After Cajal (Textura, etc.).

suggests that the olfactory cortex serves also as a gustatory cortex. There is finally to be mentioned a small tract from the dorsocaudal pole of the hemisphere which runs to the hypothalamus, taking a course over and behind the anterior commissure and separate from the tractus olfacto-hypothalamicus medialis, which runs beneath the anterior commissure. This small tract is to be compared with the fornix of the mammalian brain.

No vestige of the nervus terminalis or its center has been recognized in the amphibian brain.

THE REPTILIAN BRAIN differs from the amphibian chiefly in 
having larger hemispheres with a somewhat more complex structure in the olfactory cortex (Fig. I54), and in the position of the hippocampal commissure. The olfactory lobe occupies the anterior, lateral and ventral surfaces of the hemisphere, the base is the corpus striatum and the dorsal and medial walls constitute the hippocampus or olfactory cortex. The fiber tracts connecting the olfactory lobe with the cortex and connecting both with the hypothalamus and the nucleus habenulae seem to be identical with those in amphibia. The tract from the dorsocaudal pole to the hypothalamus is much larger than in amphibia. Overlying the striatum in the ventro-lateral wall of the hemisphere

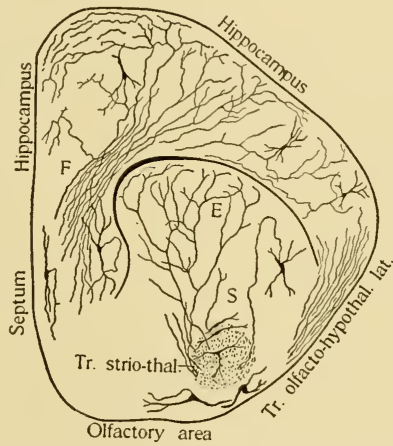

Fig. 156.-A transverse section through the right lateral lobe of the forebrain of Lacerta. After Cajal (Textura, etc.). E, epistriatum; $F$, white substance of the hippocampal formation; $S$, striatum.

is a body called the epistriatum which represents the ventral, unspecialized portion of the epistriatum in fishes. The anterior commissure (Fig. I55) includes olfactory tract fibers, fibers from the lateral olfactory area to the epistriatum, and fibers of the tractus strio-thalamicus. The commissure of the hippocampal region crosses in the upper part of the lamina terminalis and passes in front of the foramen of Monro to reach the hippocampus. The position of the commissure is the same as that of the hippocampal commissure in monotremes and lower mammals. The 
tractus olfacto-habenularis receives fibers from the dorso-caudal pole of the hemisphere. These fibers constitute a tractus corticohabenularis. A commissure is found in lizards and some other reptiles which connects the dorso-caudal poles of the hemispheres directly, above the ventricle. This commissure runs in the velum transversum and does not correspond in position to any commissure found in other vertebrates. It is therefore called the commissura aberrans (Fig. $\mathrm{I}_{58} 8$ ). The position and extent of the several parts of the forebrain are shown in Figures $1_{55}, \mathrm{I}_{5} 6$ and r57. The last figure does not show the whole extent of the hip.

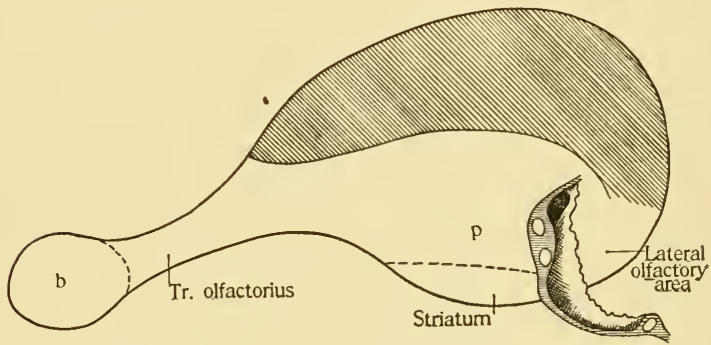

Fig. 157.-A diagram of the mesial surface of the hemisphere of a reptile to show the extent of the hippocampus and related structures. The lamina terminalis is shaded with horizontal lines and in it are shown the anterior and hippocampal commissures. The hippocampal area is shaded with oblique lines. $b$, bulbus olfactorius; $p$, paraterminal or precommissural body (septum).

pocampus but shows the position of its mesial part relative to the lamina terminalis, the foramen of Monro, the commissures and the mesial olfactory nucleus (septum).

The MAMmalian fOREBRAIN.-In monotremes and marsupials the relations of the olfactory centers are essentially as in amphibia and reptiles, although there is a higher development in internal structure. The olfactory bulbs and lobes are relatively small (Figs. 159, r60) and the rest of the hemisphere very large in proportion. Indeed, in monotremes and marsupials as in mammals, the lateral and dorsal walls of the hemispheres do not belong to the olfactory apparatus as in reptiles and lower forms, but 
constitute the somatic pallium. The olfactory cortex is now confined to a part of the mesial wall of the hemisphere. Its extent is best seen in a view of the mesial surface of the brain (Fig. 160). The dorsal part of the mesial wall belongs with the dorsal wall to the general cortex or neopallium whose functions are chiefly somatic. The region corresponding to the lateral olfactory nucleus of lower vertebrates is crowded down upon the ventral surface of the hemisphere and forms the pyriform lobe (Fig. I 59). This is separated from the general cortex by the fissura rhinalis. The mesial olfactory nucleus is in the same

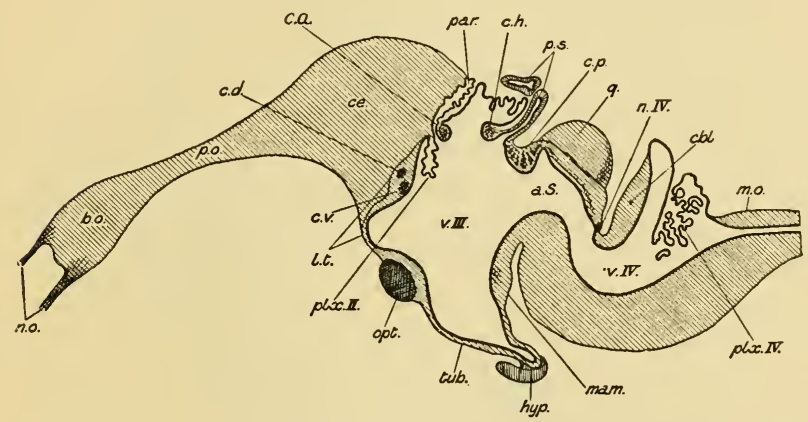

Fig. ${ }^{5}$ 8.-A mesial sagittal section of the brain of an embryo of Sphenodon punctatum. From G. Elliot Smith (Aberrant Commissure, etc.). a.S., aqueduct of Sylvius; b.o., bulbus olfactorius; c.a., commissura aberrans; c.d., hippocampal commissure; c.h., habenular commissure; c.p., posterior commissure; c.v., anterior commissure; $c e$. , cerebral hemisphere; hyp., hypophysis; l.t., lamina terminalis; $o p t$., tractus opticus; par., paraphysis; p.o., olfactory peduncle; p.s., parietal stalk; $p l x . I I$., lamina chorioidea; tub., tuber cinereum; v.III., third ventricle.

position as in lower vertebrates, forming the tuberculum olfactorium and the lower portion of the mesial wall called the precommissural body (G. Elliot Smith). In the lamina terminalis is a very large anterior commissure and above it in the dorsal border of the lamina terminalis is a smaller hippocampal commissure. This commissure crosses in front of the median ventricle and enters the hippocampus above the foramen of Monro, and therefore corresponds in position to the hippocampal commissure of reptiles. 
Above the commissures is a slender prolongation of the median ventricle, forward beyond the foramen of Monro, which corresponds

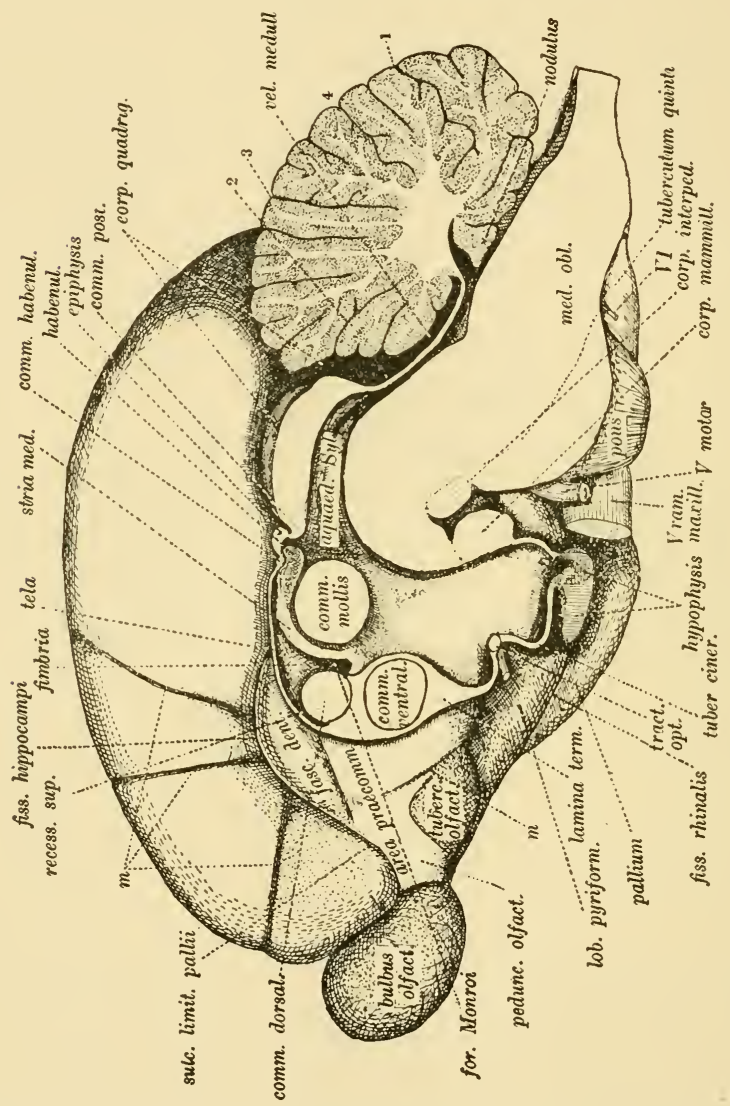

Fig. I59.-The mesial surface of the right half of the brain of Ornithorhynchus. From G. Elliot Smith.

to the anterior portion of the median ventricle in amphibia (Fig. 
I50) and reptiles (Fig. I6I), and ends in the homologue of the recessus neuroporicus of fishes. This part of the median ventricle has been called the recessus superior and in both reptiles and monotremes its walls contain nervous elements and correspond to the caudal part of the epistriatum in amphibia as explained above (cf. Figs. $\mathrm{I}_{52}$ and $\mathrm{I} 6 \mathrm{I}$ ). A transverse section through the commissures of a monotreme (Fig. I62) shows the general cortex forming the lateral and dorsal wall of the lateral ventricles, while

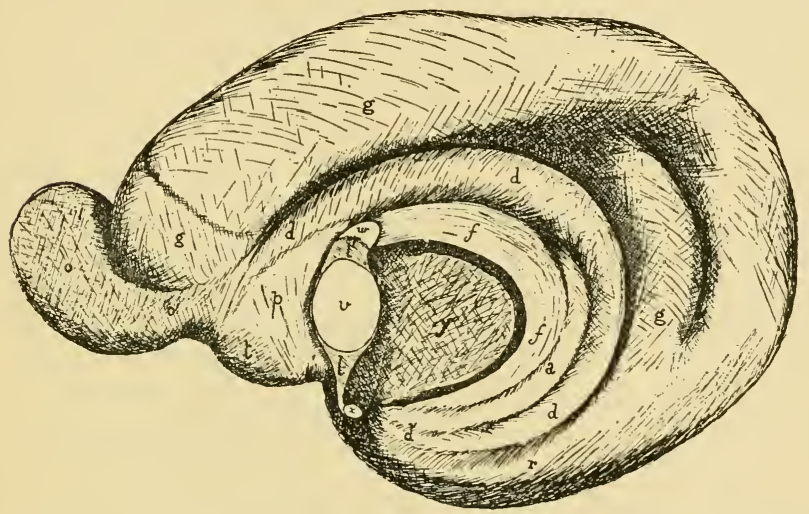

Fig. I60.-The mesial surface of the right cerebral hemisphere of a marsupial (Phascolarctos). From G. Elliot Smith (Relation of Fornix, etc.). $a$, extraventricular alveus; $d, d^{\prime}$, fascia dentata; $f$, fimbria; $g$, neopallium; $l, l^{\prime}$, lamina terminalis; $o$, olfactory bulb; $o^{\prime}$, elfactory peduncle; $p$, precommissural body; $r$, pyriform lobe; $t$, tuberculum olfactorium; $v$, ventral commissure (anterior commissure plus commissural fibers of the neopallium); $w$, hippocampal commissure; $x$, optic chiasma; $y$, thalamus.

the strongly infolded mesial wall is the hippocampus. The infolding is marked by a groove which appears on the mesial surface of the hemisphere as the hippocampal fissure (Fig. I59). The lower border of the hippocampus shows a higher specialization of structure and is known as the fascia dentata. The lower wall of the brain is formed by the pyriform lobe and the corpus striatum through which runs the large anterior commissure. 
Where the commissure crosses in the lamina terminalis the latter is thickened by gray matter which has invaded it from the adjacent mesial olfactory nucleus or paraterminal body (Fig. r63). In the upper part of the lamina terminalis the hippocampal commissure crosses in front of the foramen of Monro and covers the face of the hippocampus which bounds the lateral ventricle. Upon the upper surface of the hippocampal commissure in the middle line appears the small recessus superior. The hippocampal commissure is derived wholly from the hippocampal fold of the mesial wall of the hemisphere, while the dorsal and lateral wall or general cortex contributes fibers to the anterior commissure.
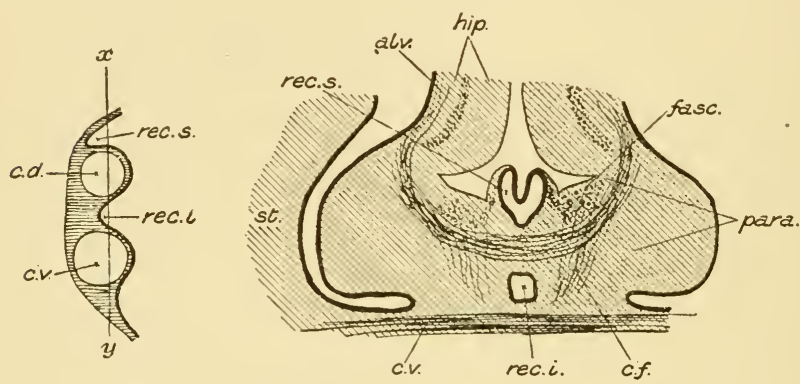

Fig. I6I.-Portion of a transverse section through the brain of a Monitor (Hydrosaurus). From G. Elliot Smith. In the figure to the left the line $x-y$, shows the plane of the section. alv., alveus; c.f., columna fornicis; fasc., fascic ulus marginalis; hip., hippocampus; para., paraterminal body; rec.s., recessus superior; c.d., hippocampal commissure; c.v., anterior commissure.

In sagittal section near the medial plane (Fig. I64) are to be seen the following tracts belonging to the olfactory apparatus. The tractus olfactorius (olfactory peduncle) enters the tuberculum olfactorium and the precommissural body and also sends a part of its fibers up into that part of the hippocampal formation known as the fascia dentata. The latter fibers are a vestige of the olfactory tract fibers which run to the epistriatum in fishes. From the tuberculum olfactorium a large tract, not shown in the figure, goes up through the precommissural body to the hippocampus. 
This corresponds to the tractus olfacto-corticalis of selachians, amphibia and reptiles (tractus olfactorius septi). A diffuse bundle of fine fibers arising in the precommissural body runs backward below the anterior commissure and is widely distributed in the hypothalamus (cf. p. 275). This tract is evidently identical with the tractus olfacto-hypothalamicus medialis of lower vertebrates. Fibers arising from the whole arch of the hippocampus (Fig. I60) collect toward the commissural region in the lamina terminalis.

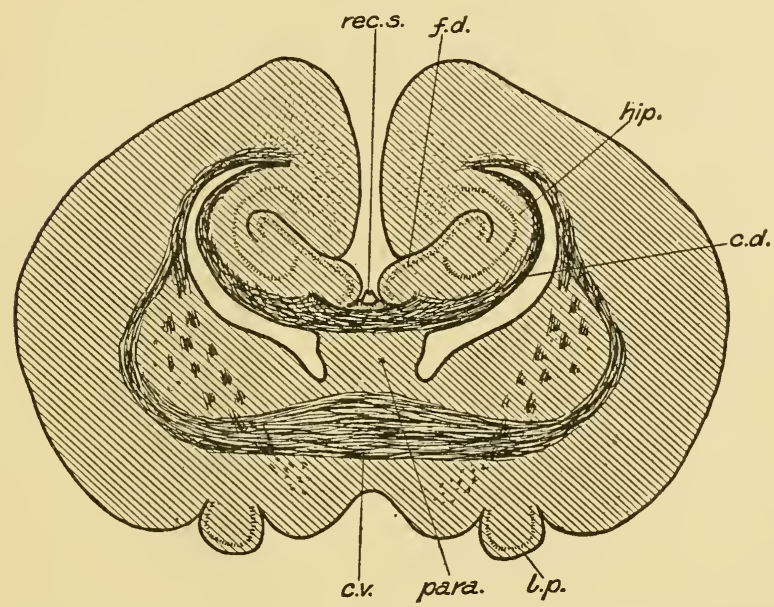

Fig. I62.-Transverse section through the cerebral hemispheres of Ornithorhynchus. From G. Elliot Smith. c.d., hippocampal commissure; c.v., anterior commissure plus neopallial fibers; f.d., fascia dentata; $h i p$. , hippocampus; l.p., lobus pyriformis; para., paraterminal body; rec.s., recessus superior.

Those from the caudal portion of the hippocampal arch run forward on its ventricular surface forming the fimbria. When the fimbria arrives at the lamina terminalis a part of its fibers go to form the hippocampal commissure (Fig. $164, w$ ). The remainder of the fimbria fibers together with numerous fiber bundles from the whole anterior portion of the hippocampal formation collect into a large bundle close upon the upper surface of the anterior com- 
missure and run backward through the hypothalamus to the corpus mammillare. This is the fornix (columna fornicis) and its course is the same as that of the bundle called fornix in amphibia and reptiles. Just above and behind the anterior commissure the fornix column crosses the stria medullaris thalami which is coming up from the nucleus amygdalae in the caudal part of the ventral wall of the hemisphere. This region corresponds to the lateral olfactory nucleus of lower vertebrates and the stria is

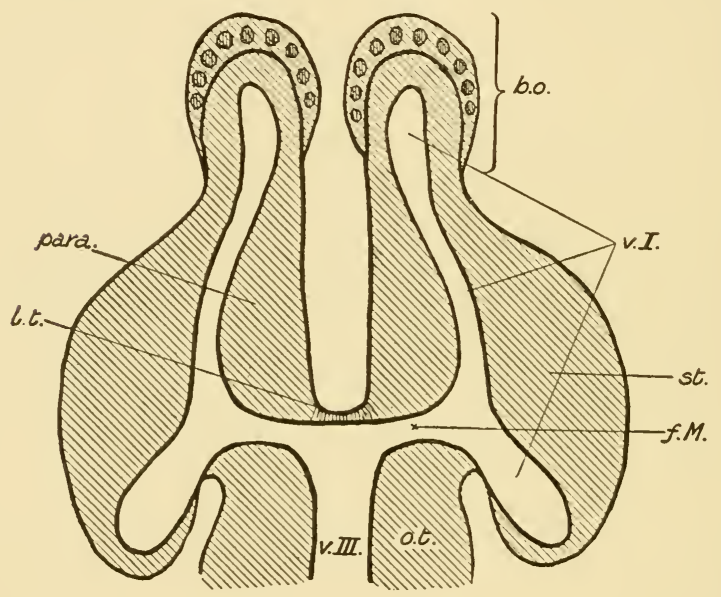

Fig. I63.-Plan of cerebral hemispheres, lamina terminalis and optic thalami in horizontal section. From G. Elliot Smith. b.o., olfactory bulb; f.M., foramen of Monro; l.t., lamina terminalis; o.t., optic thalami; para., paraterminal body; v.I., lateral ventricle; v.III., third ventricle.

identical with the tractus olfacto-habenularis. The fibers which join this tract from the fornix columns constitute the tractus cortico-habenularis. Finally, a large tract (Fig. I64,3) runs up from the region just in front of the optic chiasma through the precommissural body and enters the fimbria to go to all parts of the hippocampus. These fibers probably come from the lateral olfactory area (pyriform lobe or nucleus amygdalae). They cor- 
respond to the crossed tractus olfacto-corticalis of fishes and to the crossed sphenoido-hippocampal tract in higher mammals.

It was stated above that the region corresponding to the lateral olfactory nucleus of lower vertebrates is crowded down upon the

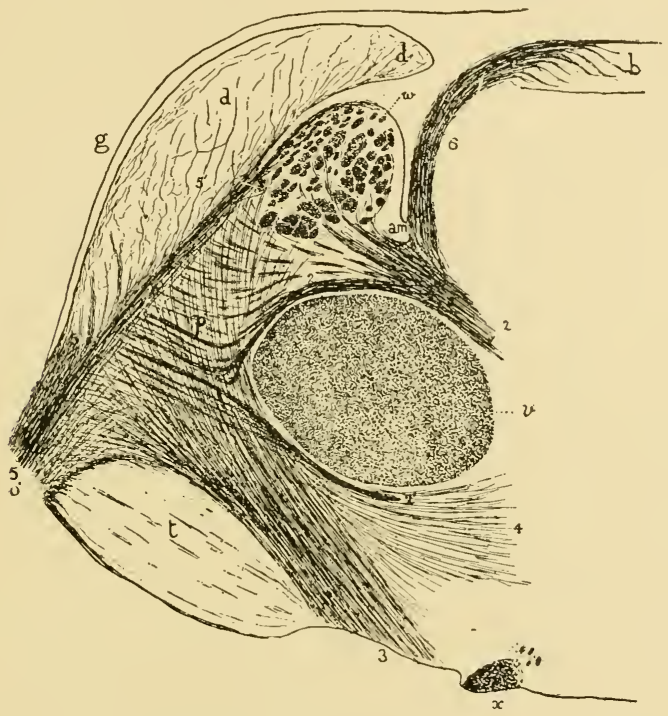

Fig. r64.-Sagittal section of the commissural and precommissural regions of the right hemisphere of Ornithorhynchus. From G. Elliot Smith. am., tractus cortico-habenularis; $b$., nucleus habenulae; $d$, fascia dentata; $g$, neopallium; $o^{\prime}$, olfactory peduncle; $p$., precommissural body; $t$., tuberculum olfactorium; $v$., anterior commissure plus neopallial fibers; w., hippocampal commissure; 2, column of fornix; $2^{\prime}$, fibers of the same from the anterior end of the hippocampus passing beneath the anterior commissure; 3 , fasciculus praecommissuralis, probably coming from the pyriform lobe; 4, tractus olfacto-hypothalamicus; 5, fasciculus marginalis, a part of the olfactory tract which goes to the hippocampus; 6 , stria medullaris thalami.

ventral surface of the hemisphere to form the pyriform lobe. This lobe appears on the ventral aspect of the brain as a ridge which extends the whole length of the lower wall of the hemisphere (Fig. 165). As the olfactory tract comes from the bulb it divides into 
a mesial portion whose connections in the tuberculum olfactorium, precommissural body and hippocampus have just been described, and a lateral portion which enters the pyriform lobe. This lateral portion, the external root or external olfactory radiation of authors, is distributed through the whole length of the pyriform lobe and to the caudal portion of the ventral wall of the hemisphere from which arises the stria medullaris thalami mentioned above. In higher mammals the anterior part of this region is known

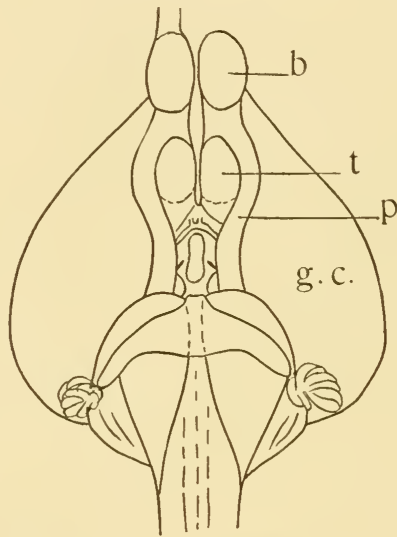

Fig. 165.-Ventral surface of the brain of Ornithorhynchus to show the position of the pyriform lobe. Outline after a figure by G. Elliot Smith. b., olfactory bulb; $p$., pyriform lobe; $t$, tuberculum olfactorium; g.c., general cortex or neopallium.

as the nucleus amygdalae, the posterior part as the pyriform lobe or sphenoidal cortex and from it arises the taenia semicircularis to the hypothalamus (Fig. I66). This is homologous with the tractus olfacto-hypothalamicus lateralis in fishes. As indicated above a tract from this same region goes to the hippocampus by way of the precommissural body and the fimbria.

This general survey shows that there is no essential difference in the arrangement of the central olfactory apparatus in monotremes and in amphibia and reptiles. The large size of the anterior 
commissure is due to the fact that it contains large numbers of fibers connecting the lateral walls of the hemispheres. These lateral walls together with the dorsal part of the mesial wall of the hemisphere correspond to the similarly placed general cortex or somatic pallium in man. This region has been called neopallium to distinguish it from the olfactory cortex (archipallium) which

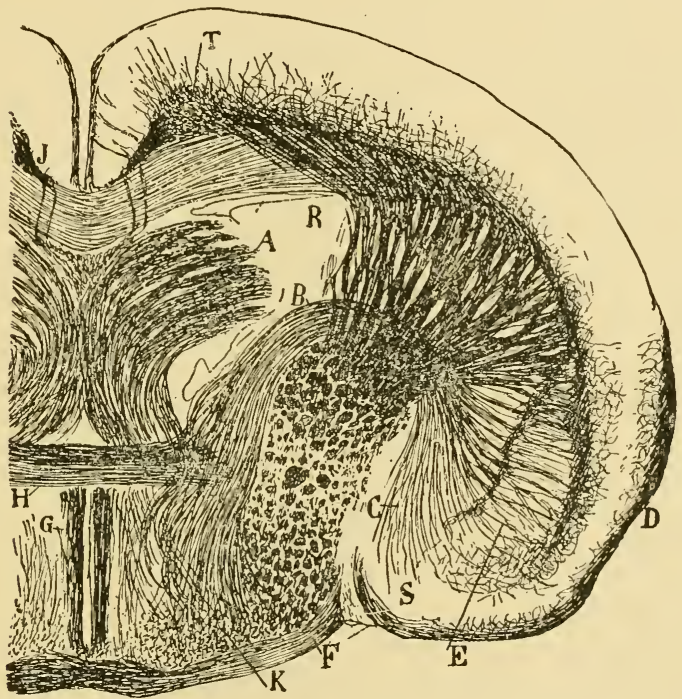

Fig. r66.-Transverse section through the brain of the rat of four days at the level of the anterior commissure. From Cajal (Textura, etc.). $A$, columna fornicis; $B, C$ and $K$ tractus olfacto-hypothalamicus ("olfactory projection tract"); $D$, lobus pyriformis; $E$, nucleus lentiformis of corpus striatum; $F$, tractus opticus; $H$, anterior commissure; $J$, cingulum; $R$, nucleus caudatus of corpus striatum; $T$, fasciculus longitudinalis superior.

is traceable continuously from selachian fishes to mammals. The neopallium has developed in the lateral and dorsal wall of the hemispheres, crowding between the mesial and lateral parts of the olfactory lobe and pushing the lateral part down upon the ventral surface. The commissural fibers of this neopallium 
in monotremes are to be compared functionally with the corpus callosum of man, but anatomically they are widely different. They run simply in the anterior commissure.

In the brain of the simpler mammals little change from that

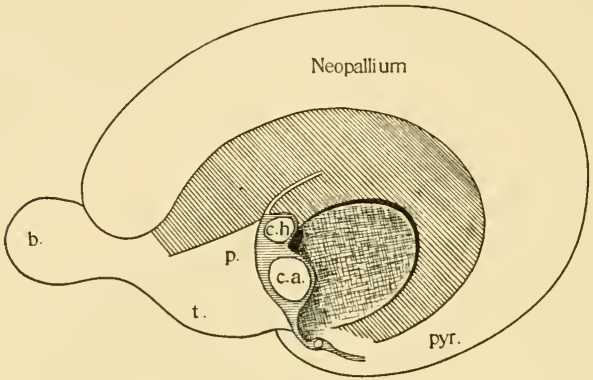

A

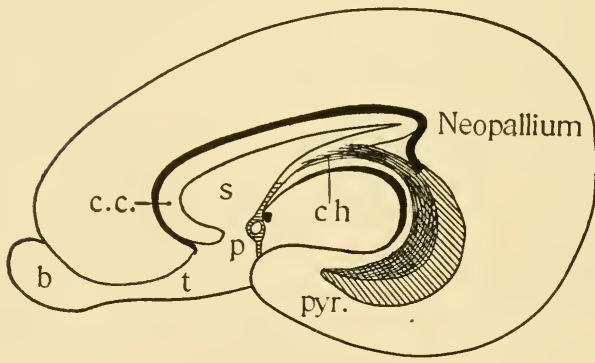

B

Fig. I67.-Diagram of the mesial surface of the hemisphere of (A) a monotreme and (B) that of a mammal to show the extent and relations of the hippocampus. Compare with Fig. 157. b, olfactory bulb; c.a., anterior commissure; c.c., corpus callosum; c.h., hippocampal commissure; $p$., paraterminal or precommissural body; pyr., pyriform lobe; $t$., tuberculum olfactorium; s., septum pellucidum.

of the monotreme and marsupial is to be noticed except in the disposition of the commissure of the neopallium. This change consists in the shifting of the commissural fibers of the neo- 
pallium from the anterior commissure to the hippocampal commissure. The fibers appear first in the front part of the hippocampal commissure, with the fibers of which they are mingled. As the neopallial fibers in this position increase in number the hippocampal fibers are displaced backward and the dorsal commissure comes to be formed of two parts, an anterior corpus callosum and a posterior hippocampal commissure or psalterium.

The further development of the mammalian forebrain consists chiefly in the enlargement and increasing complexity of the neopallium, the enlargement of the corpus callosum and the shifting of parts consequent on these changes. The enlargement of the neopallium and corpus callosum results in the degeneration of the hippocampus through the greater part of its length. The facts of chief importance are to be seen in the mesial aspect of the hemisphere of various mammals or in sagittal sections near the median plane. In the monotreme and marsupial (Fig. 167) the hippocampus begins just above and behind the olfactory peduncle, where it forms the boundary between the general cortex (neopallium) and the precommissural body, and extends back above the foramen of Monro and forms the mesial margin of the roof of the hemisphere. Some distance from its anterior end the hippocampus crosses the dorsal border of the lamina terminalis, to which it is attached by reason of the fact that its commissure crosses through the border of the lamina. Here also, just above and in front of the commissure the lamina terminalis joins the membranous roof of the median ventricle, the angle marking the position of the recessus neuroporicus in the embryo. In the marsupial and simplest mammalian brains the hippocampal commissure takes on the form of a compact lamina and the corpus callosum extends forward from it, so that the two form an inverted $\mathrm{V}$-shaped figure whose caudal descending limb is the hippocampal commissure. The two commissures cause a thickening of the lamina terminalis as indicated in the accompanying diagram (Fig. I68, C).

The fibers of the corpus callosum in assuming this position have run transversely through the hippocampal formation and have mingled with the hippocampal ends of all the longitudinal 
fiber tracts which have been described above as forming the fornix system. It is very important that this intermingling of the transverse fibers of the corpus callosum with the longitudinal fibers which connect the hippocampus with the olfactory lobe, the base of the brain and the hypothalamus should be held in mind. The effect of the corpus callosum piercing the hippocampus is to cause it to degenerate in its middle part, adjacent to the lamina terminalis. In more highly developed (mammalian) brains the hippocampus from this point forward degenerates to a mere
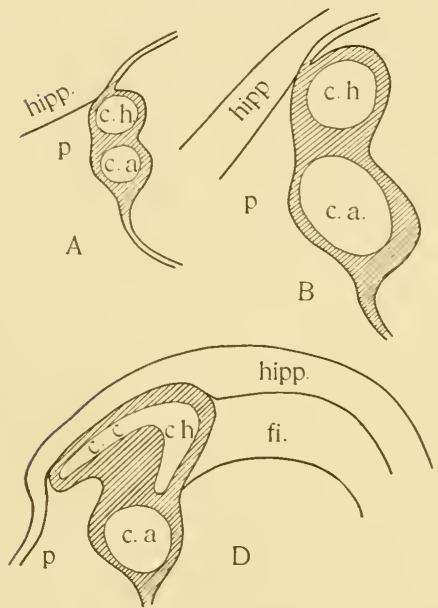

Fig. I68.- Schemes to explain the expansion of the corpus callosum and the formation of the septum pellucidum. After G. Elliot Smith. A, reptile; B, monotreme; C, marsupial; D, bat; E, higher mammal. c.a., anterior commissure; c.c., corpus callosum; c.h., hippocampal commissure; fi., fimbria; hipp., hippocampus; ind., indusium; p., precommissural body.

rudiment, the position of the original hippocampus being occupied by the enlarged corpus callosum. The rudiment of the hippocampus remains on the dorsal surface of the corpus callosum and extends forward from it along the line of demarcation between the precommissural body and the neopallium. The fibers of the 
sereral tracts of the fornix system which in monotremes entered the hippocampus anterior to the lamina terminalis are preserved in small numbers and still enter the rudimentary hippocampus, either running around the front edge (genu) of the corpus callosum or piercing it (perforating fibers of authors, fornix longus of Forel). These perforating fibers maintain the same position and course which they have in all vertebrates, the corpus callosum is a new structure which has run transversely through and mingled with them, as explained above.

The growth of the corpus callosum not only reduces the hippocampus to a rudiment but also changes its position. As the neopallium enlarges and spreads backward the callosum spreads in the same direction, pushing back part of the hippocampus before it and stretching the rudimentary hippocampus which lies on its dorsal surface. The corpus callosum is formed in the lamina terminalis and its caudal border is mingled with the hippocampal commissure. As the callosum tends to grow broader antero-posteriorly its two borders are confined. In order to widen it must either stretch the lamina terminalis backward or it must bend and fold upon itself. It does both. In the simplest mammals (bats) no change is seen from the marsupial condition, but in such animals as the rabbit and hedgehog the corpus callosum has arched upward in the form of an inverted $U$, stretching the rudimentary hippocampus (Fig. I68). In higher mammals such as the cat, and in man the callosum has grown much larger and has pushed back over the hippocampal commissure. At the same time the $\mathrm{U}$-shaped bend in the callosum has become more and more sharp until the two limbs have met and in man it appears on superficial examination that the caudal border of the callosum is merely thickened. In fact, this portion, known as the splenium, is formed by an actual folding of the callosum due to its growth in width while its borders remained fixed. The real border of the callosum is beneath its body, some distance in front of the splenial border, adjoining the psalterium (Fig. I69, $l^{\prime \prime}$ ). Not only does the folded callosum extend back over the hippocampal commissure, but it stretches that part of the lamina terminalis containing that commissure backward far from its original position. This stretching 
of the lamina terminalis is evident upon comparing a sagittal section of the bat or rabbit brain with that of the cat or man. It is shown diagrammatically in Figure I68. A further effect is to stretch the mesial walls of the hemisphere at the same time with the lamina terminalis. As the anterior, hippocampal and callosal commissures form in the lamina terminalis the lamina becomes thickened by the invasion of gray substance from the adjacent precommissural body. This gray substance forms a bed for the

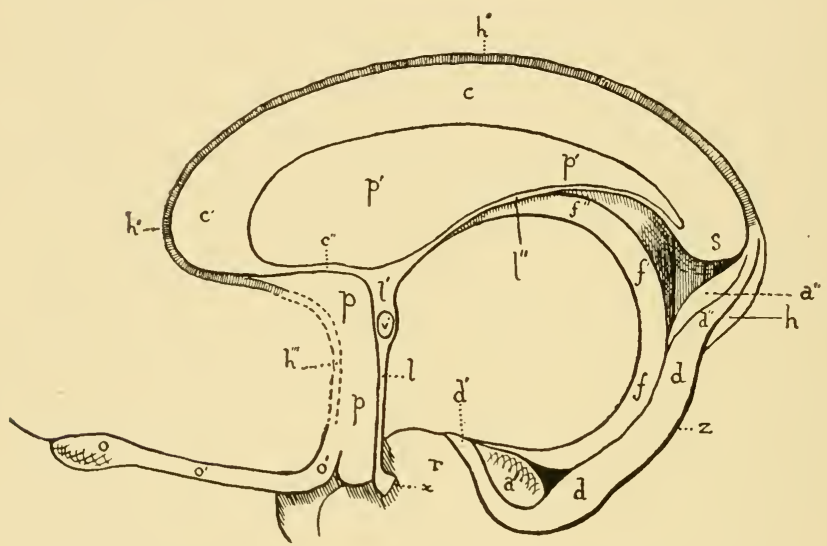

Fig. 169.-Scheme of cerebral commissures and margin of the cortex in the human brain. From G. Elliot Smith. $a^{\prime} \cdot a^{\prime \prime}$. extraventricular alveus; $c, c^{\prime}$, corpus callosum; $d$, fascia dentata; $f, f^{\prime}, f^{\prime \prime}$, fimbria; $h^{\prime}, h^{\prime \prime}, h^{\prime \prime \prime}$, reduced hippocampus; $l, l^{\prime}, l^{\prime \prime}$, lamina terminalis; $o, o^{\prime}, o^{\prime \prime}$, olfactory bulb and peduncle; $p$, precommissural body; $p^{\prime}$, septum pellucidum; $r$, pyriform lobe; $s$, splenium of corpus callosum; $v$, anterior commissure; $x$, optic chiasma.

commissural fibers. As the callosum expands and bulges and folds upward and backward it stretches the commissure-bed and also the closely related precommissural body, until the upper part of that body is drawn out into a thin membrane. As this occurs in the mesial walls of both hemispheres two thin membranes are formed facing each other and filling in the somewhat triangular space between the two limbs of the callosum. These membranes 
contain a few nerve cells and fibers of the fornix system and constitute the two leaves of the septum pellucidum. The space between the two leaves of the septum pellucidum is merely a part of the great sagittal fissure of the brain which by this process becomes roofed in by the corpus callosum and is called the "fifth ventricle". While these changes in the commissures are taking place the part of the hippocampus which retains its full development is pushed back until it no longer touches the lamina terminalis in higher mammals (Fig. 169).

While the expansion of the neopallium and its commissure has been so profoundly affecting the form of the hemisphere and the relations of the archipallium, the hippocampal formation itself has undergone changes of form and become more complex in structure. In monotremes and marsupials the hippocampus occupies the mesial wall of the hemisphere and is slightly infolded into the lateral ventricle, the line of infolding being marked by the hippocampal fissure. Along the lower border of the hippocampus the cells multiply and proliferate from the ventricular layer to form the fascia dentata. As the hippocampus folds more strongly and the fissure deepens the thick fascia dentata which forms the lower limb of the fold retains its position on the surface and the upper limb, or hippocampus proper, is drawn deeper in and wrapped around the fascia dentata (Fig. I 70 ) until the greater part of it is submerged within the hippocampal fissure. In most mammals the in-rolling goes so far that a larger or smaller part of the ventricular surface of the hippocampus is brought out upon the external surface of the brain where it is exposed except for a thin layer of fibers belonging to the fimbria. This inverted portion is the only part of the hippocampus, except the fascia dentata, which is exposed to view in the human brain. Of the two parts of the hippocampal formation the fascia dentata seems to serve wholly for the reception of olfactory impulses and to send its fibers into the hippocampus proper, while the hippocampus receives fibers from olfactory and other centers and sends out commissural fibers and fibers of projection to the corpus mammillare and nucleus habenulae.

This long and complex history of the evolution of the cerebral 


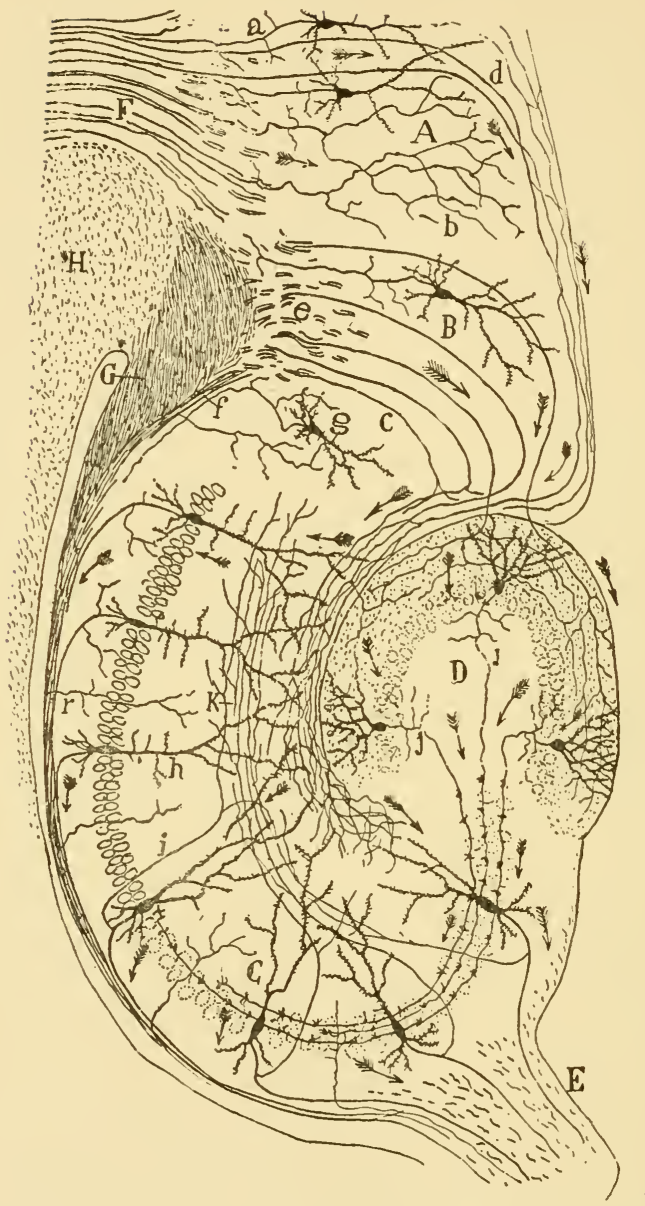

Fig. I 70.-Scheme of the structure and connections of the hippocampus. From Cajal (Textura, etc.). $A$, ganglion of the occipital pole; $B$, subiculum; $C$, hippocampus; $D$, fascia dentata; $E$, fimbria: $F$, cingulum; $G$. crossed sphenoidohippocampal tract; $H$, corpus callosum; $a$, neurites entering the cingulum; $b$, fibers of the cingulum ending in the occipital pole; $c$, perforating fibers of the sphenoido-hippocampal tract; $g$, cell of the subiculum. 
hemispheres may be summarized by giving a brief review of the chief parts of the hemisphere of a higher mammal or man, with an indication of their homologues in lower vertebrates. The base of the hemisphere is formed chiefly by the corpus striatum which includes the caudate and lentiform nuclei and is traversed by ascending and descending fiber tracts to the general cortex and hippocampus. In addition to these, many fibers come up to the corpus striatum from the lower parts of the brain and end in it, and a smaller number from the pyramidal cells of the general cortex also end here. Fibers arising from the cells of the striatum end in the centers of the thalamus, forming a tractus strio-thalamicus. The nucleus caudatus, from its position next to the ventricle and from the fact that a large part of its fibers end in the nucleus lentiformis, strongly reminds one of the unspecialized epistriatum of fishes.

The ventral surface of the striatum is covered by the nucleus amygdalae which is continuous with the pyriform lobe or sphenoidal cortex. These areas together correspond to the lateral olfactory area of fishes, amphibia and reptiles. From this region arise three tracts; first, the stria medullaris or taenia thalami, to the nucleus habenulae (tractus olfacto-habenularis); second, the thaenia semicircularis, to the hypothalamus (tractus olfacto-hypothalamicus lateralis); third, a tract to the hippocampus by way of of the precommissural body (gyrus subcallosus) and the fimbria (tractus olfacto-corticalis).

The inner surface of the corpus striatum forms the floor of the lateral ventricle, the anterior horn of which extends in front of the striatum into the frontal lobe of the hemisphere and reaches into the olfactory bulb, except where it becomes obliterated in the adult as in man. This is homologous with the primitive lateral or olfactory ventricle in lower vertebrates. The ventral and mesial wall of the anterior horn in front of the lamina terminalis is formed by the anterior and mesial part of the secondary olfactory center, homologous with the mesial olfactory nucleus in fishes. In man this region includes the tuberculum olfactorium and the small region in front of the lamina terminalis known as the gyrus subcallosus, better called the precommissural body. In the lamina 
terminalis in front of the median ventricle is a small anterior commissure connecting the corpora striata. This is largely made up of olfactory tract fibers coming from the olfactory bulb. The lamina terminalis is continued upward and greatly stretched backward to join the splenium of the corpus callosum. In this stretched portion of the lamina terminalis runs a thin band of transverse fibers constituting a commissure of the hippocampi, the psalterium. The corpus callosum is a thick lamina of transverse fibers belonging to the neopallium, slightly arched. The mesial wall beneath it is formed of the stretched and thinned dorsal portion of the precommissural body and is known as the septum pellucidum.

The floor of the temporal horn of the lateral ventricle is formed by the hippocampus which approaches the under side of the splenium of the callosum. The hippocampus does not end here but bends backward and curves over the splenial border of the callosum to run forward upon the dorsal surface of the latter. The portion of the hippocampus in this position consists of paired rudiments of the hippocampal fold (indusium falsum) in which runs a strand of fibers belonging to the fornix system, the striae Lancisii, and a median film of gray matter connecting the hippocampal rudiments (indusium verum). This rudimentary hippocampus runs the whole length of the callosum in man, and in some mammals continues forward to the olfactory peduncles, forming the boundary line between the praecommissural area and the neopallium in the original position of the hippocampus in monotremes and marsupials. From the chief part of the hippocampus in the temporal region fibers run forward over its surface forming the fimbria. When the hippocampus bends back to gain the upper surface of the callosum the fimbria continues forward in the lamina terminalis, and is usually termed the body of the fornix. The two bodies converge forward and the triangular space between them is bridged by the exchange of fibers which form the psalterium. This is a true commissure of the hippocampus and is homologous with the hippocampal commissure of reptiles and monotremes. In the lamina terminalis the bodies of the fornix bend downward in front of the foramina of Monro and 
then backward to become the pillars of the fornix. From the rudimentary hippocampus above the callosum similar fibers run in the striae Lancisii and eventually break through the callosum or run around its anterior border and through the septum to join the pillars of the fornix. The latter then run into the thalamus and end in the corpus mammillare. Fibers of the olfactory tracts and fibers from the tuberculum olfactorium and precommissural body enter the hippocampus by way of the septum and fimbria or as fibers perforating the callosum. Fibers running by the same routes come to the hippocampus from the pyriform lobe and nucleus amygdalae. The hippocampus also receives or sends out fibers through the corpus striatum. It is possible that these latter include the equivalent of the tractus lobo-epistriaticus of fishes and that they bring up gustatory impulses from the hypothalamus. It is especially interesting in this connection to note that gustatory sensation is thought by Flechsig to be localized in the hippocampus or the area immediately adjoining it.

A remarkable constance and similarity of structure is seen in the olfactory central apparatus throughout the classes of vertebrates. Speaking broadly, the primary (bulb) and secondary centers (lobe) and cortex with their respective tracts are already formed in selachians upon a plan which is retained in all higher vertebrates. A relative increase in the tertiary (cortical) centers and an increasing complexity of structure in these centers is the chief difference between higher and lower vertebrates. In fishes, amphibia and reptiles, as far as known, the whole forebrain with the exception of the center for the nervus terminalis in those forms which possess it, is devoted to the olfactory functions. The cortical center also serves the gustatory system. Apparently suddenly in monotremes appears a large lateral and dorsal cortex which is devoted to somatic functions. This is the neopallium whose structure and functions will be considered in the next chapter. Its position and the relations of its commissure show that it began its history in a dorso-lateral position at the anterior end of the forebrain between the mesial and lateral olfactory nuclei, and that it spread back from this point, pushing the two olfactory areas down upon the ventral surface and crowding the olfactory cortex to the extreme 
dorso-mesial margin. The neopallial commissure at first ran in the primitive forebrain commissure (anterior commissure) and later followed the movements of the hippocampal commissure upward to the dorsal edge of the lamina terminalis. The longitudinal tracts of the neopallium pass up and down through the corpus striatum lateral to and independent from the olfactory tracts and to quite different destinations (Fig. r66). It is impossible to believe in the face of all that we know of the evolution of structure in the central nervous system that the neopallium has appeared spontaneously as a new formation in the brain of primitive mammals. It has arisen by the greater development of some structure previously existing in the vertebrate brain. That it should have arisen by modification of some part of the olfactory centers is inconsistent with all that has gone before in the present volume. The neopallium may be wholly absent from the brains of existing members of the classes below mammals but those brains have by no means been studied exhaustively enough to warrant such a statement. Indications of the existence of a homologue of the neopallium are to be looked for in the form of tracts connecting somatic sensory centers with centers in the forebrain isolated from the olfactory apparatus. A tract is certainly present in fishes running from the tectum opticum to the forebrain, but the center has not been isolated, perhaps because of its small size in all submammalian classes. The existence of a cutaneous nerve connected with the forebrain in many fishes (nervus terminalis) gives encouragement to the expectation that a forerunner of the neopallium may be found in lower vertebrates in the form of a segment of the somatic sensory column in the forebrain. It is to be expected that further study of amphibia and reptiles from this point of view will reveal the rudiment of the neopallium, whose rapid development in primitive mammals led to the dominance of this class of vertebrates.

\section{DEMONSTRATION OR LABORATORY WORK.}

I. Upon careful dissections of the forebrain of a selachian, a bony fish, an amphibian and a mammal verify the general morphological relations described in this chapter. 
2. Upon Golgi or Weigert sections study the forebrain tracts in the selachian and amphibian brain and if possible in the brain of a small rodent, bat or mole.

3. If material is available, study with the aid of Smith's descriptions the history of the hippocampus and the fornix system by means of dissections and Weigert sections of the brain of the opossum, bat, mole, guinea pig, rat, rabbit, and cat.

\section{LITERATURE.}

Barker, L. F.: The Nervous System. I899.

Bochenek, A.: Die Nervenbahnen des Vorderhirns von Salamandra maculosa. Bull. Internat. Akad. Sci. Krakovie. I899.

Cajal, S. R.: Textura del sistema nervioso del Hombre, etc.

Catois, E. H.: Recherches sur l'histologie et l'anatomie microscopique de l'encephale chez les poissons. Bull. Sci.d. France. Tome 36. IgoI.

Edinger, L.: Untersuchungen u.s.w. I. Das Vorderhirn. I888.

Van Gehuchten, A.: Contribution a l'étude du système nerveuse des Téléostéens. La Cellule, Tome ro. 1894.

Goldstein, Kurt: Vorderhirn und Zwischenhirn einiger Knochenfische.

Johnston, J. B.: The Brain of Acipenser. The Brain of Petromyzon.

Kappers, C. U. A.: The Structure of the Teleostean and Selachian Brain.

Ramon, P.: Investigaciones micrográficas en el encéfale de batracios y reptiles. Zaragoza. I894.

Ramon, P.: L'encefale des amphihiens. Bibliographie anatomique. 1896.

Smith, G. Elliot: The Brain of a Foetal Ornithorhynchus. Quart. Jour. Mic. Sci., Vol. 39. I896.

Smith, G. E.: The Morphology of the True Limbic Lobe, etc. Jour. Anat. and Physiol., Vol. 30. 1896 .

Smith, G. E.: The Fornix Superior. Jour. Anat. and Physiol., Vol. 31. 1897.

Smith, G. E.: The Relation of the Fornix to the Margin of the Cerebral Cortex. Jour. Anat. and Physiol., Vol. 32. 1897.

Smith, G. E.: The Origin of the Corpus Callosum, etc. Trans. Linn. Soc. London, Vol. 7. 1897 .

Smith, G. E.: Further Observations on the Fornix, with special reference to the Brain of Nyctophilus. Jour. Anat. and Physiol., Vol. 23. I897.

Smith, G. E.: Further Observations on the Brain of the Monotremata. Jour. Anat. and Physiol., Vol. 33. 1898.

Smith, G. E.: On the Morphology of the Cerebral Commissures in the Vertebrates, with special reference to an aberrant Commissure found in the Forebrain of certain Reptiles. Trans. Linn. Soc. London., Vol. 8. I903.

Unger. L.: Untersuchungen über die Morphologie und Faserung des Reptiliengehirns. Sitzungsb. d. k. Akad. d. wiss. Wien, Math.-Naturw. Classe, Bd. II3. 1904 . 


\section{CHAPTER XIX.}

\section{THE NEOPALLIUM.}

The evolution and general morphology of the cerebral hemispheres have been described in the last chapter and as full a description of the archipallium given as the limits of this book will permit. The neopallium, although it occupies the greater part of the mammalian hemisphere, is essentially dorso-lateral in position, lying between the pyriform lobe ventro-laterally and the hippocampal formation dorso-mesially. It is connected with the lower parts of the brain by large bundles of fibers which run down through the corpus striatum, forming the capsula interna (Figs. 162 and 166). By means of the corpus callosum the neopallial areas of the two hemispheres are connected with one another.

STRUCTURE OF THE CORTEX.-The neopallium everywhere consists of a thick internal layer of fibers and of a superfical layer of cells, the cortex. This cortical layer varies in thickness from about $1.70 \mathrm{~mm}$. to about $3.50 \mathrm{~mm}$. Its total volume increases enormously from lower to higher mammals on account of the increasing size of the hemisphere as a whole, and still more on account of the superficial folding in the higher forms. The cortex consists of several zones of cells of different forms which are to be recognized with certain modifications in all parts of the pallium. The typical structure of the cortex as seen in Golgi sections is illustrated in the accompanying Figure $\mathrm{I} 7 \mathrm{I}$, which is combined from numerous figures of Cajal representing sections of the frontal and parietal cortex of the young child. As indicated by arabic numerals at the left of the figure, seven layers are distinguished according to the size and form of their cells and the disposition of their neurites.

I. Plexiform layer. This layer contains (a) small and medium sized cells with short neurites and $(b)$ large horizontal cells whose 
neurites form tangential fibers of this layer. The layer also con-

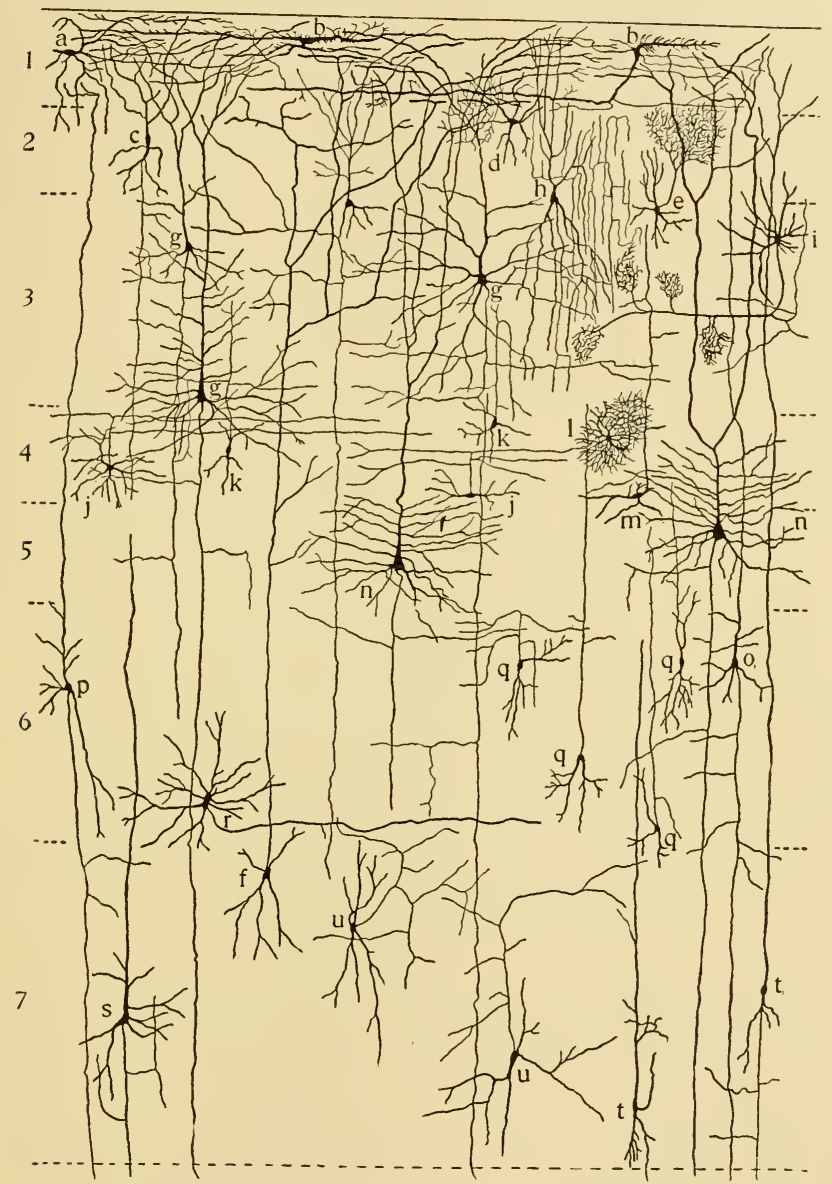

Fig. I 7r.-Structure of the cerebral cortex. Explanation in the text.

tains the terminal branches of the dendrites of pyramids and of 
other cells situated in deeper layers, and the end branches of the neurites of various cells of deeper layers.

2. Layer of small pyramids. This layer contains four types of cells: (c) small pyramids, each provided with a number of small basal dendrites and an apical dendrite which ascends to the

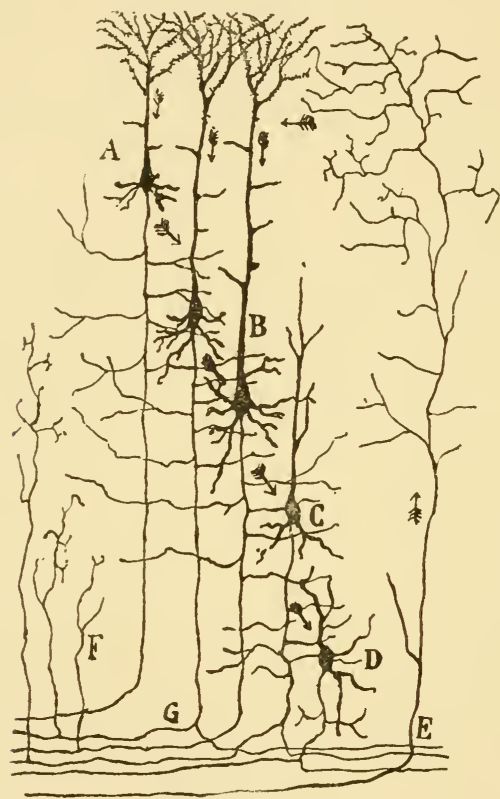

Fig. 172.-Diagram showing the probable course of impulses in the cerebral cortex. From Cajal (Nouvelles idees, etc.). $A$, small pyramid; $B$, large pyramid; $C$ and $D$, polymorphic corpuscles; $E$, terminal fiber from other centers; $F$, collaterals from the white substance; $G$, fiber bifurcating in the white substance.

plexiform layer, and having a long neurite which descends to the white substance; $(d)$ large cells with short neurites; $(e)$ small cells with short neurites which end in a very rich and dense arborization; $(f)$ fusiform, oroid, stellate or triangular cells without radial dendrites whose neurites form the "fibers of Martinotti" 
which ramify in the plexiform layer. Cells of the last type are found in all layers of the cortex and one is shown in the seventh layer in Figure I7I.

3. External layer of medium and large pyramids. In addition to $(g)$ the pyramidal cells, whose form is well shown in the figure, this layer contains several varieties of cells with short neurites, two of which are shown in the figure. One of these $(h)$ is found in other layers as well. It has two sets of dendrites and a neurite with a great number of regular, smooth branches. The second (i) gives rise to a neurite which bears one or more pericellular baskets ending about the bodies of pyramidal cells.

4. Layer of small stellate cells and of pyramids, usually called the layer of granules. This layer contains a few small, medium and large pyramids similar to those in the adjacent layers, but the most numerous and characteristic elements of the layer are the small stellate cells. By reason of their great number and the distribution of their neurites these cells are very important elements of the cortex. They are of several varieties of which there are shown in the figure: $(j)$ cells whose neurites form long horizontal branches in the fourth layer; $(k)$ cells whose neurites ramify in the third layer; $(l)$ cells with ascending neurites with very numerous and exceedingly fine branches; and $(m)$ cells whose neurites ascend to the first or second layer.

5. Deep layer of large pyramids. In various regions of the cortex are found discontinuous groups or islands of giant pyramidal cells, two of which are shown in the figure $(n)$. The layer contains also cells with short neurites distributed to the fifth and sixth layers, or ascending to the first layer.

6. Deep layer of medium pyramids. This layer contains in addition to the pyramids $(o)$ and triangular $(p)$ and fusiform cells related to the pyramids, cells with short neurites of which several are shown in the figure $(q, r)$.

7. Layer of triangular and fusiform cells. Some of the elements of this layer are true pyramidal cells $(s)$, others fusiform or triangular cells $(t)$ related to pyramids. The remainder are cells with short neurites $(u)$, including cells $(f)$ which give rise to fibers of Martinotti. 
Fibers of THE CORTEX.-Four categories of fibers are connected with the neopallium. (I) Afferent or exogenous fibers, coming to the cortex from other parts of the brain. Such fibers come from the sensory nuclei in the thalamus and perhaps from other sensory centers, such as the corpus quadrigeminum anterior and the nuclei of the VIII nerve. Such fibers therefore bring sensory impulses to the cortex, in which they end by widely spread arborizations. In addition to these fibers, collateral fibers of unknown significance rise into the cortex from the white matter. (2) Intracortical fibers. This group includes a great variety of fibers which serve to spread impulses in the cortex or to bring into relation more or less distant areas. There may be mentioned: $(a)$ short neurites

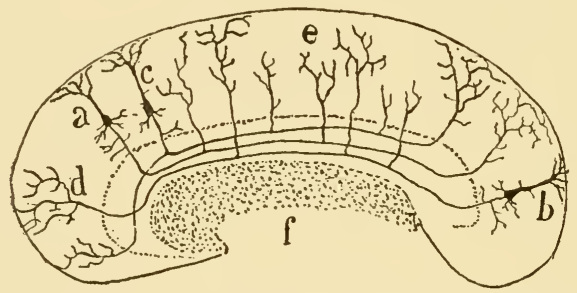

Fig. 173.- Scheme of long association tracts in the hemisphere. From Cajal (Nouvelles idees, etc.). $a, b, c$, pyramidal cells; $d$, terminal arborization; $e$, collaterals of the fibers of association.

connecting the superficial layers with the deeper; $(b)$ short neurites which connect more or less distant elements in the same or adjacent layers; $(c)$ neurites which connect distant parts of the plexiform zone; $(d)$ homolateral fibers of association which connect various parts of the cortex in the same hemisphere. (3) Fibers of the corpus callosum. These connect the cortex of one hemisphere with that of another and are in part direct neurites of pyramidal cells and in part collaterals of fibers of association or of projection of one hemisphere which cross to the other. The place and manner of ending of the callosal fibers in man is not fully known, but it is thought that they are distributed to the motor and association areas. In some mammals they 
have been traced to endings in the motor sphere of the cortex. (4) Fibers of projection. These arise from the pyramidal cells and descend through the white matter to form constituent fibers of the internal capsule of the corpus striatum and end in various lower centers of the brain or spinal cord. They are therefore efferent fibers which carry impulses from the cortex and bring other parts of the nervous system under its influence.

FunCtIONAL AREAS OF THE NEOPALLIUM.-The archipallium, as described in the last chapter, is devoted to olfactory and possibly gustatory functions. The neopallium is concerned with visual,

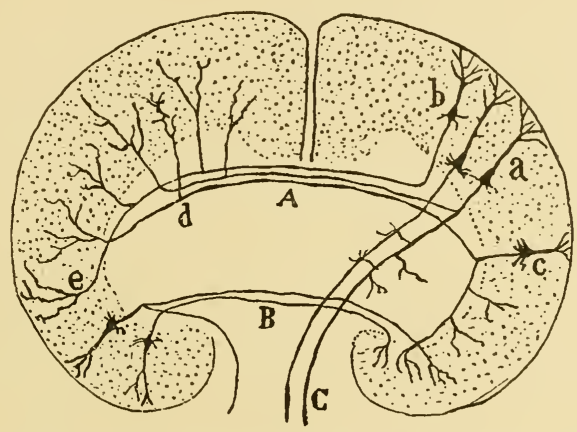

Fig. 174.-Scheme of commissural and projection fibers of the cortex. From Cajal (Nouvelles idees, etc.). $A$, corpus callosum; $B$, anterior commissure; $C$, pyramidal tract.

auditory and general bodily sensations, with voluntary actions and with all the complex associational processes involved in our more highly organized activities, and in the formation and expression of ideas. But the whole of this large cortical area is not des. voted indifferently to these several functions. It is shown by several independent methods of investigation that there exists in the neopallium a division of labor which is expressed by the term cerebral localization of functions. Thus, in case of any disease or injury which produces a lesion of a part of the cerebral cortex, one or more bodily functions may be interfered with and the study 
of many cases has shown clearly that the functions affected depend upon the specific regions of the cortex injured. A sufficient number of facts of this sort have been collected from clinical observations, post-mortem examinations and surgical operations to render fairly certain and accurate the determination of the area of the cortex involved in case of a brain tumor, degeneration of cortical substance or other cause of disturbance. If the patient shows symptoms of disturbance in the functions of sight, hearing, bodily sensation, or voluntary movement including speech, certain specific areas of the cerebral cortex may be pointed out as the seat of the disease, and in the case of bodily sensation or movement certain subdivisions of the cortical area may be assigned to certain parts of the body.

These clinical observations on man are supported by experimental investigations on animals in which either certain areas of the cortex in the living animal are directly stimulated and the effect noted, or the degenerations produced by the extirpation of certain cortical areas are studied by the method of Marchi. These investigations combined with the study of degenerations in human brains where the symptoms have been recorded during life, have led to the mapping out of functional areas on the cortex and to the description of the course of the tracts connected with those areas. Now the histological study and comparison of the areas thus marked out shows that in the normal brain certain differences exist between the different regions of the cortex and these differences are in some cases sufficiently marked to be of assistance in determining the limits of the various areas. Thus the cortex in various regions differs in total thickness; in the relative thickness of its layers, in the presence, number and arrangement of giant pyramids and other cells; and above all, in the character of fibers connected with it. The skilled observer can distinguish between sections from various cortical areas. In the case of the cortical area for hearing, the thickness alone is sufficient guide and in the visual area the tangential fibers connected with it are so well marked that the limits of the area may be seen in dissections with the naked eye.

The differences in the fiber tracts connected with the several 
areas give by far the most simple and direct and probably the most accurate means of mapping them out. The clinical and pathological data come into account here, but the most illuminating studies are those based upon the order of myelinization of the fiber tracts (method of Flechsig). Flechsig has shown that in the developing human brain certain fiber tracts produce their myelin sheaths earlier, others later, and that the order of myelinization is measurably regular and constant. Certain practical advantages in tracing fiber tracts were gained by this discovery. The tracts which are myelinated early may often be traced with great ease in early stages before adjacent tracts have received their myelin. When the tracts which are myelinated early are fully known in early stages of development the tracts which become myelinated later may be studied with greater certainty. The - great advantage for the study of cerebral localization, however, lies in the fact that the majority of fibers connected with any nerve center or engaged in carrying impulses of the same category, become myelinated at the same time. If, then, the fibers which go up to the cortex from the centers for hearing, for example, become myelinated at the same time, the area of the cortex concerned with hearing will be indicated by the distribution of this tract when it is first myelinated and can be traced most easily. Furthermore, the production of myelin seems to be the result of the beginning of functional activity of nerve fibers and the myelin appears first near the cells of origin and is progressively formed toward the end of the fiber and so indicates the direction in which the impulses travel. Thus, when a sufficient series of developing brains are studied this method should give three classes of facts: first, the course of the fibers engaged in a specific function and the cortical area to which they are related; second, the order in time when various nervous pathways begin to function; and third, the direction in which impulses are carried by given fiber tracts.

THE SENSO-MOTOR AREAS.-The afferent or sensory fibers which come to the neopallium from lower brain centers end in certain regions, and from these regions alone (Flechsig) arise the great majority of the efferent or motor fibers which carry impulses to the motor centers of the brain and spinal cord. Hence these 
regions are given the name of the senso-motor areas. Three sensory centers are recognized, the visual, the auditory and the somaesthetic areas. The last is the area for general bodily sensations. Since motor tracts descending from the visual and auditory fields are not well known, a general area corresponding roughly to the somaesthetic area is commonly known as the motor area. The only way of describing the limits of these areas is

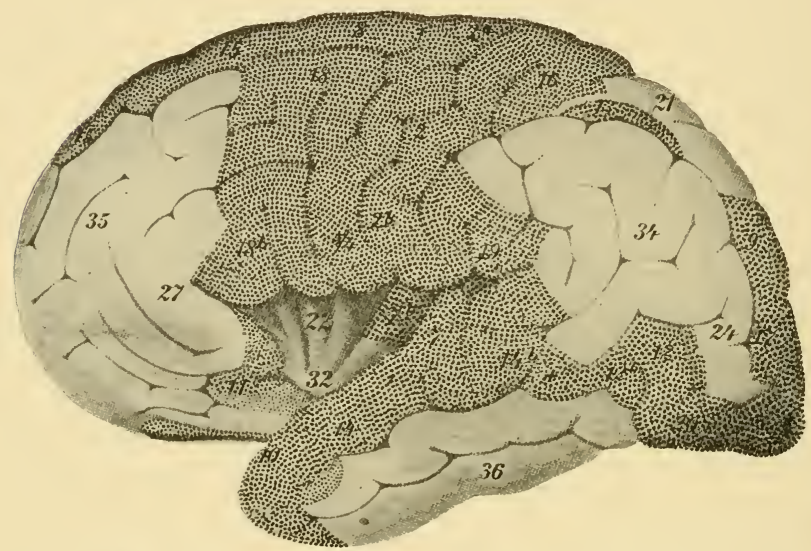

Fig. $175 .<$ The primordial areas in the cerebral hemispheres, lateral surface. From Flechsig (Einige Bemerkungen u.s.w.). The numerals indicate the order of myelinization of the several areas. The areas 9-13, although myelinated early have no projection fibers. The areas $I-8$ belong to the primary sensory areas (compare Figs. I79 and I80).

by means of the superficial sulci and gyri of the brain. Their position will be described here in a general way; for their exact boundaries the student must be referred to the original articles dealing with the subject.

I. The somaesthetic area. This includes the central gyri, the lobulus paracentralis and part of the adjacent frontal gyri and of the gyrus fornicatus; that is, a part of the lateral and mesial surfaces of each hemisphere in the middle region. The extent 
of the area is indicated in the accompanying Figures 175 and $\mathrm{I} 76$. This area receives fibers from the chief sensory nucleus of the thalamus and perhaps from other centers of the general cutaneous apparatus (cf. p. 259). With respect to the time of myelinization these fibers are divided into three groups. The fibers of the first group receive their myelin at the beginning of the ninth month of foetal life and are the first fibers entering the neopallium to become myelinated. Part of the fibers of the olfactory tract are myelinated somewhat earlier. The fibers which are first myelinated

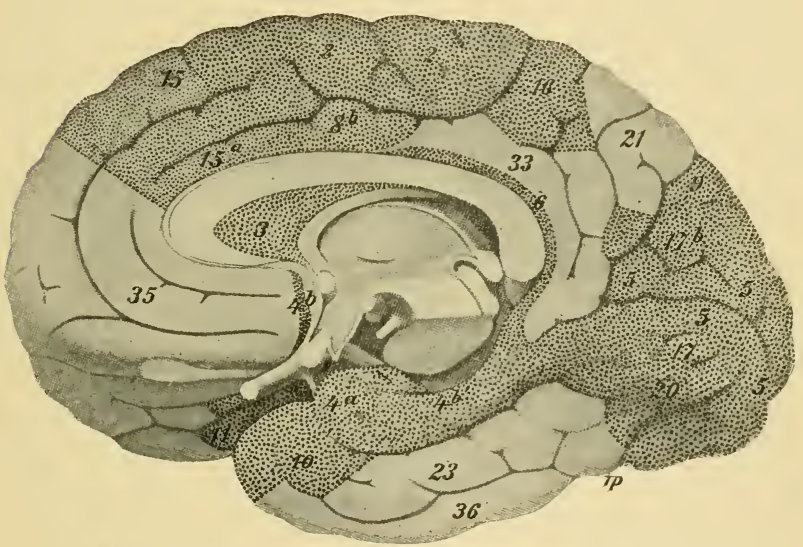

Fig. 176 , - The primordial areas in the cerebral hemispheres, mesial surface. From Flechsig. See Fig. I75.

carry impulses from the limbs and this accords with the evident importance in the early life of the infant of the tactile impressions received through the limbs. The fibers carrying impulses from the trunk and head are myelinated later.

2. The visual area. This occupies a small part of the lateral surface and a large part of the mesial surface in the occipital region. The fibers from the optic centers in the thalamus (p. 26I) receive their myelin just later than the greater part of the fibers of 
the olfactory pathways and earlier than the last group of somaesthetic fibers.

3. The auditory area. This area on the lateral surface of the temporal lobe close to the island of Reil is better defined than most other areas, since its cortex is much thicker than that of the immediately adjacent regions. Its afferent fibers are myelinated soon after those of the visual field.

4. The gustatory area. As already suggested in the previous chapter, the gustatory center is closely related to the olfactory. Injury to the cortex or fiber tracts close to the splenium of the corpus callosum in one hemisphere leads to loss of taste on the opposite half of the tongue. Whether the taste center is located in this area of the cortex (area 6 of Flechsig's figures) which is continuous, with the subiculum cornu Ammonis, or in the hippocampus itself is uncertain. When the gustatory connections in lower vertebrates are taken into account it seems very probable that gustatory as well as olfactory sensation is provided for in the archipallium and that both come into relation with the mechanism for conscious and voluntary actions only through the association centers.

5. The motor area. This is practically co-extensive with the somaesthetic area. In this area the pyramidal cells reach a greater development than elsewhere and the large pyramids are especially numerous. In those areas in which arise fibers which run to the lower part of the spinal cord many of the pyramidal cells are of gigantic size (e.g. the giant cells of the lobulus paracentralis, the center for the lower limb). The motor fibers always develop myelin later than the sensory fibers of the corresponding area. From the whole motor area arise fibers which descend through the internal capsule and cerebral peduncle and continue through the pons and medulla oblongata into the spinal cord. 'In the internal capsule they make up the knee and two-thirds of the posterior limb and they constitute about three-fifths of the cerebral peduncle. In the base of the midbrain and pons many of the fibers terminate in relation with the motor neurones of the III, IV, V, VI and VII nerres, most of them crossing to end in the nuclei of the opposite side. Many fibers end also 
in the nuclei of the pons. Those fibers which pass through the pons form in the medulla oblongata the well-known pyramidal tracts. From these, fibers are given off to the motor nuclei of the IX, X and XII nerves and at the posterior end of the medulla oblongata the two tracts enter into the pyramidal decussation. The decussation is not complete but the smaller part of the fibers continue into the cord on the same side, forming the ventral cerebro-spinal fasciculus. The crossed fibers together with a small number of the uncrossed fibers form the lateral cerebrospinal fasciculus. Both of these bundles decrease in size as they descend the spinal cord, the ventral bundle being used up in the cervical and thoracic region and the lateral bundle gradually diminishing but extending even into the sacral cord. The fibers end in relation with the motor neurones of the spinal nerves. Part of the fibers of the ventral bundle cross to the opposite side and since the lateral bundles also contain uncrossed fibers it is probable that throughout the whole length of the spinal cord there are both direct and crossed connections of the cerebral cortex with the motor nerves.

6. The areas of association. When the areas which have been described are myelinated there remains two-thirds of the cortical area without myelinated fibers. At the same time the projection tracts of the cerebral cortex seem to be fully formed. Although it is quite possible that a certain number of projection fibers may receive their myelin after this time and that some of such fibers may be connected with parts of the cortex not included in the above areas, it is clear that these are the supreme projection areas of the cortex. Although the method of Golgi and the degeneration methods give evidence that projection fibers arise from the whole cortex, the method of Flechsig is the more reliable for this question and it must be regarded as clearly established that the number of projection fibers connected with other parts of the cortex is small compared with the number connected with the senso-motor areas above described.

The remaining two-thirds of the cortex is intercalated between the several senso-motor areas so that each of them is separated by a considerable space from the others. This whole area constitutes, 


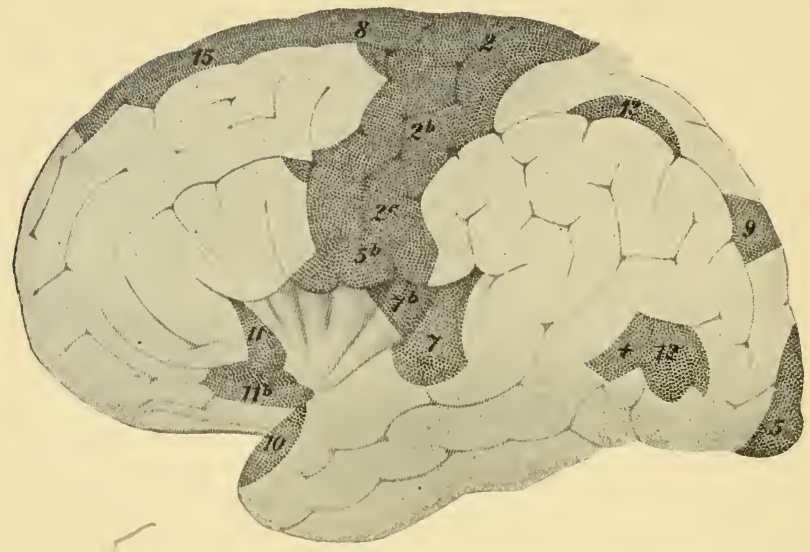

Fig. 177 - The primordial areas and the border zones of the association fields, lateral surface. From Flechsig. The figure represents the extent of myelinization in the hemisphere of a newborn infant $54 \mathrm{~cm}$. in length. The primary sense areas and a part of the border zones are myelinated and the numerals indicate the order in which they receive their myelin. The anterior and posterior association fields stand out sharply as light areas. The middle association field is exposed to view by drawing aside the temporal lobe.

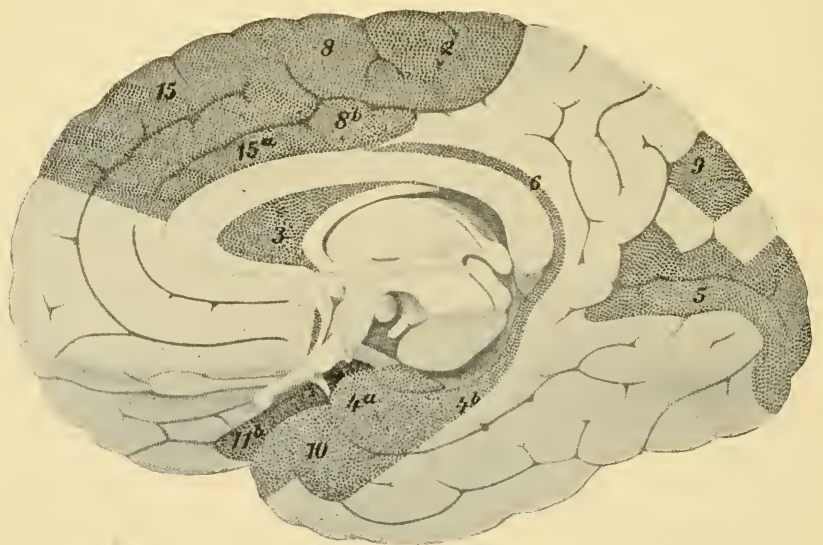

Fig. 178. - The primordial areas and the border zones of the association fields, mesial surface. From Flechsig. See Fig. I77. 
according to Flechsig, the association centers and it may be divided into three main fields, the anterior, middle and posterior association fields (Fig. 179). That these fields are primarily related

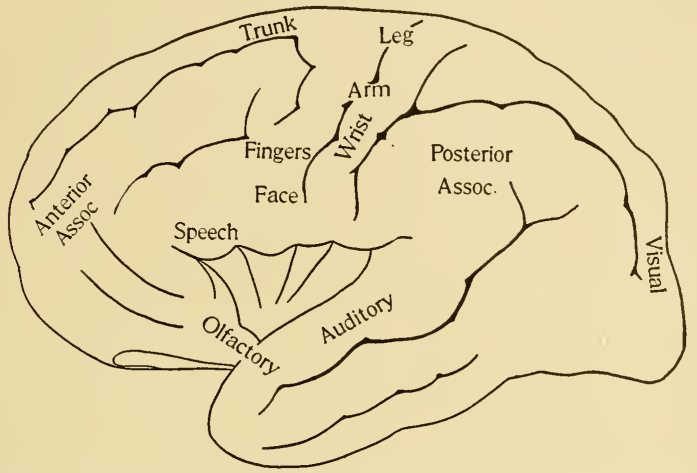

Fig. I79.-Diagram of lateral surface of hemisphere showing localization of functions.

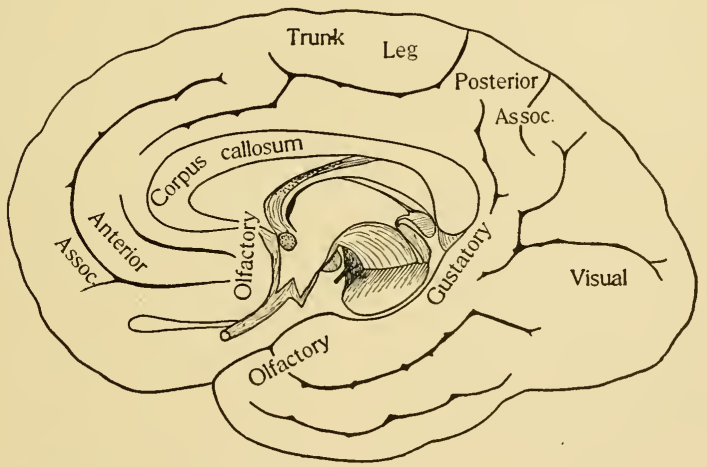

Fig. I80.-Diagram of mesial surface of hemisphere showing localization of functions.

to the senso-motor areas is shown by the fact that the myelinization of the cortex spreads from the senso-motor areas to the cortex 
bordering on them. A comparison of Figures 175 and 176 with Figures 177 and 178 shows that around the senso-motor areas a number of border zones have been myelinated while the central zones of the association fields remain without myelin. This seems to indicate that when the senso-motor areas become functional the association areas immediately adjoining them first come into relation with them, and the central parts of the association fields become functional last. A difference in function, then, is probably to be attributed to the border zones and the central zones of the association fields.

By association fields must not be understood areas in which the functions of association are carried out without the aid of the senso-motor areas. This would be physically impossible and the term correlation centers would more truly express the function of the association fields. In other words, the function of the association centers is to correlate the actions of the sensomotor centers. The cells in the senso-motor areas are by no means all connected with projection fibers; only a few of them give rise to such fibers. The remainder give rise to association fibers of greater or less length. The shorter ones serve to connect the layers in the same gyrus or to carry impulses to adjacent gyri. The longer ones carry impulses to more distant parts of the cortex. It appears that these fibers do not go from one senso-motor area to another, but that the sereral senso-motor areas are brought into relation through the association centers. The fibers reach first to the adjoining border zones of the association fields and later to the central zones and even to more distant association centers. The longer association fibers enter into the formation of certain long association tracts of which there may be mentioned: (I) the fasciculus longitudinalis superior or arcuatus, apparently connecting the occipital and frontal lobes; the fasciculus longitudinalis inferior, connecting the occipital and temporal lobes; the cingulum, connecting the hippocampus and perhaps other olfactory nuclei with the lower gyri of the frontal lobe; the fasciculus uncinatus, connecting the temporal lobe with the same region of the frontal lobe; and the fasciculus occipito-frontalis (tapetum) which Dejerine belieres consists of fibers arising in 
the frontal lobe and ending in the occipital lobe. In addition to these tracts which connect distant lobes, within each lobe are numerous association bundles, such as the calcarine, vertical, and transverse bundles in the occipital lobe. These various association bundles are very complex, consisting in most cases of fibers running in both directions and of fibers which enter and leave the bundles at various points of their course. Their grouping into bundles is due merely to mechanical conditions arising from the form of the brain. The greater part of the corpus callosum fibers go to the anterior and posterior association fields; the middle field receives few commissural fibers.

In order to understand the functions of the association centers it is necessary to define more exactly the functions of the sensory areas. The phenomena of clear and sharp sense impressions is dependent upon the sense areas. Disease or injury to one of these centers interferes with the clearness and definiteness of the sensations with which that area is concerned. At the same time the memory of such sense impressions and percepts formed from several kinds of sense impressions may remain intact. Also, according to Flechsig, the perception of the spatial and temporal relations between sense perceptions depend upon the sense areas. Thus the clear recognition of the form of an object when felt by the hand depends upon the proper functioning of the hand and arm portion of the somaesthetic area, while the memory picture of the same object made up from previous sense impressions (tactile, visual, etc.) is a function of some of the association centers and may be preserved when the somaesthetic area is diseased.

As the sense areas send fibers into the adjoining border zones of the association fields the participation of these zones will provide for the combination of simple sense impressions into perceptions of slight complexity. Thus general images of form based upon the examination of various objects by the hand may be localized in the border zone adjoining the sense area for the hand. In some such way the border zones stand in relation with the several sense areas and provide for relatively simple association of sense impressions from nearly related regions of the body. More complex images of the form of objects dependent upon the com- 
bination of tactile and visual impressions, for example, require the cooperation of association centers which receive fibers from both somaesthetic and visual areas. The order of myelinization of association centers corresponds to the order of development of more and more complex actions and mental states in the child. The central zones of the association fields, then, serve for the higher psychic states and more complex processes of thought.

The specific functions of the three association fields are determined in large part at least by their position with reference to the senso-motor areas. The middle association field (island of Reil) situated as it is between the auditory area and that part of the somaesthetic area which receives sensation from the lips, tongue, throat, etc., is chiefly the association center for speech. The anterior and posterior fields have much more complex relations and functions. The posterior field, situated between the somaesthetic, visual and auditory areas, receives from those areas impressions concerning the external world. The functions of this field are to construct external objects from the several kinds of sense impressions and to form ideas concerning the relations of objects and physical processes to one another and to the self. In a word, the objective relations of the individual and all those processes which we commonly call "intellectual" are the peculiar province of the great posterior association field. That this is at least in general the true interpretation of this field is evidenced by the mental symptoms in cases of disease affecting the posterior association field. The most common phenomena met with are various forms of loss of memory and of the power of association. If the sensory areas are not affected the perception of sense impressions by the touch, sight and hearing is not impaired, but these impressions can not be combined into objects which are recognized as previously experienced. The individual presents to the observer the phenomena of mind-blindness, mind-deafness and the like, while he himself loses the power of connecting his several impressions into orderly experience. Whatever set of associations are thus affected the corresponding set of sense impressions cease to interest and finally cease to attract the attention of the individual and he appears listless with regard to things 
which once interested him, or is unable to recognize objects, to give the proper names to things, to remember appointments, etc. When larger areas of the posterior field become affected these symptoms become more general and the patient loses his interest in the external world and practical affairs. He may, however, retain his interest in his own personal relations, his self-respect may be perfectly preserved, and so far as his powers of intelligent action enable him, he may be entirely true to his personal duties and engagements. The posterior association field deals then with order and relation in the external world, with recognition, memory and imagination, with judgment and the weighing of processes and events.

The anterior association field lies in proximity to the somaesthetic area, but removed from the other sensory areas. It would receive in common with the posterior area the impressions due to contact with external objects and to the movements of the body, limbs, organs of speech, etc. Although the distant connections of the frontal lobe are not well understood, it seems clear that fibers from the visual and auditory areas are of subordinate importance, while association bundles from the olfactory (and gustatory) centers are next in importance to those from the somaesthetic areas. In the light of comparative neurology it is more than possible that all sensation from the viscera reaches the archipallium and comes to play a part in conscious states through the association tracts to the frontal lobes. If so, this would strengthen the view already expressed by Flechsig that the impulses which enter the frontal lobes have to do especially with experiences of the individual and hence the anterior association field is concerned with subjective states, and with the emotions, with action and with the will. Here are to be sought the mechanisms corresponding to the bodily states which accompany or constitute the emotions, and those connected with attention and apperception. Certain bodily conditions, such as muscular tension, are connected with attention and active apperception, and the association centers which deal with these are related to the somaesthetic and somatic motor area. Here, also, clinical observation supports the reasoning from anatomical data. In cases of disease of the frontal lobes 
the symptoms which appear during life involve loss of appreciation of the individual's personality and of the value of things to him. Self-depreciation and lack of confidence or the opposite extremes, incapacity for moral and aesthetic judgment, uncertainty of action and lack of will, are common in such persons. Their self-control suffers and under the influence of excitement their conduct becomes immoral or criminal. The anterior association field has to do, then, with ideas of the individual's personality and with the appreciation of his personal relations. For conduct in the full sense, that is for moral conduct, there is required the normal functioning of both anterior and posterior association fields; since both objective and subjective relations must be considered, both judgment and will are involved. For moral conduct the individual must respond to both the external or objective and the individual or subjective factors in his situation, and the perfection of the response depends upon the grade of organization of the association centers and the balance between them.

The evolution of THE NEOPALlium.-The general subject of the origin of the neopallium has been considered in the last chapter, but a certain interest attaches to the order and grade of development of its various parts. The direct data for the study of these subjects are very meager. The collection of such data would require the study of cerebral localization in the various orders of mammals together with the study of habits and the grade of organization of intelligent action. Such studies are not yet complete enough for this purpose but the facts of localization in the human brain give some indications of the probable course of development. First, the facts that the senso-motor areas are everywhere separated by association areas and that myelinization proceeds from the sensomotor areas into the association areas warrant the inference that the association areas have been differentiated from the borders of already existing senso-motor areas. The senso-motor areas must have occupied the greater part or the whole of the neopallium in lower mammals and the greater size of the hemispheres in higher mammals is due chiefly to the expansion of the association areas. Second, the position of the several senso-motor areas indicates the order of development in the neopallium. The phy- 
logenetic and ontogenetic development of the several main regions of the forebrain show that the neopallium began its history at the front end of the forebrain and that it has expanded backward. Consequently the centers which were first developed must now be found in the posterior part of the hemisphere and those which were last developed, in the anterior part. The visual centers, then, which occupy the extreme occipital pole, were first formed, next the auditory which are depressed into the temporal lobe by the development of the association centers, and last the somaesthetic and somatic motor area. It was pointed out in the last chapter that a forerunner of the neopallium is probably present in the fish brain in the form of a tract from the tectumopticum to the forebrain, and this accords well with the conclusion that the visual center was the first to be developed in the cortex. The order indicated by the position of the organs in the cerebral cortex of man accords also with the order of importance of the sense organs in phylogenetic history. While the cutaneous system is the oldest it is also the least specialized. The eye is the first special somatic sense organ in vertebrates and the auditory system followed it. It may easily be seen that these special sense organs which give knowledge of objects at a distance would be of greater value for the development of a higher correlating center such as the cortex than the cutaneous system. Although the cutaneous system was the last to reach the cortex its center in the neopallium has become larger than both visual and auditory combined. The relative areas are approximately proportional to the number of peripheral sensory fibers. The great importance of the somaesthetic area in apes and man is connected with the development and mobility of the limbs; especially with the high organization of the hand as a grasping and tactile organ, and the use of tools. It may be supposed that while the senso-motor areas were being developed, association centers made their appearance between them, and that the posterior association center is therefore older than the anterior. The expansion of the association centers has helped to determine the position of the several areas in man. Indications of this are seen in the shifting of the visual area from a position about half on the mesial surface and half on the lateral 
surface in the apes to a position almost wholly on the mesial surface of the hemisphere in man, and also in the position of the auditory area in the temporal lobe. Finally the anterior association field has developed from the front border of the somaesthetic area and is relatively small in the apes and probably absent in the lower mammals. The development of this field seems to be directly proportional to the grade of self-consciousness and in the several races of men, to the grade of civilization. So, the full appreciation of the self has probably been the last and highest factor in the development of individual and social conduct.

The development of the several areas demands an increase in cortical surface. This is secured by surface foldings which form the gyri and sulci. Such foldings took place (I) within the sensory areas themselves, serving to increase their surface; (2) at the border of the sensory areas and so forming the boundaries between sensory and association areas; and (3) within the association fields themselves. The deeper and more constant furrows belong to the first and second groups, since the furrows in the association fields appear much later than the others. After the fundamental furrows were formed they were mechanically prolonged, branched and bent until it is difficult to compare the furrow patterns of the brains of different mammals.

One other consideration concerning the association centers should be touched upon in closing this book, namely their significance for education and morals. The object of human knowledge is the world in its multitudinous forms and man's manifold relationships in it. The knowledge already acquired-when taken in comparison with the simplicity of the child's brain and knowledge-has become enormously complex. It is so complex that when it is systematized and divided and subdivided many times, the average man can grasp only one small subdivision. How many of these shall the child entering school today learn to understand, with how many can he become reasonably familiar, in how many will he be able to add to human knowledge? This will depend chiefly upon the number of related facts which come to his notice during the plastic period of his brain. If he is early brought into contact with the world of matter and of life under 
many aspects, a corresponding number and variety of association tracts in his brain will be developed and fixed through use and will be ready for the correlation of the experience of later years. Either in the schoolroom, on the playground or in vacation time a richness of experience must supply the association centers with the condition for their high organization. Without this there can be in later years no richness of mental life and no great power of research, invention or constructive statesmanship. So on the moral side, the realities of human relationships must come into the experience of the youth during the period of plasticity of his brain if he is to rise to the higher planes of moral life.

\section{DEMONSTRATION OR LABORATORY WORK.}

I. Dissect the brain of a cat, dog, sheep or man, working out the relations of the neopallium to the archipallium and corpus striatum. With the aid of figures in a larger text-book or atlas trace the limits of the neopallium in man and the chief gyri and sulci and the location of the senso-motor and association areas.

2. As far as time and material permit, the structure of the cortex, the course of projection and commissural fibers and the arrangement of association bundles may be studied in Golgi or Weigert sections of a mammalian brain.

\section{LITERATURE.}

Beevor and Horsley: A record of the results obtained by electrical excitation of the so-called motor cortex and internal capsule in an Orang-Outang. Phil. Trans. $\cdot$ i $890-9$ r.

Beevor and Horsley: An experimental investigation into the arrangement of the excitable fibers of the internal capsule of the bonnet monkey. Phil. Trans. I890-9I.

Beevor and Horsley: A further minute analysis of the electric stimulation of the so-called motor region (facial area) of the cortex cerebri in the monkey. Phil. Trans., I895.

Cajal, S. R.: Textura del sistema nervioso del Hombre y de los Vertebrados. Cajal, S. R.: Les Nouvelles idees sur la structure du système nerveux. Paris. 1895 .

Dejerine, J.: Anatomie des centres nerveuses. I895-1904.

Dejerine, J.: Sur les fibres de projection et d'association des hémisphères cérébraux. C. R. Soc. Biol., Paris. I897.

Donaldson, H. H.: The Growth of the Brain. 1895 . 
Edinger, L.: Volesungen über den Bau der nervösen Centralorgane. 1904. Flechsig, P.: Gehirn und Seele. Leipzig. I896.

Flechsig, P.: Die Localization der geistigen Vorgänge insbesondere der Sinnesempfindungen. Leipzig. I896.

Flechsig, P.: Einige Bemerkungen über die Untersuchungsmethoden der Grosshirnrinde, insbesondere des Menschen. Leipzig. 1904.

Golgi. C.: Sulla fina anatomia degli organi centrali del sistema nervoso. Riv. sper. di freniatr., Reggio-Emilia, Vol. 8, 1882; Vol. 9, I883; Vol. 10, I885. Koelliker, A.: Gewebelehre. 6te. Aufl. Bd. .2. 1896.

von Monakow, C: Ueber den gegenwärtigen Stand der Frage nach der Localization in Grosshirn. Asher und Spiro's Ergebnisse, I. Jahrg., II. Abth. 1902.

Retzius, G.: Das Menschenhirn. I896.

Smith. G. Elliot: Studies in the Norphology of the Human Brain with Special Reference to that of the Egyptians. No. I. The Occipital Region. Rec. Egypt. Gov. School Med., Vol. 2. 1904. 


\section{INDEX.}

The numerals in ordinary type refer to pages, those in bold-face type refer to figures.

Abducent nerve, see N. abducens

Acustico-lateral system, IOI, I 24 nerves and centers, $124,253,5 \mathrm{I}$, $62,63,70,79$

placodes, $5^{8}, 33$

sense organs, I24, 5 I, 62

Adaptation of activities, 95

Afferent impulses and fibers, 8I, 96

Amphibia

acustico-lateral system, 59, I38, 79

brain, $31,249,256,284,305,36$, 8 I, I 25, I 27, I 50

cranial nerves, 79

histogenesis, I 4, I 5, I 6, 26, 27

neural tube, $35,13,14,15$, I 6

optic vesicles. 43,22

placodes, 59

segmental relations of nerves, I9 I sensitiveness to light, I43

Ampullae of Lorenzini, 60, I25

Anterior head cavities, 64, 38

Aqueduct of Sylvius, 24

Archipallium, 301-336, I 45-I 70

Arcuate fibers

external, I35, 229, 243, 245

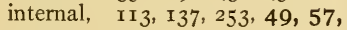
59,70

Association centers, 349-356, I 75I 80

apperception, 355

attention, 355

imagination, 354

judgment, 354

memory, recognition, 354

personality, 355

speech, 354

Association tracts, $35^{2}$

Auditory apparatus, IOI, I24, 253, 70

area of cortex, 348,357

centers, primary, $124,64-70$

secondary, I 24, 253, I 27 , I 29
Auditory apparatus

cochlea, I27

cochlear nerve, r 40

nerve, see $\mathrm{N}$. acusticus

sac, 58,65

semicircular canals, I 28

sense organs, I26, 33, 6 I

vestibular nerve, I 38

Birds, 39, 6I, 258, I9, 74

Bony fishes

brain, I8, 24, 27, 30, I61, I69, $223,229,27 \mathrm{I}, 284,302,4,8$, I $9,89,90,9$ I, I 27, I 48

cranial nerves, 106, $128,166,63$, 88

gustatory paths, $169,89,90$

neuromeres, 38 , I 9

taste organs, I64, 85

Brachium conjunctivum, 229, 238 ,

243,245 , I I 2-I I 7, I 24, I 25,

I 26

pontis, 239

Brain

posterior, 238

general morphology, I4, 2, 3, 4, 7-I 2, 20, 36, I 59, I60, I 65

flexures, 40, 20

histogenesis, 45, I 3-I 6

longitudinal zones, I6, 48, IOI,

3 , I I, 46, 47

neuromeres, 38 , I8, I9

secondary segments, I4, 43, 2, 20

Branchiomeres, 66, 28, 29, 38

Bulbus olfactorius, $28, x 77,293,298$, $302,305,3$ I $6,2,7,8$, I 2, 9498 , IOI, I 45-I 48, I 50, I 59, I 60

Canal organs, I24, 5I, 62

Capsula interna, $33^{8}, 348, \mathbf{6 2}, \mathbf{1} 66$

Carcinas, 79, 40

Cardiac plexus, 206, 2 I 2 
Centers of correlation, 2 I $8,226,253$, 269

central gray, 2I9

substantia reticularis, 2 I 9

tract cells, 2 I 9

Cephalization in vertebrates, 69,72

Cerebellar crest, I32, 64-68

Cerebellum, 24, II 5, I3I, 226, 2, I I, I I 2-I 20

basket cells, 240, I 2 I

brachium conjunctivum, 229, 238, 243,245, I I 2-II 7, I 24, I 25, I 26

cortex of, 239, I 2 I, I 23

deep gray nuclei, $237,245, \mathbf{1} 26$

fiber tracts, 240

function, 248-25I

general cutaneous center, II4, 59

granular layer, I32, 239, I 2 I, I 23

gustatory nucleus, I69, 247

inferior commissure, 169,288

molecular layer, 240, I 2 I, I 23

moss fibers, 240 , I 2 I

motor connections, 245

net-like endings, 240, I 2 I, I 22

origin, 44

phylogeny, 226, 248

Purkinje cells, 239, I 2 I

special cutaneous center, I30, 69

superior commissure of, 227,288 valvula, I 72, 9 I

Cerebral hemispheres, 28, I86, 292, $33^{8}, \mathrm{x} 45^{-1}-80$

amphibians, 305,36 , I 50-I 52

bony fishes, $302, x_{48}$, I 5 I

cortex of, $33^{8}$, I 7 I-I 80

cyclostomes, 293, 94, I 45, I 46

evolution of, 292

ganoids, 3.02, x or, I 49

gyri and sulci, $35^{8}$

localization in, $343, x 75-180$

mammals, 3 I6, I 59- I 80

reptiles, 3I4, I 54-I 58, I 6 I

selachians, 298, I I, I 47, I 5 I

Chiasma opticorum, 28, I46, 2, 7, I I, $36,94, x$ oo

Chief sensory nucleus of thalamus, $259,60,128$

Chorda tympani, I68

Clarke's column, I56, I 59, 78
Colliculus, I 37,255, I 27, I 29, I 30

Commissura aberrans, 3 I6, I 58 ansulata, I I 9,289

anterior, 30, 289, 295, 30I, 304, 307, 3I 5, 99-IOI, I 45-I 50, I 62, I 64, I 66

dorsalis of spinal cord, 112,287 , $49,53,78$

inferior cerebelli, I69, I 72, 288, 9I, I I 6, I I 7

infima, $159,287,81,82,83,92$ habenularis, $26, \mathrm{I} 84,289$, I o I, I 45, I 47, I 48 , I 50, I 58 , I 59 hippocampi, 3I 3, 3I 5, 3I 7-324, 334, I 50, I 52, I 55, I 58-I 62, I 63, I $67, \mathrm{I} 68$

posterior, $25,265,59$, I 32, I 35 , I 45

superior, see C. habenularis

Corpora albicantia, see C. mammillaria

mammillaria, $27,44,269,322$, 47 , г о I, I 33, I 36, I 48 , I 59 quadrigemina, $25,254-26 \mathrm{I}, 47$, $60,127, x 59$

striata, 30, I85, 292-3I5, 333,

I $45^{-1} 50$, I 56

Corpus callosum, 289, 327-33I, 338, 342, I 66- I 69

ectomammillare, $26 \mathrm{I}$

geniculatum laterale, I50, 26I, I 28 , I 3 I, I 4 I

mediale, $25^{8}$

interpedunculare, 277

restiforme, 239, 243, I 26

Cortex cerebri, 338 , I 7 I-I 74

Cortex cerebelli, 239, I 2 I-I 23

Cranial nerves, I8, 49, I0I, 5 I, 63, 79

Cryptobranchus, 305, 309

Cutaneous-motor reflex, 82, 4I, 49 52,78

Cutaneous sensory apparatus, IOI, I05, I 24, 253

general cutaneous centers, IIo, 52-60

components, 105, 49, 50,

$$
51,63,79
$$

endings, I05, 48

general cutaneous subdivision, IOI, IO4

special cutaneous subdivision, IOI, I 24 
Cyclostomes

acustico-lateral system, 59, I 30 , 28,5 I

brain, I8, 30, I16, 130, I59, I 77 , I $83,227,265,293$, I $2,57,58$,

94, I 00, I 05, I 45, I 46

cranial nerves, 23, I05, I90, I94, 5 I

neural tube, 35

placodes, 59,28

spinal nerves, I3, I

Decussatio dorsalis tecti, I 48, 254, 73

olfactoria, I8I, I85, 295, 304, 334

I O I, I $45, I 48$

veli, 229, I I 2, I 24, I 25

Degeneration of nerve fibers, $7,90,9 \mathrm{I}$

Dendrites, $47,77,80,39$

Development, 34-73

acustico-lateral system, 58,33

cranial ganglia, 49-63, 26-32

neural tube, $34, \mathbf{1}$ 3-1 6

olfactory epithelium, 6I, 34

peripheral nerves, 49, I 3-I 6, 26 $-33$

Schwann's sheath, $5^{\text {I }}$

spinal ganglia, 49, I 3-I 6

Diencephalon, $25,44,253,269$, I 3 II 52

Differentiation of brain cells, 47,23 ,

Dipnoi

$$
24,25
$$

brain, 3 I

N. terminalis, $3 I$

Direct cerebellar tract, 245,247

Dorso-lateral zone, 49

Ear, I 26

see also auditory apparatus

Epiphysis, 27, I02, I 52, I I, I 2, I9, 36,76

Epistriatum, I84, 297, 300, 304, 309, $3{ }^{1} 5,333$, I 5 $^{-1} 52$, I 55, I 56

Equilibration, I 27

Excito-glandular impulses and fibers, 8I, 2 II

Excito-motor impulses and fibers, $8 \mathrm{I}$, I90, I99, 2 II

Eye, 44, I 43, I 50, 2 I, 22, 7 I, 72, 75 see also visual apparatus

Eye muscles

origin, 64

innervation, 194

reflexes, 263

Facial nerve, see N. facialis
Fascia dentata, 3I9, 33I, I 59, I60, I 62, I64, I69, I70

Fasciculus communis, $160,81,92$

Fasciculus solitarius, $160,82,83$

Fasciculus longitudinalis medialis, dorsalis or posterior, I96, 3, 64, 65

thalamic nucleus of, 196,270 , I 34

Fasciculus spino-cerebellaris ventralis, 243

Fimbria, 32I, 334, I 59, I60, I67, I 68, I 69, I 70

Fissures

of spinal cord, I2, I

of cerebellum, 234, I I 8, I I 9

Fissura hippocampi, 3I9, 33I, I59, I 60,162

Fissura rhinalis, 317 , I 59

Floor plate, 48

Food habits, 96

Foramen of Monro, 28, 295-320, 8, I 45, I 50

Fornix, 3I4, 322, 334, I6 I, I 64, I66

Frog, 8I

sensitiveness to light, I 43

Funiculus dorsalis, I $10,52-55,59$, 60

Functional divisions, $3,45,46,47$

definition of, 95, IOI

fate in mesencephalon and diencephalon, 285

longitudinal zones of brain, I6, 48

Ganglion cells

bipolar and unipolar, 62, 35

Ganglion habenulae, isthmi, etc., see Nucleus habenulae, etc.

Ganglion ciliare, 6I, 2I6, 38

Ganglion Gasseri, 22, 6o, 5, 27, 28, $29,30,51,63,79$

Ganglion of Ehrenritter, I06, 20, 32

Ganglion jugulare, I06, 20, 32

Ganglion nodosum, 55, 20, 30, 3 I, 32

Ganglion petrosum, 55, 20, 30, $3 \mathrm{I}$, 32

Ganglion superior glossopharyngei,

Ganoids I06, 20, 32

acustico-lateral system, 62

brain, I30, 261, 270, 280, 302, 3, IOI, I 27 
Ganoids

bulbus olfactorius, $178,95,96$, 97

cerebellum, I 7 I, 229, 64-68, I I 3 - I I 7

fasciculus longitudinalis medialis, $270,3,64,134$

gustatory paths, I I 7

inferior commissure of cerebellum, I 72, I 16 , I I 7

inferior lobes, 270, 23, I 33, I 34, I 35

N. terminalis, $3 \mathrm{I}$, 106

nucleus habenulae, 280, I 40

optic chiasma, 146

saccus vasculosus, 282, I 33, I 43

special cutaneous centers, I3O, 64-68

taste buds, I 64

tectum mesencephali, I47, 73, I I 5, I I 6

tuberculum acusticum, I30, 6468

valvula cerebelli, I 7 I, I I 5, I I6, I I 7

General cutaneous subdivision, IoI

centers, Iro, $45,46,47,49,52$ 60

peripheral components, 105,50 , 5I, 63, 79

phylogenetic history, I 20

Germinal cells, 46, I3-I 6

Giant cells, 37, I 7

Gill clefts, $65,28,29,38$

relation of nerves to, I9, 54,58

Glossopharyngeal nerve, see $\mathrm{N}$. glossopharyngeus

Granular layer of cerebellum, I32, 239, I 2 I

Granule cells

of cerebellum, I 32, 239, I 2 I

of olfactory bulb, I8I, 95, 96

Gustatory apparatus, I6 4 , 85-92

Acipenser, 65, 84, I I 3-I I 7

Amia, 165

Amphibia, I65, I 25

area of cortex, 348, I 76, I 78 , I 80

bony fishes, I64-I7I, 85, 88, 89

brain centers and paths, 168,275 ,

$89,90,92$, I I 2-I I 7

diencephalic centers, 169,273
Gustatory apparatus

inferior gustatory nucleus, I69, $81,82,83$

origin of taste buds, 164

peripheral fibers, $166,51,63$, 79,88

Petromyzon, I64, 86, 87

relation to olfactory, $\mathrm{I} 87$

selachians, 92, I I 2, I 24

sense organs, I6 $5,85,86,87$

superior gustatory nucleus, I69,

89,92 , I I 2-I I 7

tactile correlations, 169

tertiary tract, $169,89,92$, I I 2-

I 7

Gyrus subcallosus, 333

Heptanchus, 28, 2

Hippocampus, 307-335, I 50-1 70

commissure of, 3I3-334, I 50, I 52, I 55, I 58-I 62, I 64, I 68

Histogenesis, 45, I 3-I 6, 23-27

Hyomandibular line of neuromasts, 59,5 I $, 62,63$

Hyomandibular nerve, see R. hyom. Hypogastric plexus, 206

Hypoglossal nerve, see $\mathrm{N}$. hypoglossus

Hypophysis, 27, 66, 2, 7, I I, 36, 37

Hypothalamus, 27, 269, I I, I 33-I 39, I $45^{-1} 5^{\circ}$

Indusium falsum, 334

Indusium verum, 334

Inferior lobes, 27, 44, 269, 2, I I, I 2, I 33-I 39, I 45-I 50

Infraorbital line of neuromasts, 59, $5 \mathrm{I}, 62,63$

Infraorbital neuromast nerve, 59, I30

Infundibulum, 27 ,

Isthmus, 44

Iter, see Aqueduct of Sylvius

Lamina terminalis, $30,295-330$, I45I 50

Lateral horn, 200

Lateral line nerves, 124, 253, 51, 62, $63,70,79$

Lemniscus system, $253,59,60,127$, I 28, I 33, I 34

see also Tr. bulbo-tectalis

Light, sensitiveness of skin to, I43

Lobi inferiores, 27, 44, $169,269,2$,

I I , I 2, I 33-I 39, I 45-I 50

Lobus facialis, I $7, I_{59}, 3,89$, I 4 I impar, I8 
Lobus facialis

lineae lateralis, I8, 3, 64, 66

olfactorius, $182,296-307,316,12$, 99, I 45-I 50

pyriformis, $317,323,333$, I 59, I6o, I62, I65, I66, I67, I 69

vagalis, $I_{7}, I_{59}, 3,4,89$

visceralis, I $7, I_{59}, 3,4$, I I, 89 , I4 I

Localization in cerebral cortex, 343 , I $75-180$

Mammals

auditory centers, I38, 70

cerebellum, 233, I I8, I I9, I 2 I, I $22,123,126$

cerebrum, cortex, 338, I 7 I-I 74 localization in, 343 , I 75-180 morphology of, 316, I45-I70

corpora quadrigemina, 253,47 , 60, I 27, I 59

general cutaneous centers, IIO, $52,54,56,60$

fibers, 106

gustatory fibers, 167

hypothalamus, 273 , I36, I 37 , I 38

olfactory centers, $180,332,98$, I 69, I 70

placodes, $55,3 \mathrm{I}$

visual centers, 26I, 347, I 28, I 30, I 3 I, I 79, I80

Mauthner's fibers, 223

Mesencephalon

collicular region, $137,253, \mathbf{1 2 7}$,

I 29, I 30

correlation centers, $253-26 \mathrm{I}$

general morphology, 24, 44

tectum mesencephali, II7, I37,

$254,2,7$, I 2, I 27

tectum opticum, I $47,255,26 \mathrm{I}$,

\section{3}

Metencephalon

general morphology, 24, 2, 7,

$$
\text { I I, I } 2
$$

origin of cerebellum, 44

Methods, general, 2

of Flechsig, 344

Molecular layer of cerebellum, 240, I 2 I

Morphology of the head, 63,38

Motor area of cortex, 345,348

Mouth, 66
Müllerian cells, 223

Muscles

of eyeball, 64

somatic, 64

sub-branchial, 64

trapezius, 203

visceral, 66,200

Myelencephalon

general morphology, I4, 2, 3, 4, I I, I 2

origin of cranial nerves, $x 8,2,3$, $7, \mathbf{1} 2$

Neopallium, 338, I 7 I-I 80

evolution of, $35^{6}$

Nerve components

general cutaneous, I05, 50, $5 \mathrm{I}$, 63,79

special cutaneous, $\mathrm{I} 28, \mathbf{5} \mathrm{I}, \mathbf{6 2}$, 63,79

general visceral, I $_{55}, 5 \mathrm{I}, 63,77$,

79

gustatory, I66, $5 \mathrm{I}, 63,79$

somatic motor, I90, $51,63,79$, IO2

visceral motor, $200,5 \mathrm{I}, 63,79$, ro6

Nerve fibers

origin and growth, 49, $9^{\text {I }}$

degeneration, 90

regeneration, $9 \circ$

sheath of Schwann, 5I

Nerve impulses, 76

afferent and efferent, 8I

Nerve sacs of ganoids, I 26

Nerves

branchial, I9, 5, 51, 63, 79

development of, 49, 26-34

motor, 23-25, 8I, I90, I99, 45, I $02,104,106$

segmental relations, 49, 70, I9I, 38

sensory, I 8, 8I, I05, I 28, I 55, I $76,45,49,77$

shifting of, 70

spino-occipital, $23,52,63$, I05, I 90, 20, 30, 3I, 32, I 04

Nervous system

development of, $34,13-36$

functions of, 76,95

functional divisions of, $95,3,45$, 46,47

general plan of structure, 77 , 95 
Nervus abducens, 23, 194, 2, 7, 63 acusticus, $20, \mathrm{I}_{3} 8,6_{3}$ centers, I $30-14 \mathrm{I}, 64-7 \mathrm{O}$ development, 58,33 cochlearis central connections, I38, 258, 70

facialis, $21,2,3,7, \mathrm{I} 2$ components of, 108, 155, I66, 200, 5 I $, 63,79$

development, 57

motor nucleus, 202

relation to auditory sac, 57,70 gill cleft, 22,58

placodes, 58

sensory centers, 108, I59, 64, 90,92

glossopharyngeus, 20, 2, 3, 7, I 2

components of, 106, 155,167 , 200, 5 I, 63, 79

development, $52-57,26$

motor nucleus, 200,107

relation to gill cleft, 20,55

myotomes, 54

placodes, 55,3 I

sensory centers, I06, I59, 89, 92

hypoglossus, 23, 193, 2, 7, 12, I04

lineae lateralis, $20,3,7$, I 2, 5 I, 63

development, 58,33

relation to $\mathrm{N}$. vagus, 20,130

oculomotorious, 25, 190, 195, 2, $7,12,63,105$

olfactorius, 28, 3I, I77, 292, 2, $7,12,95$

development, 6I, 34

ophthalmicus profundus, 22,20 , 5o, 5I, 63, 79

development, 6I

distribution, I Io

opticus, see Tr. opticus

spinalis accessorius, $20,203,20$, 30-32

relation to sympathetic, 207

terminalis, 3I, 6I, 106, 302, 336, 2, 147

thalamicus, 6I, 29

trigeminus, $22,2,5,7,12,50$

components of, 106, 200, 5 I, 63,79

development, 6o, 27-30
Nervus trigeminus

distribution, 22

motor nucleus, 202

relation to mouth cleft, 22

sensory center, I I4, 253, 56

trochlearis, 24, I94, 2, 7, I 2, 63, I 24

vagus, I9, $2,3,7$, I 2

components of, 106, I57, 166, $200,51,63,79$

compound of segmental nerves, 70

development, 52-57, 28-32

motor nuclei, 200, 202

origin, $19,157,200$

relation to gill clefts, I9, 54,28 myotomes, 54 placodes, $55,3 \mathrm{I}$

sensory centers, IIO, I59, I67 $84,89,92$

vestibularis, I 38,70

Neural crest, 37, I 3, I 4, I 5

Neural plate and folds, $34, I_{3}$

Neural tube, $35,14,15,16$

Neurilemma, origin of, $5 \mathrm{I}$

Neurite, $47,77,91-92$

Neuroblasts, 46 , I 6

Neurofibrillae, 88, 92, 44

Neuroglia, 46

Neuromasts, 20, 58, I24, 6I

Neuromeres, 38,44 , I 8, I 9

Neurones

arrangement of, 8I

functions of, 76

fusions between, $87,92,44$

polarity of, 77 , 9I

trophic relations, 9I, 92

types $\mathrm{I}$ and II, 78, 39

Neurone theory, 85-93

Nucleus acustici spinalis, I39

amygdalæ, 322, 333,

caudatus, $333, \mathbf{1} 66$

commissuralis, I $59,81,82,83$

dentatus, 245, I 26

emboliformis, $247, \mathbf{I} 26$

funiculi, III

globosus, $247, \mathbf{1} 26$

gustus inferior, $169,81,82,83$

gustus superior, $169,89,92$,

I I 2-I I 7

habenulae, 26, I84, 277, I I, I O I, I 36, I 40, I4I, I42, I 45I 50 
Nucleus

isthmi, 26r

lentiformis, 333, r 66

magnocellularis tecti, 148,73 , I 35

of posterior commissure, 265 , I 32

of fasc. long. medialis, 196,270 ,

I 34

olfactorius lateralis, 300,99 ,

I 45-I 50

olfactorius medialis, 299, IOI,

I 47, I 48, I 50

praeopticus, $297,304, \mathbf{1 4 5}, \mathbf{1} 49$,

I 50

praetectalis, 266

rotundus, 28I

ruber, 243,246

tecti, 247 , I 26

thaeniae, $183,296,300,303$

ventralis thalami, 258 , $\mathbf{2} 28$

Oculomotor nerve, see $\mathrm{N}$. oculomotorius

Olfactory apparatus

bulb, 28, II $7,293,298,302,305$, $3 \mathrm{I} 6,2,7$, I 2, 94-98

centers, I82, 292, 94-98, I 45I 70

decussation, I8I, I85, 295, 304, 334 , I о I, I 45, I 48

epithelium, 3I, 6r, I76, 34

glomerulus, $177,94-97$

granule cells, I8I, 95, 96

lobe, $182,296-307,316$, I 2, 99,

I 45-I 50

mitral cells, 178,95

nerve, see $\mathrm{N}$. olfactorius

relation to gustatory apparatus, I 88

relation to mouth, $176,28,37$

Olive, 224

Operculum, cutaneous nerve supply, 107,63

Optic centers, I 47, 26I $, 73,74$, I 28 ,

$$
\text { I } 30 \text {, I } 3 \text { I, I } 4 \text { I }
$$

prosencephalization, 264

see also visual apparatus.

Optic lobes, 24, I47, 254-26r, 2, 7,

$$
\text { I 2, 73, } 74
$$

Optic nerves, see Tr. opticus

Optic thalami, 25, 44, 246, 258-265, I 28, I4 I

Optic tract, see Tr. opticus
Optic ventricle, $254, \mathbf{1} 27, \mathbf{1} 34$

Optic vesicle, 44, I43, I50, I 8-22, 75

Pallial tract, see Tr. olfacto-hypothalamicus lateralis

Pallium, see archipallium and neopallium.

of bony fishes, 304, $147, x_{5} \mathrm{r}$

Paraphysis, 30, 3I 2, I I, 36, I 50, I 52, I 53

Parietal eyes, $27,102,152$, I I, I 2 I $9,36,76$

Paraterminal bodies, $306, \mathbf{I} 6_{3}$

Pathways of impulses, 84, 92, 220

Peripheral nerves development of, 49, I3-16, 2633

Pineal eyes, 27, I02, I52, I I, I 2, I 9, 36,76

Pit organs, 58, I 24

Pituitary body, 27

Placodes dorso-lateral, 58, 28, 33

Plexuses epibranchial, $55,28,3 \mathrm{I}$

in palate, 42,43

of Auerbach, 206

of Meissner, 206

Polarity

of nervous system, 8 I

of neurones, 77,39

Pons, 24, 224, 243, 245

Posterior commissure, 25, 265, 59, I 32, I 35, I 45

Preauditory pit, 59

Precommissural body, 3I 7, 330, I 57I 69

Protopterus, 106, 288

Psalterium, 3I3, 3I5, 3I 7-324, 334, I 50, I 52, I 55, I 58-163, I 67, I 68

Pulvinar, 26I

Purkinje cells, I33-г 37, 239, 67, 68, I 2 I

Pyramidal tract, 349

Pyriform lobe, 317, 323, 333, I 59, I6o, I62, I 65, I66, I67, I 69

Rami communicantes, I4, I56, 207 , $45,77,108$

relation to N. spinalis access., 207

Ramus buccalis, 21, 59, $\mathrm{r}_{3} \mathrm{O}, 5 \mathrm{I}, 6 \mathbf{2}$, 63,79

hyoideus, 22, 58, 79 
Ramus

hyomandibularis, 22, 59, I30, $5 \mathrm{I}, 62,63$

lingualis IX, 20, I59, 63, 79 lingualis $\mathrm{V}, \mathrm{I} 68$

mandibularis $\mathrm{V}, 22,106,5 \mathrm{I}, 63$, 79

maxillaris, 22, I06, I Io, $5 \mathrm{I}, 63$, 79

ophthalmicus superficialis V, I Io. $5 \mathrm{I}, 63$

ophthalmicus superficialis VII. I 30,5 I, 63

palatinus IX, 20, 5

palatinus VII, 22, I $57,5,63$, 79

pharyngeus IX, 20, 55, I59

pharyngeus $\mathrm{X}, 20,55, \mathrm{I} 59$

posttrematicus $\mathrm{X}, 20,55,5,5 \mathrm{I}$, 63,79

posttrematicus IX, 20, 55, 5, $5 \mathrm{I}$, 63,79

posttrematicus VII, 22, 5, 5I, 63,79

general cutaneous component, I08, 5 I

praetrematicus $\mathrm{X}, 20,55,5,63$,

79

praetrematicus IX, 20, $55,5,63$, 79

praetrematicus VII, 22, 5, 63

Recessus praeopticus, 45, 295, I I.

I 45, I $47, \mathrm{I}_{4} 8, \mathrm{I}_{50}$

neuroporicus, 295, I I , I 45, I 50 superior, 319, I52, I59, I6I, I 62

Reflexes, 8I -85

Reflex arc, 83,4 I

Regeneration of nerve fibers, 90

Regio uncinata, 299, 8, 9

Reissner's fiber, I4 8

Relationships of nervous system, I, 9

Retina, I45, 7 I, 72 centrifugal fibers, 148,265

evolution of, $\mathrm{I}_{5} \mathrm{I}$

Roof-plate, 48

Root ganglion of glossopharyngeus, 106, 20, 32

Saccus vasculosus, $27,282,7$, I I, I $43-148$

Sections, planes of, ro

Segmentation, $38,63,38$

relations of nerves, 49,70 , I9I
Selachians

acustico-lateral system, 58 , I 25

brain, I8, 24, 28, I30, I33, I 7I, I $85,228,26 \mathrm{I}, 266,298,2,8$, 9, I I, I8, 66, 92, I I 2,124 , I 27, I 47

general cutaneous fibers, 105, I06 gustatory centers and tracts, I $7 \mathrm{I}$ I 73,92

olfactory centers, I 77, I85, 298,

\section{47}

posterior commissure, 266

spino-occipital nerves, 53,2

Sensations, 345,353

somatic and visceral, IOI, 354 , 355

Sense organs

auditory, 126

gustatory, I64, $85,86,87$

olfactory, 3I, 6I, I 76, 34

tactile, I05, 48

visual, I43, I52, 7 I, 72

Senso-motor area of cortex, 345, I 75I80

Sensory impulses and fibers, 8 I

Septum pellucidum, 334, I68, r69

Sheath of Schwann, 5 I

Shifting of organs, 69,72

Shoulder girdle, 203

Solar plexus, 206

Soma, the, 96

Somaesthetic area of cortex, 346, I 75I 80

Somatic motor division, IOI, 45,46 , 47, r 02

column in brain and cord, 98, I9o impulses coming to, 196

nerves, I90, $5 \mathrm{r}, 63$

Somatic sensory division, see general and special cutaneous subdivisions

Somatic sensory column, I $8,97,45$, 46,47

fate in mesencephalon and diencephalon, 286

Somatic pallium, 293, 31 7, 325, 335, 338,17 I- 180

Somites, mesodermic, 64, 38

Special cutaneous subdivision, IO2 centers, I $30,64-70$

function, 127

peripheral nerves, $20,58, \mathrm{I} 28,5 \mathrm{I}$, $62,63,79$ 
Special cutaneous subdivision phylogenetic history, I27 sense organs, I24, 6I

Spinal cord, I2, I central canal, I 2 dorsal tracts, I Io, $\mathbf{5 2 - 5 5}, 59,60$ longitudinal zones, 48 neuromeres, 38 white and gray matter, 13

Spinal nerves, dorsal, I3, I components, IOI, I05, I55, 200, 45

Spinal nerves, ventral, I3, I90, 200, I, 45

Spino-occipital nerves, $23,52,63$, I05,

Spongioblasts, 46 I $90,20,30,31,32$, I 04

Stimulus, 76

Striae Lancisii, 334

Stria medullaris, 322, 333 see $\mathrm{Tr}$. olfacto-habenularis

Striatum, see Corpus striatum

Subiculum cornu Ammonis, 348, I 70

Substantia gelatinosa, II $5, \mathbf{5 6}$

Substantia reticularis, 2 I9

Supraorbital neuromasts and nerve, 59, I 30,5 I $, 62,63$

Sympathetic system, 206, I08, I09, I IO

axone-reflex, 2 I 4 , I I 0

chain ganglia, 206

development, 206

efferent fibers, 2 IO

excitatory cells, 2 II

peripheral ganglia, 206

prevertebral ganglia, 206

rami communicantes, I4, ${ }_{5} 6$, $207,45,77$, I06, 108

relation to visceral divisions, 2 I 4 216

sensory cells, 2 I 3, I 08

sensory fibers, $208,77,108$

Tactile impulses, I05, I 55

Tacto-motor collaterals, 82, I Io, 197, 41,52

Taenia semicircularis, 324 , I 66

Taenia thalami, 322, 333, Io I, I45150

Taste buds, I64, $85,86,87$

distinct from neuromasts, $16_{5}$

distribution, 22, I64

origin of, 164

phylogenetic history, I 73
Tectum opticum, I47, 255, 26I, 73, 74

Tela chorioidea, $28,305,2$, I45-I 5 I

Telencephalon, $28,2,7,8$, I I, I2,

I 45-I 70

evolution of, 292

Tertiary gustatory tract, $169,89,92$, I I 2- I I 7

Tract of Gowers, 243

Tractus bulbo-tectalis, I I 7, 59, I I 2I I 7, I 24, I 25, I 33, I 34

see also Lemniscus system

Tractus cortico-habenularis, 322 , I 52 , I 64

Tractus gustus secundus, $I 69,89,90$, 92, I I 2-I I 7

Tractus gustus tertius, $169,89,90$, 92, I I 2- I I 7

Tractus habenulo-peduncularis, I 84 , 277 , I I I, I 33, I 34, I 36, I 40, I42, I45-I 50

Tractus lobo-bulbaris, I 7I, 89, 92, I o I, I I6, I 33

Tractus lobo-epistriaticus, 297, 92, I $45, I_{50}$

Tractus mammillo-bulbaris (peduncularis), 275,92, I O I, I 36

Tractus mammillo-thalamicus, 275 , I 36

Tractus olfactorius, $\mathrm{I} 82,295,2$, I O I, I $45^{- \text {I } 50, ~ I ~} 57$

Tractus olfactorius septi, $307, \mathbf{1}_{50}$, I 55

Tractus olfacto-corticalis, 301, 307 , I 47, I 50

Tractus olfacto-habenularis, I84, 297 ff., I I I, I45-I50, I 64

Tractus olfacto-hypothalamicus, I84, 297

lateralis, $300,303,307$, I o I, I 47, I 50

medialis, $275,300,303,307$, I O I, I 37 , I 45-I 50, I 64

Tractus olivo-cerebellaris, 243

Tractus opticus, 28,70 , I 28 , I 35 , I 4 I

centers of, $147,26 \mathrm{I}, 73,74$, I 28 , I $30, I_{3}$ I, I 4 I

centrifugal fibers, $\mathrm{I} 48,265,72$ chiasma of, 28 , I 46

Tractus sacco-thalamicus, 282, I 34, I 44

Tractus spinalis trigemini, I 4456 , $59,60,64$ 
Tractus spino-cerebellaris dorso-lateralis, 245,247

Tractus spino-cerebellaris ventralis, 243

Tractus strio-thalamicus, I85, $297 \mathrm{ff}$., I O I, I 34, I 35, I 45-I 50

Tractus tecto-bulbaris et spinalis, II 7 , I $48,59,65$, I 33

Tractus tecto-cerebellaris, I48, 228, 229, I 27, I 33, I 34, I 35

Tractus tecto-lobaris, I 48 , I 34

Tractus thalamo-spinalis, $245,28 \mathrm{I}$, I 48

Tractus thalamo-saccus, 282, I 34 , I 35, I 43, I 44

Trapezius musculature, 203

Trigeminal nerve, see $\mathrm{N}$. trigeminus

Trochlear nerve, see $\mathrm{N}$. trochlearis

Tuber cinereum, 275, I 37, I 38

Tuberculum acusticum, I8, 3, I I, $58,59,64-69,84$, I I 8 general cutaneous center, II $5 \mathrm{ff}$. motor connections, I 35 special cutaneous center, I30

Tuberculum olfactorium, 317,333 , I 59, I 60, I 64, I 67

Vagus nerve, see $\mathrm{N}$. vagus

Valvula cerebelli, 24, I 72, 89, 9 I, I I 6

Velum medullare anterius, 24, I72, I I 2, I I 8 , I 24

Velum transversum, 316, I I, 36, I 53, I 58
Ventricles, I5, 24, 28, 8, 9, I o, I I lateral, $28,295 \mathrm{ff}$.

Ventro-lateral zone, 49

Vesicles of Savi, 60, I 25

Viscera, the, 96

Visceral motor division, 98, 199,45 , 46, 106

relations to sympathetic, 208 , 210,215

Visceral sensory division, $97,155,45$, $46,47,77$

relation to sympathetic, 208,2 I 6

Visceral sensory column, $97, I_{55}, 3$, I I, $45,46,77-84,89,92$

diencephalic representatives of, I 88, 269-28I, I 33-I 42

intrinsic neurones, I6I

secondary tract, $16_{3}, \mathbf{I} 69,89$, 92

stimuli, nature of, $\mathrm{I}_{55}$

Viscero-motor connections, 204

Visual apparatus, 27, 102, I43, 26I centers, I47, 26I, 73, 74, I 28 ; I 30, I 3 I, I 4 I

eye, 44, I 43, I50, 2 I, 22, 7 I, 72, 75

optic tract, $28, \mathrm{I} 46, \mathrm{I} 48,265,70$, I $28, I_{35}, I_{4}$ I

perception, 263

reflexes, 264

visual area of cortex, 347 , I 75I 80 








97 


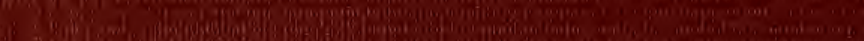

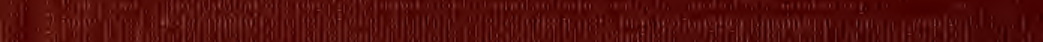

3. 1.5. 1.5.

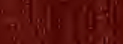

(4)

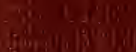

7.0.7.

3.

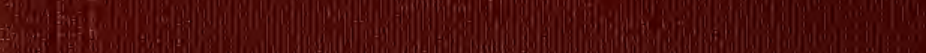

